\title{
Blended Action Learning: Supporting Leadership Learning in the New Zealand ECE sector
}

\author{
Kathryn Ruth Thornton
}

School of Information Management

Victoria University of Wellington 


\section{Abstract}

The purpose of this research study was to explore the use of information communication technology (ICT) to support leadership development in the New Zealand early childhood education (ECE) sector. There is currently a lack of policy and provision supporting leadership development in this sector. Previous research has identified the value of leadership development programmes that encourage reflective practice, peer collaboration, and a focus on problem-solving in real-life situations. ICT has the potential to support leadership learning using action learning, a process that involves groups of learners working on issues or problems that they face in their professional contexts with the support of a facilitator. Although action learning groups most often meet face-to-face, ICT is increasingly being used to support or in some cases replace traditional meetings. This research study, which took the form of interpretive case research, involved the establishment of two blended action learning groups facilitated by the researcher. The participants in this study both met face-to-face in facilitated workshops and interacted online while back at their respective workplaces for ongoing reflection, discussion and the sharing of knowledge and resources. The open source software Moodle was the enabling technology used in this study and the ICTs employed included email, online reflective journals, forum discussions and chat sessions. A model of leadership learning using ICT was developed through the analysis of data from this study. This model illustrates the leadership journeys taken by participants who increased their awareness of leadership through a process of recognising, reflecting, realising and responding. This led to increased confidence in their leadership practice and in some cases resulted in a greater distribution of leadership. Four key factors contributing to the leadership learning process were identified to be the blended action learning process, the blended action learning groups, the ICT tools used and the role of the blended action learning facilitator who acted as both an enabler of learning and a trusted inquisitor. This study contributes to our understanding of the process of leadership development using ICT, in particular the role of the blended action learning facilitator and the process of leadership learning. 


\section{Acknowledgements}

"Rivers know this: there is no hurry. We shall get there some day". (A.A. Milne)

As I near the end of my doctoral study, a journey that at times seemed never ending, and that I found mostly enjoyable, at times challenging and occasionally frustrating, there are many people I would like to thank. These people, who supported me along the way, include my supervisors, my fellow PhD students, my work colleagues and of course my family.

I would firstly like to acknowledge the 12 research participants who made this study possible. I greatly appreciate the trust they showed in committing to be part of the study and their willingness to share their personal and professional lives with me and with each other. I am grateful for the time they spent contributing to both face-to-face and online interactions and I have greatly enjoyed getting to know and working with each of them. I value the fact they ground me in the reality of leadership in ECE services and that our interactions are ongoing.

This thesis would not have been possible without the support and guidance of my primary supervisor and mentor Professor Pak Yoong. Pak encouraged me to apply for the scholarship that allowed me to study full-time and gently guided me through the processes of designing the research study, gathering data and writing the thesis. I particularly value his vision, his continual support and availability, and his sense of humour.

I would also like to thank my second supervisor Dr Cedric Hall for his input at various times. I particularly appreciated his useful and focused comments on the draft chapters and the final draft.

The loneliness of a PhD journey is often commented on, however I never felt alone in the time I was involved in this study due to the support of a wonderful group of fellow students, Janet, Jocelyn, Carmel, Silke, Maria, Julie and Alan. It was great to be able to share ideas and progress and to know that others understood what the experience I was going through.

I would also like to thank my colleagues at the Victoria University Wellington College of Education who supported me in my much reduced workload and allowed me to move in and out of the life of the school during the course of my study.

A special thank you to Deborah Wansbrough, who provided a listening ear, supported me along the way and gave me useful feedback on my final draft, and also to Sue Kaiser for her careful editing. 
Lastly I wish to thank my family. Thank you Adam for both your practical and emotional support. Thank you also to my children Sam, Claire, Anna and Guy for your interest in my progress and faith in my abilities. You were all very tolerant of the ongoing time commitment and the resulting impact on family life. A special thank you to Sam for his amazing skills in helping me design diagrams and format the final thesis, and to Claire for her editing. 


\section{Table of Contents}

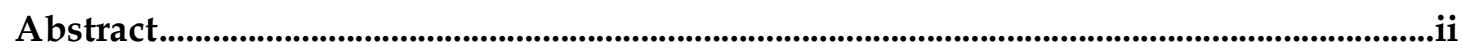

Acknowledgements....................................................................................................... iii

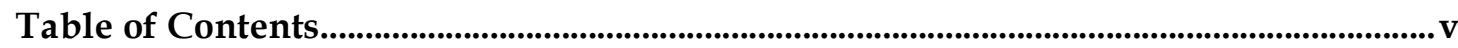

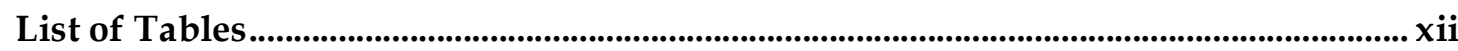

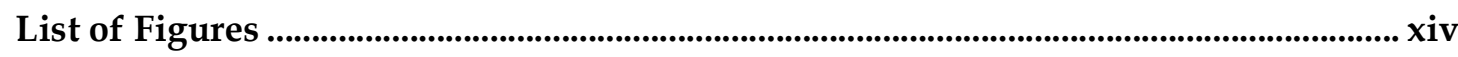

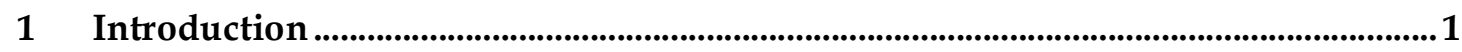

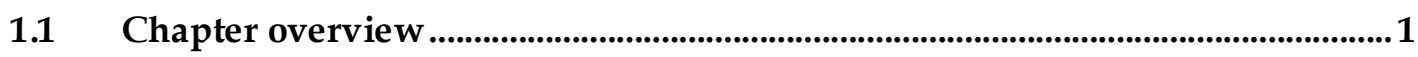

1.2 The use of ICT in the education sector.................................................................

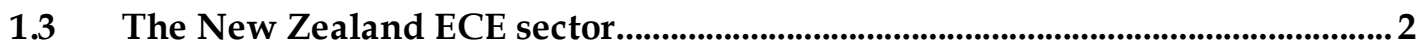

1.4 Leadership development within the ECE sector................................................2

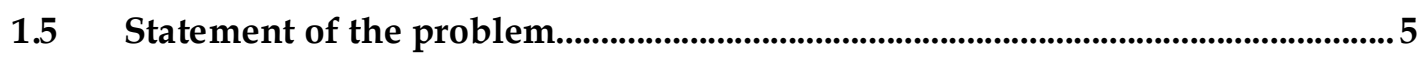

$1.6 \quad$ Purpose of the study ......................................................................................................

$1.7 \quad$ The research question ...................................................................................

$1.8 \quad$ Methodology ......................................................................................................................

1.9 Significance and benefits of the study ................................................................6

1.10 Researcher background ...................................................................................................6

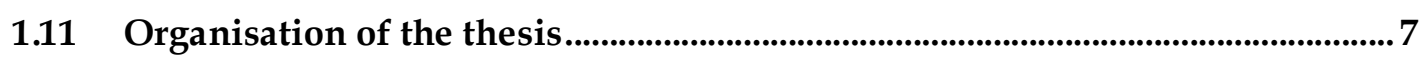

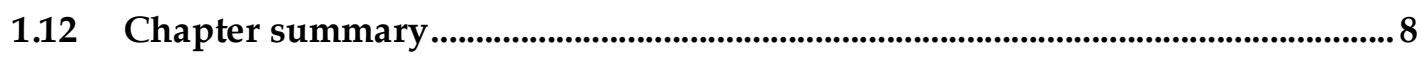

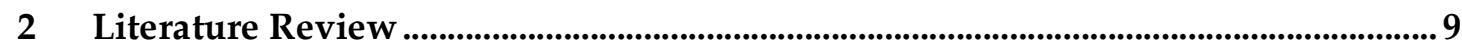

2.1 Chapter overview ............................................................................................................

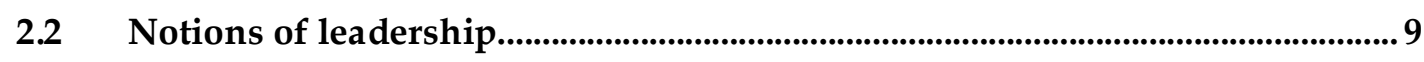

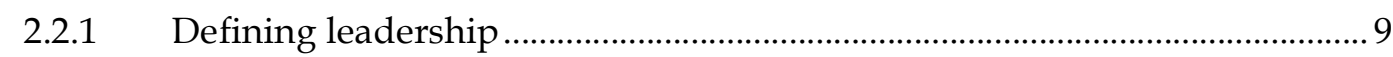

2.2.2 Current thinking on leadership theory and practice....................................10

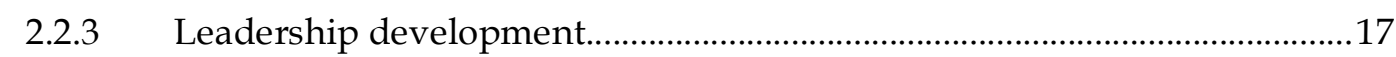

2.2.4 Implications for leadership development in the New Zealand context ....22

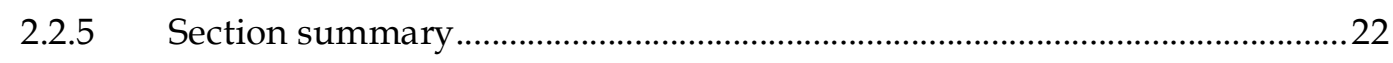




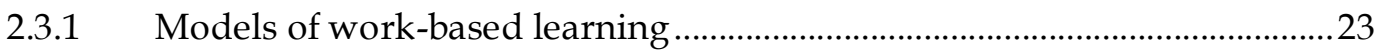

2.3.2 Work-based learning and leadership development......................................25

$2.4 \quad$ Communities of practice ......................................................................................25

2.4.1 Communities of practice and knowledge management.................................22

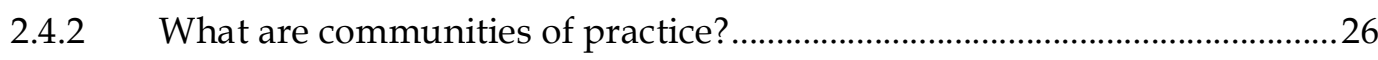

2.4.3 Naturally evolving versus planned communities of practice ......................22

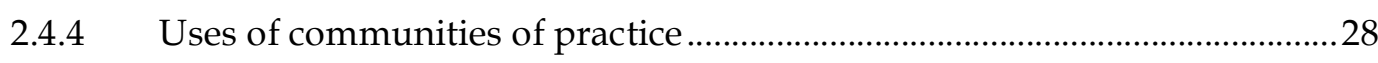

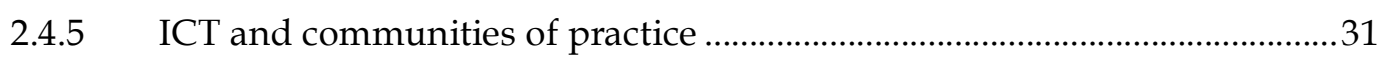

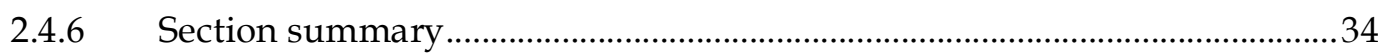

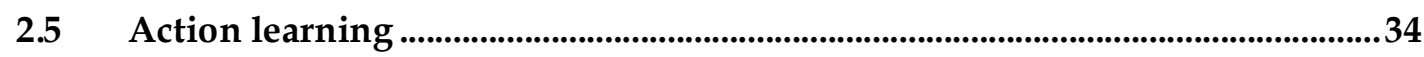

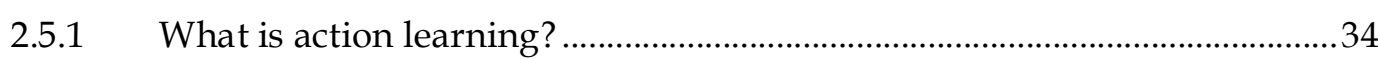

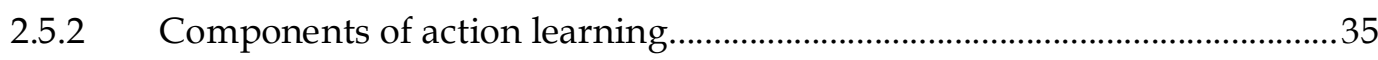

2.5.3 Differences between action learning and action research.............................37

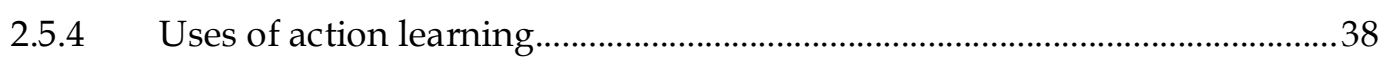

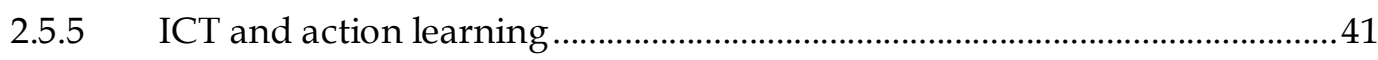

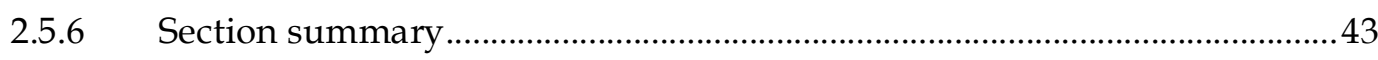

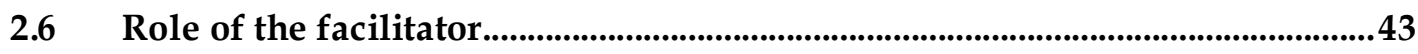

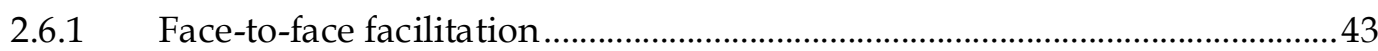

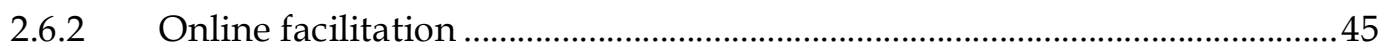

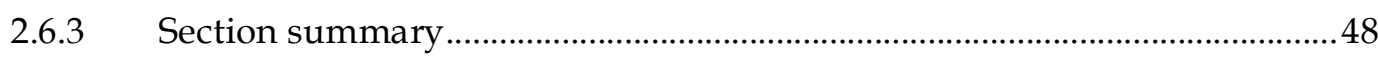

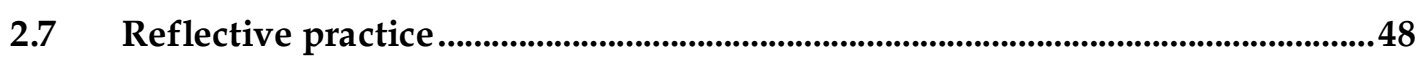

2.7.1 What is reflective practice? .......................................................................... 48

2.7.2 Critical reflection and reflective practice.........................................................49

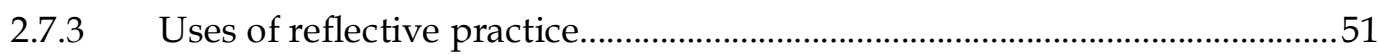

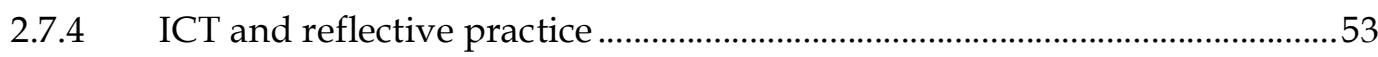

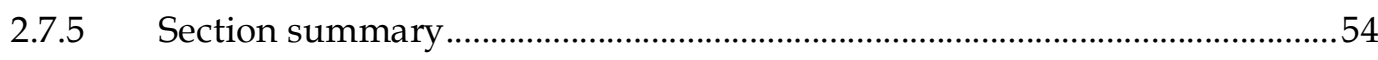

\subsection{Links between communities of practice, action learning and reflective} practice..........................................................................................................................................5

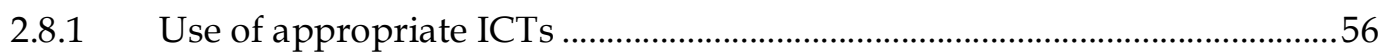

2.8.2 Implications of the literature on communities of practice, action learning and reflective practice for research into leadership development using ICT 


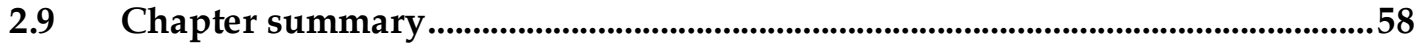

3 Research Methodology ……...............................................................................................59

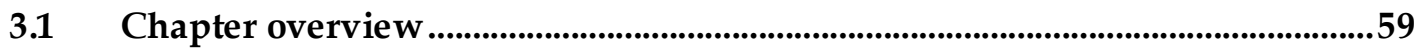

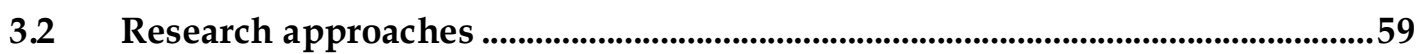

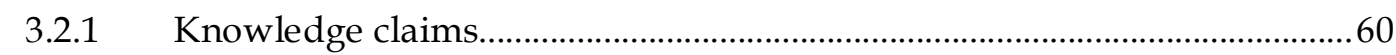

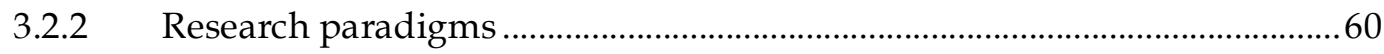

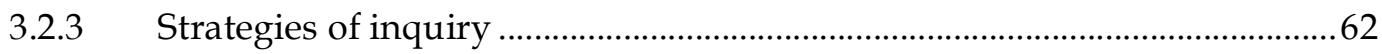

3.2.4 Characteristics of qualitative research.............................................................63

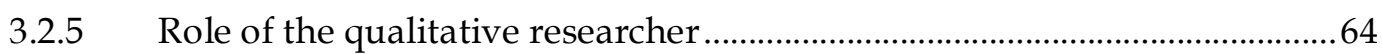

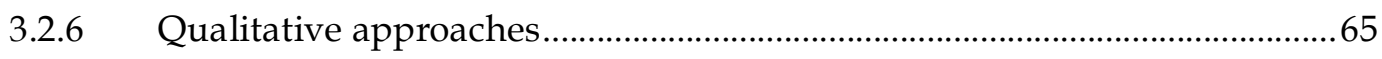

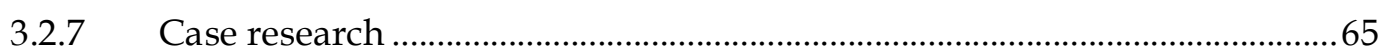

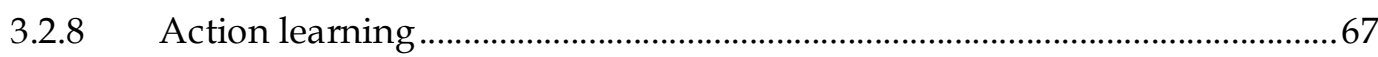

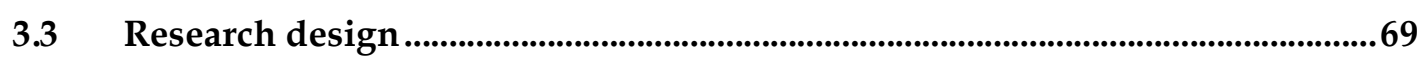

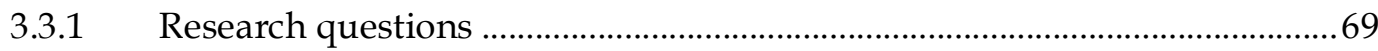

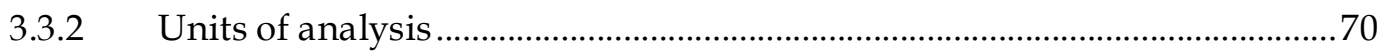

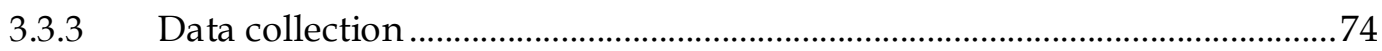

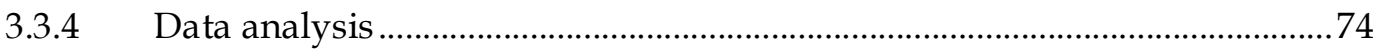

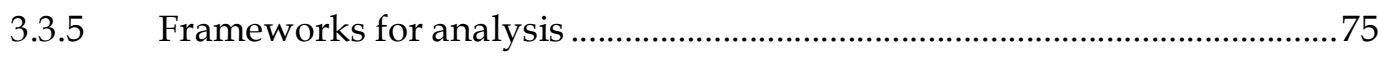

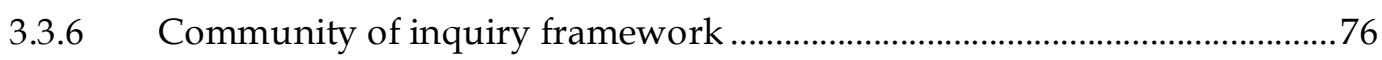

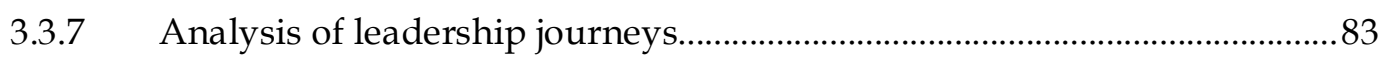

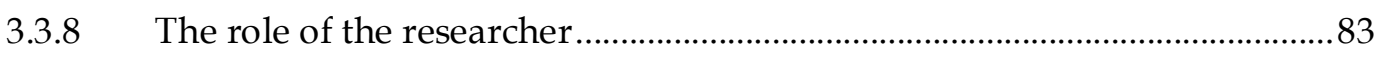

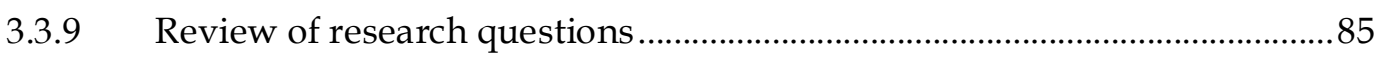

3.4 Chapter summary .............................................................................................................. 85

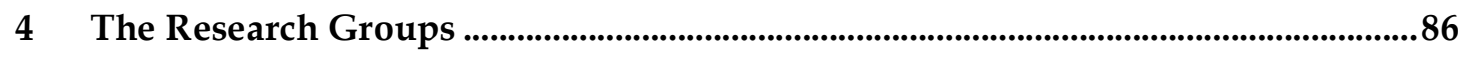

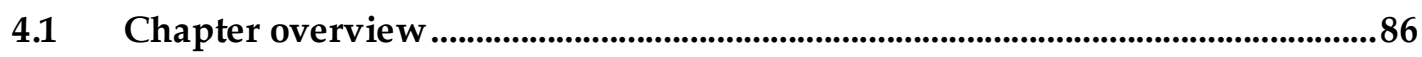

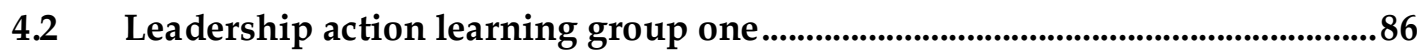

4.2.1 Group composition and preparation............................................................. 86

4.2.2 LALG1 first group meeting ............................................................................ 87

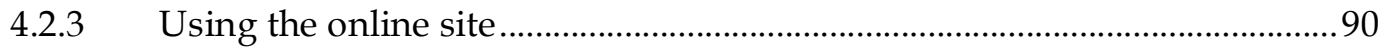

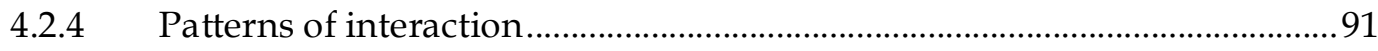

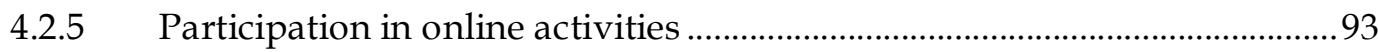


4.3 Leadership action learning group two ……................................................................99

4.3.1 Group composition and preparation..............................................................96

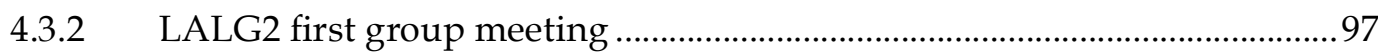

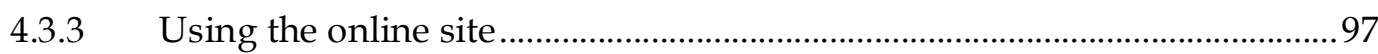

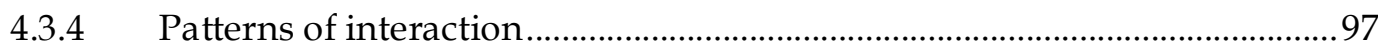

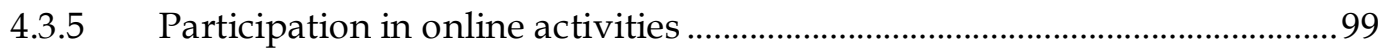

4.4 Comparison between the two research groups .........................................................101

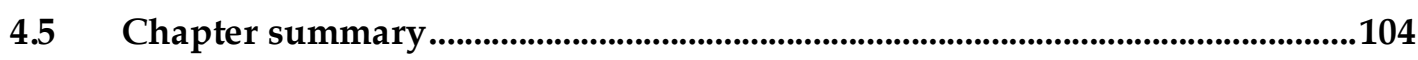

$5 \quad$ Individual Leadership Journeys...............................................................................105

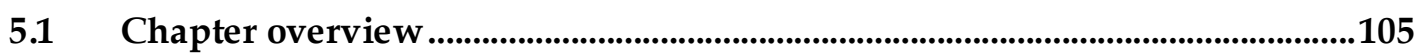

$5.2 \quad$ Key words.......................................................................................................................... 105

5.3 Active participation ................................................................................................106

5.3.1 Diana's leadership journey - 'Peace at all costs' ......................................... 106

5.3.2 Fiona's leadership journey - 'I used to do it all' ...........................................109

5.3.3 Grace's leadership journey - 'Out of my comfort zone' .............................112

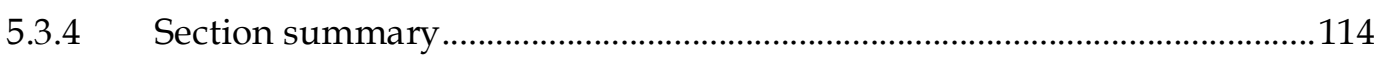

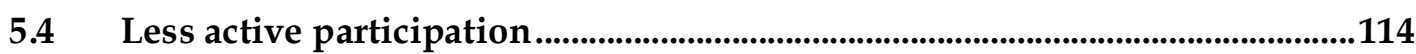

5.4.1 Emma's leadership journey - 'I'm far too soft' .......................................115

5.4.2 Jane's leadership journey - 'What kind of leader do I want to be?' ..........116

5.4.3 Lisa's leadership journey - 'I want to be prepared' .......................................119

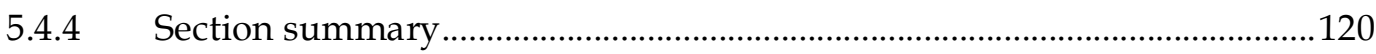

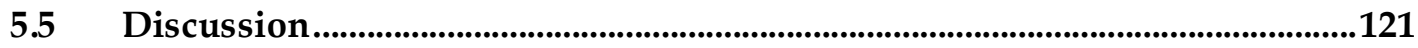

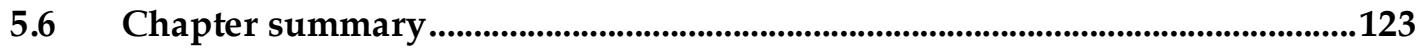

6 The Blended Action Learning Group Process: An Analysis.....................................124

6.1 Chapter overview ................................................................................................................124

6.2 The blended action learning process .........................................................................124

6.2.1 The action learning process ...........................................................................124

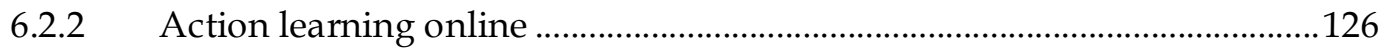

6.2.3 The blended learning approach...............................................................130

6.2.4 The empowering nature of action learning..............................................132

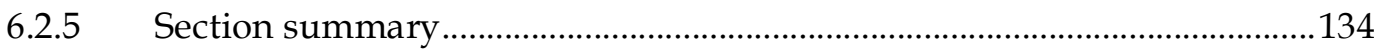


6.3 Participation in the action learning groups..............................................................135

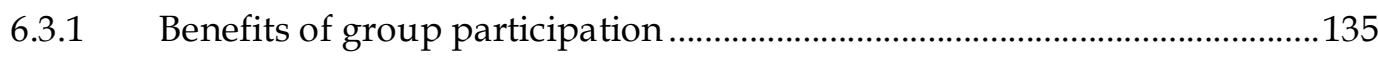

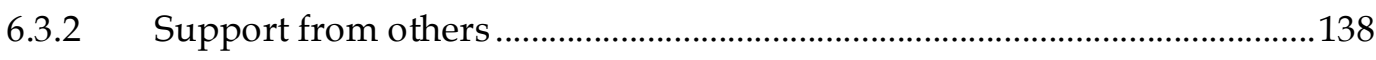

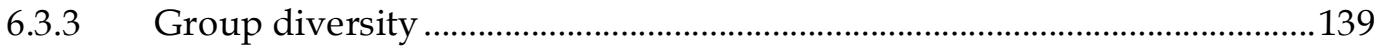

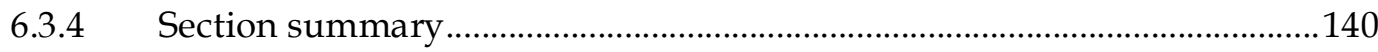

6.4 Using the different technologies...............................................................................140

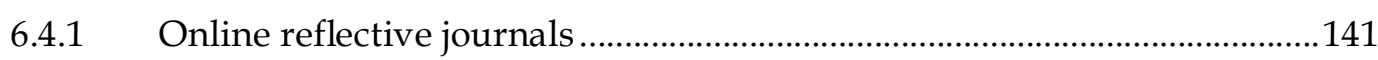

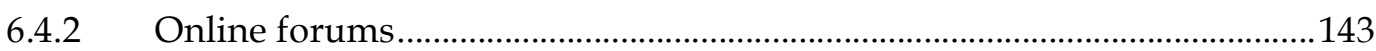

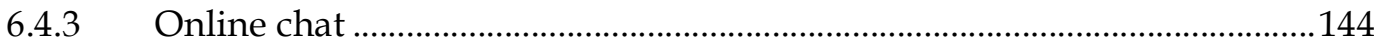

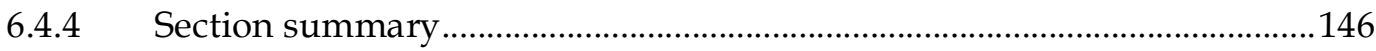

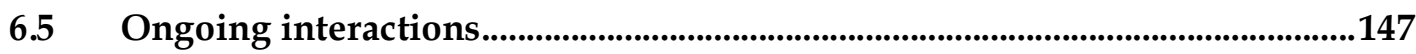

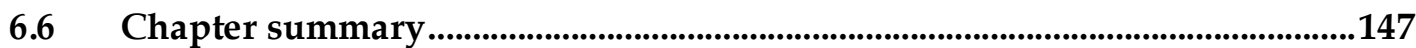

$7 \quad$ Role of the Blended Action Learning Facilitator .......................................................149

7.1 Chapter overview ............................................................................................................149

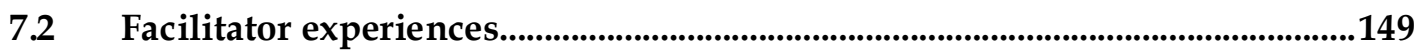

7.2.1 Facilitator or action learning coach? ........................................................149

7.2.2 Previous experience in blended facilitation ...............................................150

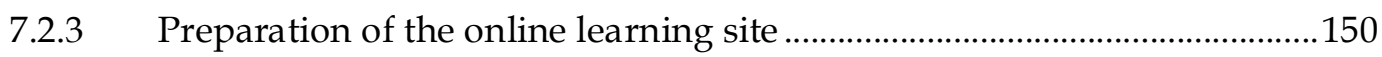

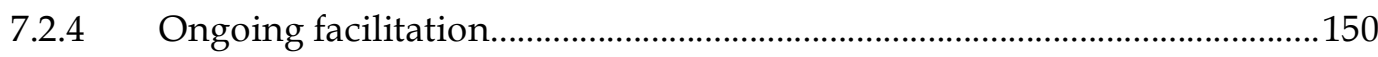

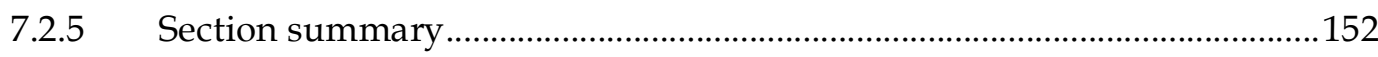

7.3 Participants' perspectives on the facilitator role...............................................153

7.3.1 Role in relation to different technologies..................................................153

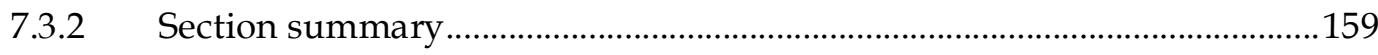

7.4 Analysis of the blended action learning facilitator role......................................159

7.4.1 An enabler of leadership learning ................................................................159

7.5 Stages of blended action learning facilitation ...............................................163

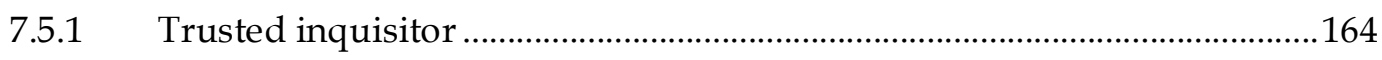

7.5.2 Balance between acting as enabler and trusted inquisitor............................173

7.6 Stages of blended action learning facilitation .....................................................174

7.6.1 Balance between roles in various stages ....................................................... 177 
$7.8 \quad$ Chapter summary ..........................................................................................................178

8 The Leadership Learning Process ....................................................................180

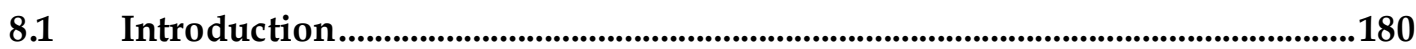

8.2 Revised community of inquiry framework ...........................................................180

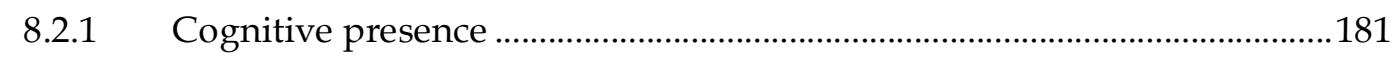

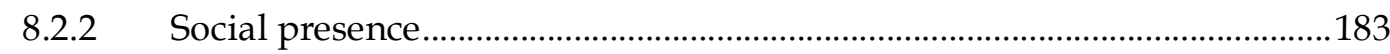

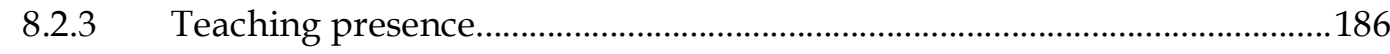

8.2.4 Revised community of inquiry in relation to the facilitator role................190

8.2.5 Revised community of inquiry in relation to online tools ............................191

8.2.6 Revised community of inquiry model and LALG2 _.....................................192

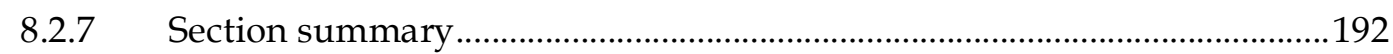

8.3 Leadership journey data analysis ..............................................................................193

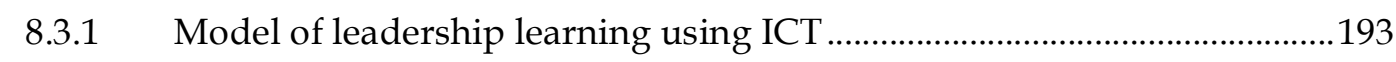

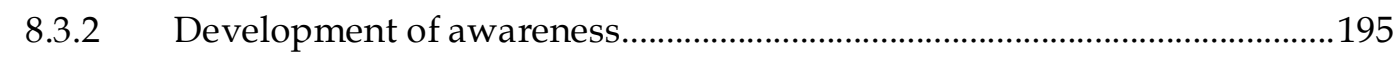

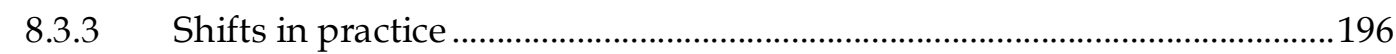

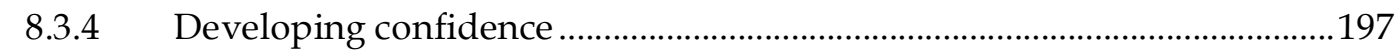

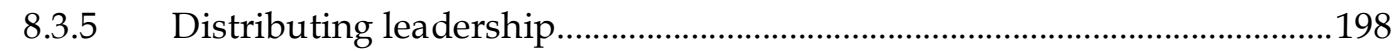

8.3.6 Further revisions to community of inquiry model........................................199

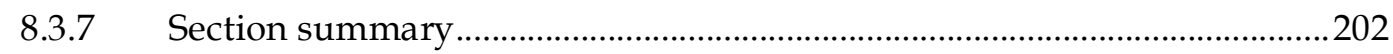

8.4 Components of the model of leadership learning using ICT ...........................203

8.4.1 From awareness to confidence ........................................................................ 203

8.4.2 Evolving stages of cognitive presence............................................................2. 204

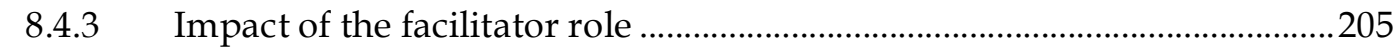

8.4.4 Impact of the blended action learning process.............................................206

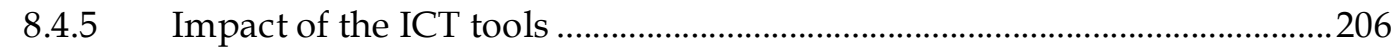

8.4.6 Impact of participation in the blended action learning group ....................207

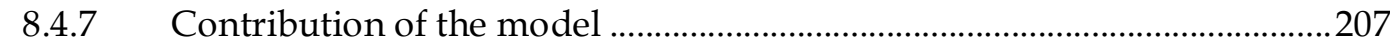

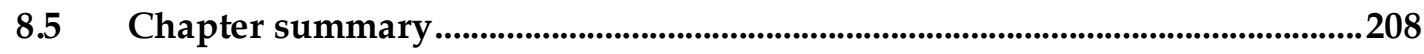

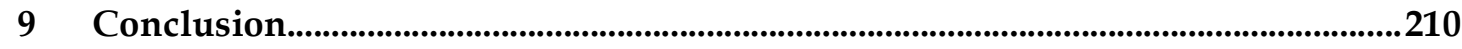


9.1 Chapter overview ......................................................................................................210

9.2 Overview of the research process ..............................................................................210

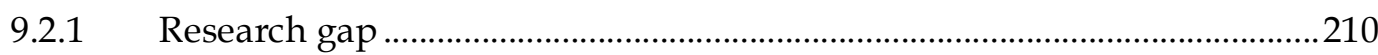

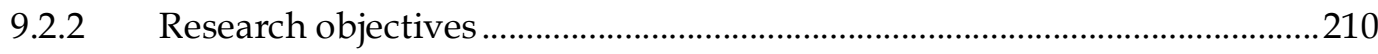

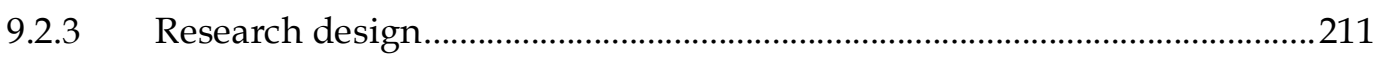

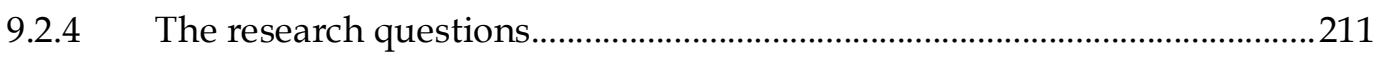

$9.3 \quad$ Researcher role

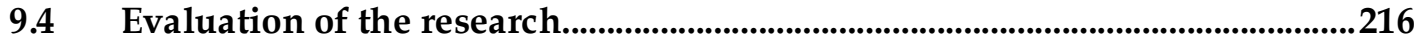

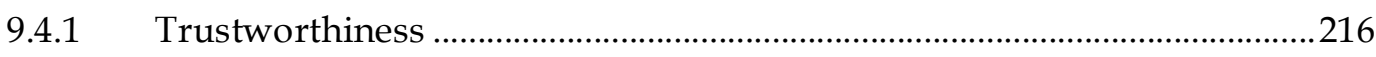

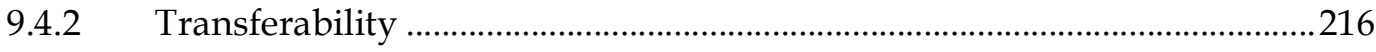

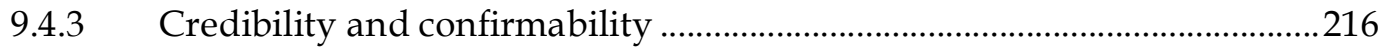

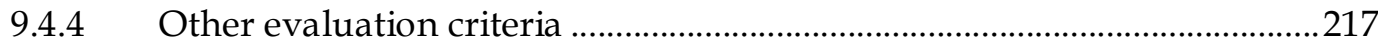

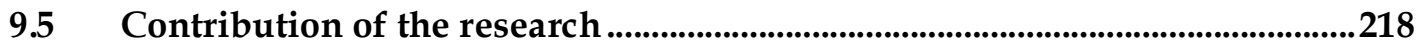

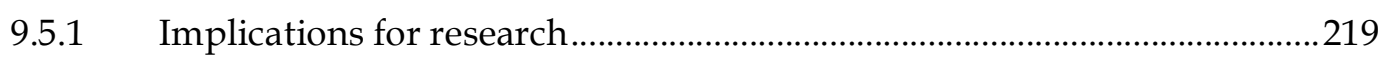

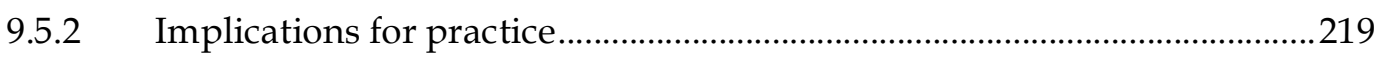

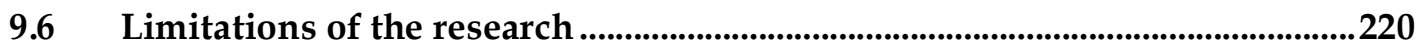

9.6.1 Limitations of this approach to leadership development ............................221

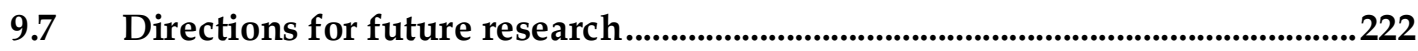

$9.8 \quad$ Chapter summary .............................................................................................................223

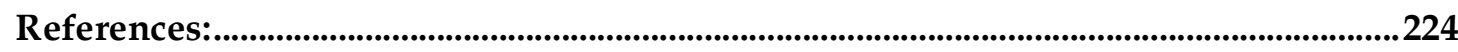

Appendix A - Participant Information Sheet ............................................................................250

Appendix B - Consent to Participation in Research ..............................................................252

Appendix C - Additional Leadership journeys..........................................................................253

Appendix D - Extract from Charlotte's second interview ...................................................259

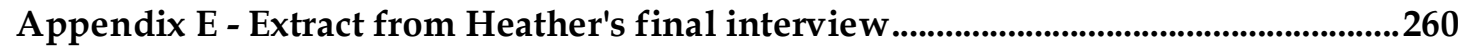

Appendix F - Forum discussion: Reflection on a quote ........................................................261 


\section{List of Tables}

Table 2-1: A model of work-based learning (Individual level) ..............................................2

Table 2-2: A model of work-based learning (Collective level) ...............................................2

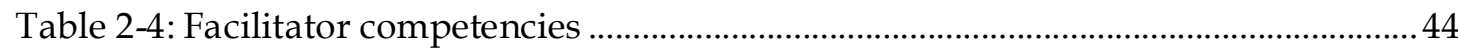

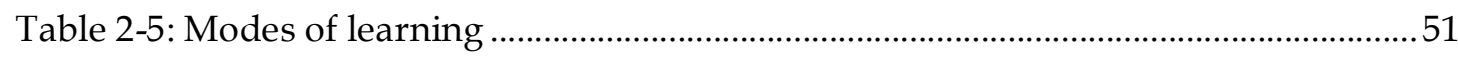

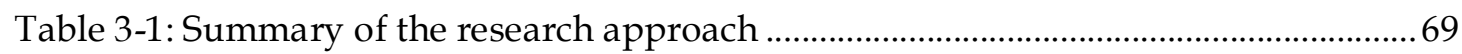

Table 3-2: Community of inquiry category and indicators..................................................79

Table 4-1 : Previous experience of LALG1 participants ............................................................ 87

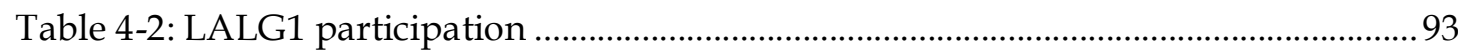

Table 4-3: Previous experience of LALG2 participants ............................................................ 96

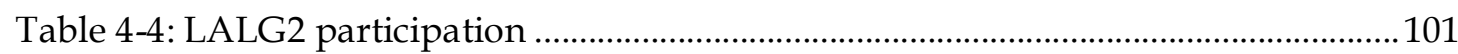

Table 5-1 : Summary of participation of more and less active group members..............122

Table 6-1: Sample online action learning forum ................................................................129

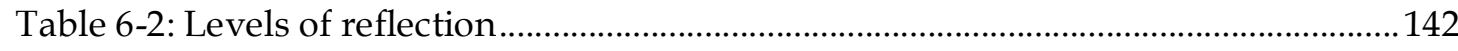

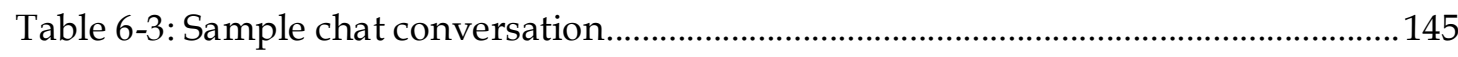

Table 7-1: Facilitator emails to encourage participation......................................................151

Table 7-2: Facilitator responses to reflective journal entries...............................................155

Table 7-3: Facilitator responses to forum entries ...............................................................156

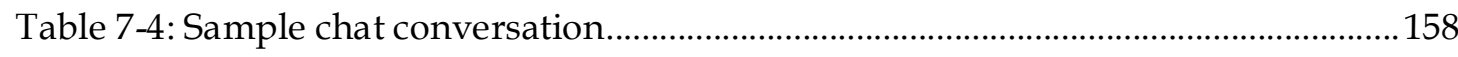

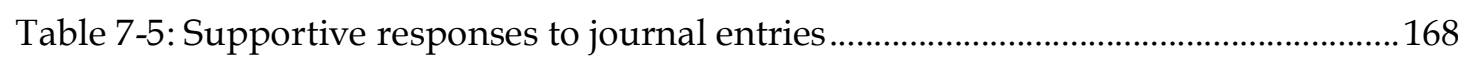

Table 7-6: Facilitator questions that encourage reflection....................................................169

Table 7-7: Stages of blended action learning facilitation ....................................................175

Table 7-8: Balance of roles in the different stages ...............................................................177

Table 8-1: Revised cognitive presence categories .................................................................183

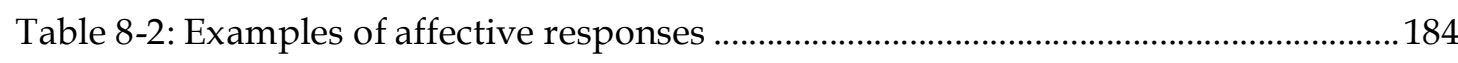

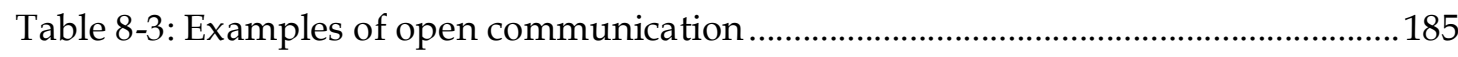




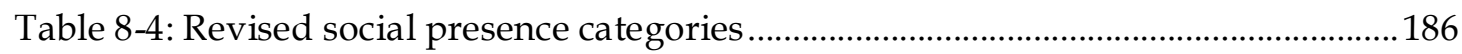

Table 8-5: Examples of facilitated discourse ……............................................................. 187

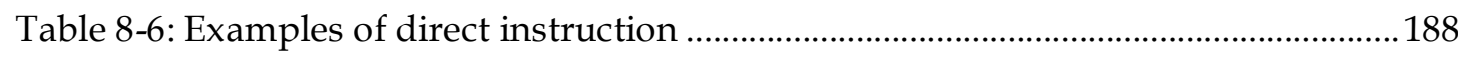

Table 8-7: Revised teaching presence categories...................................................................189

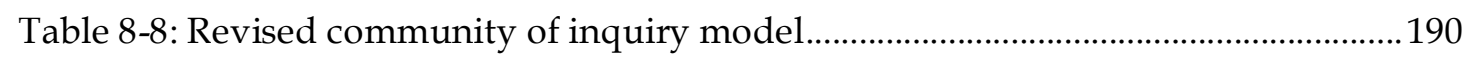

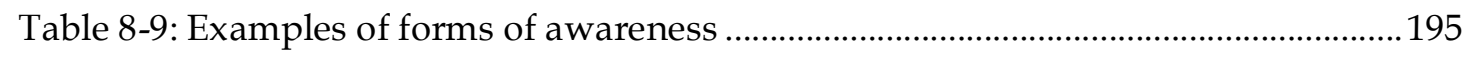

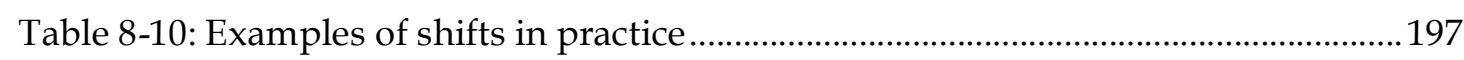

Table 8-11: Examples of increased self-confidence.............................................................197

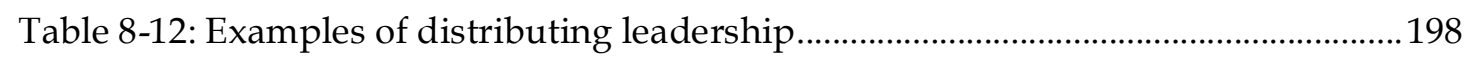

Table 8-13: Examples of recognising, reflecting, realising and responding......................2202 


\section{List of Figures}

Figure 2-1: The six components of action learning .............................................................. 36

Figure 2-2: Single and double loop learning ....................................................................... 50

Figure 2-3: Communities of practice, action learning and reflective practice ...................55

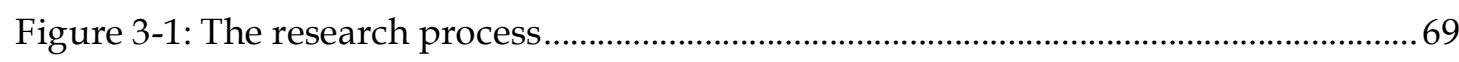

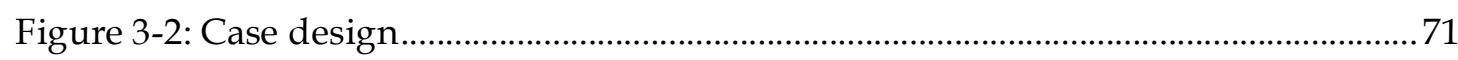

Figure 3-3: Components of Data Analysis: Interactive Model................................................ 75

Figure 3-4: Elements of an educational experience ...............................................................

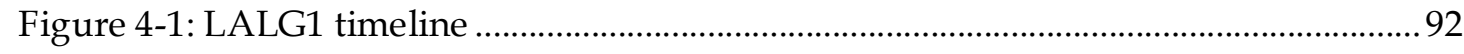

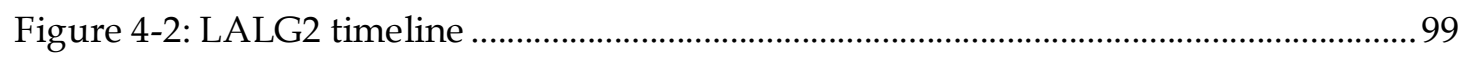

Figure 7-1: Process used in formulating responses to journals............................................ 154

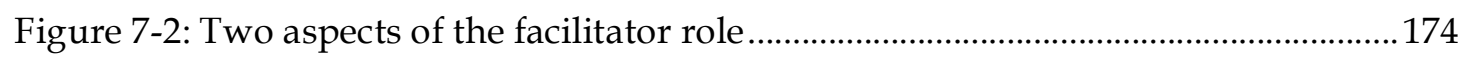

Figure 7-3: Stages of blended action learning facilitation .................................................175

Figure 8-1: Linking facilitator role to revised model............................................................191

Figure 8-2: Linking online tools to revised model..............................................................192

Figure 8-3: Model of leadership learning using ICT ............................................................. 194

Figure 8-4: Links between the of inquiry model and aspects of leadership learning

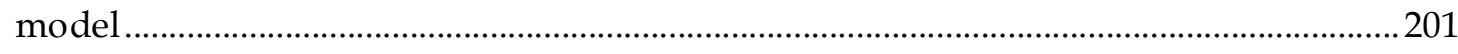

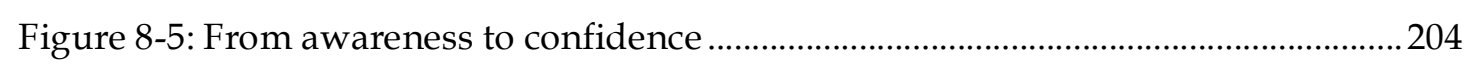

Figure 8-6: Recognising, reflecting, realising \& responding ...............................................2. 205

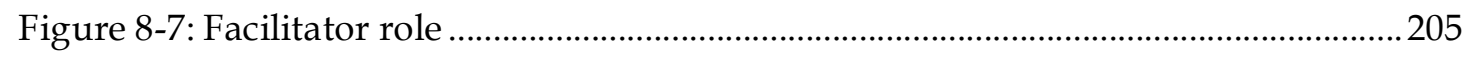

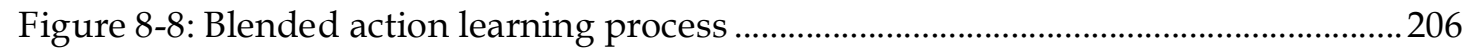

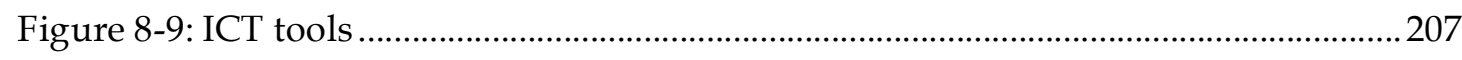

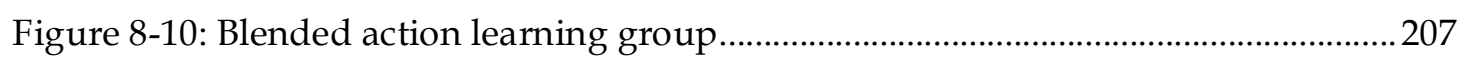




\section{Introduction}

"A journey of a thousand miles must begin with a single step." (Lao Tzu)

\subsection{Chapter overview}

This introductory chapter provides an overview of the research study. The chapter begins by discussing the use of information and communications technology (ICT) in the New Zealand education sector, and this discussion is followed by an overview of the New Zealand early childhood education (ECE) sector and leadership development within that sector. The problem of the lack of support for leadership development in the New Zealand ECE sector is stated before the purpose of the study and the research questions are outlined. This is followed by a brief explanation of the methodology and a discussion of the background of the researcher. The chapter concludes by outlining the organisation of the thesis.

\subsection{The use of ICT in the education sector}

The New Zealand Government has made a commitment to creating a digital future through the use of "the power of information and communications technology (ICT) to enhance all aspects of our lives" (New Zealand Government, 2005, p. 4). This initial Digital Strategy set out the direction New Zealand would take in order to become a world leader in the use of ICT and was updated in November 2008 with the release of the Digital Strategy 2.0. While the focus of the 2005 strategy was on connecting people to each other and the information needed in everyday lives, the updated strategy looks further, to "the creativity and opportunities for collaboration unleashed by the interactive, participatory digital world" (New Zealand Government, 2008, p. 7). The updated strategy acknowledges the influence of Web 2.0 in emphasising the role people play in making content as well as consuming it, and promotes the use of online collaboration tools such as wikis and blogs. The enablers of this digital development are seen to be connection, capability, confidence and content, and educators and researchers are among the groups identified as collaborators in the change process.

The use of ICT in the New Zealand education sector is also seen as a priority. The Ministry of Education developed a 4-year e-Learning Action Plan for schools in 2006, entitled Enabling the 21 ${ }^{\text {st }}$ Century Learner, that outlined how e-learning will be integrated into the school sector. Proposed outcomes of this action plan include the use of online communities of practice to "strengthen collegial support, professional dialogue, and reflective practice" (Ministry of Education, 2006a, p. 11). ICT use is also promoted in the ECE sector. A framework for supporting learning in ECE, Foundations for Discovery, (Ministry of Education, 2005a) emphasises the importance of ECE services using ICT 
tools in diverse ways. Building online communities of practice is one possible development for the sector signalled in this framework.

\subsection{The New Zealand ECE sector}

The New Zealand ECE sector is characterised by its range of provision with "a diverse range of private and community-owned providers operating with a variety of philosophies and approaches" (Ministry of Education, 2007a, p. 7). Although there is some consistency within the sector with a national curriculum document, Te Whaariki (Ministry of Education, 1996), and a common regulatory framework, there are a number of different service types operating throughout the country. Some of these services such as kindergartens, playcentres ${ }^{1}$ and kohanga reo $^{2}$ receive support from national umbrella organisations, whereas the teachers in others, such as education and care (childcare) services, are more isolated. The critical role the sector plays in supporting children and their families has been recognised by the government over recent years. There has been a significant increase in financial investment in the ECE sector over the past decade with the percentage of government expenditure on early childhood education increasing from 5\% in 2000 to 9\% in 2008 (Ministry of Education, 2008a). An ECE strategic plan, Pathways to the Future: Nga Huarahi Arataki (Ministry of Education, 2002) has been developed to set out a framework and direction for the sector until 2012.

The ECE sector in New Zealand is seen as a world leader in several key areas (May, 2001; Meade, 2000). It is one of the few countries to have integrated the education and care of young children in administration, policies and training and was the first country to adopt a national bilingual ${ }^{3}$ curriculum document (Te Whaariki, Ministry of Education, 1996) that applies to children from birth to six years. New Zealand is also leading the way internationally in aiming to have all regulated teachers in the sector fully qualified and registered by 2012. One area in which the sector is not a forerunner is the recognition of the importance of leadership and support for leadership development.

\subsection{Leadership development within the ECE sector}

Early childhood education has been identified as a crucial step in "building the foundation for a child's ongoing learning and development" (Ministry of Education, 2002, p. 2). The importance of participation in high quality education has also been emphasised (Ministry of Education, 2008a). One of the factors identified as contributing to quality in ECE settings is effective leadership (Bloom \& Bella, 2005; Grey, 2004;

\footnotetext{
${ }^{1}$ A parent cooperative ECE service unique to New Zealand

${ }^{2}$ Māori language nests

${ }^{3}$ A curriculum that has both Māori and English text
} 
Kagan \& Bowman, 1997; Rodd, 2006). It has been suggested that professional leadership is "second only to effective teaching among all education-related factors that contribute to students' learning" (New Zealand Educational Institute (NZEI), 2006, p. 13), and that it accounts for approximately $25 \%$ of total centre or school effects. This link between quality and leadership has been recognised in the ECE strategic plan, Pathways to the Future: Nga Huarahi Arataki (Ministry of Education, 2002). The 10-year plan contains the action of providing "leadership development programmes to strengthen leadership in ECE services" (Ministry of Education, 2002, p. 15), under the goal of improving quality, although no policy has yet been developed on what leadership development programmes in the ECE sector may look like.

The low priority given to leadership development in the ECE sector contrasts with the support provided for leadership development in the school sector. In a 2005 speech to the Principals' Federation the former Secretary of Education stated that "supporting school principals' professional leadership is an important key to raising student achievement" (Ministry of Education, 2005b). Government initiatives supporting leadership in the school sector since 2001 have included an induction programme for first-time principals, a development centre programme for more experienced principals, an electronic principals' network and a guiding framework for professional development (Robinson, Irving, Eddy \& Le Fevre, 2008). Support for leadership development in the school sector includes the use of ICT. The LeadSpace website, for example, provides a "one-stop-shop for the information needs of principals" (Feltham, 2005) and electronic networks have been set up to promote the transfer of knowledge and information. Specific positions exist in the Ministry of Education relating to leadership in schools.

At present there is no equivalent support for leadership in the ECE sector. However, there are some signals that leadership is finally on the agenda of national bodies (Thornton, 2008). Although the 2006 Ministry of Education's annual report listed strong professional leadership as a priority for policy development in both the ECE and schooling sectors, subsequent annual reports published in 2007 and 2008 focus only on leadership in the school sector (Ministry of Education 2006b; 2007b; 2008b). Two other groups whose role is to support teachers, NZEI and the New Zealand Teachers Council, have both recently taken the initiative to promote leadership within the ECE sector. An NZEI position paper, Quality Education for the 21st Century (NZEI, 2006), discusses the importance of professional leadership in both the ECE and school sectors and suggests that the notion of shared leadership should be further explored. NZEI also co-hosted a Kindergarten Leadership Symposium aimed at the presentation and sharing of research on leadership in the New Zealand ECE sector in October 2008. The New Zealand Teachers Council set up an Early Childhood Leadership Think Tank in 2008 with the purpose of focusing on where the interests of the Council and the sector intersect so that leadership within this part of the profession can be supported. Initiatives from this think tank included the development of a position paper to highlight what leadership looks like in ECE, in particular issues, models and future directions. 
Some small scale leadership development initiatives currently exist as part of professional development programmes in different parts of the country but there is no coordination of leadership development and no use of ICT to support leadership learning or knowledge sharing across the sector. A review of New Zealand and international literature on the role and potential of ICT in ECE (Ministry of Education, 2004, p. 79) suggests that "further investigation of the ways to use ICT to strengthen information sharing across settings could provide useful information and understanding".

Research has identified the value of leadership development programmes that encourage reflective practice, peer collaboration, and a focus on problem-solving in real-life situations (West-Burnham, 2003). Wenger's (1998) concept of communities of practice, in which learning occurs through interaction with others, provides a useful framework for exploring the sharing of knowledge about effective leadership between early childhood settings. According to Wenger, "communities of practice fulfill a number of functions with respect to the creation, accumulation, and diffusion of knowledge in an organization" (p. 5). Friesen and Clifford (2003) have suggested that using ICT in teacher professional development provides opportunities for groups of teachers to build knowledge and to create "new interactive professional learning spaces that blend innovative thinking in both e-learning and face-to-face environments" (p. 5). Bradshaw, Powell and Terrell (2004) also promote the use of ICT in supporting the development of communities of practice. They emphasise the importance of the "methods of communication employed to build cohesion and to develop the community's shared understanding of goals, development of knowledge, and sense of belonging" (pp. 199-200).

While communities of practice have potential to support leadership development, it is unlikely their informal nature will provide sufficient structure for a professional development programme. Another process that has potential for supporting leadership development using ICT is action learning. Action learning involves people working in small groups or sets with the support of a facilitator, and has a stronger focus on learning than communities of practice, which have a stronger practice focus. Action learning processes allow set members to share problems or issues from their workplace and through a questioning process, come up with actions that they can implement. The differences and similarities between action learning and communities of practice and their links to reflection will be clarified in the literature review chapter that follows. There appears to be little published research on the use of ICT to support action learning, and what little there is, cautions against totally replacing face-to-face interactions (Powell, 2001; Roche \& Vernon, 2003; Stewart \& Alexander, 2006). Another area of interest is the growing awareness of the benefits of blended learning, which is seen to have the potential to enhance learning experiences (Garrison \& Vaughn, 2008). These authors describe blended learning as "a complex weaving of the face-to-face and online communities so that participants move between them in a seamless manner each with its complementary strengths" (p. 27). 


\subsection{Statement of the problem}

Leadership in the New Zealand ECE sector has long been overlooked and underresourced (McLeod, 2002). Those in leadership positions in ECE settings have few opportunities to learn about leadership or to work collaboratively on issues or challenges arising from their work. The pace of change affecting services and their diversity contribute to the isolation experienced by leaders in the sector. There is currently a lack of research addressing the issue of leadership development in the New Zealand ECE sector. This mirrors the lack of leadership development literature generally (Iles \& Preece, 2006). The importance of support for leadership development has been mentioned in international research studies (Muijs, Aubrey, Harris \& Briggs, 2004); however, most of these do not relate to the New Zealand context and do not offer practical and workable solutions to address the needs of those teachers wanting to learn about and improve their leadership capabilities. ICT has the potential to support leadership development though the formation of online communities of practice as signalled in the Ministry of Education policy documents mentioned above and through the use of action learning. The use of ICT could reduce the isolation experienced by those in leadership positions as it allows frequent contact between leaders from different services, and it could also reduce the amount of face-to-face meeting time required for leadership professional development.

\subsection{Purpose of the study}

The purpose of this research study was to explore how ICT could be used to support leadership development in the New Zealand ECE sector. Action learning groups involving those in leadership positions and those interested in leadership were established and these provided the research participants and data for this study. The action learning groups involved both face-to-face and online interactions, a process known as blended action learning, and the role of the online facilitator and the use of appropriate technologies were of particular interest in this study.

\subsection{The research question}

How can ICT be used to support leadership development within the New Zealand early childhood education sector?

Sub-questions:

- How does the blended action learning process support leadership learning?

- What is the role of the facilitator in a blended action learning group?

- What technologies are most appropriate for supporting leadership development through blended action learning? 


\subsection{Methodology}

This qualitative study took the form of case research with action learning groups as the units of analysis and sources of data. My role as an interpretive researcher involved direct and intensive interaction with the research participants and included the facilitation of a number of action learning sets using a combination of face-to-face meetings and online interactions (blended action learning), as well as collecting data in the form of interviews, emails, online reflective journals, forum entries and chats. Data collection and analysis was concurrent and 'theory for explaining'4 (Gregor, 2006), which helps the understanding of how and why phenomena occur, was developed. The research has been evaluated according to its trustworthiness, transferability, credibility and confirmability in line with constructivist research paradigms (Denzin \& Lincoln, 2000).

\subsection{Significance and benefits of the study}

This study was significant given the fundamental importance of quality early childhood education and the link between effective leadership and quality services. Leadership development is a critical factor in increasing the professionalism and effectiveness of the sector. The role and impact of ICT in supporting and enhancing the effectiveness of those involved in leadership in early childhood settings is an important research topic. This research contributes to our understanding of the role of the facilitator in a blended action learning context and the use of various technologies to support online professional learning. It also has the potential to guide the direction of future policy regarding leadership development programmes in the New Zealand ECE sector.

\subsection{Researcher background}

I have spent my working life in the education sector and since 1997 have worked as a professional development facilitator in the ECE sector in Wellington, New Zealand. My interest in leadership has its origins in my experiences in the playcentre movement. I was involved with playcentre for over 11 years and had many opportunities to develop my own leadership skills and capabilities both through training programmes and experiences such as office holder positions at both local centre and regional level. When I began to work with a more diverse range of services in my role at the Wellington College of Education, later to become part of Victoria University of Wellington, I began to realise that leadership was not much thought about or discussed in ECE.

\footnotetext{
${ }^{4}$ This theory will be elaborated on in Section 3.2.7
} 
I completed a Masters of Education degree focusing on leadership in ECE in 2005. My thesis, entitled Courage, Commitment and Collaboration: Notions of Leadership in the New Zealand Early Childhood Education Centres of Innovation, explored how leadership was defined and enacted in the Centres of Innovation programme funded by the Ministry of Education. This study highlighted the lack of support for leadership development, the lack of leadership development opportunities, and the need to further explore how leadership in ECE can be strengthened by building professional learning communities.

In 2005 I completed a 4-month secondment to the Ministry of Education from my position at the Victoria University of Wellington College of Education. This experience gave me a broader perspective on the education sector and an increased awareness of the need to have research evidence to support policy development. The launch of the ICT framework, Foundations for Discovery (Ministry of Education, 2005a) during the time I was working at the Ministry provided a catalyst for the exploration of how ICT could be used to support leadership development. Over the time I have been involved in this study, I have contributed to a number of the initiatives in the sector aimed at raising the profile of leadership and leadership development, including the kindergarten leadership symposium and the leadership think tank referred to in section 1.4.

\subsection{Organisation of the thesis}

This thesis is organised into nine chapters. Following this introductory chapter is an extensive literature review which examines relevant literature on leadership, leadership development, work-based learning, communities of practice, action learning, facilitation, and reflective practice. The literature chapter concludes with an identification of the gaps in research and theory that will be explored in this study. Chapter 3 discusses the methodology that will be used in this study. The choice of interpretive case research is explained and justified and the research design is outlined including the research question and methods of data collection and analysis. This chapter also introduces the framework employed for the initial phase of data analysis. Chapter 4 describes and compares various aspects of the two research groups including their composition, patterns of interaction and participation in online activities. This is followed by Chapter 5 which presents the leadership journeys undertaken by some more active and some less active participants. This chapter illustrates the differences and similarities between the learning pathways taken by participants. Chapter 6 presents an analysis of the blended action learning process used in this study based on the views of participants. Three aspects of the process: the action learning process; the action learning tools; and the use of different technologies will be discussed and analysed. The focus of Chapter 7 is the role of the blended action learning facilitator. This chapter discusses facilitator experiences and participants' perspectives on the facilitator role in the context of this study before providing an analysis of the blended action learning facilitator role. The chapter concludes with the presentation of a model of stages of blended action learning facilitation which is one of the main contributions 
of the study. The penultimate chapter, Chapter 8 presents a model of leadership learning using ICT, the other major finding, and describes the process by which this model was developed from the research data, namely through the revision of the community of inquiry framework and an analysis of leadership journeys. The final chapter provides an overview of the research process and an evaluation of the various aspects of the study including the researcher role. The contribution of the research and its limitations are discussed and directions for future research suggested.

\subsection{Chapter summary}

This introductory chapter has provided the context for the present research into the use of ICT to support leadership development in the New Zealand ECE sector. It has outlined the use of ICT in the New Zealand education sector and argued that the lack of support for leadership development is a problem that needs attention. Background information has been provided on the New Zealand ECE sector and current leadership development within the sector. The research problem and research questions have been presented along with a short summary of the research method. The background of the researcher has been explained in relation to the context of this study and the structure of the thesis has been outlined. 


\section{Literature Review}

"If your actions inspire others to dream more, learn more, do more and become more, you are a leader." (John Quincy Adams)

\subsection{Chapter overview}

This chapter provides a review of current literature in areas related to this study. The chapter has seven sections. The first section explores both current thinking on leadership theory and practice, in particular the concept of distributed leadership, and approaches to leadership development. The second section provides an overview of the concept of work-based learning and identifies the importance of communities of practice, action learning and reflective practice to the sharing of both tacit and explicit knowledge. These three concepts are then each discussed in some detail. This discussion includes an exploration of their nature, their uses in organisations, leadership development and research, and also how ICT is currently used to support them. The role of the facilitator in both face-to-face and online environments is also discussed. The chapter concludes with an analysis of the links between these concepts and a reflection on how they can be used in the process of researching the use of ICT to support leadership development in the ECE sector.

\subsection{Notions of leadership}

Although the focus of this research is leadership development in the ECE sector, in order to place this study in context, it is necessary to consider literature from the wider field of leadership, in particular the school sector. This section will begin with an attempt to define leadership in the context of this study. This will be followed by discussion on current thinking on leadership theory and practice in general and the concept of distributed leadership in particular. The next section will focus on leadership in the ECE sector and the section will conclude with an exploration of leadership development approaches and strategies.

\subsubsection{Defining leadership}

The need to define leadership in order that we understand how it can best be supported and developed has been emphasised by a number of authors (Bennis, 2007; Dickson, 2008; Lambert, 2003a; Rodd, 2006). The lack of a common understanding of the term may result in a lack of engagement with the concept of leadership. As Lambert (p. 4) suggests, "How we define leadership frames how people will participate in it." The use of the term 'leadership' rather than the word 'leader' has also been promoted by Lambert (2003b) who believes this puts greater emphasis on the collective nature of 
leadership. Dickson agrees suggesting that this differentiation opens up the possibility of leadership being shared and not held only by individuals in formal positions of power.

Defining leadership can be problematic as it can vary so widely between contexts (Scrivens, 2003; Smith \& Piele, 2006). A dilemma also exists as to how broad or narrow to make a definition. Too broad a definition will render it meaningless; however, too narrow a definition can be restrictive (Dickson, 2008). Many definitions of leadership have been proposed, and most conceptualise leadership as a relationship between leaders and followers that involves power (Drath et al., 2008; Kort, 2008). A typical example of such a description would be the following often quoted definition from Burns (1978, p. 18), "leadership over human beings is exercised when persons with certain purposes mobilize, in competition or in conflict with others, institutional, political, psychological and other resources so as to arouse and satisfy the motives of followers."

Drath et al. (2008) have proposed a shift in the way that leadership is conceptualised. These authors promote leadership ontology that reflects the more collaborative nature of modern leadership practice and that will stimulate the growth of new leadership theory and practice. Drath et al. suggest that the tripod conceptualisation of leadership proposed by Bennis (2007), where the three essential elements are leader(s), follower(s) and common goals, should be replaced by three different elements, direction, alignment and commitment. Direction in the context of this model relates to shared goals and understandings, alignment to collectively organising and coordinating knowledge and work, and commitment to the willingness of group members to act for the benefit of the collective. This new ontology, in particular the shift of focus away from interactions between leaders and followers, supports the distribution of leadership across multiple leaders.

For the purposes of this research study I have chosen a recent definition of leadership that I believe supports this revised ontology and that fits with the ideas around educational and distributed leadership that will be discussed in the following sections of this literature review. Leadership in the context of this study can be defined as "the capacity to influence people to work together to achieve a constructive purpose" (Dickson, 2008, p. 155).

\subsubsection{Current thinking on leadership theory and practice}

The thinking around leadership in the field of education has shifted in the last two decades in three significant ways (Robinson, 2004). The first shift is a greater emphasis on educational leadership, that is leadership of teaching and learning, rather than generic leadership and management skills that could apply in any context. The second shift is a focus on leadership practice rather than leadership style. Robinson suggests that the style approach does not help us understand what leaders actually do or what 
effect they have. The third shift involves the challenging of the idea that leadership is something carried out by one person in a formal leadership role, often known as the heroic model of leadership. This model is gradually being replaced in the literature with distributed leadership models which view leadership as a set of activities that can be shared.

The significance of these three shifts is supported by a number of other writers in the field. Educational leadership has been described as "informed actions that influence the continuous improvement of learning and teaching" (Robertson, 2005, p. 41). It also refers to the development of learning communities through capacity building among students, teacher, and parents (Day, Harris, Hadfield, Tolley \& Beresford, 2000). Characteristics of educational leaders include: a willingness to work in innovative and transformative ways that will enhance learning opportunities; an ability to engage in critical reflection; and enthusiasm and energy (Robertson). Stoll, Fink and Earl (2003) suggest that in order to be effective, educational leaders "are continuously open to new learning because the journey keeps changing" (p. 103). The learnings necessary for educational leaders or leaders of learning include: having a deep understanding of the learning process; fostering connections between people in the school community; thinking about the future; understanding the context in which their school operates; thinking critically; having political acumen; and having emotional understanding (Stoll et al.).

This focus on educational leadership provides a contrast with much of the earlier literature which focused on leadership styles such as transactional and transformational leadership. Transactional leadership has been defined as the leadership that takes place when "one person takes initiative in making contact with others for the purpose of exchanging valued things" (Leithwood, Jantzi \& Steinbach, 1999, p. 28). It involves the manipulation of people and situations and is not seen to encourage leadership in others. Transformational leadership is concerned with influencing, inspiring and motivating others in order to make changes in an organisation. Fink (2005) believes that both these models "have serious and conceptual flaws" and are "artificial and disconnected from reality" ( $p$ 5). Day (2003) agrees, suggesting that these theories "do not adequately reflect or explain the current practice of effective leaders" (p. 188).

A focus on leadership practice rather than style is seen to be essential for understanding the effect of leadership in school contexts (Spillane, Halverson \& Diamond, 2004). Four complementary leadership practices that characterise successful leadership have been identified by Leithwood and Day (2007). These are setting directions, developing people, redesigning organisations, and managing instructional programmes. Fink (2005) suggests that leadership practice centres on the how and why of what leaders actually do, and that rather than adopting a particular style, effective leaders play a diversity of roles depending on the situation and context. Goleman, Boyatzis and McKee (2002) do promote a model of leadership styles linked to different components 
of emotional intelligence, but emphasise that effective leaders will use different styles in different contexts. It has been suggested that a better understanding of leadership would be gained by more closely connecting leadership to the realities of the workplace (Gronn, 2002). Spillane (2006) considers that understanding leadership practice or how leadership actually happens "is imperative if research is to generate usable knowledge for school leaders" (p. 7). A practice approach views leadership as something that is distributed over leaders, followers and their situation, rather than a function of an individual's style (Spillane et al.). This view is supported by Sergiovanni (2009) who promotes the practice of leadership being distributed among those who are entitled because of their expertise and commitment.

\section{Distributed leadership}

The notion of distributed leadership was first used in the field of social psychology in the early 1950s and reemerged in the early 1990s in organisation theory and then education (Gronn, 2002). A definition of distributed leadership, developed in the context of self-managing teams, refers to multiple leaders seeking and taking responsibility for different leadership functions and assuming complementary roles (Barry, 1991). This view is premised on the notion that "leadership is a collection of roles and behaviours that can be split apart, shared, rotated, and used sequentially or concomitantly" (Barry, p. 34). According to Gronn, the term distributed leadership has two broad meanings. The first meaning refers to leadership being shared or dispersed across multiple leaders with no particular individuals providing more leadership than others. Gronn describes this view of distributed leadership as minimalist, as it does not involve an increase in leadership potential. The second meaning offers a more holistic perspective and suggests that distributed leadership involves interdependence and coordination. The interdependence aspect of distributed leadership is also emphasised in a case study of the development of a knowledge sharing system (Zhang \& Faerman, 2007). These authors found that distributed leadership was characterised by two factors: interdependence, in that multiple leaders relied on each other; and the emergence and negotiation of leadership roles throughout the course of the project.

Spillane (2006) agrees with the idea that distributed leadership means more than shared leadership and states that it is the "collective interactions among leaders, followers, and their situation that are paramount" (p. 4, original italics). The interactive nature of distributed leadership is also discussed by Timperly (2005, p. 396), who notes that "distributed leadership is not the same as dividing tasks and responsibilities among individuals who perform defined and separate organisational roles, but rather it comprises dynamic interactions between multiple leaders and followers". These comments reflect the notion of distributed leadership as a conjoint activity that produces an additional dynamic. In this second view of the concept, the whole is greater than the sum of its parts. A model of distributed leadership developed by Ancona, Malone, Orlikowski and Senge (2007) suggests that leadership should be viewed as a set of four interdependent capabilities: relating (building trusting 
relationships); sense-making (understanding contextual factors); visioning (developing an image of future possibilities); and inventing (moving from the vision to reality). They believe that the idea of a complete leader is a myth and that leaders need to be cultivating and coordinating the actions of others in their organisations in order that everyone's leadership can be drawn upon.

Although there may be slightly differing understandings of the concept of distributed leadership, according to a literature review carried out in 2003, distributed leadership is distinguished by three key elements:

- leadership is an emergent property of a group of individuals who interact rather than an individual phenomenon;

- the boundaries of leadership are open and fluid; and

- different types of expertise are distributed across many rather than a few (Bennett, Wise, Woods \& Harvey, 2003).

These authors believe that it is the first distinction, that of distributed leadership being a product of collective group activity, which is critical to its understanding. For the purposes of this study, distributed leadership will be defined as leadership that is distributed across group members and is characterised by interdependence and cooperation.

\section{Leaders and followers in models of distributed leadership}

Distributed leadership blurs the distinctions between leaders and followers and opens up the possibility of all members of an organisation exerting influence and demonstrating leadership behaviour at various times (Harris, 2003). Although some writers such as Spillane (2006) still refer to both leaders and followers when discussing distributed leadership, others such as Gronn (2002) do not make this distinction. According to Harris, "the categorisation of leaders and followers becomes redundant as leadership is distributed throughout the organisation" (p. 76).

Distributed models of leadership do not mean that there is not a place for formal or positional leadership roles. A study of 12 high impact nonprofit organisations found that a key to distributed leadership was the positional leaders who operated at the hub of a network rather than from a hierarchical position (Grant \& Crutchfield, 2008). The positional leaders in this study developed leadership in others by sharing information, ideas and resources. Other roles taken by formal leaders that may empower others in the organisation to become involved in leadership activities are role modelling, facilitating and coaching. It has been suggested that the person in a formal leadership position has a major role in managing the organisational dynamics and provides the 'psychological glue' for the organisation (James, Mann \& Creasy, 2007). According to Harris (2004, p. 14), "the job of those in formal leadership positions is primarily to hold the pieces of the organisation together in a productive relationship" and to ensure the maximisation of the organisation's human capacity. She also describes formal leaders as "the gatekeepers to distributed leadership practice" and suggests that they create the 
conditions under which distributed leadership can flourish (Harris, 2008, p. 175). This coordination role can be compared to that of an orchestra conductor whose job it is to ensure that the orchestra members' actions are synchronised and that the skills of the musicians are heard to their best advantage.

\section{Advantages and disadvantages of distributed leadership}

Distributed leadership has a number of advantages over traditional models of leadership. These include that a leadership vacuum is not created when positional leaders leave an organisation, that all members of a group have the opportunity to contribute their strengths and skills, and that organisations with distributed forms of leadership will be more responsive to change. As Harris (2004) has suggested, distributed leadership "concentrates on engaging expertise wherever it exists in the organisation rather than seeking this only through formal position or role" (p. 13). This has the effect of maximising the capacity of people within organisations. According to Hargreaves and Fink (2003), collective intelligence is preferable to individual intelligence:

In highly complex, knowledge-based organisations, everyone's intelligence is needed to help the organisation to flex, respond, regroup and retool in the face of unpredictable and sometimes overwhelming demands. Locking intelligence up in the individual leader creates inflexibility and increases the likelihood of mistakes and errors (p. 443).

The importance of organisations being responsive to changing needs has also been emphasised by Harris (2008) who suggests that leadership sources need to be creative and fluid.

Distributed leadership does have its disadvantages however. Timperly (2005) cautions against distributing leadership in all situations, intimating that, in some cases, the result may be "a greater distribution of incompetence" (p. 417). In Barry's (1991) study of selfmanaging teams, distributed leadership worked only in teams where members realised the potential for different kinds of leadership to coexist. Harris (2004) suggests that traditional hierarchical structures can be a barrier to the adoption of distributed leadership as those in formal positions can resist involving and sharing information with others. There is also the challenge of deciding how to distribute leadership and who makes the decision about the distribution. Other obstacles to the adoption of models of distributed leadership include the belief that one person holds the key to the success of the organisation, and the tendency to equate leadership with position rather than function (Southworth, 2005).

The concept and practice of constructivist leadership has been advocated by Lambert (2003a) who defines it as "the reciprocal processes that enable participants in an educational community to construct meanings that lead toward a shared purpose" 
(p. 10). She suggests that constructivist leaders encourage the construction of meaning through reflection and dialogue, and the challenging of assumptions. Constructivist leadership encourages learning within communities that leads to shared purpose and action. According to Sergiovanni (2009), this notion of leadership encourages capacity building and collective responsibility.

\section{Leadership in ECE}

In contrast to the literature relating to leadership in the school sector, a paucity of research focusing on leadership in ECE exists. This is despite the considerable potential for leadership activity in the sector (Muijs et al., 2004). Rodd (2006) believes that the concept of leadership has received only sporadic attention by theorists and researchers over recent decades. Muijs et al., who conducted an extensive international literature review on leadership in the early years' sector, concluded that research is "limited and dominated by a relatively small number of researchers" (p. 158). They suggest that reasons for this lack of research included reluctance from professionals in the field to engage with the notion of leadership and a lack of willingness to connect with models of leadership from the school sector and beyond.

Rodd (2006) has suggested that leadership is still an enigma for many teachers in the sector. The consequences of this lack of engagement with the concept of leadership are dire. According to Rodd:

Unless there is an active and strong identification and recognition of the leadership role and a broader conceptualisation of their professional role and associated skills, members of the early childhood field will not be able to meet increasing demands for competent administrators, supervisors, educators, researchers and advocates (p. 6).

The need for "further research and dialogue in order to determine what supports and underpins effective leadership in this family-focused, female dominated and often under-resourced field" has been emphasised (Henderson-Kelly \& Pamphilon, 2000, p. 9). Muijs et al. (2004) also highlight the consequences of the lack of engagement with the concept of leadership suggesting "the relative lack of research activity on leadership in the field and by association the lack of leadership development programmes would seem to be a major oversight given the growth and importance of the EC sector" (p. 160).

Other studies have identified a lack of awareness and a level of discomfort with leadership roles amongst those in leadership positions in ECE settings (Geoghegan, Petriwskyj, Bower \& Geoghegan, 2003). Scrivens (2002, p. 52) has commented "there is still confusion in the minds of leaders, particularly at centre level, about how they should construct leadership". The unwillingness of those in the ECE sector to engage with the concept of leadership may be attributed to a number of factors including a lack 
of identification with commonly accepted notions of leadership and a lack of support for leadership development. The view that leadership is about a single person and that leaders are concerned with competitive and product-oriented organisations obviously does not fit the early childhood sector, which has a non-hierarchical structure and is dominated by women (Ebbeck \& Waniganayake, 2003). Hard (2004) suggests that traditional definitions of leadership in male terms may be a significant contributing factor in the unwillingness of the ECE sector to embrace the concept of leadership. The high proportion of women in leadership roles in the sector may be one explanation for the "potential aversion to leadership often found in the sector" (Muijs et al., 2004, p. 159). Henderson-Kelly and Pamphilon (2000) stress the importance of developing models of leadership that maximise the leadership strengths of females who numerically dominate the sector. They suggest that these strengths include wisdoms related to people, emotions, roles and resources.

A lack of connection between the literature on school leadership and leadership in ECE has been noted (Muijs et al., 2004). Reasons for this may include differences between the sectors and the diversity of the early childhood field. The lack of understanding and consensus on what leadership involves has also been attributed to the "complexity of the field and the wide variety of program types" (Schomburg, 1999, p. 215). Rodd (2001, p. 10) has argued that "leadership is a contextual phenomenon, that is, it means different things to different people in different contexts". Scrivens (2003), drawing on Southworth's (2002) work, agrees. She has contended that "there is not just one way to be a leader" and that "leadership will vary from culture to culture and situation to situation" (p. 30). The diversity of the sector makes a common understanding of the notion of leadership problematic.

There has been debate about the similarities and differences between leadership in ECE and in the school sector or corporate world. Although some characteristics of leadership such as vision, courage and ethics; consideration of work culture; and productive work style (Kagan \& Hallmark, 2001) appear to be universal, several writers have identified and discussed major differences between leadership in early childhood and in other settings. Henderson-Kelly and Pamphilon (2000, p. 9), in a discussion of the relevance of generic leadership and management language and practices to childcare, comment that "many ideas provided structure and affirmation to the children's services leaders' work; however, an equal number provided contradictions". Kagan and Hallmark claim that "the intimacy, flexibility, diversity and individualization of early childhood programmes create a decidedly different leadership context than the formality, uniformity, rigidity, and bureaucratization that has been conventionally associated with the corporate setting" (p. 8). Many of the commonly accepted definitions of leadership are not appropriate for early childhood settings because of the more collaborative way early childhood teachers work and the lack of a hierarchical structure in the profession (Morgan, 1997). 
More recent literature has minimised the differences between ECE and the wider field of education. Rodd stated in an interview (as cited in Ebbeck \& Waniganayake, 2003) that "being a leader is not at all different from being a leader in any other field. Effective leadership, be it of a large multi-national company or a child-care centre, requires certain attitudes, attributes and skills" (p. 22). The more recent literature on conceptions of leadership in the wider field of educational leadership discussed above (Hargreaves \& Fink, 2003; Harris, 2003; Lambert, 2003b) suggest frameworks more in line with the collaborative leadership approaches favoured in the ECE sector, so it appears the differences are becoming less significant. Aubrey (2007) supports the early childhood sector adopting distributed models of leadership as she believes these embrace the notion of leadership occurring within learning communities. There seems to be general agreement in the literature that identification with leadership is related to how it is defined. As Hard (2004, p. 127) suggests, "if leadership were to be considered in terms of more democratic and collaborative models, then ECEC (early childhood education and care) personnel will be more positive about adopting leadership activities".

A study exploring notions of leadership in the New Zealand Centres of Innovation programme found that leadership in these centres was characterised by courage, commitment and collaboration (Thornton, 2005). The Centres of Innovation programme is a government funded initiative designed to "help improve quality in early childhood education services by demonstrating competent practice and innovation" (Meade, 2003, p. 1). Centres that are able to demonstrate innovative practices can apply for Centre of Innovation status which allows them to work in partnership with research associates over a 3-year period to develop, document and share their learning and teaching practices. A definition of leadership developed as a result of this study is "working collaboratively in a learning community towards a shared vision" (Thornton, p. 93). This notion of leadership fits with the literature on distributed leadership as it suggests that leadership is a joint and collaborative activity. It also fits with the definition offered in Section 2.2.1. This earlier research highlighted a lack of clarity about educators' understandings of leadership, and a lack of support for leadership development, a situation that will be discussed in more detail in Section 2.2.4.

\subsubsection{Leadership development}

A distinction between leaders and leadership was made in Section 2.2.1 of this chapter, and a similar distinction has been made between leader development and leadership development (Day, 2000; Drath et al., 2008; Iles \& Preece, 2006). According to Iles and Preece, most leadership development programmes are actually leader development programmes as they focus on individual leaders rather than on wider organisational contexts and processes. Day, in a discussion on the difference between the two, suggests that leader development focuses on human capital and the development of intrapersonal competences, while leadership development focuses on social capital and 
is based on building interpersonal competences. Both Day, and Iles and Preece caution against choosing one approach over another as they agree that both have their place. The development of individual leadership skills is important; however, this should not be at the expense of relationships and interactions within a social context (Day). Leadership development has been defined as "expanding the collective capacity of organizational members to engage effectively in leadership development roles and processes" (Day, p. 582). James et al. (2007) promote models of leadership development that encourage distributed leadership and also believe that formal leaders "need to learn how to support distributed leadership" (p. 79).

\section{Approaches to leadership development}

The conceptualisation of leadership development described in the previous paragraph involves an ongoing process of learning that occurs in context and that benefits the whole organisation. This contrasts with traditional approaches to leadership development that involve removing individuals from their work contexts and training them in the skills deemed to be necessary for effective leadership. Marquardt (2004a) has suggested that many leadership programmes are ineffective because experts rather than practitioners are seen as the source of knowledge and "little, if any, of the knowledge ever gets transferred to the workplace" (p. 31). The lack of opportunities for reflection and self-questioning in many leadership development programmes has also been noted (Dotlich, Noel \& Walker, 2004). Raelin (2004) cautions against detaching leadership learning from leadership practice. He suggests that typical approaches to leadership development such as the 'list approach', where training is designed to teach people a set list of leadership attributes, or the 'position approach', where leadership development is targeted only at people in certain positions in an organisation, are unlikely to have long-term benefits for either the individual or the organisation. This is because these approaches remove people from real-life situations so that learning is not contextualised, and promote singular rather than collective approaches to leadership. Other authors such as Southworth (2005), and Walker and Dimmock (2005) also emphasise the importance of context in leadership development, suggesting that much leadership development is too generic and may lack relevance for individuals. The importance of leadership development being an ongoing process rather than a one-off experience has also been stressed (lles \& Preece, 2006).

A range of strategies that need to be in place for effective leadership learning to occur has been proposed by West-Burnham (2003). These include:

- learning activities that are based on problem-solving in real-life situations;

- $\quad$ reflection on actual experiences based on appropriate feedback;

- $\quad$ challenge derived from new ideas, confronting performance etc.;

- $\quad$ coaching to help mediate the perceived gap between actual and desired performance;

- $\quad$ and the creation of a community of practice to support the above (p. 58). 
Day et al. (2000) also emphasise the importance of problem solving and reflective practice in leadership development programmes and promote the analysis of professional and personal values and an emphasis on intrapersonal and interpersonal skills. James et al. (2007) promote a collaborative approach to leadership development that supports the formal leaders' role in distributing leadership in their organisation. The importance of embedding teachers' professional development in practical activities in order that they are able to keep up with and adapt to the rapid change occurring in their daily work has been promoted by Stoll and Bolam (2005), who support leadership development that occurs at all levels in educational institutions and the building of collaborative relationships with others both within and outside of schools.

One leadership development programme that appears to incorporate many of the characteristics described above is the New Visions programme for new head teachers, which has been operated by the National College for School Leadership in Britain since 2000. The aims of this programme include supporting new leaders, connecting leaders with each other, and building collaborative learning habits (National College for School Leadership, 2005). This programme, which has been extensively evaluated, uses a mixture of "active, collaborative and dialogic approaches" (Paterson \& West-Burnham, 2005, p. 108). Several areas that are not usually provided for in leadership development are addressed in this programme, including time for analysis and reflection, opportunities for interacting with peers, and advice and support from more experienced leaders. Three fields of knowledge, the knowledge of individual head teachers, the knowledge informed by research and theory, and the knowledge created within the community of head teachers, guide the learning in this programme. Activities within the programme are "designed to extend, deepen and connect these three fields of knowledge" (p. 115). A number of features of this programme offer a useful model for leadership development. These include: the value put on the personal knowledge and experience of these leaders and the opportunities for them to articulate this and develop shared knowledge; the focus on deep and profound learning which is achieved principally through reflective practice and approaches such as action learning; and the development of communities of practice that offer opportunities for supporting both individual and collaborative learning. Paterson and West-Burnham also report on other studies highlighting the importance of interacting with peers in leadership programmes, with the most beneficial types of support shown to be networking and personal discussions with other leaders, and critical friendships.

The importance of leaders developing self-awareness and social awareness, and having a commitment to ongoing learning is emphasised in much of the leadership development literature. Goleman et al. (2002) promote the importance of both selfawareness, and social awareness, the most important characteristic of which is empathy. Self-awareness is described as "having a deep understanding of one's emotions, as well as one's strengths and limitations and one's values and motives" (p. 40). These authors suggest that heightened self-awareness encourages 
thoughtfulness and reflection. George, Sims, McLean and Mayer (2007) contend that self-awareness is the most important capability leaders can develop and that as they become more self-aware, leaders are more likely to demonstrate authentic and effective leadership. These authors recommend that leaders learn by understanding how their life stories have impacted on their leadership. They also suggest that authentic leaders are more likely to empower those around them to become involved in leadership. A model of leadership development for school leaders promoted by Donaldson (2008) encourages the development of three knowledge domains, cognitive, interpersonal and intrapersonal. The core knowledge areas involved in interpersonal learning in this model are forming relationships and mobilising others. The intrapersonal learning process which includes both self-awareness and self-management occurs largely through reflection and feedback. This focus on developing self-awareness is also promoted in the New Visions programme described earlier. One of the fundamental principles the programme is based on is the development of personal understanding, and participants are encouraged to analyse and reflect on their personal leadership practice (National College of School Leadership, 2005).

\section{Leadership development in ECE}

The literature discussing effective leadership development programmes in the school sector contrasts with the lack of research and practice in ECE. The lack of leadership development programmes has been identified as a key issue in the ECE sector (Muijs et al., 2004). Studies in a number of different countries report a lack of preparation for leadership roles and a lack of training opportunities particularly at national levels (Aubrey, 2007; Bloom \& Bella, 2005; Nupponen, 2006; Rodd 2006). The lack of support for leadership training and professional development has also been suggested as a contributing factor to the low profile leadership has in the sector (Ebbeck \& Waniganayake, 2003). Initial teacher training is aimed at developing capable and competent teachers and although there are many similarities between good teaching and good leading, there is general agreement that those in leadership roles need to be further supported through the provision of appropriate training and professional development opportunities (Aubrey, 2007; Bloom \& Bella, 2005; Geoghegan et al., 2003; Hard, 2004; Rodd, 2006; Schomburg, 1999; Smith, 2005). Muijs et al. (2004) suggest that the consequences of a lack of leadership training programmes will be that those in leadership positions are unprepared for their leadership and management responsibilities. They state that there is a compelling reason for "investing substantially in leadership research and development" (p. 167) and suggest that this is long overdue.

Recent New Zealand studies have revealed a lack of support for leadership development in the ECE sector (Reynolds \& Cardno, 2008; Thornton, 2005). Reynolds and Cardno interviewed leaders in education and care centres to establish the incidence and nature of leadership dilemmas they faced. They concluded that in order for these leaders to feel confident to deal with dilemmas they needed professional development that included "forums to discuss their dilemmas and build confidence to confront 
them" (p. 27). None of the participants in Thornton's Centre of Innovation study mentioned any formal leadership development and support opportunities and several commented that they felt unprepared for some of the leadership roles they were expected to take. Study participants made a variety of suggestions for future leadership development programmes. These included leadership development for all teachers, particularly as professional leadership is one of the criteria for teacher registration in New Zealand, and support from mentors. Strategies for supporting leadership need to encourage the development of distributed or teacher leadership. The evidence that this collaborative style of leadership is influenced by the support and encouragement provided by those in designated leadership positions also needs to be taken into account in planning leadership development. Mentoring and formal opportunities for reflecting on models of leadership and emotional intelligence were both mentioned as important aspects of leadership development.

\section{Current forms of leadership development}

Most teachers who have experienced leadership training report that it has taken the form of disparate workshops with no follow-up support (Muijs et al., 2004). A number of longerterm programmes do, however, exist in some countries. The National Professional Qualification in Integrated Centre Leadership (NPQICL) in Britain provides opportunities for study towards a professional qualification in leadership and management equivalent to the programmes available to senior staff in schools. The NPQICL is a programme of study and research that involves participants working collaboratively with others and emphasises the importance of reflective practice (Jones \& Pound, 2008; Pen Green Research, 2004). Several 1 or 2-year-long programmes are offered in different parts of the United States that involve leadership training and mentoring (Bloom \& Bella, 2005; Smith, 2005). Bloom and Bella, in a discussion of the impact of leadership training initiatives in the State of Illinois, reported that participants experienced a sense of empowerment, an increase in their advocacy roles, and a shift in priorities from day-to-day management tasks to broader leadership challenges. Bloom and Bella have proposed a number of key elements that serve as a framework for planning effective leadership development programmes. These include: basing the programme on participants' assessed needs; making the training problem focused and specific to the workplace context; focusing on the role of the leader as change agent; ensuring the needs of busy working professionals are met; providing opportunities for collegiality and networking across different ECE services; promoting active learning; and ensuring follow-up support is available.

In the New Zealand ECE context, recent research has suggested that aspects of professional development that support distributed leadership include mentoring and coaching, networking and collaboration and long-term involvement (Clarkin-Phillips, 2007). This study, which explored a particular model of professional development, focused on the impact of effective leadership on pedagogical change. Findings of the research included that distributed leadership is "a significant factor in empowering teachers and affording them opportunities for ongoing learning and leadership" (p. 132). 


\subsubsection{Implications for leadership development in the New Zealand context}

There are currently no national leadership development programmes in place in the New Zealand ECE sector. Despite the Government's Strategic Plan stating under the goal of improving the quality of ECE services, that leadership development programmes will be provided to strengthen leadership in ECE services (Ministry of Education, 2002), no policy has yet been developed or strategies put in place. Some small scale programmes do exist as part of the general professional development contracts funded by the Ministry of Education; however, these only cover some areas of the country and are not on a scale that allows widespread participation. There is potential for leadership development in the sector. The literature reviewed so far in this chapter helps to identify key aspects of leadership development that can inform future leadership development in the sector. The New Visions leadership programme described above, with its emphasis on the three fields of knowledge and its use of communities of practice and action learning, is of particular interest. Opportunities to engage in reflective practice and to work on real-life issues and problems in collaboration with others are important aspects of effective leadership development that will be explored further in this literature review.

\subsubsection{Section summary}

This discussion on notions of leadership has highlighted the rather frail state of leadership and leadership development in the New Zealand ECE sector. Although the increasing acceptance of the value of distributed approaches to leadership in the wider education sector is encouraging as it is supportive of the way leadership is enacted in the ECE sector, considerable progress still needs to be made to raise the profile and awareness of leadership in the sector. The diversity of the sector makes a common understanding of the notion of leadership problematic and the lack of a coordinated approach to leadership development is of concern. The next section of this literature review will consider different approaches to work-based learning, including communities of practice, action learning and reflective practice all of which are potentially beneficial approaches to leadership development.

\subsection{Work-based learning}

A number of different terms have been used to describe learning that occurs in context rather than in isolation. These terms include student-centred learning, situated learning and work-based learning. Student-centred learning environments have the purpose of supporting "individual efforts to negotiate meaning while engaged in authentic activity" (Land \& Hannafin, 2000, p. 2). Jonassen and Land (2000) suggest that studentcentred learning environments differ from traditional instruction in that the learning is embedded in experience rather than being decontextualised, it involves interpretation and construction rather than transmission and retrieval, and is collective rather than 
individual. The concept of situated learning (Lave \& Wenger, 1991) emphasises the social nature of learning and suggests that learning is situated in social processes rather than in the minds of individuals. The advantages of online learning environments in supporting situated learning has been discussed by McConnell (2006), who suggests that virtual learning environments encourage social learning environments and selfdirected learning.

The concept of work-based learning will be explored in more detail as it offers opportunities for leadership development using communities of practice, action learning and reflective practice. Work-based learning involves people learning through a process of reflecting on actual experiences. It does not necessarily refer to learning that actually occurs at the workplace, but rather to learning that is based on issues related to real life situations. Raelin (2000) has proposed three elements critical to the process of work-based learning. These are:

1. that learning is based on actual workplace issues;

2. that knowledge creation is a collective responsibility; and

3. that the learners are encouraged to question underlying assumptions of practice.

Work-based learning combines action and theory. According to Raelin, "theory makes sense only through practice, but practice makes sense only through reflection as enhanced by theory" (p. 53).

\subsubsection{Models of work-based learning}

Work-based learning involves the sharing of both explicit and tacit knowledge, whereas conventional learning methodologies tend to rely on the transmission of explicit knowledge (Raelin, 2000). Explicit knowledge has been described as knowledge that can be "expressed in words, numbers, or sounds, and shared in the form of data, scientific formulas, visuals, audiotapes, product specifications, or manuals" (Takeuchi \& Nonaka, 2004, p. 3). Explicit knowledge can be transmitted through formal language, unlike tacit knowledge which has a personal quality and cannot be easily shared through formal language (Nonaka, 1994). Tacit knowledge, which includes knowledge about practice, is seen to be more personal and is "deeply rooted in an individual's action and bodily experience, as well as in the ideals, values, or emotions that they embrace" (Takeuchi \& Nonaka, pp. 3-4).

Different views exist concerning the transferability of the different forms of knowledge. Cook and Brown (1999) suggest that tacit, explicit, individual and group knowledge are all distinct forms of knowledge and that "each form does work the others cannot" (p. 382). They believe that tacit knowledge cannot be changed into explicit knowledge and vice versa; however, each can be used as an aid to generating the other. The dialogue between tacit and explicit knowledge has also been explored by Takeuchi and Nonaka (2004), who argue that they are both complementary and interdependent and that "there 
is some explicit knowledge in every tacit knowledge, and some tacit knowledge in every explicit knowledge" (p. 7). Nonaka (1994) suggests that knowledge held by individuals and organisations can be increased and enhanced through "the spiral, interactive amplification of tacit and explicit knowledge" (p. 34). He describes four modes of knowledge creation: socialisation, in which tacit knowledge is created through shared experience; combination, in which different bodies of explicit knowledge are combined; externalisation which is the conversion of tacit knowledge into explicit knowledge; and internalisation, which is the conversion of explicit knowledge into tacit knowledge. Externalisation involves making tacit knowledge verbally explicit and occurs through a process of sharing and reflecting with others (Jarvinen \& Poikela, 2001). This process of collective reflection is a key aspect of communities of practice and action learning that will be discussed in the following section.

Raelin (2000) has proposed models of work-based learning that apply to both individuals and collectives, and that address both theory and practice and tacit and explicit forms of knowledge. These models are presented in tables 2-1 and 2-2 below.

\begin{tabular}{|l|l|l|}
\hline & \multicolumn{2}{|c|}{ Forms of Knowledge } \\
\hline Modes of Learning & Explicit & Tacit \\
\hline Theory & Conceptualisation & Experimentation \\
\hline Practice & Reflection & Experience \\
\hline
\end{tabular}

(Raelin, 2000, p. 55)

Table 2-1: A model of work-based learning (Individual level)

This individual level model describes processes that help individuals learn effectively within their work contexts. Conceptualisation involves using theory to form concepts whereas experimentation involves trying out theoretical knowledge in practical situations. Reflection involves making one's practice explicit, whereas experience "reinforces the tacit knowledge acquired in experimentation" (Raelin, 2000, p. 57). Reflection will be revisited in a later section of this chapter in a discussion of the concept of reflective practice. Raelin suggests that it is the interplay between these different processes that makes work-based learning at an individual level most effective.

\begin{tabular}{|l|l|l|}
\hline & \multicolumn{2}{|c|}{ Forms of Knowledge } \\
\hline Modes of Learning & Explicit & Tacit \\
\hline Theory & Applied science & Action learning \\
\hline Practice & Action science & Community of practice \\
\hline
\end{tabular}

(Raelin, 2000, p. 61)

Table 2-2: A model of work-based learning (Collective level) 
This model describes work-based learning at a collective level. It is the processes of sharing tacit knowledge through communities of practice and action learning that are most relevant to this research; however, before these concepts are explored in detail, the explicit processes of applied science and action science will be briefly explained. Applied science refers to knowledge that is seen to be objective, has been scientifically tested, and offers theories of action. Raelin (2000) describes applied science as "the classic and familiar approach to learning used in most of the world" (p. 61). Action science aims to bridge the concepts of action and science and has been described as a "science of practice" (Argyris, Putnam \& McLain Smith, 1985, p. 4). Action science allows members of a community or organisation to increase their professional effectiveness by reflecting on and resolving complex workbased problems (Action Science Network, 2006).

\subsubsection{Work-based learning and leadership development}

The contextual nature of leadership makes work-based learning particularly suited for leadership development (Raelin, 2004; Southworth, 2005). Raelin believes that aspects of work-based learning that encourage leadership development include the demonstration of a learning-to-learn orientation; viewing learning as obtained in the process of acting; and viewing knowledge creation as a collective activity. Skills and leadership styles that worked in stable environments will not necessarily work in rapidly changing environments; therefore leadership development needs to empower those in leadership roles to create new knowledge and build new insights into their leadership practice (Stott \& Sing Kong, 2005).

\subsection{Communities of practice}

Communities of practice are seen as an important vehicle for work-based learning and for sharing knowledge about practice. Before communities of practice are defined and discussed in more detail and their uses explored, they will be placed in the context of knowledge management and knowledge sharing.

\subsubsection{Communities of practice and knowledge management}

Communities of practice have been described as "the cornerstones of knowledge management" (Wenger, 2004, p. 2) and "the single most significant, tangible example of knowledge management at work in an organization" (Saint-Onge \& Wallace, 2003, p. 50). Wenger suggests that although much time has been spent in the definition of the term knowledge, everybody intuitively knows what it is. Davenport and Prusak (2000) contend that knowledge is a mixture of various elements: information; experience; insights; and values, and suggest that it "provides a framework for evaluating and incorporating new experiences and information" (p. 5). Knowledge has been defined more specifically by Bartol and Srivastava (2002, p. 65) as "information, ideas, and expertise relevant for tasks performed by individuals, teams, work units, and the organization as a whole". 
Knowledge management involves building on past experiences and finding new ways of creating and exchanging knowledge (Kakabadse, Kakabadse \& Kouzmin, 2003). Swan, Newell, Scarborough and Hislop (1999) define knowledge management as "any processes and practices concerned with the creation, acquisition, capture, sharing and use of knowledge, skills and expertise" (p. 264). Three major mechanisms for individuals to share their knowledge in organisations have been identified by Bartol and Srivastava (2002). These are: contributions to organisational data bases; the sharing of knowledge in both formal and informal interactions; and sharing of knowledge within communities of practice. Some overlap between these mechanisms is acknowledged.

The interplay between explicit and tacit knowledge is seen as a crucial factor in organisational learning (Davenport \& Hall, 2002). Both tacit and explicit knowledge can be exchanged through the sharing of experiences (Saint-Onge \& Wallace, 2003). It has been suggested that the embodied expertise existing in tacit knowledge is more valuable to the process of knowledge management; however, this is also more difficult to transmit to others (Archer, 2006). Processes inherent in communities of practice such as conversation, coaching and apprenticeship are particularly well suited to the sharing of tacit knowledge.

\subsubsection{What are communities of practice?}

The term community of practice was coined by Lave and Wenger during their study of apprenticeships as a model of learning (Wenger, 2006). Wenger et al. (2002) define communities of practice as "groups of people who share a concern, a set of problems, or a passion about a topic, and who deepen their knowledge and expertise in this area by interacting on an ongoing basis" (p. 4). As mentioned above, communities of practice are one way in which knowledge can be shared between individuals in organisations. According to Wenger (2004), communities of practice "explicitly enable the management of knowledge to be placed in the hands of practitioners" (p. 2). The operation of communities of practice has been described as "a meeting of the minds" through which "community members are able to pool their expertise, share their experience, test new ideas, improve on past processes and procedures, and find solutions that result in increased capability and improved performance" (Saint-Onge \& Wallace, 2003, p. 31).

According to Wenger et al. (2002), communities of practice share three fundamental elements: a shared domain of interest; joint activities and information sharing; and shared practice. These authors believe that it is the combination of the three factors that enables communities of practice to manage knowledge. The domain creates a sense of common identity and purpose and "inspires members to contribute and participate, guides their learning, and gives meaning to their actions" (p. 28). A domain consists of "key issues or problems that members commonly experience" (p. 32). The community will not succeed if the domain does not inspire its members. The joint activities and 
information sharing engaged in by community members comprise the community aspect of a community of practice. Regular interactions are essential for building the community element and include relationship building, learning together, and a sense of belonging and mutual commitment. The final element of the community of practice structure, the practice, refers to the knowledge developed, shared and maintained by the community or more specifically as "a set of common approaches and shared standards that create a basis for action, communication, problem solving, performance, and accountability" (p. 38).

Communities of practice can benefit organisations through the management of knowledge in three ways: accessing existing knowledge; exchanging knowledge gained through sharing knowledge; and creating new knowledge. As well as benefiting the organisation through managing the knowledge they need to be successful, communities of practice also advantage individuals as they allow practitioners to develop expertise by engaging with others in similar situations (Wenger et al., 2002). The following quote explains how a community of practice benefits both individuals and organisations:

Communities of practice members typically solve problems, discuss insights and share information. They talk about their lives, interests and ambitions. They mentor and coach each other, make plans for community activities (meetings and conferences as well as social gatherings), and develop tools and frameworks that become part of the common knowledge of the community. Over time, these mutual interactions and relationships build up a shared body of knowledge and a sense of identity (Wenger \& Snyder, 2000, p. 3).

Communities of practice support reflective practice by allowing members to both engage and distance themselves from the community (Wenger, 1998). Buysse, Sparkman and Wesley (2003) put forward reflective practice and situated learning as two central principles of the community of practice framework. They emphasise the importance of reflection suggesting that "ongoing reflection with others about the intersection of professional knowledge and experience is one of the cornerstones of the community of practice approach" (p. 267). They also suggest that shared inquiry, a focus on issues of relevance to practice, and learning that takes place within a social context make communities of practice reflect a situated learning perspective.

\subsubsection{Naturally evolving versus planned communities of practice}

There has been considerable debate over whether communities of practice are likely to evolve naturally or should be designed (Barab, 2003). The term cultivation is often used when discussing the development of communities of practice, as organisations can create environments in which communities can flourish and reach their full potential (Wenger et al., 2002). There does, however, appear to be a dilemma regarding the cultivation of communities of practice, described as an 'odd irony' by McDermott (2001). This dilemma concerns the belief that communities of practice are organic and 
naturally occurring versus the reality that unless they are supported and organised to some degree they are unlikely to survive and prosper. Saint-Onge and Wallace (2003) note that communities of practice do not "represent an organisational form that people naturally gravitate toward", therefore they usually "need to be assisted in their creation and development" (p. 78). McDermott suggests that although communities are often informal and organic, they also require support and legitimacy in order that they can reach their full potential. According to Wenger (1998), communities of practice "can be recognized, supported, encouraged, and nurtured, but they are not reified designable units" (p. 229).

The creation of communities of practice for the purpose of improving teacher practice has been promoted by Palincsar, Magnusson, Marano, Ford and Brown (1998). They report on a community of practice that brought 18 teachers together who were interested in improving their teaching of science. It was decided to create this community rather than allow a natural evolution, as the authors suggest "the contexts in which teachers generally work are not conducive to the natural flourishing of communities of practice" (p. 17). Although this community was artificially created, it has since shown many of the characteristics of a naturally evolving community such as negotiation of meaning, multiple funds of knowledge, and opportunities for meeting the social and professional needs of community members. Wesley and Buysse (2001) contrast the communities of practice approach to professional development with typical top-down approaches to learning. They suggest that communities of practice promote the acceptance of "the conceptual analyses and interpretive knowledge of practitioners and families as part of a redefined knowledge base, rather than relying on the traditional approach of discovering new knowledge through the scientific method" (p. 122).

\subsubsection{Uses of communities of practice}

Communities of practice exist in a wide variety of domains and organisation. They vary from informal groups to communities with formal structures and comprehensive technical support. This section will provide an overview of some of the current uses of communities of practice focusing on general organisational use, use in leadership development, and in research.

\section{In organisations}

Many people belong to communities of practice that are so informal and unstructured that the members are often unaware of their existence. The focus in this literature review is on participation in communities of practice that have some degree of organisation. Communities of practice have existed for many centuries. The earliest communities may have been informal groups of craftsmen that eventually developed into craft guilds and then professional associations (Archer, 2006). Lave and Wenger (1991) studied various communities of practice including butchers, midwives, tailors 
and non-drinking alcoholics. Wenger et al. (2002) list a variety of organisations in a range of sectors and industries that are encouraging the development of communities of practice. These include banks, software companies, car manufacturers, military services, social workers, educational groups and not for profit organisations. Nicholls (2006) suggests that communities of practice are best suited to organisations in which the tacit knowledge to be shared relates to a craft, such as aluminium smelting or glass manufacturing. He describes how practitioners in these industries participate in communities of practice in order to strive for best practice and improve the efficiency of organisational processes.

Communities of practice are most commonly used in the field of education to support teacher professional development as they offer opportunities for improving classroom practice (Palincsar et al., 1998). Schlager, Fusco and Schank (2002) suggest that the idea of a community of practice is "central to effective teacher professional development" (p. 155). Buysse et al. (2003) define a community of practice in the context of professional development as "a group of professionals and other stakeholders in pursuit of a shared learning enterprise, commonly focusing on a particular topic" (p. 266). A community of practice approach offers professional development that is grounded in everyday activities (Moore \& Barab, 2002) and in which "learners work to solve ill-defined problems through engagement with authentic tasks" (Friesen \& Clifford, 2003, p. 3). Teachers, who are often isolated in their classrooms, benefit from opportunities to share teaching practices and to participate in reflective discussions.

Examples of online communities of practice described in some of the recent literature cover a wide range of professions and industries and include: coordinators of adult learning councils (Gray, 2004); teachers of maths and science (Moore \& Barab, 2002); knee patients and science teachers (Jones \& Preece, 2006); and providers of virtual community services including health and library services (Horan \& Wells, 2005).

\section{For leadership development}

Although communities of practice are frequently used to support teacher professional development, there seem to be very few examples of how they are used specifically to support leadership development. The Talking Heads online learning community for head teachers in English schools, developed by UltraLab in partnership with the National College for School Leadership, is one programme that has used a community of practice model (Talking Heads Team, 2002). It is an informal online learning community set up with the purpose of supporting head teachers to participate in discussions on current issues and to provide and receive advice and support. Talking Heads provides a variety of online spaces including the 'Community of Talking Heads', a news and conversation space for all head teachers, home communities and cohort communities for smaller groups. These different communities have slightly different purposes and head teachers participate in them in different ways. An evaluation of the Talking Heads initiative found that isolation had been reduced, head teachers had been 
encouraged to share effective practices leading to the development of a body of knowledge, and stronger links had been developed between those in leadership positions in schools (Talking Heads Team).

Another example of an online learning community designed to support leadership learning is described by Sernak (2005/2006). The purpose of this online community was to "enhance teachers' leadership ability and to build a learning community among teachers" (p. 148). Graduate students studying educational leadership at two universities in different parts of the United States took part in face-to-face classes at their own sites and were paired with students from the other university for the purpose of online discussions. A listserv was also available for all students to explore and discuss issues. A qualitative study of this programme found that the more contact students had in the early stages, the more trust they had in their partners and the more information they consequently shared about their professional beliefs and actions.

\section{In research}

Communities of practice can be used in various ways to both promote and support research. Communities of practice can be a site for research, a support for researchers and can also help break down the barriers between research and practice. Buysse et al. (2003) have identified the importance of practitioners being involved in the process of identifying recommended educational practices rather than solely relying on researchers to do this. They suggest that encouraging more teacher involvement in educational research will result in a closer match between research and practice, and they specifically recommend communities of practice as offering:

The most promise for altering the linear relationships through which knowledge is handed down from those who discover the professional knowledge to those who provide and receive educational service. The potential for practitioners and researchers to co-construct knowledge exists in this model because communities of practice represent an ongoing enterprise that invites both groups to share, build upon, and transform what they know about effective practices (p. 265).

Buysse et al. also caution that working in a community of practice can be a challenge for researchers as there needs to be an acceptance that it is the practice community that has mastery rather than the expert.

Communities of practice also provide a site for research activity. Some researchers have studied existing communities of practice and others have formed communities for research purposes. Buysse et al. (2003) suggest that a community of practice perspective can be incorporated into existing practice and research activities. Davenport and Hall (2002) comment that "from a constructivist perspective, communities of practice, like other socio-technical systems, provide useful explanatory frames to study the 
development of collective knowledge" (p. 210). These authors also describe communities of practice as "a compelling unit of analysis" (p. 212). Schlager and Fusco (2003) believe that analysing the online activities of community of practice members could "help uncover patterns of interaction, group and individual relationships, and roles played by different members - the social structures through which knowledge is generated and spread through the community" (p. 214).

\subsubsection{ICT and communities of practice}

Communities of practice are increasingly relying on ICT to enable members to communicate and share their practice. The use of online communities of practice is strongly promoted by the New Zealand Ministry of Education in both schools and ECE settings as discussed in the introductory chapter. The degree of ICT use varies between communities. Some communities have no face-to-face contact and are often known as virtual communities, whereas others rely on a combination of face-to-face meetings and online technologies. Lai, Pratt, Anderson and Stigter (2005) distinguish between online communities of practice that use primarily computer-mediated communication possibly supported by face-to-face meetings, and co-located communities of practice that primarily communicate face-to-face but may be supplemented by computermediated communication. In this section a number of issues relating to the use of ICT to support communities of practice will be discussed including the best use of technology and the benefits of blended communities.

\section{Online technologies}

A variety of technologies are used to support communities of practice including email, telephone, asynchronous discussion forums, synchronous web-based chat forums, and audio and video-conferencing. Several writers have emphasised the importance of technology supporting rather than leading the development of communities of practice (Chua, 2006; Kling \& Courtright, 2003; Schlager \& Fusco, 2003). Chua stresses that communities of practice "cannot and should not be driven by technology alone. Instead, the role of technology is to support community dynamics rather than to create structural elements" (p. 451). Schlager and Fusco caution against the use of online learning environments, such as Blackboard and WebCT, that are primarily designed for e-learning, and promote the use of technologies that will allow community members to "build and manage their professional identity, find and collaborate with one another, and function in multiple roles" (p. 213). This view is supported by Friesen and Clifford (2003), who suggest that most e-learning environments tend to reinforce "the dominant features of face-to-face classroom structures" (p. 3) rather than encouraging interactive learning.

Bradshaw et al. (2004) discuss different technologies used by the team of remote workers from UltraLab, who support the Talking Heads programme discussed in Section 2.4.4 above. These collaborative tools include: an asynchronous discussion 
forum for communicating and sharing ideas; telephone conferencing to keep up to date on team progress; synchronous text-based online discussions to promote social cohesion; and various technologies that allow remote workers to participate in monthly staff meetings. Bradshaw et al. emphasise the importance of using methods of communication that build cohesion and support the development of knowledge and shared understandings. The use of a variety of technologies in virtual communities is also supported by Johnson (2001). Wagner and Bolloju (2005) have reviewed the use of conversational technologies such as discussion forums, wikis and weblogs or blogs for collaborative knowledge sharing. They suggest that the most effective conversational technologies for use in communities of practice will vary according to the purpose of the community. According to their research, discussion forums work well in communities with a focus on helping or providing information, weblogs have greatest benefits in innovative communities, and wikis are best suited to communities in which wise practice is shared.

There is a considerable amount of literature exploring how online communities of practice can specifically support teacher professional development. Schlager et al. (2002) suggest that there is a misconception that applying online communication technologies over existing teacher professional development practices will result in online communities of practice. They advise that to ensure technologies are used effectively, those facilitating teacher professional development "must take the time to learn to conduct meaningful online activities" (p. 153). Schlager and Fusco (2003) propose that using internet technology to support already existing networks and programmes could be more effective than trying to create new online communities. They also recommend using technologies that are already part of the culture of teachers.

\section{Blended communities of practice}

Blended communities of practice are those that combine face-to-face and online interactions. Much of the literature supports the establishment of blended rather than virtual communities of practice which have no face-to-face contact. The reasons for preferring blended communities of practice include the difficulties around building trust, sustaining participation and sharing practice inherent in virtual communities. According to Hildreth, Kimble and Wright (2000), the most problematic aspect of virtual communities of practice is the facilitation of participation which they see as central to the development of the community. In virtual communities, participation can require a greater effort. Issues around the sharing of tacit knowledge about practice in online communities have been raised (Schwen \& Hara, 2003; Schlager \& Fusco, 2003). It has been suggested that online interactions are more suited to the sharing of explicit rather than tacit knowledge as the sharing of tacit knowledge may rely more on personal discussions and accounts of practice. 
The importance of developing a sense of trust before people are willing to share their knowledge and experiences has been emphasised in much of the literature (Hildreth et al., 2000; Johnson, 2001; Raja, Huq \& Rosenberg, 2006). Kling and Courtright (2003) suggest that the development of sustainable trust is complicated by online environments and note that it can be "easier to develop the bases for trust in online groups through face-to-face means, and then continue to group work online" (p. 227). Kimble and Hildreth (2005) agree stating "One of the keys to a successful virtual COP (community of practice) is an occasional, non-virtual, face-to-face meeting" (p. 2993). According to Cordoba and Robson (2006, p. 562), "technology mediated interaction does not substitute for physical interaction, and efforts should be made to develop continuous and regular encounters". These authors suggest that ICT should be blended with face-to-face encounters to provide a balance that fits with how the community functions.

Not all the literature considers trust building in virtual communities of practice to be problematic. Raja et al. (2006) suggest that trust can be built and maintained in both virtual and co-located environments if the members are willing to work together and there is good communication and strong leadership. This view is supported by McConnell (2006) whose research showed that close trusting relationships can be developed in online communities. Online communities may have some advantages over co-located communities; for example the discussion boards in online communities of practice, while lacking the richness of face-to-face interactions, allow conversations to be accessed and revisited by all community members (Sharrat \& Usoro, 2003). This time delay may lead to a greater depth of reflection and dialogue (Friesen \& Clifford, 2003). The absence of traditional group norms in a virtual community can also be seen as an advantage as asynchronous communication is unaffected by the physical presence, such as voice and body language of contributors (Johnson, 2001).

\section{Further research into online communities of practice}

The need for further research into online communities of practice, in particular the balance of face-to-face and online interactions and the appropriate use of technologies, has been identified. According to Barab (2003, p. 198), "building online communities in the service of learning is something about which we have much to learn". Research into understanding how teachers' professional activities can be supported by online technologies has also been promoted (Schlager \& Fusco, 2003). Davenport and Hall (2002) suggest that research should be focused on issues "such as appropriate mix of online and face-to-face interaction, or the effectiveness of tools to represent diverse points of view or visualize different actors in a group" (p. 210). Johnson (2001) proposes further research in the form of a case study that would explore questions such as:

- How can virtual communities support learning from real-life situations?

- How can internet technologies be used in combination to support emerging communities of practice? 


\subsubsection{Section summary}

Communities of practice are groups of people who are connected together by a shared interest and who interact to share knowledge and practices. Communities of practice have potential for encouraging knowledge sharing and reflection in the context of leadership development programmes. Although communities of practice are generally thought to be most successful when they develop organically, research has shown that online communities set up to support teacher professional development can be effective. Such communities allow for the participation of teachers with varying levels of experience in leadership and also fit with the crucial role of the facilitator as someone who leads from behind and supports the participation of community members. Although there are a wide variety of technologies available for use with communities of practice with an online component, it seems that these are best used to support rather than replace face-to-face interactions.

\subsection{Action learning}

This section of the chapter focuses on action learning, a process that facilitates the sharing of tacit knowledge. Understandings and components of action learning, the differences between action learning and action research, its use in organisations, leadership development and research, and the use of ICT to support action learning will all be discussed.

\subsubsection{What is action learning?}

A number of authors have commented on the lack of a single or common definition of action learning (Koo, 1999; Pedler, Burgoyne \& Brook, 2005; Weinstein, 1995, ZuberSkerrit, 2002). Pedler et al. suggest that despite the lack of an agreed definition, action learning is well understood in terms of key features of practice. McGill and Brockbank (2004, p. 11) describe action learning as "a continuous process of learning and reflecting that happens with the support of a group or 'set' of colleagues, working on real issues, with the intention of getting things done". According to Marquardt (2004a, p. 28), all types of action learning "share the elements of real people resolving and taking action on real problems in real time and learning while doing so". Weinstein (1995) describes action learning as "a 'process' underpinned by a belief in individual potential: a way of learning from our actions (and from what happens to us and around us) by taking the time to question and reflect on this in order to gain insights and consider how to act in the future" (p. 9). She adds that the other two important elements of action learning are a group of people who work together, and regular meetings of this group to allow for the process of questioning and reflection to occur.

Reg Revans has been described as the father figure of action learning (Bourner \& Lawson, 2003). As a Cambridge physicist in the 1930s, he observed scientists working at 
the Cavendish Laboratory helping each other to solve their scientific problems through a process of sharing their thinking and questioning each other (Margerison, 2005). When Revans moved on to a position in the National Coal Board after the Second World War he introduced action learning programmes to managers in the coal mines of England and Wales (Marquardt, 1999). In the mines where managers worked in small groups to solve problems they faced in their work contexts, output significantly increased (Marquardt \& Waddill, 2004). Revans' ideas on action learning later spread internationally and action learning is now used in many contexts all around the world.

Revans himself (1997) described action learning as a form of learning by doing in which "managers may learn, with and from each other, how to manage in the course of their daily tasks" (p. 3). He also said that "action learning suggests that, only if a man, particularly the expert, can be persuaded to draw a map of his own ignorance, is he likely to develop to his full potential" (p. 5). This quote illustrates Revans' view that it was important when solving complex problems to express doubts rather than certainty (Margerison, 2005). Pedler et al. (2005), in their discussion of Revans' classic principles, emphasise the importance of action learning participants focusing on problems that have no right answer rather than puzzles that do. They also suggest that questioning insight is more important in action learning than expert knowledge.

Revans described a learning equation $\mathrm{L}=\mathrm{P}+\mathrm{Q}$, where $\mathrm{L}$ is learning, $\mathrm{P}$ is programmed knowledge, and $\mathrm{Q}$ is questioning insight (Mumford, 1997). $\mathrm{P}$ describes traditional learning methods where the knowledge is already available to answer the questions, whereas $\mathrm{Q}$ is an unknown quantity. Revans believed that traditional methods of education placed too much emphasis on $P$ at the expense of $Q$ (Morris, 1997). Several authors have adapted Revans' original equation including Mumford who proposes the equation, $\mathrm{Q} 1+\mathrm{P}+\mathrm{Q} 2=\mathrm{L}$, because of his belief that the learning process should begin with a problem. In this equation $\mathrm{P}$, the issue, is redefined upon the acquisition of relevant knowledge hence Q2. Weinstein (2002, p. 11) suggests that this equation is relevant for "more academically-based programmes". She describes another variation as $P+Q+A+R=L$, where $A$ is action and $R$, reflection.

\subsubsection{Components of action learning}

There seems to be general agreement on the components of an effective action learning process. Marquardt (2004b, p.2) summarises these as:

1. An action learning group;

2. A problem, challenge or issue;

3. A questioning and reflective listening process;

4. The ability to act on the problem;

5. A commitment to personal learning;

6. An action learning coach or facilitator. 
Figure 2-1 below illustrates these six components.

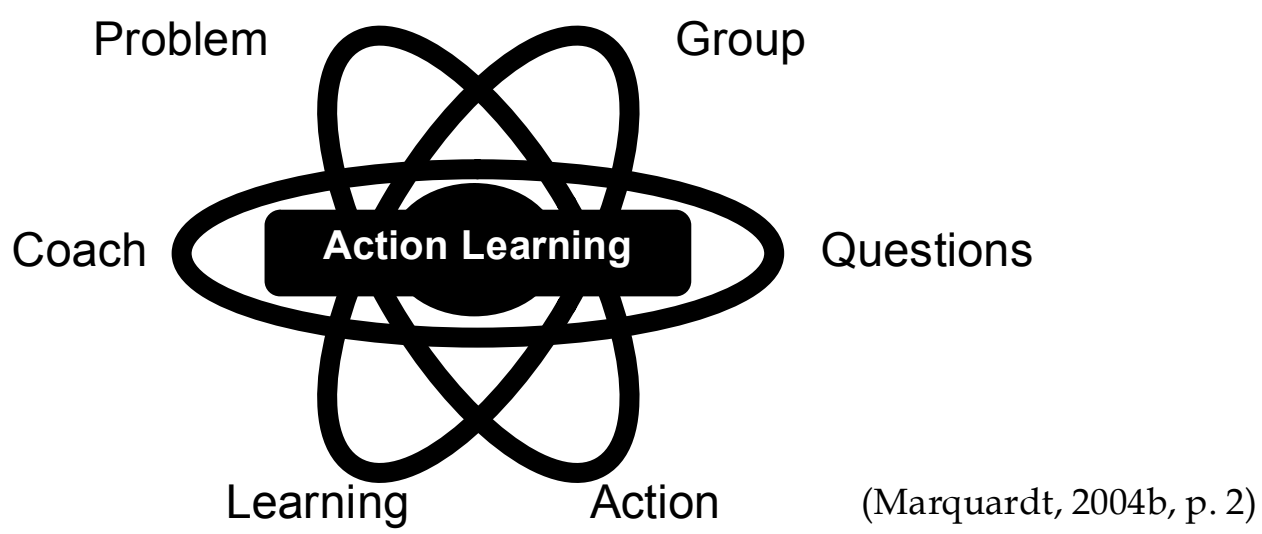

Figure 2-1: The six components of action learning

The action learning group is also known as a set and usually comprises between four and eight members. The set members, who may be from the same or different organisations, meet regularly. According to McGill and Brockbank (2004, p. 14) action learning sets "formalize reflective learning and legitimize the allocation and time and space to it". Action learning groups can operate in two ways; where all group members work on the same problem (single-problem action learning) or where each participant brings their own problem or issue to the group (multi-problem action learning) (Marquardt, 2004b). In multi-problem action learning meetings the participants take turns to discuss the issue or problem they are working on. The other group members ask questions aimed at clarifying the nature of the problem and also practise reflective listening. Marquardt (2004a, p. 28) suggests that this process "builds group cohesiveness, promotes systems thinking, introduces innovative strategies, and generates individual and team learning".

The action learning coach has the task of facilitating the group learning process. The coach or facilitator as they are more commonly known may be a set group member or an external person. The advantage of having an external facilitator is that this person can allow group members to be fully involved at each session and ensure the focus stays on the learning rather than the problem, which according to Marquardt (2004a) tends to happen in self-facilitating sets. According to McGill and Brockbank (2004), the facilitator has a significant guidance role in the early stages of a set but should eventually allow the set members to take over responsibility for how the set operates. The role of the action learning facilitator will be considered in more depth in Section 2.6.

Action learning has gradually evolved from the concept first proposed by Revans. According to Pedler et al. (2005, p. 58), action learning is a living practice that is 
"changing and developing". These authors question whether action learning is best seen as "a method with some defined and describable processes, or as an ethos, a set of abstract principles not attached to any particular form of implementation". Marsick and O'Neil (1999) describe three approaches to action learning: the scientific school; the experiential school; and the critical reflection school. The scientific school is founded on the work of Revans and thinking in this school is anchored in scientific method. The proponents of the experiential school base their work on Kolb's (1994) experiential learning cycle in which action, reflection, theory and practice are all seen to be of equal value. The critical reflection school draws on Mezirow's (1990) notion that perspectives can be transformed through critical reflection (cited in Marsick \& $\mathrm{O}^{\prime}$ Neil). Although these schools do not actually exist in practice, this classification helps describe the evolution of action learning theory.

The empowering nature of action learning is emphasised by several writers. Morgan (1983) suggests that action learning is "concerned with empowering people in the sense that they become critically conscious of their values, assumptions, actions, interdependences, rights, and prerogatives so that they can act in a substantially rational way as active partners in producing their own reality" (in Howell, 1997, p. 376). Morris (1997) considers action learning has the potential to encourage learners to be confident and courageous and to act in the light of their experiences. Marsick and O'Neil (1999) believe that action learning enables people to achieve more control of their own learning and encourages them to become more conscious of driving forces in themselves that can influence future directions.

Action learning encourages a focus on real life rather than theoretical problems. This focus results in participants finding workable solutions to problems or challenges they face in the workplace and developing teamwork and leadership skills in the process (Raelin, 2000). The importance of context is implied rather than explicit in much of the literature on action learning. In order that learning is meaningful, it must be related to the context in which the learner operates. An example of the importance of context could be the use of action learning to promote leadership development. Leadership in a business organisation would manifest itself quite differently from leadership in the early childhood sector; therefore the context would have to be acknowledged in the action learning process.

\subsubsection{Differences between action learning and action research}

There appear to be many similarities between action learning and action research (Bunning, 1997; Penney \& Leggett, 2005; Thorpe, Taylor \& Elliott, 1997). Bunning suggests that both action learning and action research create a social forum for learning and both have the same purpose of making improvements in the world, but that action learning contributes to private learning whereas action research contributes to public learning. Thorpe et al. believe that action research has a stronger academic tradition 
than action learning. They distinguish between the educational process of action learning and the research approach of action research. Coghlan and Pedler (2006) agree that action research emphasises theory building more than action learning, but maintain that "they belong to the same wider family and share many values and antecedents" (p. 128).

Yoong and Gallupe (2001), while acknowledging the close link between action learning and action research, identified three potential differences in the context of a groupware case study. Firstly, that learning in an action learning programme is unique to each participant, while in action research, the learning is collective. Secondly, that the researcher's role in each is different, with the facilitator in action research focusing more on facilitating organisational change rather than the group members' individual learning as in action learning. Finally, data gathering in action research is often more rigorous than it is in action learning.

\subsubsection{Uses of action learning}

Action learning is used in a variety of ways in a number of different organisations and training programmes. This section will review the various uses of action learning in organisations, leadership development programmes and research.

\section{In organisations}

As has been previously mentioned in section 2.5.1, action learning has been used in organisational contexts since the 1940s. Several writers (Pedler, 1997; Weinstein, 2002; Willis, 2004) have commented that some organisational learning termed action learning bears little resemblance to the characteristics of action learning described by Marquardt (2004b) in Section 2.5.2. Willis concluded from his review of 10 case histories of action learning in the US that many practitioners were designating their work as action learning without having a good understanding of the theory behind this concept. Weinstein questions the use of the term action learning to describe many programmes asking: "where do we draw the line? What is it OK to change and adapt, and what needs to remain, for the original idea to be recognized, and for any such programme to still be called action learning?" (p. 9). It appears that though different schools of action learning exist, that there are some key features that characterise action learning programmes and these have been described earlier.

According to Raelin (2000), action learning usually takes place either as part of formal university programmes or as part of management development programmes. There is a considerable amount of literature describing action learning programmes in the United Kingdom that support management education and development (Pedler et al., 2005; Powell, 2001; Thorpe et al., 1997). Action learning is seen as particularly successful in management education as it is "a context-sensitive approach that can link generalized or theory-based teaching with the actual business problems faced by participants" (Pedler et 
al., p. 66). Thorpe et al. also believe that traditional knowledge transfer models need to be supplemented by "more complex models of attitudinal change and skill development" (p. 147). They describe an action learning approach used in a postgraduate management programme in a British university and suggest that this programme differs from traditional management masters programmes in that it had a stronger focus on the participants' perspectives and experience. Among the main advantages of action learning for management development is that a rich learning environment is offered because highlevel management competencies are developed "in a social context that encourages both openness and a positive questioning attitude" (Thorpe et al., p. 170).

Other action learning studies in addition to the management development contexts mentioned above include: the use of action learning by veterinary surgeons in England (Shuttleworth, 2005); Health Boards in Ireland (O'Hara, Bourner \& Webber, 2004); and executives in American companies (Marquardt, 2004a). Action learning is also used in tertiary education as part of both undergraduate and postgraduate courses. Examples from the academic community include the use of action learning as part of a third year behavioural science course in Queensland (Lizzio \& Wilson, 2004) and study towards a doctorate at a virtual university using action learning (Bowerman, 2000). Penney and Leggett (2005) report on the development of an undergraduate unit at a Western Australian university that attempts to establish action learning as an integral part of the professional practice of newly qualified teachers. They describe the difficulties involved in establishing the notion of life-long learning in a short timeframe and recommend ongoing professional development that will enable teachers to continue their learning.

\section{For leadership development}

Much of the literature on the use of action learning focuses on management development; however, action learning is also seen to be ideally suited for leadership development (Bush \& Glover, 2004; Day, 2000; Dickson, Hamilton \& Taylor, 2006; Goleman et al., 2002; Marquardt, 1999, 2004b; O’Neil \& Marsick, 2007; Paterson \& WestBurnham, 2005). Day, in a review of six different approaches to leadership development (360 degree feedback, coaching, mentoring, networks, job assignments and action learning) suggests that action learning is the only one that offers a focus on the development of both human and social capital (refer to Section 2.2.3). Marquardt (2004b) believes that action learning is particularly effective in leadership development as it encourages the development of a number of important leadership competencies such as emotional intelligence and the ability to reflect, question and problem solve. He maintains that action learning differs from other leadership training in that the leaders are learning in context and solving real problems and that leaders (participants), rather than teachers (facilitators), are seen as the source of knowledge. Action learning has been described as an extremely powerful element of the New Visions programmes discussed in Section 2.2.3 (Paterson \& West-Burnham). Comments on action learning from participants in this programme include that it is "the most powerful process" (Bush \& Glover, 2004). The action learning protocols where set participants are 
encouraged to non-judgmentally probe the issues of others means that "each listener/supporter is developing their own listening, questioning and analytical skills whilst the narrator is reflecting on their own problem or issue" (Paterson \& WestBurnham, p. 118).

Morris (1997) believes that action learning meets the requirements for effective leadership development through the support and challenge that is provided in action learning sets. He sees action learning as a process for encouraging the development of leaders who are questioning of their practices and who are encouraging of leadership in others. The provision of both support and challenge in leadership development using action learning is also promoted by Day (2000), who also notes the lack of hard evidence to support its effectiveness. Conger and Toegel (2003), discussing the value of action learning in leadership development, suggest that learning is more useful because the learning experience is more grounded in specific and relevant issues. They have, however, described flaws in how action learning formats are currently used for leadership development. These include that action learning programmes can be singular rather than ongoing learning experiences; that the action learning projects are not always closely related to leadership challenges; that there may be few opportunities for reflective learning; and that there may be limited follow up. Conger and Toegel believe that if these issues are addressed then action learning has great potential for use in leadership development.

\section{In research}

The use of action learning in research is far less developed than its use in organisational learning. Part of the reason for this may be that action learning has individual rather than group learning as its focus and therefore action learning processes are less likely to be documented than is action research. Gray (1999) suggests that action learning has the potential for use in research "by higher education in collaboration with industry, creating a learning community to both sectors' benefit" (p. 5).

There are a limited number of studies exploring the use of action learning in information systems (IS) research. Yoong and Gallupe's (2001) study on the use of an action learning approach in a group support systems (GSS) facilitation training programme used action learning methodologies because they allowed the study of real life issues and promoted collaborative learning. Yoong and Gallupe promote the use of action learning in research because of its usefulness in "studying learning in complex, technology situations" (p. 87). They suggest that action learning helps the researcher to understand the perspectives of the learner more clearly and enables them to adapt their facilitation styles to aid the effectiveness of the learning process. Pauleen and Yoong $(2001 ; 2004)$ also used an action learning framework when researching the use of ICT in boundary-crossing virtual teams. Their research design combined action learning and grounded theory as this approach "has great potential in Information System (IS) research to promote local and practical theory development in the highly dynamic 
situations that occur when people use new information and communication technologies in organizations" (2004, p. 137). Particular benefits of using action learning as part of the research methodology included that action learning allows participants to work collaboratively on real work-place issues, and that those involved are offered relevant learning opportunities in return for being research participants. Pauleen and Yoong's study identified several challenges for facilitators using ICT with virtual teams including the importance of selecting appropriate ICTs and the need to build team member and facilitator skills.

Coghlan and Pedler (2006) discuss the use of action learning as a research tool in practice based qualification programmes such as postgraduate management education programmes. Participants in these programmes work on a problem that is relevant to their workplace, participate in action learning sets and produce dissertations that are based on actions taken. These authors suggest that this type of research "involves people in taking action in order to learn - both in terms of improving their own practice and adding to knowledge in their professional worlds" (p. 128). Learning will occur at the personal, practitioner and organisational levels. The research produced incorporates a number of strands including: the researcher's engagement with the workplace; learning from the action learning set; relevant information and literature; and personal learning.

\subsubsection{ICT and action learning}

The use of ICT to support action learning appears to be relatively new. A number of authors (Burns, 2001; Gray, 1999; Powell, 2001; Roche \& Vernon, 2003; Stewart \& Alexander, 2006) have described the use of various technologies to support or in some cases replace traditional face-to-face action learning set meetings. These ICTs include videoconferencing, audioconferencing, email, and online forums or bulletin boards. The majority of the action learning programmes discussed in this section of the literature review combine face-to-face meetings and online communications (Gray; Powell; Roche \& Vernon; Stewart \& Alexander). Burns (2001), who had previously been involved in face-to-face action learning, reports on a virtual action learning (VAL) set, run for British Telecom staff that used audio-conferencing. Although the set members who were based in different parts of the country did not meet face-to-face during this programme, all knew each other already. Burns concluded that VAL was not as successful as face-to-face set meetings. He believes more, rather than less, interpersonal skills, particularly listening skills, are needed in audio-conferencing than in face-to-face meetings.

The importance of face-to-face contact between set members particularly at the beginning stages of an action learning process is acknowledged by Powell (2001), Roche and Vernon (2003), and Stewart and Alexander (2006). Powell describes a study involving the use of ISDN-based videoconferencing to remotely support a number of 
existing action learning sets involving employees of small and medium enterprises through Salford University in Manchester. He suggests that the startup stage of a set, which he describes as a nurturing process, is not conducive to remote meetings. Roche and Vernon describe an action learning project, supported by electronic technology including videoconferencing, conference calls, email networks, and bulletin boards, used to develop a virtual learning community of Australian rural and remote health services managers. The conclusions from this study are that although the online technologies were useful in reducing isolation, face-to-face interaction was also important to develop a sense of community. Stewart and Alexander's research involved managers from small and medium enterprises who used a blended action learning process with mixed success. This study found that trust was stronger in face-to-face interactions and that there was some reluctance to collaborate and share experiences online.

Bird (2006) has explored the use of asynchronous online computer mediated conferencing $(\mathrm{CMC})$ to facilitate action learning. His literature review examines the nature of action learning and how it fits within a social constructivist paradigm. He emphasises the importance of social interaction within learning communities and suggests that:

For an action learning set to function online a situation needs to be created in which facilitated, shared reflection and the social construction of knowledge can proceed in a text format. The virtual medium must allow the apposite questioning, discussion, and emotional support that leads to new thoughts, ideas and wider perspectives being shared by the set in a communal way. In short, a socially constructed knowledge must be created through the key ingredient of language. (p. 4)

Bird cites evidence from a number of sources that text-only discussion formats have some advantages over face-to-face communication in that participants may have more time to reflect and may take more care over their contributions. Bird concludes that "online learning sets appear well worth striving for and the concept is supported in the literature" (p. 7).

The use of ICT to support action learning has some obvious advantages particularly in programmes where participants come from different organisations and/or live some distance apart. Yoong, Thornton and Watson (2006) report on the Pacific Village project in which action learning was used in an online community of public servants based in a number of different Pacific nations. Online action learning was found to support knowledge sharing in this distributed environment though a number of factors inhibiting the success of this online community were identified including: time constraints; technology factors; and organisational support. The ability of participants to access and use appropriate technology as well as the issue of narrow band width in 
some countries were limiting factors in this particular study; however, these are all able to be overcome.

It has been suggested that there are considerable advantages for learners in using ICT particularly as it gives them more responsibility to manage their own learning (Gray, 1999). Koo (1999) notes that action learners have ready accessibility to almost unlimited sources of information through the development of electronic media and can also use the internet to discuss their ideas and seek assistance from each other. There are still some barriers to be overcome such as access to ICT; skills and confidence in using ICT; and the quality of the technology (Powell, 2001). Burns (2001) suggests that VAL has potential particularly for multi-national organisations but cautions organisations to pilot it with care.

\subsubsection{Section summary}

Action learning is a process involving both action and reflection that takes place in a group situation and is supported by a facilitator. Action learning is widely used in a number of organisations and although there is potential for its use in supporting leadership development; it is not widely used in this field. Action learning also has potential as a research strategy as it encourages practitioner research and learning at a number of levels. ICT is increasingly being used to support action learning. The conclusion can be reached that although there are many advantages in using ICT to support action learning, there are a number of challenges still to be addressed including media selection; how best to use the available technologies; and how to build trusting relationships among set members either face-to-face or remotely.

\subsection{Role of the facilitator}

This section will focus on the role of the facilitator, firstly in face-to-face settings and secondly in online environments. Facilitation will be defined and the competencies required by facilitators discussed. The literature related to effective facilitation in both communities of practice and action learning groups will also be reviewed.

\subsubsection{Face-to-face facilitation}

Facilitation has been defined as "the art of guiding the group process towards the agreed objectives" (Hunter, Bailey \& Taylor, 1992, p. 62), and involves "encouraging open dialogue among individuals with different perspectives so that diverse assumptions and options may be explored" (Hogan, 2002, p. 10). A facilitator acts as a process guide (Hunter et al.) and is someone who helps the group "increase its effectiveness by improving its process and structure" (Schwarz, 2005, p. 3). Facilitators require a broad range of competencies in order to work effectively with groups. Some of these competencies relate to the task functions of a group or work that is done by the 
group, and others relate to the group process or the way in which the group members interact (Kolb \& Rothwell, 2002). Stewart (2006) has proposed a model of competencies based on the capabilities and characteristics demonstrated by high-performing facilitators in the context of workshop facilitation. This model includes interpersonal competencies, management process competencies, understanding context, and personal characteristics. The interpersonal competencies in this model include both competencies related to communication such as perceptive listening and awareness of non-verbal communication, and additional competencies such as conflict resolving capabilities, use of a range of leadership styles and relationship building. Included in the personal characteristics in Stewart's model are adaptability, self-awareness, selfconfidence and emotional resilience. Five areas in which facilitators should demonstrate proficiency and that encompass both task and process competencies have been identified by McFadzean (2002). These are: planning; group dynamics; problemsolving and decision-making; communication; and personal growth and development. The facilitator competencies identified by these and other authors are summarised according to their task or process functions in Table 2-3 below.

\begin{tabular}{|l|l|}
\hline \multicolumn{1}{|c|}{ Task roles } & \multicolumn{1}{c|}{ Process roles } \\
\hline $\begin{array}{l}\text { Clarify purpose and expectations } \\
\text { (Hunter et al., 1992; McCain \& Tobey, } \\
\text { 2004; McFadzean, 2002) }\end{array}$ & $\begin{array}{l}\text { Acknowledge and affirm participants } \\
\text { (Hunter et al.; McCain \& Tobey; } \\
\text { McFadzean) }\end{array}$ \\
\hline $\begin{array}{l}\text { Guide the group to desired outcomes } \\
\text { (McFadzean) }\end{array}$ & $\begin{array}{l}\text { Honour each group member and recognise } \\
\text { diversity (Hunter et al.; McFadzean; } \\
\text { Stewart) }\end{array}$ \\
\hline $\begin{array}{l}\text { Use questions skillfully (Hunter et al.; } \\
\text { Kolb \& Rothwell, 2002) }\end{array}$ & $\begin{array}{l}\text { Create a climate of safety and trust } \\
\text { (McFadzean; Stewart) }\end{array}$ \\
\hline $\begin{array}{l}\text { Negotiate and contract (Hunter et al.; } \\
\text { Stewart, 2006) }\end{array}$ & $\begin{array}{l}\text { Demonstrate effective communication skills } \\
\text { including active listening (Kolb \& Rothwell; } \\
\text { McCain \& Tobey; McFadzean; Stewart) }\end{array}$ \\
\hline $\begin{array}{l}\text { Paraphrase and summarise (Kolb \& } \\
\text { Rothwell) }\end{array}$ & $\begin{array}{l}\text { Demonstrate flexibility (Hunter et al.; } \\
\text { McCain \& Tobey; McFadzean; Stewart ) }\end{array}$ \\
\hline $\begin{array}{l}\text { Ability to take on and move between } \\
\text { multiple roles (Stewart) }\end{array}$ & $\begin{array}{l}\text { Recognise and manage conflict (Hunter et } \\
\text { al.; McFadzean; Stewart) }\end{array}$ \\
\hline
\end{tabular}

Table 2-3: Facilitator competencies

\section{Facilitation of communities of practice}

Although communities of practice do not always have a designated facilitator, one member often acts as a facilitator or coordinator and helps the community to "focus on its domain, maintain relationships, and develop its practice" (Wenger et al., 2002). Saint-Onge and Wallace (2003) have identified three principles that should guide a community of practice facilitator and that have similarities to some of the competencies 
discussed above. These are being clear about the purpose of the community and ensuring that this is kept to the forefront, helping the community move towards its stated goals, and assessing the appropriate level of intervention in the community's activities. Additional coordinator roles identified by Wenger et al. include: recognising important issues; planning and facilitating events; and fostering the development of community members. Many of these roles are shared by members of the community rather than being the sole responsibility of a facilitator.

\section{Facilitation of action learning groups}

Many of the competencies listed in Table 2-3 above also have relevance for the facilitation of action learning groups. McGill and Brockbank (2004) suggest that action learning set facilitators need to be skilled in active listening, managing emotions, challenging participants and showing empathy. An additional action learning facilitator skill suggested by Pedler and Abbott (2008) is that of helping set members acquire facilitation skills themselves. The various roles a set facilitator may take have been described in different terms by different authors. Marquardt (2004b) explains the roles a facilitator may take in a set meeting as: catalyst for the action learning process; mirror for group reflection; and role model for the listening and questioning skills needed by the group. Bennett (1997) divides the tasks of a set facilitator into process roles, academic roles, interpersonal roles and validation roles. According to Bennett, process roles aid in the effectiveness of the action learning process and may include initiating tasks, liaising between set members and managing procedures. Academic roles include acting as a mentor, expert, innovator or tutor according to the needs of the group. Interpersonal roles help group interactions and may take the form of negotiating, supporting and motivating, and validation roles may include challenging and evaluating progress. Action learning interventions rather than roles are discussed by O'Neil (1997). She suggests that facilitators intervene in the action learning process in a variety of ways such as: asking naïve questions that lead to a reframing of understandings; fostering critical reflection; releasing and enhancing capacity; and enabling learning. The importance of the facilitator of an action learning group not offering their own opinions or advice but relying on the expertise of group members has been emphasised by Revans (1998), who also recommended that sets should eventually become independent of an outside facilitator.

\subsubsection{Online facilitation}

There appear to be both differences and similarities between facilitation in face-to-face and online environments. A study of the role taken by facilitators in computersupported meetings (Clawson, Bostrom, \& Anson, 1993) identified 16 facilitator dimensions in the context of electronic meetings. The majority of these dimensions were relevant to both face-to-face and electronic facilitation, and many such as demonstrating flexibility, questioning, listening, managing conflict and creating a participative environment were referred to in Table 2-4. Three dimensions particular to 
electronic meetings according to these authors were: appropriately selecting and preparing technology; creating comfort with and promoting understanding of technology; and understanding technology and its capabilities.

The differences between face-to-face and online facilitation include a stronger focus on encouraging participation in online environments, and a greater emphasis on promoting collaboration and self-directed learning. Research into online facilitation has shown the importance of the facilitator encouraging participation (Tarmazi, de Vreede and Zigurs, 2007), and attending to and facilitating the course of online communication (King, 2002). Ways of encouraging participation include sharing experiences, posing questions and encouraging peer-to-peer interactions. Gray's (2004) research found that participants saw the role of the online facilitator as critical in establishing the online environment, sustaining the group process and giving technical support. The participants in Gray's study also indicated that their learning was enhanced by the use of techniques such as "summarizing, weaving, and nudging the discussion to a deeper level" (p.31).

The greater flexibility of online compared to face-to-face environments has been emphasised by Palloff and Pratt (1999). These authors discuss the ways in which the facilitator in an online learning environment guides the discussion by asking challenging and meaningful questions and then following the discussion wherever it may lead. Garrison and Vaughn (2008) suggest that the facilitator has less of a role as a knowledgeable expert and a greater role in encouraging self-directed learning. Brockbank and McGill (2007) maintain that there is greater potential for transparency and authenticity in online facilitation. They also imply that the facilitator in an online environment takes more risks and is more vulnerable than in a traditional face-to-face environment. The more collaborative nature of facilitation in an online environment is discussed by McConnell (2006) who promotes consultation and the sharing of power with community members over learning processes.

\section{Online community of practice facilitation}

Research that has been carried out on the facilitation of online communities of practice informs our understanding of the changed role of the online facilitator and the links between leadership and facilitation. Kimball and Ladd (2004) discuss facilitation in the context of launching, leading and sustaining virtual communities. They argue that facilitators need to transfer all the skills they have used in co-located groups to online environments. In addition, they emphasise the importance of the facilitator clarifying the community's purpose, establishing group norms, creating ambience, modelling conversations, creating connections, reinforcing participation and completing housekeeping tasks such as deleting or archiving out-of-date discussions.

Links between leadership and facilitation have been made in studies involving online communities of practice. Tarmazi et al. (2007) suggest that facilitators in online 
environments may need to show leadership to a greater extent than in a face-to-face setting. Their research, which involved surveying community of practice facilitators, found that these facilitators took a variety of both internal and external roles. Internal roles included being an internal source of information, encouraging active participation and guiding and assisting the participants. External roles included being an external source of information, representing the community to the outside world and searching for and collecting information for the community and its members. Tarmazi et al. recommend suggest that a well-designed community of practice with a clear purpose and focus will encourage participation. Their suggestions for technology to support the effective functioning of a community include member profiles, photos and activity tracking, notification alerts and listings of what has changed on the site.

Leadership in online communities of practice has been discussed by Storck and Storck (2004) who suggest that leaders should lead from behind; that is by trusting in the knowledge of the group and the group processes. Their six principles for successful online leadership, which could also be applied to online facilitation, are:

- Lay down clear guidelines but allow others to set the agenda and start discussions.

- Participate regularly and be consistent.

- Act in the service of the community by walking the talk.

- $\quad$ Be authoritative with regard to professional matters.

- Do not allow scapegoating.

- Welcome and farewell community members appropriately.

Johnson (2001) also discusses leadership roles within communities of practice and suggests that the facilitator should both encourage interactions between peers and between experts and novices.

\section{Online action learning facilitation}

Although there is a scarcity of literature regarding online action learning in general, the changed role of the online action learning facilitator has been noted in several studies. Gray (1999) maintains that the use of virtual technology changes the role of the facilitator, who in the case of action learning programmes run as part of university programmes may be an academic staff member, from "the provider of knowledge to facilitators and designers of learning methods" (p. 10). Bird (2006) also comments on the altered role of the facilitator suggesting that it has changed from that of "a skilled, face-to-face listener, to one of a more reflective online discourse analyser" (p. 9). An interesting finding from Stewart and Alexander's (2006) study involving blended action learning was that some participants were uncomfortable with the less formal role of the online action learning facilitator as they were used to a more formal teaching role. 


\section{Further research into the role of the online facilitator}

Although there is a growing body of research on the role of online community of practice facilitators, there is still a lack of research into the changed role of the online or blended action learning facilitator. Further research into the role of the online facilitator is supported by a number of authors. Tarmazi et al. (2007) promote research that includes community of practice member perspectives rather than just the perspectives of facilitators. Johnson (2001) proposes further research in the form of a case study that would explore how facilitator techniques can compensate for some of the difficulties arising from online communication and Stewart and Alexander (2006) support further investigation of the facilitation of online communication and collaboration.

\subsubsection{Section summary}

Facilitators require certain competencies, both task and process related, in order to effectively facilitate groups. Although many facilitation competencies such as acknowledging and affirming participants, effectively communicating, clarifying, and questioning are equally important in both face-to-face and online environments, there appear to be some significant differences between these two contexts. These include the emphasis on encouraging participation and promoting collaboration that is more critical in online contexts. Facilitators working with both online and blended communities of practice and action learning groups are required to adapt their facilitation strategies and there appears to be little literature to guide them in this changed role.

\subsection{Reflective practice}

This section of the chapter focuses on reflective practice. Definitions and understandings of reflective practice and critical reflection will be presented and the use of reflective practice in organisations, leadership development and research will be discussed, as will how ICT can be used to support it.

\subsubsection{What is reflective practice?}

The term reflective practice appears to have multiple meanings, rather like the term action learning. Brookfield (1995, p. 216) suggests that reflective practice "has become a catch-all term embracing ideas and ideologies that are often contradictory". He warns that both the terms reflection and reflective practice "are becoming buzzwords denuded of any real meaning". Hackett (2001) also discusses the variety of implementations and interpretations of reflective practice suggesting that this results in a lack of "consistent and unified practice" (p. 109). According to McGill and Brockbank (2004), the notion of reflective practice was first proposed by Schon in his book The Reflective Practitioner published in 1983. While this volume did not provide a clear definition of reflective practice; Schon more recently defined it as "thoughtfully 
considering one's own experiences in applying knowledge to practice while being coached by professionals in the discipline" (Schon, 1996, in Ferraro, 2000, p. 1). Buysse et al. (2003) suggest that reflective practice assumes "knowledge is derived from professionals' own experience and observations as well as from formal knowledge gained through theory and research, and that each informs the other" (p. 268).

Schon developed the concept of reflective practice in his work with emergent professionals. He began with the assumption that competent practitioners demonstrate tacit knowledge or knowing-in-practice. Schon called the way in which professionals enhanced their practice while engaging in it, professional artistry, describing this as "an exercise of intelligence, a kind of knowing, though different in crucial respects from our standard model of professional knowledge" (1987, p. 13). Schon (1983) challenged the prevailing notion of the time that professional practice should fit the model of Technical Rationality, an objective model that did not allow for uncertainty and complexity, but assumed a rational solution to every problem. Schon distinguished between two types of reflection, reflection-in-action and reflection-on-action. He named the process by which professionals reflected on intuitive knowledge while they were engaged in action, reflection-in-action. He believed that reflection-in-action was central to the way in which professionals dealt with uncertain and unstable situations. Reflection-on-action involves reflecting on experiences after the event and has the effect of influencing future actions. It occurs when reflection interrupts the flow of action (Schulz, 2005). Schon suggested that in organisations where reflective practice is encouraged, practitioners challenge prevailing ways of thinking, surface conflicts and dilemmas and that these processes can lead to restructuring of principles and values.

The importance of bringing reflection out into the open has been emphasised by Raelin (2002). His definition of reflective practice, "the practice of periodically stepping back to ponder the meaning of what has recently transpired to ourselves and to others in our immediate environment" (p. 66), promotes the public sharing of reflection. Raelin (2000) suggests that open reflection helps develop self-awareness through hearing the perspectives of others. He believes that when someone subjects their assumptions to the review of others, learning moves from the individual to the team level. According to Raelin, public reflection can create "a collective identity as a community of inquiry" (p. 101). The value of collective reflection has also been promoted by Hoyrup (2004) who suggests that it assists people "in finding common meanings in making sense of the collective work they are doing" (p.443).

\subsubsection{Critical reflection and reflective practice}

A distinction between reflection and critical reflection has been made by Hoyrup (2004) who believes that critical reflection is a broader concept than reflection as it involves questioning the beliefs that inform our assumptions. He suggests that while reflection implies transformation of knowledge, critical reflection implies changes in the way we 
interpret our world, hence it involves deeper level learning. Reynolds (1998) identifies a number of distinctions between reflection and critical reflection including that critical reflection has a social rather than an individual focus and that it pays attention to the analysis of power relations. Critical thinking has been described as a concept of reflective practice by Hackett (2001) who suggests that "reflection is not inherently critical, and nor is non-critical reflection without value in the teaching and learning process" (p. 107). Merriam and Brockett (1997) believe that the value of critical reflection lies in its potential to broaden the view of what it means to be a professional (cited in Hackett).

Critical reflection involves challenging accepted ways of doing things. This occurs through double loop rather than single loop learning (Argyris, 1999). Single loop learning occurs when the learner acts to maintain what is, rather than developing what might be. Any changes serve to satisfy the governing variable so little significant change occurs. In contrast, double loop learning involves allowing things that have previously been taken for granted, to be seen as problematic and therefore changes address the governing variable (see Figure 2-2 below). Single-loop learning occurs "when matches are created or when mismatches are corrected by changing actions" (Argyris, p. 68). Double loop learning occurs as the result of correcting the mismatches by considering then changing the governing variables and subsequent actions. Double loop learning confronts the assumptions behind views and publicly tests hypotheses (Brockbank, McGill \& Beech, 2002). Learning then occurs through reflecting on and changing practice.

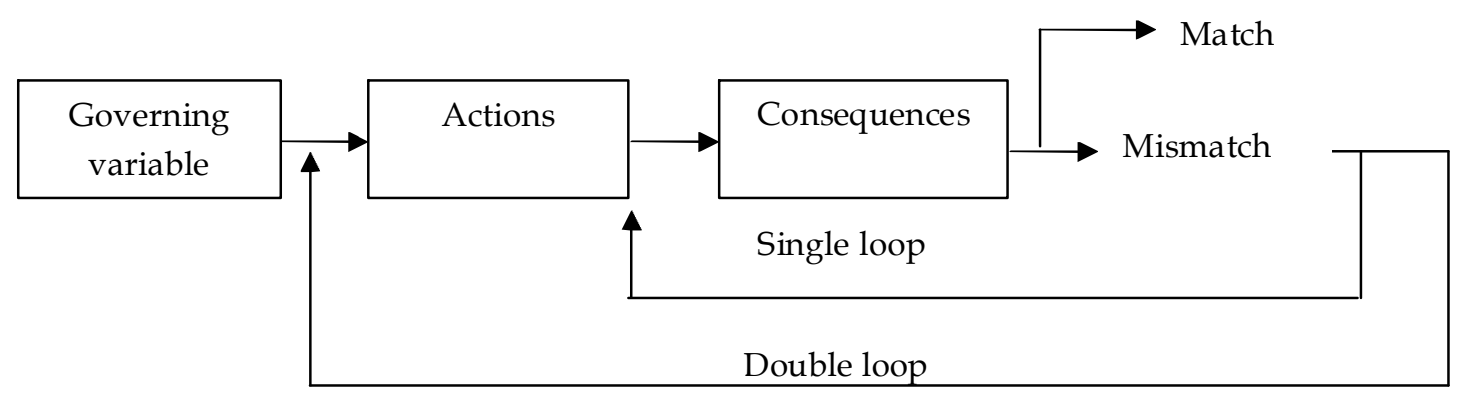

(Argyris, 1999, p.68)

Figure 2-2: Single and double loop learning

A third form of learning, triple loop learning, has also been proposed. This concept which is originally attributed to Bateson (1972), is described by Yuthas, Dillard and Rogers (2004, p. 239) as "continual reflection on the learning process, the contexts within which learning occurs, and the assumptions and values motivating the learning and influencing its outcomes". Both double loop learning and triple loop learning are seen to lead to deeper forms of learning than single loop learning. Paterson and WestBurnham (2005) have developed a model of three modes of learning: shallow; deep; and profound, each of which links to one of these three forms of learning as shown in Table 2-4 below. 


\begin{tabular}{|l|l|l|l|}
\hline & Shallow & Deep & Profound \\
\hline Means & Memorisation & Reflection & Intuition \\
\hline Outcomes & Information & Knowledge & Wisdom \\
\hline Evidence & Replication & Understanding & Meaning \\
\hline Motivation & Extrinsic & Intrinsic & Moral \\
\hline Attitudes & Compliance & Interpretation & Challenge \\
\hline Relationships & Dependence & Independence & Interdependence \\
\hline & $\begin{array}{l}\text { (Single-loop } \\
\text { learning) }\end{array}$ & $\begin{array}{l}\text { (Double-loop } \\
\text { learning) }\end{array}$ & $\begin{array}{l}\text { (Triple-loop } \\
\text { learning) }\end{array}$ \\
\hline
\end{tabular}

(Paterson \& West-Burnham, 2005, p. 116)

Table 2-4: Modes of learning

Shallow learning is characterised by the memorisation and replication of information, whereas deep learning involves the demonstration of understanding and the translation of that understanding into action. Profound learning is characterised by intuitive knowledge, involves the creation of personal meaning and is the culmination of any effective learning process (West-Burnham, 2003). Deep and profound learning both occur in the context of social relationships. It has been suggested that leadership development programmes should be centred on deep learning which occurs through reflection, and creates the capacity for profound learning (National College for School Leadership, 2005).

The value of keeping a reflective journal to facilitate reflective practice has been emphasised by a number of authors (Boud, 2001; Cyboran, 2005; Daroszewski, Kinser \& Lloyd, 2004; Fielden, 2005; Loo \& Thorpe, 2002; Raelin, 2000; West-Burnham, 2003). Cyboran, summarising literature on the benefits of workplace journalling, suggests that it can improve job performance, skill transfer and learning. Loo and Thorpe found that reflective learning journals were an effective way of encouraging critical reflection on both group and individual learning as well as empowering participants to take action to improve their own learning. The importance of reflective journalling in enhancing learning is emphasised by Boud, who suggests that it is a useful means of "puzzling through what is happening in our work and our personal lives" (p. 11). Boud recommends journal writing for supporting three forms of reflection: reflection in anticipation of events; reflection during events; and reflection after events.

\subsubsection{Uses of reflective practice}

Reflective practice is common in a number of different professions and its use in adult education has been well documented. This section will provide an overview of some of the uses of reflective practice and critical reflection in organisations, in leadership development and in research. 


\section{In organisations}

According to the literature, professional contexts employing reflective practice include social work (Osmond \& Darlington, 2005); nursing (Daroszewski et al., 2004); teaching (Brookfield, 1995; Ferraro, 2000; Sergiovanni, 2001; Southworth, 2005) and adult education (Fielden, 2005; Jarvinen \& Poikela, 2001). Boud (2006, p. 158) comments that "it would now be unusual to find university courses in any of the professions that did not in some way acknowledge the importance of reflection or reflective practice in professional formation." The benefits of reflective practice in education have been emphasised by Barth (2001) who suggests that it allows practitioners to stand back from their situation and gain a sense of perspective on it.

Daudelin (1996) argues that managers have historically placed a higher value on action than on reflection and emphasises the importance of managers valuing and encouraging reflection as a tool to support organisational learning and change. It has also been asserted that critical reflection is not encouraged in many workplaces as it can seem irrelevant to profit making, and that questioning workers can be viewed as troublesome (Hoyrup \& Elkjaer, 2006). Reynolds (1998) believes that those in management education have focused on reflection rather than critical reflection with the result that management learning has focused on problem solving rather than the emancipatory nature of critical thinking. He believes critical thinking has the potential to ask questions of purpose and confront taken for granted assumptions and ideologies.

\section{For leadership development}

The vital role of reflective practice in leadership development has been discussed by a number of authors (Day, 2003; Jones \& Pound, 2008; Raelin, 2004; West-Burnham, 2003). The use of critical reflection in leadership development has been promoted by Densten and Gray (2001) who believe that it can help leaders deal with challenges, generate a range of perspectives, and actively construct meaning. A programme to develop leadership capabilities in school principals piloted by the Christchurch College of Education used reflective practice as one of its key components (Williams \& Leitch, 2005). Participants were encouraged to keep a reflective journal and share a significant incident from their journal at group meetings. The use of reflective journals to facilitate leadership development has also been recommended in the contexts of early years' leadership development (Jones \& Pound, 2008) and in the wider education sector (Donaldson, 2008).

\section{In research}

Reflective practice is seen as an essential part of an action research process rather than as a research tool in its own right. Zuber-Skerritt (1992) advocates that research be assessed on its success in improving practice. For this reason she believes that theory developed by or in collaboration with practitioners through action research is particularly valuable. Zuber-Skerritt has suggested that reflective practitioners integrate 
both theory and practice. Schon (1987) argues that the technical rational approach separated research from practice, whereas reflective practice encourages research in a practice context. The practitioner, who reflects on their actions, constructs new theory because of the unique context in which they operate. Brookfield (1995) supports the view that reflective practice theorists encourage teachers and other professionals to research their own workplaces and generate rather than import theories. He sees participatory action research as one way of encouraging teacher reflection.

\subsubsection{ICT and reflective practice}

ICT seems to have been used to support reflective practice predominantly in the education sector. A number of studies have described how technologies such as computer-mediated communication (CMC) and conferencing on the web (COW) encourage teachers' communications and reflections. McNair (2004) reports on a programme fostering reflective practice in a group of student teachers using an online environment. The teachers in this study were successfully encouraged to both engage in professional dialogue with each other and with qualified teachers, and to become more reflective and critical of the teaching practice of others. Maher and Jacob's (2006) study found that asynchronous CMC supported teachers' reflection on their practice through peer interactions. The peer teachers in this study were able to assist in the reflection process and suggest alternative ways of viewing issues. Angeli, Valanides and Bonk (2003), in their study investigating how COW promotes the development of critical thinking skills and peer discourse, found that the facilitator's role was extremely important in fostering critical reflection. Left to themselves, the students in their study tended not to engage in critical thinking but offered only ungrounded opinions.

Makinster, Barab, Harwood and Andersen (2006) studied how the use of different online technologies supported reflection among preservice science teachers. Students using private journals initially wrote better reflections than those using an asynchronous discussion forum or a discussion forum within a web-supported community; however, those using the forums reflected more on their teaching practice when they shared with other students and also valued their reflections. These authors concluded from this study that reflection can take many forms, such as an internal dialogue, a spoken conversation or a written reflection, and that facilitation can support the development of reflective practice. They also found that web-based collaborative discussion forums encouraged shared reflection and encouraged students to acknowledge and verbalise their identity as teachers.

The use of ICT to support teacher reflection seems to have been most successful in programmes that also have a face-to-face component. King (2002) describes the use of both online and face-to-face learning as a hybrid format and believes that this option has much to offer the field of teacher professional development. She suggests that online communities have the potential to serve as a "foundation for reflective practice 
and constructivist discovery" (p. 240). King also believes that hybrid formats foster collaboration and in-depth dialogues and make learning more transferable by bringing it closer to the context in which teachers operate. The value of blended learning approaches in encouraging reflection is also emphasised by MacDonald (2008) and Garrison and Vaughn (2008) who suggest that the online element encourages rigour and reflection.

The value of reflective journaling has been mentioned earlier. The use of online reflective journals has been documented in a number of studies (Cyboran, 2005; Daroszewski et al, 2004; King, 2002; Maher \& Jacob, 2006; Moon, 2006). Elgort (2006) asserts that online journaling implies communication between the author and an audience. She suggests that online journals may be public such as web logs (blogs) or may be restricted to members of a professional group or participants in a course. Cyboran lists a number of potential benefits of online journaling; the most important being the existence of a sequential record that can be reviewed and can strengthen relationships between journaling partners as "both parties can trace the thread of their developing dialog for evidence of expanded meaning, clarification and support" (p. 36). Cyboran also suggests that online journals have potential for supporting mentoring relationships, providing innovative solutions to problems, transferring skills and knowledge from face-to-face training opportunities and challenging organisational norms. Daroszewski et al. conclude that online journals are more easily accessible than conventional journals and provide greater opportunities for reflection. The importance of journalling in facilitating learning from experience is emphasised by Moon who also promotes journal writing as a tool for enhancing the development of the self as a professional.

\subsubsection{Section summary}

Reflective practice is a valuable tool as it helps support both individual and organisational learning and encourages the challenging of accepted ways of doing things. There is a limited amount of literature on the use of reflective practice to support leadership development; however, it appears that various ICTs designed to support reflective practice, including online journaling, may also have potential for supporting leadership development.

\subsection{Links between communities of practice, action learning and reflective practice}

Communities of practice, action learning and reflective practice all have their origins in practice and are processes that remove learning from the classroom and situate it in the workplace context. They are all used in the context of teacher professional development as well as in other organisational learning situations. Communities of practice, action learning and reflective practice all elevate the role of the practitioner over that of the expert and they also surface uncertainty and encourage practitioners to challenge accepted assumptions 
and ways of doing things. Communities of practice take a variety of forms and may be naturally evolving or planned. Action learning is a structured, public process as it involves people meeting together in learning sets. Action learning sets are more formal groups requiring a greater commitment than communities of practice which may have a fluid membership. Action learning also has a greater focus on learning than do communities of practice which focus more on practice. Reflective practice may be a public or private process although there is increasing support for it being a shared endeavour in order that assumptions can be challenged and self-awareness can develop.

The diagram (Figure 2-3) below illustrates how communities of practice and action learning have commonalities, both being strategies for encouraging work-based learning and reflective practice, and differences, in that communities of practice have a stronger focus on practice, and action learning a stronger focus on learning.

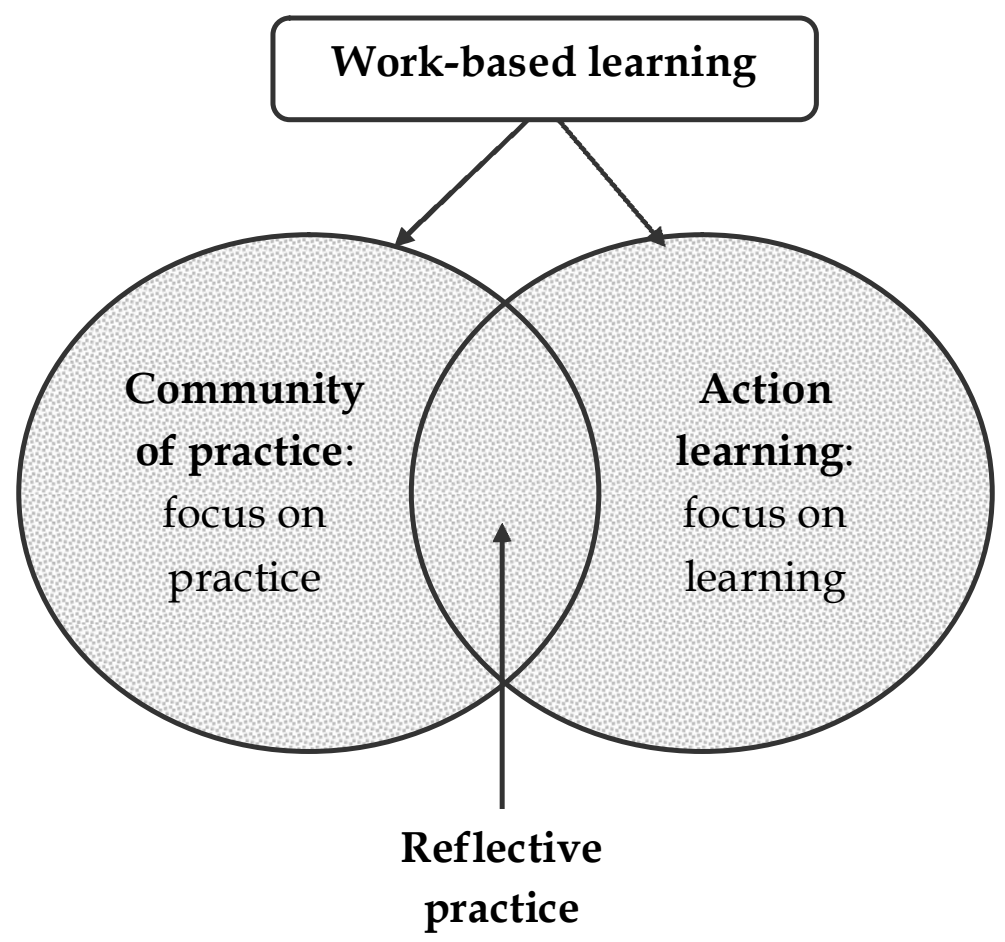

Figure 2-3: Communities of practice, action learning and reflective practice

Reflective practice has been linked with both action learning and communities of practice in earlier sections of this review; however, the links between communities of practice and action learning are more tenuous. It has been suggested that action learning could be applied in community of practice settings though so far this does not seem to be have been tried or documented to any extent (Smith, 2006). The Pacific Village project (Yoong et al., 2006) appears to be one of the first studies to link action learning to online communities. Action learning has the potential to support learning in communities of practice as it provides a structured process that promotes both individual and group learning. It is also possible that action learning groups could 
evolve into communities of practice and although this is not documented in any literature reviewed so far, it could be investigated in future research. In summary, both communities of practice and action learning processes can and should include reflective practice.

\subsubsection{Use of appropriate ICTs}

The use of a variety of ICTs in the support of communities of practice, action learning and reflective practice has been discussed in this chapter. The selection of appropriate ICTs for use in facilitating communication will depend on the type of communication and on the context in which the communication takes place. Media richness theory was developed to hypothesise what media were most effective in what situations (Dennis \& Valacich, 1999). Daft, Lengel and Trevino (1987) first suggested that media vary in their richness, that is, their ability to enable users to communicate effectively and build understanding. They put forward the idea that there were two influences on information processing, the concepts of uncertainty and equivocality. Uncertainty refers to the situation where there is a lack of information but an accepted framework for interpreting information, whereas equivocality refers to ambiguity or lack of agreement about a situation. According to Daft et al., equivocal messages require the use of rich media to facilitate understanding, whereas less rich media are appropriate in situations of uncertainty.

The theory of media richness has been further developed into the theory of media synchronicity (Dennis, Fuller \& Valacich, 2008; Dennis \& Valacich, 1999). Media synchronicity is defined as "the extent to which the capabilities of a communication medium enable individuals to achieve synchronicity" (Dennis et al., p. 581). Dennis and Valacich argue that two communication processes, conveyance and convergence, make up all basic communication. Conveyance refers to the exchange of information which is then followed by consideration of its meaning. Convergence refers to the process of agreeing on the meaning of information. The key to the effective use of media is the matching of the media capabilities to either conveyance or convergence as appropriate. Generally, high media synchronicity will support convergence while low media synchronicity will support conveyance. Dennis et al. also suggest that no single medium will be as effective as a set of media that a group will choose to use depending on their current communication process. These processes may differ in newly formed groups who may have more of a focus on socially related communication technologies compared with well-established groups who may require less use of media with high synchronicity.

\subsubsection{Implications of the literature on communities of practice, action learning and reflective practice for research into leadership development using ICT}

Communities of practice, action learning and reflective practice all seem to be appropriate tools for supporting leadership development. The contextual nature of 
leadership means that it is essential for those in leadership roles to address real life issues and challenges in the course of leadership development programmes in order that learning is relevant and meaningful. Communities of practice and action learning sets have the potential to promote leadership development if they are structured to: address current leadership challenges; encourage questioning of current practices; promote ongoing learning; and encourage reflection. According to West-Burnham (2003), the most powerful base for profound learning is supported reflection. He suggests that reflective journalling and peer review and feedback are important ways of supporting reflection in leadership development.

ICT has the potential to support leadership development in communities of practice using action learning and to foster reflective practice. The literature suggests that ICT has a useful role in supporting communities of practice and action learning programmes that use a combination of face-to-face meetings and online communication. This combination, known as blended learning, has been described as "the thoughtful fusion of face-to-face and online learning experiences" (Garrison \& Vaughn, 2008, p. 5) and is seen to be more valuable than either approach used on their own (Rovai \& Jordan, 2004). Blended learning approaches have been shown to promote collaborative learning and to increase participant satisfaction (So \& Brush, 2008). One of the advantages of the online aspect of blended learning is that asynchronous text-based communication allows time for deeper reflection (Garrison \& Anderson, 2003; Barth, 2001; Bird, 2006; MacKnight, 2000). Blended learning also allows flexibility and convenience particularly for working professionals (Rovai \& Jordan).

The difficulty of building trust in virtual communities has been highlighted by a number of authors. The crucial role of the facilitator in establishing a collaborative culture and ensuring that communities of practice and action learning sets function effectively is also well established. Johnson's (2001) suggestion that research is conducted into how facilitator techniques can compensate for the difficulties inherent in online communication is mirrored by Stewart and Alexander's (2006) call for more investigation into "how to facilitate trust, collaboration and open communication" (p. 155) in blended action learning situations. It has been established that an online facilitator has a different role from a facilitator in a face-to-face environment and this changing role is worthy of further research. According to King (2002, p. 234) "the facilitation skills that many educators have cultivated in the traditional classroom need to be further explored and their online counterparts need to be developed and transformed". The recognition of the expertise of the practice community rather than the researcher themselves also needs to be taken into consideration when planning leadership development programmes.

Other issues arising from this literature review that have implications for this study include investigating which ICTs are most appropriate for supporting leadership development through communities of practice and action learning, and how these can 
best be employed. The use of various asynchronous and synchronous tools such as email, online forums, and online journaling will be further investigated. The importance of technology supporting rather than leading the development of the learning will also need to be considered. ICTs that build cohesion and support the sharing of knowledge and understanding will be most useful.

The use of communities of practice, action learning and reflective practice as part of research methodologies has much potential for further studies in the field of IS. Previous studies suggest that using action learning as a research methodology can provide participants with relevant learning opportunities in return for their input and may also help the researcher to understand the perspectives of the learner more clearly. Involving practitioners in researching their own practice can also encourage reflective practice and lead to meaningful theory construction. Although communities of practice are generally thought to be self-generating, research in teacher professional development programmes supports the deliberate establishment of communities of practice to connect isolated teachers. The suggestion that communities of practice can be incorporated into existing practices and research activities is also relevant to this study.

\subsection{Chapter summary}

This literature review has established a gap in the literature in the area of the use of ICT to support leadership development using communities of practice, action learning and reflective practice. Specific authors have commented on the lack of research into the use of ICT to support communities of practice (Davenport \& Hall, 2002; Johnson, 2001), action learning (Gray, 1999; Stewart \& Alexander, 2006), and critical reflection (Angeli et al., 2003). Links between action learning and communities of practice are also underresearched. The few studies that explore the use of ICT in these areas identify a number of challenges. These include the importance of building relationships between the participants before encouraging online communication and reflections; the choice and use of appropriate ICT; and the critical role of the facilitator in encouraging online participation and critical reflection. These areas appear to be crucial to the success of communities of practice, action learning and reflective practice using ICT and are worthy of further investigation. As King (2002, p. 243) has suggested, research into this area "provides a large universe of potential". There is a gap in the literature that this study into the use of ICT to support leadership development using action learning can contribute towards. This study will consider how ICT can be used to support leadership development within the New Zealand early childhood sector and will explore how the blended action learning process supports leadership learning, the role of the facilitator in blended action learning groups, and the most appropriate technologies for supporting leadership development through action learning. 


\section{Research Methodology}

"Research is to see what everybody else has seen, and to think what nobody else has thought." (Albert von Szent-Györgyi)

\subsection{Chapter overview}

This chapter outlines the research methodology used in this study. The first section explores different research paradigms and approaches, including knowledge claims and strategies of inquiry, in order to explain and justify the selection of interpretive case research as the research methodology. This section also justifies the use of blended action learning groups as the units of analysis. The second part of the chapter outlines the research design of this study. This section includes a description of the research questions, units of analysis, methods of data collection and data analysis, and a framework used for analysis. The role of the researcher is explored in the final section of the chapter. Relevant literature will be drawn on to position this study within a theoretical framework.

\subsection{Research approaches}

A wide range of possible approaches face researchers deciding on their particular research methodology. Cohen, Manion and Morrison (2000) suggest that research is concerned with "understanding the world" and therefore "is informed by how we view our world(s), what we take understanding to be, and what we see as the purposes of understanding" (p. 3). Hence it is important that a researcher considers assumptions about how and what they will learn when deciding on their research methodology. A researcher needs to consider not only what methods and methodologies should be employed but also how this choice can be justified (Crotty, 1998). Creswell (2003), building on Crotty's work, poses the following questions that he believes are central to research design:

1. What knowledge claims are made by the researcher?

2. What strategies of inquiry will inform the procedures?

3. What methods of data collection and analysis will be used? (p. 5).

Each of these questions will be considered in setting out the framework for this research study. 


\subsubsection{Knowledge claims}

Knowledge claims are contentions about the nature and forms of knowledge and how it can be acquired and communicated (Cohen, Manion \& Morrison, 2000). According to Creswell (2003), knowledge claims include both theories of knowledge and theoretical perspectives or paradigms. Paradigms can be seen as a combination of the ontological, epistemological and methodological premises of a researcher, and guide their actions (Denzin \& Lincoln, 2000). Ontology concerns the nature of reality; epistemology, the relationship between the enquirer and the unknown; and methodology, the process of research (Creswell, 1994).

A number of different frameworks can be used in a discussion of theoretical knowledge claims. Cohen et al. (2000) contrast two paradigms: normative and interpretive. The normative paradigm, which they see as positivist, suggests that human behaviour is rule-bound and is best investigated by methods of natural science. The interpretivist paradigm seeks "to understand the subjective nature of human experience" through understanding people's points of view (p. 22). Researchers working in these two paradigms approach theory creation differently. In the normative or positivist paradigm, general theories are devised to explain human behaviour and then validated through data gathered by quantitative research methodologies. In the interpretivist paradigm, the world is understood and interpreted through its actors; theory is emergent and follows rather than precedes research. The theory "must make sense to those to whom it applies" (p. 23). Interpretive research most often uses qualitative methods. According to Braa and Vidgen (1999, p. 2), "positivism is concerned with reducing the area of investigation in order to be able to make reliable predictions and explanations, while interpretivism is concerned with making a reading of a situation in order to gain understanding". Lee (1991), however, challenges the notion that interpretivism and positivism are irreconcilably opposed. He suggests that each paradigm represents diverse methods but that they can be combined in a way that strengthens the research outcomes.

\subsubsection{Research paradigms}

Of the two paradigms considered by Cohen et al. (2000), the interpretive paradigm fits better with the knowledge claims made in this research. Interpretive approaches have the intention of understanding the interpretations of individuals and their worlds. In this research seeking to understand how ICT can support leadership learning in the ECE sector, the views of the participants are paramount and their thoughts and perceptions form the basis of the data collected and analysed. Other aspects of this study that fit with the interpretivist paradigm are that the importance of context is acknowledged and that theory emerged throughout the study rather than being devised at the beginning and then tested. Interpretive research is increasingly being seen as a valid and important research approach in the field of information systems (Klein \& Myers, 1999; Nandhakumar \& Jones, 1997; Orlikowski \& Baroudi, 1991; 
Walsham, 1995). Interpretive studies have the intention of increasing the understanding of phenomena in natural settings and allow research participants to draw on their own experiences and describe their own reality (Orlikowski \& Baroudi). Interpretive approaches assist researchers to understand how people think and act in the context of their organisations and have "the potential to produce deep insights into information systems phenomena" (Klein \& Myers, p. 67). These authors classify IS research as interpretive if "it is assumed that our knowledge of reality is gained only through social constructions such as a language, consciousness, shared meanings, documents, tools, and other artifacts" (p. 69).

Klein and Myers (1999) have proposed a set of seven principles, derived from hermeneutics, phenomenology and anthropology, that can be used to both carry out and evaluate interpretive field research in information systems. They suggest that these principles may help researchers improve "the plausibility and cogency" of their studies (p. 79). The principles are:

1. The Fundamental Principle of the Hermeneutic Circle. This principle, which is seen to be central to all the other principles, suggests that understanding of a system is gained through iteration between the whole and its interrelated parts.

2. The Principle of Contextualisation. The principle of contextualisation is based on the awareness that the author and the reader of a text have different understandings and that the author needs to set the subject matter in its historical context in order to help the intended audience understand that context.

3. The Principle of Interaction between the Researchers and the Subjects. This principle emphasises the important role of the participants as interpreters and analysts, and their critical impact on the research data.

4. The Principle of Abstraction and Generalisation. This principle requires relating broader theoretical concepts and abstractions to particular findings from the data. This process enables the reader to follow the process by which theory is developed.

5. The Principle of Dialogical Reasoning. This principle involves the researcher confronting their prejudices and being explicit about the philosophies underpinning their research.

6. The Principle of Multiple Interpretations. This principle requires the researcher to be sensitive to and confront the different interpretations of research participants.

7. The Principle of Suspicion. This principle involves authors not taking the views of research participants at face value but rather being suspicious of any possible biases.

While the first principle is an overarching one that relates to the study as a whole, some of the other principles are particularly relevant to different stages of the research. Two 
that have particular relevance in the planning stages of the research are the principles of contextualisation and of dialogical reasoning. These principles require the researcher to place the study in context (as was done in the introductory chapter) and to be explicit about the paradigms influencing their direction, part of the purpose of the present chapter. The principle of abstraction and generalisation, which emphasises that the development of theories must be linked clearly to field data, influenced the data analysis process. Principles three and six relate to the relationship between the researcher and participants and will be discussed more fully in the context of the researcher's role towards the end of this chapter. The principle of suspicion does not seem relevant to this study and is one that according to Klein and Myers (1999), researchers may choose not to follow.

Denzin and Lincoln's (2000) description of research within the constructivist paradigm as "oriented to the production of reconstructed understanding of the social world" (p. 158) appears closest to the theoretical perspective that fits with this research. The constructivist paradigm is seen by some authors to sit alongside interpretivism (Schwandt, 2000) and by others to be a subset of interpretivism (Denzin \& Lincoln, 2000; Lincoln \& Guba, 2000). Social constructivism can be explained as "the view that all knowledge claims and their evaluation take place within a conceptual framework through which the world is described and explained" (Schwandt, p. 197). According to Charmaz (2000), constructivism "assumes the relativism of multiple social realities, recognizes the mutual creation of knowledge by the viewer and the viewed, and aims towards interpretive understanding of the subjects' meanings" (p. 510). In the constructivist paradigm, the researcher relies to a large extent on the participant's views of the situation being studied and asks broad and general questions (Creswell, 2003). Different criteria are used to evaluate the quality of research within constructivist paradigms compared with those used to evaluate positivist research and these differences will be discussed in a later section of this chapter.

The basic beliefs of alternative paradigms proposed by Lincoln and Guba (2000) link the research framework with the knowledge claims discussed above. They suggest that a constructivist paradigm assumes multiple realities (relativist ontology), a coconstructed understanding (a subjectivist epistemology) and naturalistic or hermeneutical methodologies. The theory is in a substantive-formal form and the type of narration may be based on interpretive case studies (Denzin \& Lincoln, 2000). Users of constructivist paradigms are "oriented to the production of reconstructed understandings of the social world" (Lincoln \& Guba, p. 178).

\subsubsection{Strategies of inquiry}

The second question in Creswell's (2003) framework concerns strategies of inquiry. Denzin and Lincoln (2000) describe strategies of inquiry as "a bundle of skills, assumptions, and practices that the researcher employs as he or she moves from the 
paradigm to the empirical world" (p. 22). Strategies of inquiry may be classified as quantitative, qualitative or mixed method. Quantitative research methods are those in which the researcher makes "postpositivist claims for developing knowledge" using strategies such as surveys and experiments that produce statistical data (Creswell, p. 18). Quantitative approaches originated in the field of natural sciences and were first used in the study of natural phenomena. Qualitative methods originated in the social sciences and were developed to enable researchers to study social and cultural phenomena (Myers, 2004). Mixed method approaches use a combination of quantitative and qualitative approaches. Creswell suggests that mixed methods research has "come of age" (p.4) and is particularly valuable when the researcher is making pragmatic knowledge claims. As qualitative strategies of inquiry clearly fit within the constructivist paradigm, the characteristics of qualitative research will be explored in more detail.

\subsubsection{Characteristics of qualitative research}

Qualitative research has been defined as:

An inquiry process of understanding based on distinct methodological traditions of inquiry that explore a social or human problem. The researcher builds a complex, holistic picture, analyzes words, reports detailed views of informants, and conducts the study in a natural setting (Creswell, 1998, p. 15).

Several important characteristics of qualitative research are referred to in this definition. These are: the process of understanding; the descriptive nature of qualitative research; and the natural setting in which qualitative research is carried out. The process of understanding is a key characteristic as qualitative researchers are striving to understand unique situations and ways in which people make sense of their experiences. The descriptive nature of qualitative research is also referred to in the definition. The product of a qualitative inquiry is characterised by rich description, and the researcher uses words and images to portray the reality of people's experiences (Merriam, 2002a). Qualitative research is also characterised by its contextual nature. Qualitative researchers focus on the actual contexts in which people live and work in order to understand these natural settings (Creswell, 2003).

Qualitative research methods fit well with the nature of this research study. The exploration of the use of ICT to support leadership learning involved supporting the participants to solve problems and tackle issues of importance to them. This in turn involved gaining some understanding of the contexts in which these leaders work and of the issues that they faced in their leadership roles. 


\subsubsection{Role of the qualitative researcher}

The role of the researcher provides another contrast between qualitative and quantitative methodologies. In quantitative research, the researcher is seen to be independent and is expected to remain distant from the research subjects. In contrast the qualitative researcher often minimises the distance between them and their research participants and may interact closely with them (Creswell, 1998). Stake (1995) describes the role of a qualitative researcher as follows:

Most of them favour a personal capture of the experience so, from their own involvement, they can interpret it, recognise its contexts, puzzle the many meanings while still there, and pass along an experiential, naturalistic account for readers to participate themselves in some similar reflection (p.44).

In qualitative research, the researcher is the main instrument for data collection and analysis (Merriam, 2002b). According to Denzin and Lincoln (2000), "qualitative researchers deploy a wide range of interconnected interpretive methods, always seeking better ways to make more understandable the worlds of experience they have studied" (p. 19). This broad approach enables the researcher to gain a better understanding of their subject as "each practice makes the world visible in a different way" (Denzin \& Lincoln, p. 4). The role of the qualitative researcher has been likened to that of a bricoleur or maker of quilts (Denzin \& Lincoln). The researcher or bricoleur uses a variety of strategies and tools and pieces together their research from a number of different sources.

In qualitative research it is understood that the beliefs, values and assumptions of the researcher will influence their view of the subject and their interpretation of the research findings (Orlikowski \& Baroudi, 1991). In a constructivist paradigm, researchers "recognise that their own background shapes their interpretation, and they "position themselves" in the research to acknowledge how their interpretation flows from their own personal, cultural, and historical experiences" (Creswell, 2003, p. 8). This acknowledgement involves reflexivity, defined by Lincoln and Guba (2000, p. 183) as "the process of reflecting critically on the self as researcher". According to Patton (2002), to be reflexive is to "undertake an ongoing examination of what I know and how I know it" (p. 64, original italics). He suggests that attention be paid to the perceptions and voices of those studied and those receiving the study as well as the self.

The inquirer posture of the constructivist researcher has been described as that of "passionate participant" and "facilitator of multi-voice reconstruction" (Lincoln \& Guba, 2000, p. 171). My role in this research study was close to that of a participant observer. As the facilitator of the action learning groups I was closely involved with the research process. Nandhakumar and Jones (1997) describe the personal involvement of the researcher in the research context as engaged data gathering. They suggest that 
engaged methods, which involve direct and intensive interaction between researchers and participants, can provide a potential richness of data and additional insights into the research context. These insights allow the interpretive researcher an inside view (Walsham, 1995). The data in this research study were directly gathered from the research participants and took the form of their ideas, thoughts and reflections.

\subsubsection{Qualitative approaches}

There are a number of possible traditions of inquiry within qualitative research, as qualitative research "privileges no single methodological practice over another" (Denzin \& Lincoln, 2000, p. 6). Case research is the approach that was employed in this study and action learning sets were used to generate the research data. These two approaches will each be described before data collection and analysis methods are discussed in more depth.

\subsubsection{Case research}

Case research involves the in-depth study of a bounded system using multiple data collection methods over a period of time (Creswell, 1998). A number of key characteristics of case research have been described by Benbasat, Goldstein and Mead (1987). These include that: phenomena are looked at within their natural settings; contemporary events are the main focus; 'how' and 'why' questions are studied; there is flexibility in both site selection and methods of data collection as the research proceeds; there is extensive study of the complexity of the unit of analysis; and there is no manipulation or experimental controls involved.

There has been an increase in the use of case research in the field of information systems in recent decades due to the recognition of the importance of social issues in the field (Walsham, 1995). Benbasat et al. (1987) have suggested three reasons why case research is a particularly suitable option for IS research. Firstly, case research allows researchers to study systems in their natural settings and to generate theories from the knowledge of practitioners. Secondly, the type of questions asked in case research can facilitate an understanding of the complex processes taking place in organisational settings. Thirdly, case research is particularly appropriate in areas where little prior research has been carried out. This is often the case in the information systems field because of rapid changes in technology.

Stake (1995) believes that case research is particularly suited to the study of educational programmes. He identifies three types of case study: intrinsic; instrumental and collective. Intrinsic case studies are described as those chosen by the researcher primarily because they want to gain a better understanding of a particular case, rather than because the case is representative in any way. According to Stake, intrinsic case research does not generally lead to theory building. Instrumental case studies are those which provide insight into a particular issue or facilitate our understanding of a wider phenomenon or 
area of interest. The cases themselves will be of secondary interest but will contribute to an understanding of the phenomenon. Collective case studies involve the joint study of a number of cases, in order to investigate "a phenomenon, population, or general condition" (Stake, p. 437). Of these three types of case studies, instrumental case studies seem to fit most closely with the aims of this research, as the use of ICT to support leadership development was the issue or area of interest that is under investigation, and this study will contribute to an understanding of this phenomenon.

Case research fits within both positivist and interpretivist paradigms and may use quantitative and/or qualitative approaches. Braa and Vidgen (1999) make a distinction between hard and soft case studies, suggesting that hard case studies are positivistinformed whereas soft case studies are informed by interpretivist perspectives. Some of the differences between hard and soft case studies relate to the use of theory and the role of researcher. Both positivist and interpretivist perspectives would view theory as a valuable product of case research. Theory is more likely to be used to inform the early stages of hard case studies in the development of initial concepts that will guide the research process. According to Yin (2003) who writes from a positivist view, theory development is an essential part of the design phase of a study "whether the ensuing case study's purpose is to develop or test theory" (p. 28). Other authors have cautioned against theory building in the early stages of case research. Eisenhardt (1989) suggests that "theory building research is begun as close as possible to the ideal of no theory under consideration", as she believes findings may be limited or biased by "preordained theoretical perspectives or propositions" (p. 536). Walsham (1995) promotes the use of theory at the initial stages in soft case studies but cautions that there needs to be a willingness to remain open to issues arising from the research, and "to preserve a considerable degree of openness to the field data and a willingness to modify initial assumptions and theories" (p. 76).

The nature of theory in information systems has been explored by Gregor (2006). She distinguishes five interrelated types of theory: theory for analysing; theory for explaining; theory for predicting; theory for explaining and predicting; and theory for design and action. All five theory types are seen as equally important and the type of theory developed will depend on the nature of the research problem and questions. The theory developed from this research study is theory for explaining, which increases understanding of how and why phenomena occur and explains something that was previously not well understood. Gregor suggests that case studies are one research approach used to develop this type of theory, which fits within an interpretivist paradigm.

The differing role of the researcher in hard and soft case studies has parallels with the earlier discussion on the differing roles of the quantitative and qualitative researcher. The interpretive or soft case researcher has a less objective role compared to the outside observer role taken in hard case studies. Stake (2005) emphasises the close involvement of the qualitative case researcher who is likely to spend "extended time on site, 
personally in contact with activities and operations of the case, reflecting, and revising descriptions and meanings of what is going on" (p. 450). Walsham (1995) also highlights the insider role of the interpretive case researcher who is likely to have a personal stake in the research. He cautions that the researcher should develop a clear view of their role within the research process and be able to articulate this. Patton (2002, p. 546) suggests that constructivist case research is "explicitly informed by attention to praxis and reflexivity, that is understanding how one's experiences and background affect what one understands and how one acts in the world."

The different roles a case researcher may play include those of teacher, advocate and interpreter (Stake, 1995). In the role of teacher, the researcher is helping their readers learn about their research, as advocates, they are trying to convince their readers of their description, and as interpreters they are recognising and substantiating new meanings and knowledge. Stake suggests that researchers have to decide "consciously or unconsciously" (p. 91) how much emphasis to give each role, but advises that "perhaps the most important choice is how much will the researcher be her- or himself" (p. 103). Stake also emphasises the responsibility inherent in case research suggesting "all researchers have great privilege and great obligation: the privilege to pay attention to what they consider worthy of attention and the obligation to make conclusions drawn from those choices meaningful to colleagues and clients" (p. 49).

\subsubsection{Action learning}

Action learning has been described in the literature review as "a process of learning and reflecting that happens with the support of a group or 'set' of colleagues, working on real issues, with the intention of getting things done" (McGill \& Brockbank, 2004, p. 11). The primary purpose of action learning is to encourage problem solving and reflection on work-place issues in a supportive group environment. It has been little used as a research methodology, though there are some studies that use action learning either as the basis for a research dissertation or as an approach that generates data in a qualitative research study. Coghlan and Pedler (2006), in a discussion of the structure, supervision and examination of action learning dissertations, compare action learning research with traditional research. They suggest that action learning research begins with a problem experienced by an organisation and that this is followed by action taken to resolve the problem resulting in both personal and organisational learning. This contrasts with traditional research in which a topic or field is selected, literature is reviewed, field work undertaken, and the findings presented and conclusions drawn. Coghlan and Pedler caution writers of action learning theses against assuming that their personal story is all that is necessary. They suggest three criteria for assessing action learning research: evidence of real problems recognised by participants, rather than by the researcher being addressed; evidence of action being taken to solve the problem or change the situation; and evidence of learning that has occurred. This learning may be personal learning by the researcher, practitioner learning or organisational learning. 
There are a limited number of studies exploring the use of action learning in information systems research. Yoong's (1996) study focusing on how facilitators make the transition from facilitating conventional meetings to facilitating face-to-face electronic meetings used an action learning approach to generate data. This approach encouraged a focus on real life issues and promoted collaborative group learning. Research participants were offered training in group support systems facilitation in exchange for their participation in the research. Pauleen and Yoong (2004) promote the use of action learning in research because of its usefulness in "studying learning in complex, technology situations" (p. 157). It has also been suggested that action learning approaches help the researcher to understand more clearly the perspectives of the learner and enables them to adapt their facilitation styles to aid the effectiveness of the learning process (Yoong \& Gallupe, 2001).

Lau (1999) comments on the lack of IS research that uses either action learning or a closely related methodology, participatory action research. He suggests that these research methods, which involve experiential learning in organisational contexts, have potential for use in IS research as they provide "a unique opportunity to bridge theory with practice, allowing one to solve real world problems while contributing to the generation of new knowledge" (p. 170). Particular benefits of using action learning as part of the research methodology include that action learning allows participants to work collaboratively on real work-place issues and that those involved are offered relevant learning opportunities in return for being research participants. Action learning approaches have the potential to empower learners to be confident and courageous and to act in the light of their experiences (Morris, 1997). It has also been suggested that action learning enables people to achieve more control of their own learning and be more conscious of driving forces in themselves that can influence future directions (Marsick \& O'Neil, 1999). Action learning is particularly appropriate as a research approach in this study as in addition to the reasons articulated above, its suitability for use as a powerful research methodology has been established in Section 2.5.4.

Figure 3-1 below shows how the two approaches of action learning and case research were employed in the present study. The action learning sets generated data in the form of interview transcripts, online reflective journals, forum entries, chat postings and emails, and case research, in particular an instrumental case study, informed the data collection and analysis process. 


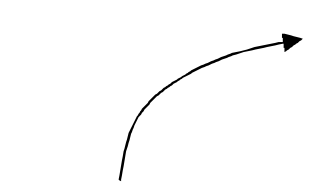

Themes/issues

identified

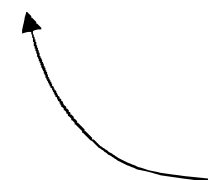

Action learning sets

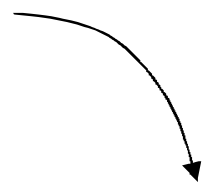

Data generation

Case research

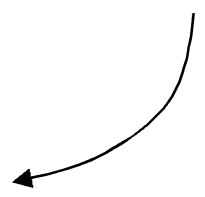

Figure 3-1: The research process

Table 3-1 below summarises the main elements of the research approach; that is the research paradigm, strategy of enquiry, methodology and methods of data collection.

\begin{tabular}{|c|c|l|l|}
\hline $\begin{array}{c}\text { Research } \\
\text { paradigm }\end{array}$ & $\begin{array}{c}\text { Enquiry } \\
\text { strategy }\end{array}$ & \multicolumn{1}{|c|}{ Methodology } & \multicolumn{1}{|c|}{ Data collection methods } \\
\hline $\begin{array}{l}\text { Interpretivism/ } \\
\text { Constructivism }\end{array}$ & Qualitative & $\begin{array}{l}\text { Case research } \\
\text { using blended } \\
\text { action learning sets }\end{array}$ & $\begin{array}{l}\text { Interviews, online reflective } \\
\text { journal entries, forum } \\
\text { discussions, chats and emails. }\end{array}$ \\
\hline
\end{tabular}

Table 3-1: Summary of the research approach

\subsection{Research design}

Research design has been defined as "a logical plan for getting from here to there, where here may be defined as the initial set of questions to be answered, and there is some set of conclusions (answers) about these questions" (Yin, 2003, p. 20, original italics). Whereas quantitative designs may be quite explicit, qualitative research designs need to remain flexible and open to allow for the exploration of whatever emerges through the data collection process (Patton, 2002). This section will outline the research questions, the units of analysis, the methods of data collection and analysis including the framework for analysis, and the role of the qualitative researcher.

\subsubsection{Research questions}

Research questions in case research often take the form of 'how' and 'why' questions and can be described as explanatory questions (Yin, 2003). Although they are usually developed at the outset of the study, they may be refined later on in the course of data collection (Miles \& Huberman, 1994). In this study, the initial overall research question "How can ICT be used to support leadership development within the New Zealand 
early childhood education sector?" fits within an explanatory frame. Sub-questions arising from the literature relate to:

- $\quad$ how the blended action learning process supports leadership learning;

- what role the facilitator takes in a blended action learning environment; and

- $\quad$ the most appropriate ICT tools for use in blended action learning.

\subsubsection{Units of analysis}

As part of the research design process, the case researcher needs to decide on the unit of analysis (individuals, groups, an organisation or project), and whether one or more cases should be included (Stake, 2005). Deciding on the unit of analysis involves defining the boundaries of the case and selecting the issues or phenomena to emphasise. Yin (2003) discusses four types of case study designs: single-case (both holistic and embedded) and multiple-case (both holistic and embedded). Holistic designs involve the examination of a whole organisation or programme, whereas embedded designs look at units within an organisation or programme. An example of an embedded design could be the case study of a school where the classrooms were the embedded units of analysis (Miles \& Huberman, 1994).

The merits of single versus multiple case studies have been debated by a number of authors. Yin (2003) offers several rationales for studying a single case including that: it may represent the critical case that will make a significant contribution to theory building and knowledge; it may be a unique case; it may be a representative case; it may reveal previously inaccessible information (a revelatory case); or it may be a longitudinal case that will be studied at several different points in time. Multiple cases have both advantages and disadvantages compared with single cases. One of the main advantages of multiple cases is that they allow for cross-case analysis and therefore have the potential to produce more general research results (Benbasat et al., 1987). Yin also suggests that their evidence may be seen as more compelling. The issue can be seen as one of depth versus breadth. A larger number of cases is likely to increase the breadth of the study but will risk reducing the depth of any single case (Creswell, 1998). Multiple case studies are also likely to be more time consuming and expensive to carry out.

A decision on the form of case research to be used must consider the purpose of the research, what will be useful and what will have credibility (Patton, 2002). It is also essential to choose the case or cases from which most will be learnt (Patton; Stake, 2005), and that are also relevant to the issues under investigation (Yin, 2003). This research study took the form of a single embedded case where the phenomenon of interest was the use of blended action learning to develop leadership in the New Zealand ECE sector, and the units of analysis were the action learning groups. The number of action learning groups was initially flexible, and the decision to use two 
research groups was made during the data analysis process. Although the action learning groups were the main units of analysis, the individual participants making up the two groups became secondary units of analysis as their leadership journeys formed twelve individual cases of leadership learning. Both these units of analysis are described in subsequent chapters; the action learning groups being the focus of Chapter 4, and some individual participants the focus of Chapter 5. This case design is illustrated in Figure 3-2 below.

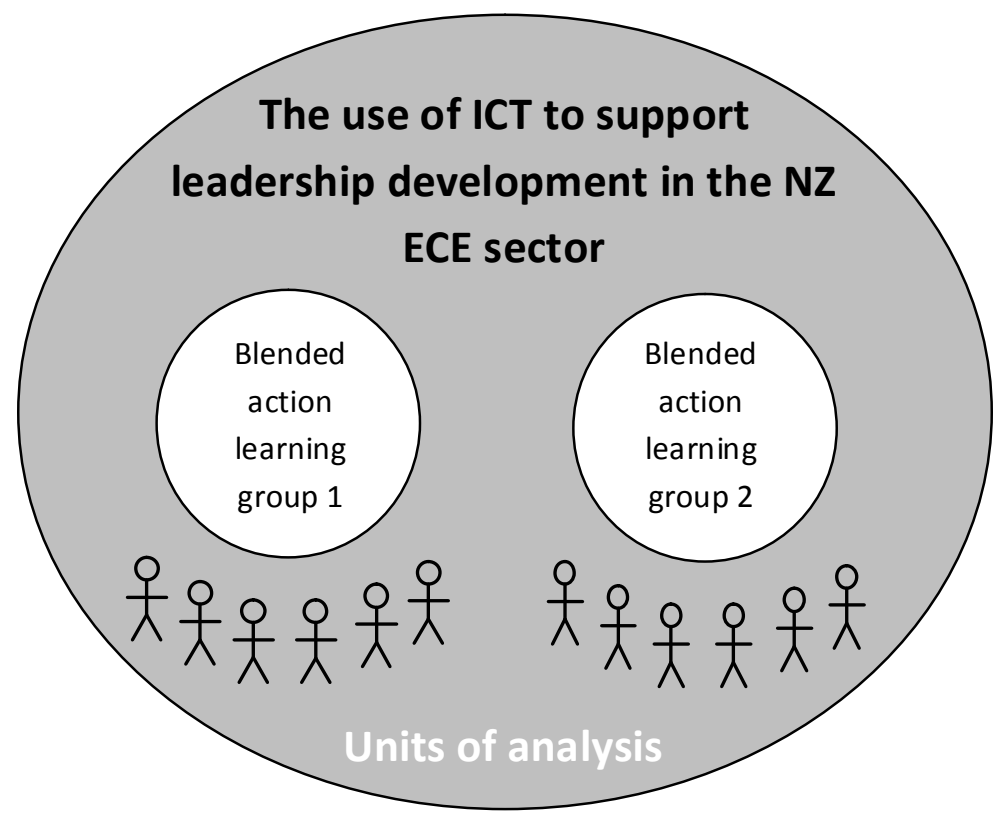

\section{The case}

Figure 3-2: Case design

\section{Research groups - composition and recruitment}

The first research group, named 'leadership action learning group one' (LALG1), was made up of six female early childhood teachers from the Wellington region. Four of the teachers responded to information in a professional development newsletter about the research and the other two were approached through their umbrella organisations. Five of the teachers were in formal leadership positions (head teachers) and the sixth took on a relieving head teacher's position during the course of the research. The teachers worked in a variety of ECE services including kindergarten, community-based education and care, and private education and care. None of the participants had met before; however, there were connections between them. These included a student from the centre of one participant being on teaching experience in another participant's service during the course of the research and one participant having a staff member who had previously worked for another participant. LALG1 first met in June 2007 and interacted both face-to-face and online throughout the remainder of 2007. Although data collection stopped at the end of 2007 , this group continued to meet throughout 
2008 and into 2009. Information about the participants' leadership experiences and a detailed description of the group interactions will be provided in Chapter 4 .

The second research group, LALG2, was also made up of six female early childhood teachers from the Wellington region. This group was recruited through their different umbrella organisations and all were in formal leadership positions. There were several connections between group members. Two pairs of teachers worked for the same organisation, though their centres were in different parts of Wellington and they did not have regular contact. One participant had also previously worked for another participant. This prior relationship did not create any difficulties as the employment relationship ceased some years ago, and the participants were now involved in different services. This group began meeting in November 2007, and their interactions continued throughout 2008 and into 2009. Data collection stopped in June 2008.

The fact that all research participants were women reflects the extremely high proportion of women in teaching positions in the New Zealand ECE sector. As at July $2008,98.8 \%$ of ECE teachers were female (Ministry of Education, 2008c), consequently it would not be expected that there would be any males in a sample of this size.

\section{Blended interactions}

Both groups engaged in a blended action learning process, which involved both face-toface and online interactions. A multiple-problem format was used where each participant brought their own issue to the group. The open source software Moodle was the enabling technology used in this study and the ICTs used include online reflective journals, forum discussions including online action learning forums, chat sessions and email. Moodle was chosen as the online learning platform as it was a learning management system my primary PhD supervisor, Professor Pak Yoong, had found useful for online action learning and that I thought would be user-friendly. Moodle has been described as a flexible learning management system that supports collaboration (Anderson, 2006; Brandl, 2005; Pfaffman, 2005). The grounding of Moodle in a socio-constructivist theory of learning means that social interactions between participants are encouraged and that participants have control of their own learning (Brandl).

\section{Ethical considerations}

Participants in this study were given an information sheet explaining the nature of the research and what participation in the study would involve. They were told that their identity would be protected and that any personal information or opinions would be kept confidential and reported only in non-attributable form. They were also informed that they would receive copies of interview transcripts for verification, clarification and if necessary deletion. The 'Participant Information Sheet' is attached as Appendix A. All participants were required to sign a consent form (Appendix B) approved by the Victoria University of Wellington School of Information Management Human Ethics 
Committee. These steps fit with the following requirements outlined by Christians (2000) for qualitative research:

- informed consent, ensuring that participants are informed about the nature of the research and the consequences of their involvement;

- deception, ensuring that no deceptive practices will be used in the course of the study;

- $\quad$ privacy and confidentiality, ensuring that safeguards will be put in place to ensure that people's identities will be protected; and

- $\quad$ accuracy, ensuring the accuracy of data.

In terms of ethical theories, the notion of relational ethics (Flinders, 1992, as cited in Miles \& Huberman, 1994) corresponds closely with the approach taken in this study. Relational ethics is concerned with respect and caring, and emphasises collaboration between researcher and participants, and avoidance of imposition. As mentioned above, member checks were used. Participants were given copies of their interview transcripts, and at different stages of the research process emerging models such as the revised community of inquiry model and the stages of facilitator role, to be addressed in later chapters, were discussed with participants and their feedback sought. Participants whose leadership journeys feature in Chapter 5 were also given copies of their journeys for comment. A final member check involved inviting all participants to a presentation of research findings and asking for their feedback. Stake (2000) considers these checks to be vital stating "it is important (but never sufficient) for targeted persons to receive drafts revealing how they are presented, quoted, and interpreted and for the researcher to listen well for signs of concern" (p. 447). Miles and Huberman emphasise the importance of regular checking and negotiation, in qualitative studies, as it is not always possible to anticipate the way the study will evolve. They suggest that the expectation be created that either the researcher or the participants should be able to call "recheck" meetings or renegotiate agreements.

Miles and Huberman (1994) invite consideration of what both researchers and study participants have to gain from their involvement in a research study. The benefits for researchers are obvious in that they are able to collect data for use in their research. Miles and Huberman suggest that study participants may benefit from improving their personal practice, being supported in taking action on recurring problems and gaining insight. This is important when considering the idea of relational ethics; fieldwork should benefit participants rather than impose on them. All the above benefits were available as participants had the opportunity to develop their leadership capabilities in exchange for their participation. These benefits were clearly articulated by the participants and will be discussed more fully in Chapter 6 . 


\subsubsection{Data collection}

Data in case research consist of "all the information one has about each case" and may include observations, interviews and documents (Patton, 2002, p. 449). Stake (1995) suggests that much data gathering is impressionistic and that it will begin even before the study formally commences. Three principles of data collection suggested by Yin (2003) that can assist in the research process are: the use of multiple sources of evidence; the creation of a database for the case study; and the maintenance of a chain of evidence. Multiple sources of evidence are a feature of case research as the researcher endeavours to build an in-depth picture of the case (Creswell, 1998). The database suggested by Yin allows for the separation of the data and the report that will be written as a result of the case research. Yin believes that this helps increase the reliability of the study as the evidence can be viewed directly by others, not only as interpreted by the researcher. The chain of evidence allows an external investigator to trace the process by which the final conclusions are reached from the initial research questions. Yin also emphasises the importance of the case researcher being willing and able to: ask good questions; listen well; be adaptable to changes; and be open to contrary findings during the data collection process.

Data were generated in this study from the two action learning groups. These data took multiple forms and included interviews, online reflective journal entries and responses, forum discussions, chat sessions, and individual and group emails. Interviews took place before each group met, after the first follow-up meetings and at the conclusion of the data collection process for each group. The Moodle platform stored all the online interactions including the reflective journals, forum discussions and chat sessions. As the focus of the research was on the use if ICT to support leadership development, faceto-face meetings were not recorded and therefore did not form part of the data collected. Facilitator responses and reflections, both online and recorded in a hand written journal also formed part of the research data.

\subsubsection{Data analysis}

Qualitative data analysis has been described as the transformation of data into findings and is a process unique to each study (Patton, 2002). Data collection and analysis in qualitative research are not separate processes as both are spread throughout the inquiry process (Huberman \& Miles, 1998). Data analysis in qualitative research involves three processes: data reduction; data display; and conclusion drawing and verification (Huberman \& Miles). Data reduction involves managing the data in order that it can be categorised. This can entail summarising, coding and finding themes. Data display involves assembling information in a way that actions can be taken and conclusions drawn. In the conclusion drawing and verification process, the researcher interprets and draws meaning from the displayed data. 


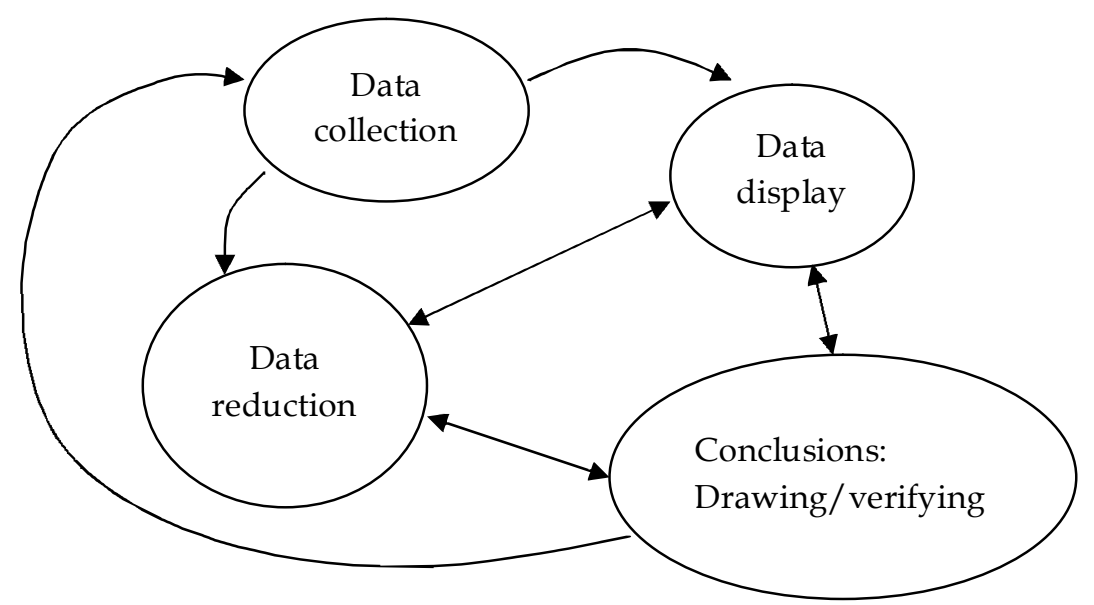

(Huberman \& Miles, 1998, p. 181)

Figure 3-3: Components of Data Analysis: Interactive Model

As Figure 3-3 above illustrates, the different components of the data analysis process are linked. Data analysis in case research is an iterative process that involves continuous interplay between data collection and analysis. Eisenhardt (1989, p. 538) views this overlap as "a striking feature of research to build theory from case studies" and suggests that it allows the researcher to remain flexible and to make adjustments to data collection processes during the course of the study. This flexibility is described as "controlled opportunism in which researchers take advantage of the uniqueness of a specific case and the emergence of new themes to improve resultant theory" (Eisenhardt, p. 539).

Data display and reduction took a number of forms in this study. Data from the first research group were initially organised in terms of the different sources such as reflective journals, forums and chat sessions. Use of a framework to analyse these preliminary data is described in detail in the following section. In a secondary phase of data analysis, data from each of the 12 participants were arranged chronologically in order to see progression in leadership learning. This process will also be discussed further in Section 3.3.7.

\subsubsection{Frameworks for analysis}

As a starting point for data analysis a number of existing frameworks were looked at to see firstly, which seemed to fit with the approach used in the study and secondly, what elements appeared to be important in the online learning process. The models considered included:

- $\quad$ Factors affecting knowledge sharing in online communities (Sharratt \& Usoro, 2003) 
- Constructivist Interaction Analysis model (Gunawardena, Lowe \& Anderson, 1997)

- Evolution of Online Group Development (Waltonen-Moore, Stuart, Newton, Oswald \& Varonis, 2006)

- $\quad$ Sociability and Usability framework (de Souza \& Preece, 2004; Jones \& Preece, 2006)

- Taxonomy of Teacher Reflective Thinking (Hough, Smithey \& Evertson, 2004)

- $\quad$ Telecollaboration framework (Redmond \& Lock, 2006)

- Community of Inquiry framework (Garrison, Anderson \& Archer, 2000).

Each of these models was briefly analysed for relevance to this study. The model that seemed most relevant was the 'Community of Inquiry' model (Garrison et al., 2000). Aspects of this model that were particularly applicable to this study were: the holistic nature of the model; its fit with the interpretive research approach; and the existence of indicators which could be modified for use in the transcript analysis process. None of the other models considered had the breadth of the community of inquiry model which encompasses three interrelated aspects of the online learning process: cognitive presence; social presence; and teaching presence. These aspects will be described in detail in the next section. Other models focus on just one of these aspects of the online learning process such as Waltonen-Moore et al.'s (2006) five stage model of online group development which focuses on 'social presence', and Hough et al.'s (2004) seven level taxonomy which focuses on individual teacher reflective thinking.

\subsubsection{Community of inquiry framework}

The community of inquiry model, which was originally designed as an online learning research tool (Garrison, 2006), comprises three elements: cognitive presence; social presence; and teaching presence. Cognitive presence is defined as "facilitating the analysis, construction, and confirmation of meaning and understanding within a community of learners through sustained discourse and reflection largely supported by text communication" (Garrison \& Anderson, 2003, p. 55). Cognitive presence is grounded in the critical thinking literature and focuses on higher order thinking processes rather than specific learning outcomes (Garrison, Anderson \& Archer, 2001). These authors make a strong connection between cognitive presence and the concept of critical thinking derived from Dewey's (1933) reflective thinking model. Cognitive presence can be explained in terms of a cycle of practical inquiry which starts with a triggering event then moves through stages of exploration, integration and resolution.

Social presence is described in terms of this model as the way individuals portray themselves in the online community and establish personal relationships (Garrison, 2006). This description contrasts to some degree with the more commonly understood definition of social presence as "the feeling of community that a learner experiences in 
an online environment" ( $\mathrm{Tu} \&$ McIsaac, 2002), which places greater emphasis on the technology aspect of social presence. Although social presence is seen as a necessary support for cognitive presence, it can also be a direct contributor to the success of the educational experience. The three elements of social presence described in this model are affective, open communication and group cohesion. Affective responses are described as emotional responses that tacitly recognise the reciprocal relationships in communities (Garrison \& Anderson, 2003).

Teaching presence is defined as "the design, facilitation, and direction of cognitive and social processes for the purpose of realizing personally meaningful and educationally worthwhile learning outcomes" (Garrison \& Anderson, 2003, p. 66). The functions of teaching presence, although normally seen to be the responsibility of the teacher, can be shared with other participants. Teaching presence is seen to support cognitive and social presence and is an important contributor to the adoption of a deep approach to teaching (Garrison \& Cleveland-Innes, 2005). Teaching presence consists of three functions: the design of the educational experience; the facilitation of the learning process; and the provision of direct instruction. Figure 3-4 below illustrates how these elements interact to provide a successful e-learning experience.

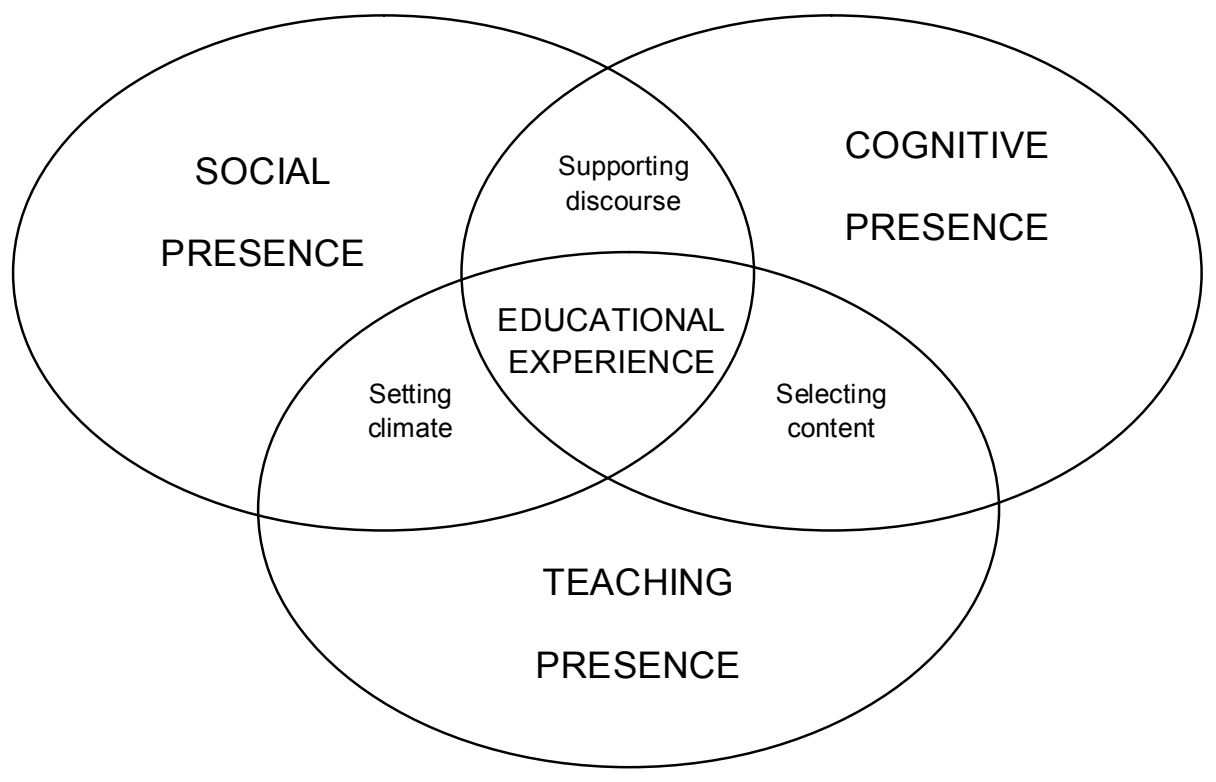

Communication Medium

(Garrison et al., 2000, p. 88)

Figure 3-4: Elements of an educational experience

The community of inquiry model fits well with the interpretivist research paradigm and qualitative strategy of inquiry used in this study. Transcript analysis has been described as "an exploratory, qualitative methodology" and may be described as 
interpretive because it involves description and a development of understanding (Garrison, Cleveland-Innes, Koole \& Kappelman, 2006, p. 6). These authors suggest that the use of a theoretical framework provides a structure for coding and analysis and also increases the rigour of the process. The existence of indicators and definitions that characterise each of the three presences, and that have been tested in a number of studies, is another reason for using this model. Other models are less specific and do not provide examples of the categories. These existing categories make the process of coding transcripts easier.

\section{Communities of inquiry}

A community of inquiry can be defined as "a teacher-guided, non-authoritarian community where societal knowledge is revealed in an equivocal, multidisciplinary manner" (Garrison \& Anderson, 2003, p. 27). The concept of a community of inquiry as used in this model is attributed to Lipman (1991), who applied the concept to a classroom where students listen to one another respectfully, build on and challenge each other's ideas and work together to identify assumptions and draw inferences. The community of inquiry model explained here is designed specifically for an e-learning environment. E-learning is described as learning that is "facilitated on-line through network technologies" (Garrison \& Anderson, p. xi). E-learning environments are able to effectively support communities of inquiry because of the reflective and explicit nature of the communication involved. The community of inquiry model emphasises the role of participants in taking responsibility for, and control of, their learning "through negotiated meaning, diagnosing misconceptions, and challenging accepted beliefs" (Garrison \& Anderson, p. 27). Each of the elements of the community of inquiry model has a number of indicators or examples which have emerged from the literature and have had their validity tested (Garrison \& Anderson). The indicators are grouped into categories in order to clarify the phase or aspect of each element demonstrated and to guide coding of transcripts. Table 3-2 below outlines the categories and indicators of each element of the model. 


\begin{tabular}{|c|c|c|}
\hline Elements & Categories & Indicators (examples only) \\
\hline Cognitive presence & $\begin{array}{l}\text { Triggering event } \\
\text { Exploration } \\
\text { Integration } \\
\text { Resolution }\end{array}$ & $\begin{array}{l}\text { Sense of puzzlement } \\
\text { Information exchange } \\
\text { Connecting ideas } \\
\text { Apply new ideas }\end{array}$ \\
\hline Social presence & $\begin{array}{l}\text { Affective } \\
\text { Open communication } \\
\text { Group cohesion }\end{array}$ & $\begin{array}{l}\text { Expressing emotions } \\
\text { Risk-free expression } \\
\text { Encouraging collaboration }\end{array}$ \\
\hline Teaching presence & $\begin{array}{l}\text { Design and organisation } \\
\text { Facilitating discourse } \\
\text { Direct instruction }\end{array}$ & $\begin{array}{l}\text { Setting curriculum and methods } \\
\text { Sharing personal meaning } \\
\text { Focusing discussion }\end{array}$ \\
\hline
\end{tabular}

(Garrison \& Anderson, 2003, p. 30)

Table 3-2: Community of inquiry category and indicators

\section{Applications of the model}

The community of inquiry model was first developed to assess the use of computer mediated communication and computer conferencing in higher education and to guide transcript analysis (Garrison et al., 2000). The authors have since made minor modifications to the framework and indicators, though the essence remains the same. The community of inquiry model has been referred to or used as a framework in a number of research studies. Some of these involve one or more of the original authors of the model and others do not. Among the independent users of the model are Redmond and Lock (2006), Shea (2006), and Stein et al. (2007). Redmond and Lock developed a framework for online collaborative learning, known as telecollaboration, which is based on the community of inquiry model. The main difference between their model and the original framework is that the intersections between the three types of presence are expanded. Redmond and Lock do not, however, clearly explain why they have adapted the model in this way or exactly how it is applied.

The community of inquiry model was used by Shea (2006) to develop a survey to measure online students' perceptions of teaching presence. This study found that perceived teaching presence, particularly directed facilitation, is closely linked to students' sense of learning community. Stein et al. (2007) examined the interactions of students in a chat learning space and used the community of inquiry model to look at how knowledge construction was supported by the learners' experience of cognitive presence. This study concluded that social presence and teaching presence exhibited by the learners contributed to the development of cognitive presence. The learners were able to come up with shared solutions through a process of questioning, information exchange, making connections and defending solutions. 
Studies involving the originators of the model include Garrison and Kanuka's (2004) research into the use of asynchronous text-based communication technologies and their contribution to higher levels of learning. In this study, methodological constructs that fitted with the model were developed and explored with experts in online instruction. Three external constructs (collaboration, discourse and management), and three internal constructs (knowledge construction, reflection, and monitoring) were identified. The research concluded that combinations of internal and external constructs played an important role in higher levels of learning. Garrison and Cleveland-Innes (2005) refer to the community of inquiry model in their study assessing depth of online learning in a variety of distance education courses. Their findings suggest that all three elements of a community of inquiry are necessary to support higher order learning and that the community of inquiry model is "a useful framework to analyze and understand interaction in an online environment" (p. 144).

Garrison et al. (2006) discuss how the community of inquiry model can assist in the analysis of transcripts from online learning communities and more specifically how transcripts can be accurately and reliably coded. Their study, which involved the coding of a sample of online transcripts for each of the three presences, revealed that there is potential for inaccuracy with multiple coders unless a negotiated and collaborative approach is taken.

\section{An analysis of the model and its usefulness}

The community of inquiry framework is one of a number of models that have been developed to study online learning environments and in particular text-based communication. Several studies have compared different models (Gerbic \& Stacey, 2005; Meyer, 2004; Woo \& Reeves, 2007). Gerbic and Stacey discuss different approaches to the content analysis of computer conferences and suggest that researchers should choose one that fits the aims and context of the research and modify it if necessary. They recommend the use of summary tables in the community of inquiry model as they provide "an excellent way of understanding the qualitative nature of conference messages" (p. 47). Meyer distinguishes between developmental frameworks which are used to understand student development in online situations, and models which measure levels of thinking such as Garrison et al.'s (2001) four stage cognitive presence model. Meyer concludes that the cognitive presence is both a useful and usable framework although she does not refer to the other aspects of the community of inquiry model. Woo and Reeves have compared different approaches to interaction analysis and suggest that different models suit different purposes. They propose deciding on the unit of analysis as an important step in choosing which model to use.

The preferred unit for the analysis of online transcripts has been discussed in the literature. Possible units that have been suggested include sentences, paragraphs and whole messages (Woo \& Reeves, 2007). Another possible entity is the thematic unit or unit of meaning (Rourke, Anderson, Garrison \& Archer, 2001). This can be described as 
a single thought or idea but may not be particularly reliable as a unit of analysis. Anderson and Kanuka (2003) suggest trying a number of different coding units then checking for ease of classification, ease of identification and reliability with regard to both processes. Garrison et al. (2001) recommend the message as the unit of coding as it is reliably identified and "provides coders with sufficient information to infer underlying cognitive processes" (p. 17) and this was the unit used in this study.

Most support for the community of inquiry model not surprisingly comes from its original authors. Garrison et al. (2006) believe that although the community of inquiry framework is relatively new and untested, it has been judged to have good validity because: it is based on mature educational literature; it has been adopted to frame research into online education; and there have been no significant critiques of it. They also suggest that it "provides a comprehensive perspective on the educational transaction" (p. 4) yet is relatively straightforward to apply and use.

\section{Links to action learning}

It is essential that the model chosen as a framework for data analysis fitted with the action learning process used in this research study. In the following section, the six components of the action learning process described in the previous chapter will be discussed with regard to their compatibility with this framework.

\section{An action learning group}

The participants in an action learning set form the community of learners in the online community of inquiry. In action learning it is important that set members support each other and that learning is seen as a social and collaborative process (McGill \& Brockbank, 2004). This involves building feelings of trust and empathy and can be seen to be similar to the development of social presence in the community of inquiry model. Social presence becomes even more important in virtual action learning sets than in face-to-face action learning (Marquardt, 2004b) and it is social presence that is most strongly linked to this component of the action learning process although cognitive presence also requires collaboration, "since cognition cannot be separated from the social context" (Garrison et al., 2000, p. 92).

\section{A problem, challenge or issue}

The problem or issue in an action learning set can be seen to be equivalent to the triggering event in the cognitive presence aspect of the model. Triggering events have been described as issues, dilemmas or problems (Garrison et al., 2001), which is very similar terminology to that used in the action learning literature. Each person in the group identifies an issue that they wish to work on and this is shared with the rest of the group. This process is less structured in the community of inquiry framework but there are clear links. 


\section{A questioning and reflective listening process}

The importance of questioning with regard to communities of inquiry is emphasised by Lipman (1991), who suggests that questioning creates doubt and encourages reflection. The second phase of developing cognitive presence involves exploration and shifting "between the private, reflective world of the individual and the social exploration of ideas" (Garrison et al., 2001, p.10). This is the most likely place for questioning and reflective listening to take place and although it has been suggested that a questionbased approach is a foundation for inquiry (Garrison, 2006), questioning is perhaps not as strongly emphasised in the community of inquiry model as in the action learning process.

\section{The ability to act on the problem}

This aspect of the action learning process has links to the stages of cognitive presence as in the integration phase actions are decided on, and in the resolution phase solutions are put in place and subsequently tested. Action learning provides a very practical way for developing critical thinking because real-life problems are addressed and worked through. Garrison et al. (2001) have suggested that the community of inquiry model has a pragmatic focus and "it considers education to be based on lived experiences, and learning in an educational context is to be applied to real-life situations" (p. 21). This view fits well with the action learning approach.

\section{A commitment to personal learning}

A commitment to personal learning can be related to both the cognitive presence and social presence elements of the community of inquiry model. A considerable personal commitment is required to engage in the cognitive presence process of sustained discourse and reflection leading to learning, and to engage with others and form relationships with others in the online community, an aspect of social presence.

\section{An action learning coach or facilitator}

The role of the action learning coach is considered in the community of inquiry framework through the element of teaching presence. Teaching presence specifically addresses the role of the facilitator in designing an online action learning environment and facilitating the action learning process. This is clearly a central element of this research.

This comparison between the community of inquiry model and the action learning process has shown that cognitive, social and teaching presence are all relevant to, and have links with, aspects of action learning. Cognitive presence is most strongly linked to the participants' problems, their ability to act on these problems, and the questioning and reflective learning process they engage in to resolve their problem through taking action. The social presence aspect is connected to the collaborative and social relationships within the action learning group and the teaching presence is most strongly linked to the role of the action learning coach or facilitator. 


\section{Using the community of inquiry framework for data analysis}

Preliminary data display and reduction included the transcription of interviews and the collation of various sources of data from the online site. This collation involved the compilations of forum discussions, reflective journal entries and responses, and chat sessions in order that the data was more clearly displayed. Data was reduced as material that was not relevant to the leadership learning process was omitted. NVIVO was used to store and analyse preliminary data from the reflective journals, forums, chats and emails from the first research group. Nodes were created using the existing categories of the community of inquiry model and the various data sources were entered into this framework. This process is similar to that of template analysis, a method of thematically analysing qualitative data that involves developing a coding template with predefined codes that may then be modified (King, 2007). Template analysis is recommended for use with large volumes of rich data such as interview transcripts (Waring \& Wainwright, 2008), and diary entries and electronic text (King). It was decided to be flexible with the unit of analysis because of the multiple sources of data. A chat comment was likely to be a single sentence and contain one idea, whereas a reflective journal entry may have been several pages long and relate to several stages or even several types of presence. Examples of the units of analysis will be presented in Chapter 8 in an explanation of the data analysis process.

\subsubsection{Analysis of leadership journeys}

The second distinct phase of data analysis involved the compilation and analysis of individual participants' chronological leadership journeys. This process involved taking all the interview material and postings, including reflective journals, forum entries and chat sessions, and arranging them in date and time order. Analysis of this material involved reading the leadership journeys and looking for commonly occurring themes. The processes of developing these themes and integrating them with the revised community of inquiry model will be explained in Chapter 8 .

\subsubsection{The role of the researcher}

The role of the researcher in a qualitative study has been discussed in general terms in section 3.2.5. It is usually characterised by close interactions with the research participants and active participation in the research process. I held dual roles in this study as I both facilitated and researched each of the action learning groups. This dual facilitator/researcher role does not seem to have been given much consideration in the literature although it does bear similarities to two other roles that have been identified, those of participant observer and action researcher. Participant observers are researchers who spend extended periods of time in a research site in order to gain an understanding of the thoughts, actions, attitudes and behaviours of the group members (Mumford, 2006). They do not tend to take a leading role in the research setting but take the part of an additional group member. Action researchers not only collect data but actively intervene in the research process in order to achieve a specified outcome 
(Nandhakumar \& Jones, 1997). My role differed from that of participant observer in that I had a different role from the action learning group members, and from that of an action researcher in that I did not attempt to intercede to achieve a particular outcome.

The holding of dual roles by engaged researchers is discussed by Nandhakumar and Jones (1997) who suggest that the roles are often not discrete and may involve "mental agility on behalf of the researcher in regularly flipping between the roles, and social dexterity in avoiding drawing the attention of the actors to the change" (p. 126). These authors also suggest that the contributions of engaged researchers should be given the same prominence as other actors and that researchers should be encouraged to critically reflect on how their assumptions influence the study findings. Yoong (1996) who took a similar dual role in his doctoral study as both a researcher and trainer for groups of facilitators learning about online facilitation reflected, "my role in the study and the resulting experiences are integral components of the research data and provide very important contextual information" (p. 250). I endeavoured to be aware of how my presence and actions influenced the research study and I reflected on and documented this understanding throughout the research process.

Two of Klein and Myers' (1999) principles, referred to in Section 3.2.2, have relevance to the researcher role in this study. The principle of interaction between the researcher and the subjects suggests that the data gathered are a result of the social interaction between the participants and researcher, rather than something independent of that relationship. My work as a facilitator did inevitably influence participants' perceptions on their leadership roles and this influence needs to be acknowledged in developing theory and drawing conclusions. The principle of multiple interpretations requires sensitivity on the part of the researcher to potential conflicts arising from differing perspectives. This principle is not as relevant to this study as the participants were all from different organisations; however, I was aware of their potentially differing interpretations of participants from the blended action learning process.

The facilitator role involved establishing each group, helping participants get to know each other, assisting in the process of building trust within the group, and providing information on and supporting the action learning process. This involved both face-toface and online facilitation. As expected, the online facilitation was more challenging as I have had much less experience in online facilitation compared with conventional facilitation. The roles taken by the facilitator of an online community of practice and an action learning facilitator or coach were explored in the previous chapter. Many of the skills needed, such as active listening, showing empathy, and dealing with conflict, apply to any facilitation situation; however, it is the online facilitation component that is most problematic.

The other important role I took in this research is that of data collection and analysis. As previously mentioned, this involved interviewing participants and accessing online 
reflective journals, forum entries, chat sessions and emails. There was overlap between my roles as facilitator and researcher and these different roles were discussed with the research participants and clarified at the beginning of the study. These different aspects of my role will be explored in more depth in Chapter 7.

\subsubsection{Review of research questions}

Three research sub-questions that arose from the literature review were signalled in the introductory chapter and confirmed in Section 3.3.1 of this chapter. Two additional research questions emerged during the course of the study. These were:

- What were the leadership journeys of the research participants?

- How can the elements of blended action learning be integrated into a model of leadership learning that describes the process experienced by the learners in this study?

The following chapters are focused on the five revised research sub-questions. Chapter 5 describes the leadership journeys of three more and three less active participants, the leadership journeys of the other six participants being included as Appendix C. Chapter 6, which is an analysis of the blended action learning process, addresses the first and third research sub-questions which ask how the process supports leadership learning and what the most appropriate tools are. The second sub-question on the role of the blended action learning facilitator is the focus of Chapter 7 and the model of leadership learning is then presented and discussed in Chapter 8.

\subsection{Chapter summary}

This chapter has outlined the research methodology used in this study. The choice of interpretive case research using blended action learning sets as the units of analysis has been justified through a discussion of possible research approaches including normative and interpretive, and qualitative and quantitative frameworks. The research design including the research questions, units of analysis, methods of data collection, the framework for data analysis and the role of the researcher have all been considered and explained. Klein and Myers' (1999) seven principles for conducting and evaluating interpretive field studies in information systems offer a useful framework for reflecting on the research methodology and will be referred to again in later chapters when aspects of the research, including the development of theory and the facilitator/researcher role, are evaluated. 


\section{The Research Groups}

"Alone we can do so little; together we can do so much." (Helen Keller)

\subsection{Chapter overview}

This chapter describes the formation and progression of the two leadership action learning groups formed as part of this study. As mentioned in Chapter 3, each action learning group is a unit of analysis within the embedded case of the use of ICT to support leadership development in the New Zealand ECE sector. The chapter begins with a description of each group; and this is followed by an account of the patterns of interaction and participation in online activities. Participants' comments and facilitator reflections on various aspects of the groups are also presented. The chapter concludes with an analysis of the similarities and differences between the two groups. In order to protect the anonymity of the participants featured in this and subsequent chapters, the terms 'centre' and 'head teacher' will be used to refer to all services and formal leadership positions, rather than the diverse range of terms such as kindergarten and supervisor actually used by participants. In this and subsequent chapters the source of the quotes will be given in the bracket following the participant's name where 'I' stands for interview, ' $R J$ ' for reflective journal, ' $\mathrm{F}$ ' for forum posting and ' $\mathrm{C}$ ' for chat posting.

\subsection{Leadership action learning group one}

This section will begin with a description of the participants of the first leadership action learning group and this will be followed by an account of the patterns of activity, including both face-to-face and online interactions. Participants' use of the online site and some of the difficulties they encountered will also be discussed.

\subsubsection{Group composition and preparation}

The first research group, named leadership action learning group one (LALG1), was made up of six early childhood teachers from the Wellington region. As previously mentioned, five of the teachers were in formal leadership positions, that is, they were head teachers or centre supervisors, and the sixth took on a relieving head teacher's position during the course of the research. In this and subsequent chapters these participants will be identified by the names Amy, Beth, Charlotte, Diana, Emma and Fiona (not their real names). I arranged to interview each participant prior to the first meeting of the group. The purpose of these preliminary interviews was for participants to meet me and to have the opportunity to ask questions about participation in the group, and for me to find out some background information. I asked each participant questions about their leadership roles and previous leadership development 
experiences, their current ways of engaging in reflective practice, and their experiences with ICT. This information is summarised in Table 4-1 below.

\begin{tabular}{|c|c|c|c|}
\hline Participant & $\begin{array}{c}\text { Leadership roles, previous } \\
\text { leadership and leadership } \\
\text { development experience }\end{array}$ & $\begin{array}{l}\text { Current ways of } \\
\text { engaging in } \\
\text { reflective practice }\end{array}$ & $\begin{array}{c}\text { Experience } \\
\text { with ICT }\end{array}$ \\
\hline Amy & $\begin{array}{l}\text { No formal ECE leadership } \\
\text { experience at start of research. } \\
\text { Had attended leadership } \\
\text { development courses in a } \\
\text { previous job. }\end{array}$ & $\begin{array}{l}\text { Reflects informally } \\
\text { but unused to } \\
\text { written reflection. }\end{array}$ & $\begin{array}{l}\text { Comfortable } \\
\text { with a range of } \\
\text { ICTs. }\end{array}$ \\
\hline Beth & $\begin{array}{l}\text { Has been in various leadership } \\
\text { roles for } 12 \text { years. Some } \\
\text { previous leadership professional } \\
\text { development. }\end{array}$ & $\begin{array}{l}\text { Reflects on practice } \\
\text { verbally but unused } \\
\text { to written reflection. }\end{array}$ & $\begin{array}{l}\text { Not very } \\
\text { familiar with } \\
\text { ICTs apart } \\
\text { from email. }\end{array}$ \\
\hline Charlotte & $\begin{array}{l}\text { In first formal leadership role } \\
\text { for } 3 \text { weeks at the start of the } \\
\text { research. No previous } \\
\text { leadership professional } \\
\text { development. }\end{array}$ & $\begin{array}{l}\text { Kept a reflective } \\
\text { journal throughout } \\
\text { teacher registration } \\
\text { process and has } \\
\text { continued this. }\end{array}$ & $\begin{array}{l}\text { Familiar and } \\
\text { comfortable } \\
\text { with a range of } \\
\text { ICTs. }\end{array}$ \\
\hline Diana & $\begin{array}{l}\text { In second formal leadership role } \\
\text { with six years of leadership } \\
\text { experience. Has participated in } \\
\text { some face-to-face leadership } \\
\text { development. }\end{array}$ & $\begin{array}{l}\text { Informally reflects } \\
\text { on practice } \\
\text { including some } \\
\text { written reflections. }\end{array}$ & $\begin{array}{l}\text { Comfortable } \\
\text { with various } \\
\text { ICTs including } \\
\text { web seminars } \\
\text { and chat. }\end{array}$ \\
\hline Emma & $\begin{array}{l}\text { In second formal leadership role } \\
\text { with five years experience. Has } \\
\text { participated in some face-to-face } \\
\text { leadership development. }\end{array}$ & $\begin{array}{l}\text { Reflects informally } \\
\text { but unused to } \\
\text { written reflection. }\end{array}$ & $\begin{array}{l}\text { Not very } \\
\text { familiar with } \\
\text { ICTs apart } \\
\text { from email. }\end{array}$ \\
\hline Fiona & $\begin{array}{l}\text { In first formal leadership role } \\
\text { with two years experience. } \\
\text { Extensive professional } \\
\text { development although not } \\
\text { specifically leadership focused. }\end{array}$ & $\begin{array}{l}\text { Reflects both } \\
\text { formally and } \\
\text { informally including } \\
\text { written reflections. }\end{array}$ & $\begin{array}{l}\text { Comfortable } \\
\text { and confident } \\
\text { with ICT. }\end{array}$ \\
\hline
\end{tabular}

Table 4-1 : Previous experience of LALG1 participants

\subsubsection{LALG1 first group meeting}

The group met for a full day in late June 2007. The aims of this day were for participants to: get to know other group members and thereby start to develop a sense of trust; become familiar with action learning; consider recent literature and thinking on leadership; reflect on their own leadership journey and aspirations; set goals for future 
learning; and become familiar with the ICT tools that would be used in the research study. Participants had been sent an article and a book chapter prior to the meeting as well as a leadership journey exercise to encourage them to start thinking about different aspects of leadership. Particularly important aspects of the day were discussions on expectations and confidentiality, building relationships, and developing familiarity with the reflection and questioning processes involved in action learning. The online site was introduced and demonstrated at the end of the day; however, a shortage of time, and problems with accessing a wireless network, meant that participants did not have an opportunity to use the site themselves.

Comments from participants' reflective journals showed that the aims of the day were well met. The small size of the group, which is standard for action learning groups, was commented on by one participant who suggested that it helped the group members begin to form strong relationships:

I really enjoyed the day on Saturday. I think that having a small group of 6 meant that we were all able to really get to know each other and feel comfortable with everyone in the group which probably led to more open discussion. (Amy, RJ)

Another participant commented on how other participants' willingness to share made her feel more comfortable and willing to contribute, and how this openness seemed to indicate that the group would work well together:

I felt more relaxed and less intimidated than I imagined I would. I was touched by the way everyone opened up with their leadership journey stories; it seemed to me a good sign of everyone's willingness to be there and intentions of becoming close as a group. (Charlotte, RJ)

The action learning process known as triads (McGill \& Brockbank, 2004) that was used in this meeting also received favourable comment. This process involved participants being split into two groups of three. One person from each group (the presenter) then discussed their task, problem or issue and was questioned by another group member (the enabler) in a process that allowed them to redefine their problem and decide on some action steps. A third person (the observer) listened to the interaction and then gave feedback on the process. Each participant had a turn in each of the three roles, some of which they found testing as the following comment shows:

The group activity was the highlight of the day for me as it was such a useful process. I found being the enabler first a challenge (but a good one) because I do like to know how to do something before I give it a go, but I'm glad I didn't have a choice to opt out and once I got started I got into the swing of things. (Fiona, RJ) 
Although some participants were discussing issues that they felt quite emotional about, the structured process worked well and encouraged them to identify strategies with which to move forward:

I found splitting into two groups and using the Observer, Enabler and Presenter roles very helpful. Although I was quite nervous presenting first as I still felt a bit upset about my situation it felt really good to talk about it and have my feelings acknowledged. It was also great to have a turn at each different role as I now feel more comfortable at using the Enabler role myself after practising. This scenario allowed me to come up with solutions that I can now put into place. (Amy, RJ)

The process of taking on specific roles and being restricted in what they could say did seem rather artificial at first but after some practice, participants began to see the benefits:

The exercise of discussing our goals was particularly meaningful for me. I must admit that at first I thought the task sounded gimmicky. I wondered at the value of assuming such unnatural-feeling roles, until we got underway. It really felt as though we were helping one another. We all had a goal which involved some kind of emotional investment, making a solution more complicated to come up with. It was empowering to be coached into coming up with one's own answer rather than to be offered suggestions and advice. (Charlotte, RJ)

\section{Facilitator reflection:}

Overall I was very pleased with how the first group meeting went; in particular, how participants were prepared to share their personal experiences and issues, and how trust seemed to develop within the group. Reasons for the success of the day and the closeness that developed included the small group size and the activities provided during the course of the day that allowed participants to get to know each other. The earlier individual meetings with me in which leadership experiences had been shared, and the readings provided prior to the meeting, had caused people to start reflecting on their leadership and meant that they were ready to identify aspects of their leadership practice that they wanted to work on.

Things I noted to change for the next research group related to the timing of the day. Participants spent a long time sharing their leadership journeys which, while interesting and conducive to trust building, meant that there was less time available for the triad exercise and in particular sharing the leadership goals they developed in the whole group. More time could have also been spent on becoming familiar with the online site, although wireless internet access issues meant that there was only one laptop through which the site could be viewed. 


\subsubsection{Using the online site}

The Moodle site was initially set up with four activities: online reflective journals; forums; chat sessions; and written resources. The reflective journal of each participant was able to be accessed only by the facilitator and could not be viewed by other participants. Participants were given written suggestions for how they could structure their journal entries but were encouraged to write in whatever way best suited them. Forums were set up for asynchronous discussions. There were two types of forums, the 'News forum' for general news and announcements, and learning forums for other discussions. Participants were asked to post their leadership goals in the forum section so that other group members could view and respond to these. They were also encouraged to begin forums on leadership related topics. Chat sessions were scheduled at agreed times and past chat sessions were able to be viewed, so that participants who had missed a session could read the conversations held. A small number of leadershiprelated articles and book chapters were posted initially and these were added to according to the interests of the group and the goals they were working on.

Participants were emailed a list of tasks with which to begin their online participation the day after the Saturday meeting. These included posting a personal profile, writing the leadership goal and actions that were decided upon in the triad exercise in a forum space, and starting their online reflective journal. Participants took varying times to begin using the site. The first person came online the day after our first meeting, two more the following day and the other three had logged on by the end of the week. Four group members posted their leadership goals and actions within the first week and the other two took one week and three weeks respectively. Goals chosen related to areas such as: gaining confidence in raising issues related to programme quality with staff; building collaborative relationships with team members; working towards sharing more responsibilities with team members; managing conflict between team members; gaining a better balance between the different requirements of the job; and time management. New forum discussions and resource sharing were begun within a fortnight of the group starting. Forum discussions that began within the first few weeks included discussions on lack of ICT skills, the power of the group exercise, and organisation and time management. With regard to the online reflective journals, the first entries were all posted within a week of the first meeting. Chats were begun the first week although not everyone participated in the first few weeks. Three chat times were originally agreed on as not all participants were available at the same time because some only accessed the site from home and others only from work. Use of these online technologies continued to develop during the four week period before the second face-to-face meeting. 


\section{Facilitator reflection:}

Participants seemed very keen to use the website after the full day meeting and although it took a few days for everyone to come online, participation over the first few weeks was quite active. I reflected on how much to encourage participants through emailing and posting online, and decided that it was important to be particularly active and encouraging initially, although this may not be necessary as people became more regular users of the site.

Participants' confusion over the purpose of the different online activities led to the revision of the instruction sheet for the second research group. Some guidelines outlining expectations of online participation were also developed as a result of the varying levels of participation of group members.

\subsubsection{Patterns of interaction}

The first follow-up meeting was held just under 4 weeks after the first face-to-face meeting. At this late-afternoon meeting, following a catch-up of personal highlights, participants were asked to report back on their leadership goals and the progress that they had made towards achieving these. Three participants presented their individual issue or problem using the following action learning questioning process to help them frame their thinking:

- What I did;

- What happened;

- What was different from what I expected;

- What I did not do - what I did instead;

- What I learnt from this;

- What is the issue now;

- What actions I can take now;

- What specific action I should take (McGill \& Brockbank, 2004, p. 79).

The facilitator and other group members asked questions of the presenter in order to assist them in identifying future actions. The participants who were not presenting in depth gave a brief update on their progress at this meeting, resources were then shared and expectations around weekly participation clarified. These expectations, which included suggestions on the frequency of journal entries and forum postings, were posted on the site.

A wiki tool was added to the site after the first follow-up meeting to summarise the discussion held as one participant missed this meeting because of a family commitment. Four of the participants contributed to this document. A wiki was also used to record the third follow-up meeting as that was when one of the participants was overseas. 
The pattern of online interactions interspersed with face-to-face meetings of the group held after work, continued over the next few months. In the second follow-up meeting, those participants who did not present at the first follow-up meeting had a turn. At the third face-to-face meeting participants chose to work on personality differences and leadership styles and only brief updates on progress were given. The action learning process of questioning and reflection was, however, continued online. This process began a couple of weeks after the second follow-up meeting and will be described in more detail in Chapter 6.

Further face-to-face interviews were held following the first and fourth follow-up meetings. The second interviews focused on participants' experiences of the online aspects of the professional development so far. They were asked: how they were finding the ICT aspect of the group and the combination of face-to-face and online learning; which of the online activities they were finding most supportive of the professional learning process; and what was helpful or unhelpful about the role of the facilitator. An extract from a sample second interview with a member of LALG1 is included as Appendix D. In the final interviews, participants were asked to reflect on their leadership journeys, their use of the online site, participation in the action learning group, and the role of the action learning facilitator. The various interactions of the group are summarised in the timeline in Figure 4-1 below.

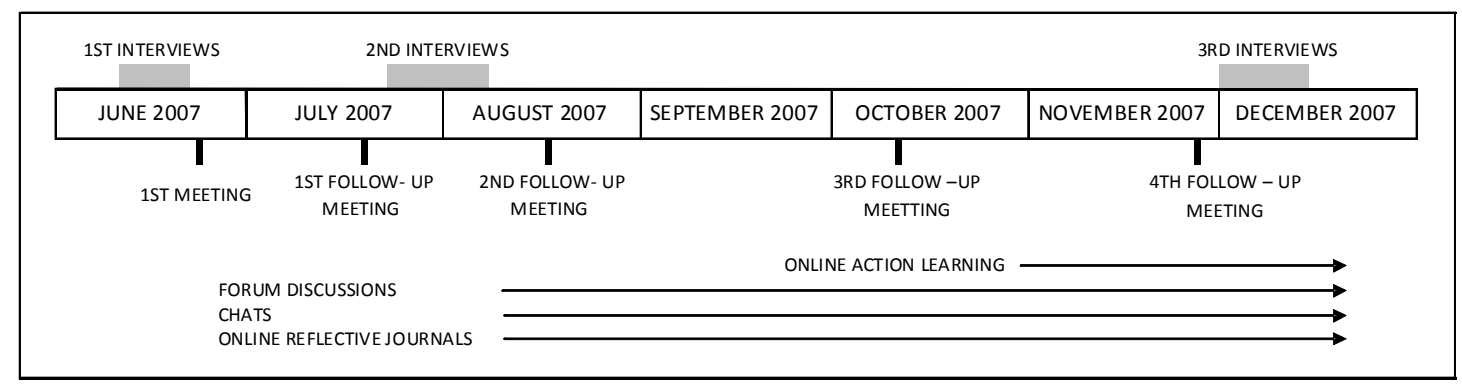

Figure 4-1: LALG1 timeline

At the fourth follow-up meeting held 5 months after the group began, I informed the group that I would stop collecting data from the site at the end of the year but was happy to continue to facilitate the group. All participants wished to continue meeting and interacting although it was agreed to reduce the frequency of the chats and to have a break over Christmas and January as centres would be closed and/or people would be away over that time. The group meetings continued throughout 2008 and the site continued to be used occasionally by LALG1 participants mainly for posting reflective journal entries or accessing resources. 


\subsubsection{Participation in online activities}

There were differing degrees of online participation by members of LALG1. The number of reflective journal entries posted by participants over the 5 months of data collection varied from 9 in one case, to 30 in another, and the total length of the journal entries varied from around 3,000 words to over 11,000 words. A total of 34 forum discussions and 36 chat sessions were held during the data collection period. There were a number of different types of forums, the vast majority of which were started by the participants. These included:

- $\quad$ forums in which participants' learning goals were shared and discussed;

- forums in which discussions were held on resources participants had come across or on leadership related articles I had posted on the website;

- forums that allowed for the sharing of ideas on leadership practices including interviewing, mentoring and coaching, conflict resolution, organisation and time management; and

- $\quad$ online action learning forums.

Participation in chat sessions also varied and tended to depend on when the participants had access to a computer and on when they had office time at work. The participation of different members of LALG1 is shown in Table 4-2 below.

\begin{tabular}{|l|c|c|c|c|c|c|}
\hline & Amy & Beth & Charlotte & Diana & Emma & Fiona \\
\hline $\begin{array}{l}\text { Reflective } \\
\text { journal } \\
\text { entries }\end{array}$ & 16 & 28 & 9 & 30 & 18 & 24 \\
\hline $\begin{array}{l}\text { Forum } \\
\text { postings }\end{array}$ & 33 & 48 & 46 & 36 & 11 & 24 \\
\hline $\begin{array}{l}\text { Chat } \\
\text { sessions }\end{array}$ & 12 & 19 & 5 & 8 & 8 & 6 \\
\hline $\begin{array}{l}\text { Emails } \\
\text { sent }\end{array}$ & 23 & 15 & 18 & 32 & 29 & 26 \\
\hline
\end{tabular}

Table 4-2: LALG1 participation

\section{Barriers and enablers to participation}

Reasons for lack of participation from group members at different times included lack of internet accessibility, health issues, and travel. One participant had difficulties in accessing the site at all for the first few months and this situation is discussed in more detail below. Another group member had no internet connection at work for nearly a month and as she only had dial-up internet at home, she 
participated very little over this time. Sickness and other health issues also affected participation at different times for several people. One group member went overseas for 6 weeks a month after the group began. Although she was able to access the site at times during her holiday and wrote a journal entry and several forum posts, she was unable to use chat and participated considerably less often than she normally would have. Another group member travelled extensively during the term breaks and was sometimes not accessible because of lack of internet access but still managed to have input at times.

Ease of access and confidence in the use of ICT varied between participants. At the start of the action learning group, two participants indicated that they would only be able to access the site at work; one only at home; two others mainly from work although they did have dial-up internet at home; and one could access the site equally well from work or home. This variation impacted on chat times and also the time that could be dedicated to the site as generally there was not a lot of free time in the work day to dedicate to going online.

At the time of the second interviews, four of the six participants were really enjoying the ICT aspect of the leadership action learning group. The fact that it was accessible at any time was particularly valued:

I've found the ICT part of it really fantastic because it's always there. (Charlotte, I)

Another appreciated aspect of the site was the fact that apart from the chat sessions, the asynchronous nature of the other activities meant that there was flexibility as to when people could participate. The following comments illustrated that this flexibility was valued:

When you have say a phone conversation you have to actually make sure everyone's there at that time which you do a little bit with the chats but the online diary I can do anytime of the day and I can do anytime that it suits and I can do 5 minutes and then go back in and finish off. (Diana, I)

Two other participants were struggling with their use of the site, one because of her inability to access it due to a very slow computer link and the other because of her lack of experience and confidence in using ICT. Emma who had the access problems commented:

The website is good but my computer is taking a long time to do anything so I've been giving up. I've been in heaps of times and just gone uh, gone away to do something that's pressing. (Emma, I) 
Beth who was struggling with using the technology found that it was restricting her input as when she did go online it would take her a while to work out how to access a particular activity so she tended to wait until she had a substantial amount of time. She also admitted in the second interview that if she had known how much ICT was involved, she may not have agreed to participate. The other group members were very supportive of her efforts and gave her positive feedback on how she was progressing:

Hi Beth, You are doing incredibly well at this computer stuff considering the hard time you give yourself about it!! (Charlotte, F)

They also turned the lack of skills into a positive affirmation of her leadership skills as she was willing to take on something she found challenging:

Hi Beth, I think you shouldn't look on it as a lack of skills, but look on it as developing new skills! It's great that you have decided to do something that involves ICT when maybe you haven't had so much experience - what a great message about leadership and learning that shows to people. (Fiona, F)

She did eventually make good progress after spending more time on the site and in the first follow-up interview she talked about how she was becoming more comfortable and confident in the use of ICT. Beth and Emma, both of whom could initially only access the internet from work, chose to get broadband access at home during the course of the research. For Emma, this involved buying a new computer and for Beth connecting up a work laptop. Emma, who struggled with a very slow internet connection at work, increased her participation once she was able to access the internet from home. By the time of the final interview Beth was quite confident in all aspects of the online site and this confidence had transferred to wider ICT use.

I look on sites on the internet now, we've got broadband at home, I sit and look on the laptop. I go in and out of the chat room, I can find my way around the site and I just can do so much more than I would probably ever have been able to do. (Beth, I)

Further comments on the value of the action learning process and the use of different technologies will be provided in Chapter 6. The leadership journeys of three of the six LALG1 participants are discussed fully in Chapter 5 which also focuses on the different levels of activity of research participants. Appendix C contains the leadership journeys of the other three LALG1 participants.

\subsection{Leadership action learning group two}

This section will begin with a description of the participants of the second leadership action learning group and this will be followed by an account of the patterns of activity, 
including both face-to-face and online interactions. Their use of the online site and any difficulties they encountered will also be discussed.

\subsubsection{Group composition and preparation}

The second research group, LALG2, was made up of six head teachers from the ECE sector who were based in the Wellington region. These participants will be identified by the names Grace, Heather, Isabel, Jane, Karen and Lisa (not their real names). I repeated the preliminary interviews conducted with LALG1, with participants of the second group and this information is summarised in Table 4-3 below.

\begin{tabular}{|c|c|c|c|}
\hline Participant & $\begin{array}{c}\text { Leadership roles and } \\
\text { previous leadership } \\
\text { development experience }\end{array}$ & $\begin{array}{l}\text { Current ways of } \\
\text { engaging in } \\
\text { reflective practice }\end{array}$ & $\begin{array}{c}\text { Experience with } \\
\text { ICT }\end{array}$ \\
\hline Grace & $\begin{array}{l}\text { In first leadership position } \\
\text { for less than a year at start of } \\
\text { research. No previous } \\
\text { professional development } \\
\text { specifically related to } \\
\text { leadership. }\end{array}$ & $\begin{array}{l}\text { Reflects formally } \\
\text { and informally but } \\
\text { unused to written } \\
\text { reflection. }\end{array}$ & $\begin{array}{l}\text { Reasonably } \\
\text { confident with ICT, } \\
\text { self-taught. }\end{array}$ \\
\hline Heather & $\begin{array}{l}\text { Two years of formal } \\
\text { leadership experience. Some } \\
\text { non-ECE leadership } \\
\text { development experiences. }\end{array}$ & $\begin{array}{l}\text { Reflects both in } \\
\text { writing and } \\
\text { verbally. }\end{array}$ & $\begin{array}{l}\text { Confident and } \\
\text { comfortable with } \\
\text { ICT. }\end{array}$ \\
\hline Isabel & $\begin{array}{l}\text { Has been in formal } \\
\text { leadership positions for over } \\
20 \text { years and attended face- } \\
\text { to-face leadership courses. }\end{array}$ & $\begin{array}{l}\text { Reflects informally } \\
\text { but unused to } \\
\text { written reflection. }\end{array}$ & $\begin{array}{l}\text { Reasonably } \\
\text { confident with ICT, } \\
\text { self-taught. }\end{array}$ \\
\hline Jane & $\begin{array}{l}\text { Has been in leadership role } \\
\text { for less than a year. No } \\
\text { previous leadership } \\
\text { professional development. }\end{array}$ & $\begin{array}{l}\text { Engages in } \\
\text { informal reflections } \\
\text { both privately and } \\
\text { publicly. }\end{array}$ & $\begin{array}{l}\text { Confident with } \\
\text { ICT. Previous } \\
\text { study had an } \\
\text { online component. }\end{array}$ \\
\hline Karen & $\begin{array}{l}\text { Has been in formal } \\
\text { leadership positions for over } \\
20 \text { years and attended } \\
\text { numerous face-to-face } \\
\text { leadership courses. }\end{array}$ & $\begin{array}{l}\text { Reflects informally } \\
\text { rather than } \\
\text { formally. Has } \\
\text { previously kept a } \\
\text { reflective journal. }\end{array}$ & $\begin{array}{l}\text { Reasonably } \\
\text { confident with ICT. }\end{array}$ \\
\hline Lisa & $\begin{array}{l}\text { Has been in formal } \\
\text { leadership positions for over } \\
10 \text { years. Some previous } \\
\text { leadership development. }\end{array}$ & $\begin{array}{l}\text { Reflects informally } \\
\text { but unused to } \\
\text { written reflection. }\end{array}$ & $\begin{array}{l}\text { Reasonably } \\
\text { confident with ICT } \\
\text { and self-taught. }\end{array}$ \\
\hline
\end{tabular}

Table 4-3: Previous experience of LALG2 participants 


\subsubsection{LALG2 first group meeting}

The second group met for a whole day on a Saturday in early November 2007. The programme for the day was very similar to that for LALG1 as there had been very positive feedback from that group about the format and content of the day. Although I did not specifically ask the participants to reflect on the day, comments were made about how helpful it was. The diversity of the group was mentioned as was the value of the triad task. The first meeting was described by one participant as the catalyst for her leadership journey:

I think probably what was the most useful was actually the face-to-face meeting on that first day. I developed that plan that helped me go forward. (Jane, I)

One difference between the ways in which the two groups were introduced to the site was that the second group was given the participation guidelines at the full day meeting. However, these guidelines were not discussed verbally which in hindsight would have been helpful. The instruction sheet was also slightly modified to clarify different aspects of the online tools as a result of feedback from the first group. These modifications included clearer instructions about the different sorts of forums and on ordering and dating online journal entries.

\subsubsection{Using the online site}

Participants were emailed the Monday after the whole day meeting, thanking them for their participation and encouraging them to add their personal profiles, learning forums and online reflection journals. Participants were prompt in accessing the site. Two participants logged on the day after the meeting and the other four over the following two days. Five of the group had posted their leadership goals within three days of the meeting although the sixth took nearly a month. Goals chosen by group members included: developing induction processes that would help build an effective team; encouraging initiative and independence within the teaching team; developing a shared team vision; and time management. Forum discussions did not really develop with this group. One participant began a forum discussion early on related to her leadership goals and had a number of responses; however, this was the only discussion begun by a participant prior to the Christmas break. Organising a common chat time was more successful with this group as everyone was free on Wednesday evenings. On the first evening all but one participant was able to join the chat session and although not everyone managed to ever get on at the same time, most sessions had four or five participants.

\subsubsection{Patterns of interaction}

The first follow-up meeting, held in the early evening, took place in early December, just over 4 weeks after the first group meeting. Three participants were asked to share 
their progress on the issue they were working on in depth, and the other three group members gave brief updates on their progress. The same questioning process outlined in Section 4.2.4 was used. Patterns of interaction in this group were influenced by the fact that the group started relatively late in the year. By the time of the first follow-up meeting, all participants were really busy with end-of-year functions and activities. Although dates for the second interviews were set at this meeting and participants were reminded through individual email messages, three of the six actually forgot I was coming to talk to them, although all managed to make time to meet with me. This end-of-year rush also meant that participants rarely used the site between the final chat session for the year in the middle of December and the Christmas holiday break. It was agreed to have a formal break from the site over January as most people were on holiday for several weeks. I also travelled overseas in the last two weeks of January and while I was able to access the site periodically, there was little activity. Online interactions began again in early February although only three of the group members came online before the second follow-up meeting held in the second half of February.

The pre-Christmas rush and the long gap over the holiday period appeared to impact on the group's use of the online site. One participant mentioned the long break when asked what could have been improved about the process commenting:

$$
\text { Having it over Christmas - I lost my flow. (Jane, I) }
$$

Although reflective journal entries and chat sessions resumed, LALG2 participants never really got into the habit of using the forums to discuss issues. Only five forums, apart from those in which leadership goals were shared, were started by participants as compared with 19 started by LALG1 members.

\section{Facilitator reflection}

The lack of engagement with some online activities by LALG2 members caused me some frustration. I reflected on why this group was less active than LALG1 and how, if at all, my facilitation had contributed to this. On reflection I decided that there were a number of factors that contributed to the differences between the two groups (these will be discussed in a later section of this chapter) and I had been particularly fortunate in how active the first group had been. I learnt that it was important to be flexible and responsive to each group and not to expect them to participate in the same way.

The pattern of online interactions interspersed with face-to-face meetings of the group outside work hours continued over the first half of 2008. In the second follow-up meeting, those participants who did not present at the first follow-up meeting had a turn. At the third follow-up meeting, all participants gave updates on their progress and in the fourth, a session on personality differences and leadership styles was held. 
One group member began an online action learning forum after this meeting; however, only one other group member contributed to this. Interviews were held at similar time intervals as with LALG1 as shown in the timeline in Figure 4-1 below. An extract from a sample final interview with a member of LALG2 is included as Appendix E.

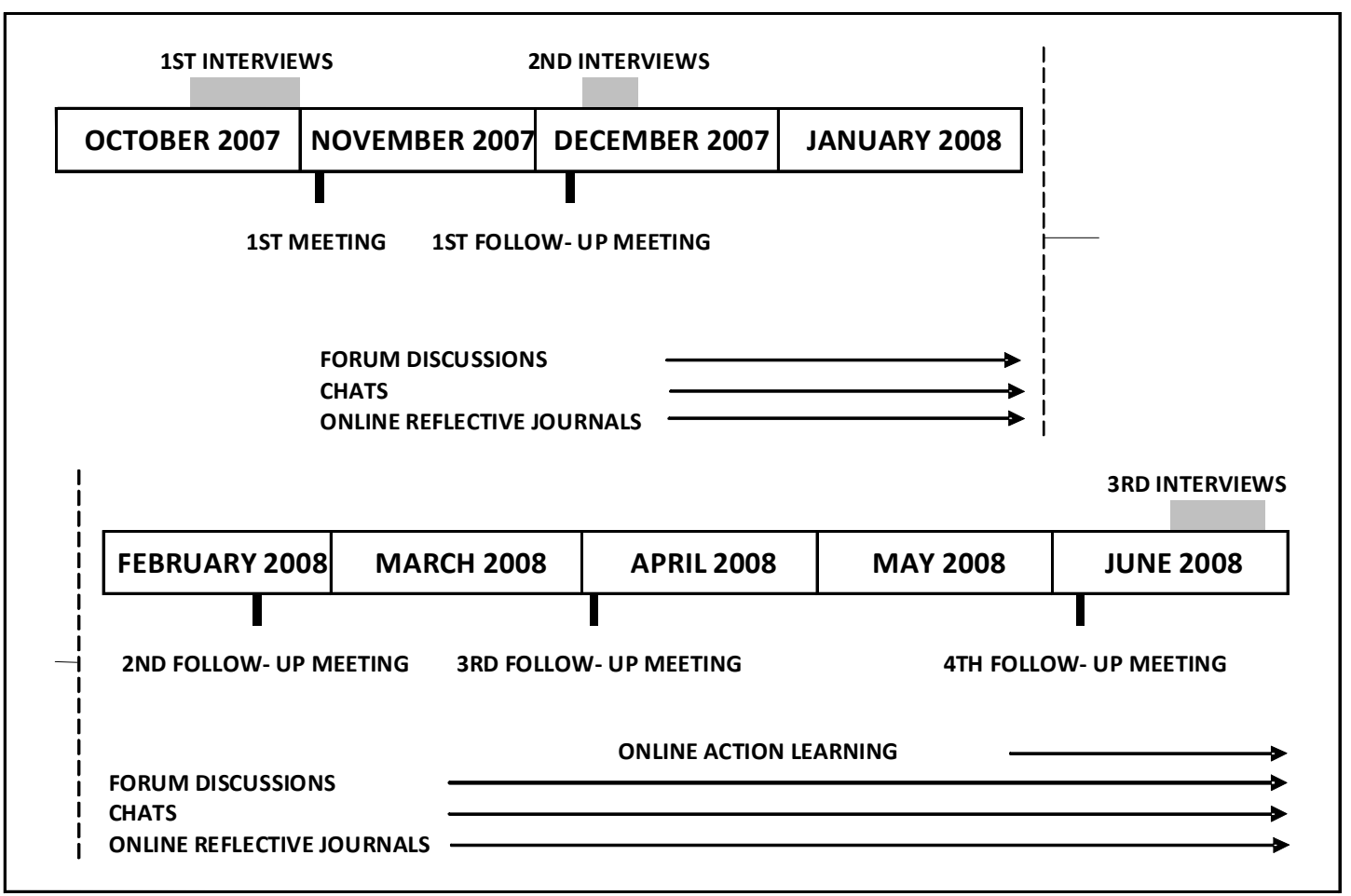

Figure 4-2: LALG2 timeline

At the fourth follow-up meeting held 7 months after the group began, I informed the group that I would stop collecting data from the site at the end of the month but was happy to continue to facilitate the group. All participants wished to continue meeting and interacting, although it was agreed to stop the chat sessions as there had not been a high level of participation recently. The group meetings continued throughout 2008 and as with LALG1, several group members continued to contribute reflective journal entries and access articles.

\subsubsection{Participation in online activities}

As with the first group, the amount of online participation varied between group members. The number of reflective journal entries varied between 8 and 23, and the total length of journal entries varied from less than 1400 words to over 12,500 words. The person with the lowest number of journal entries and least number of words did start keeping a paper reflective journal which she used frequently. Fewer chat sessions were held overall than with the first group as all group members could potentially participate in the same session. As mentioned above, the forum discussions never really developed, perhaps because the use of these was not established early in the life of the group. 


\section{Barriers and enablers to participation}

Access issues were a problem for some participants in this group. Although no-one had a problem using the site once they were connected, Lisa had ongoing problems with internet access both at home and at her ECE service. This prevented her participating in chat sessions until the New Year, a situation she found very frustrating. Other people had intermittent problems with internet access and commented on this in the interviews when asked about the ICT aspect of the group:

Nothing to do with the site, the only problems have been the major internet ones which are absolutely nothing to do with you but obviously Wellington-wide. (Karen, I)

Most participants were able to access the site from both home and work. One participant chose not to have a computer at home but was happy to go back into work to participate in chat sessions and often wrote her journal entries at work in the weekends. When asked about barriers to participation she mentioned how she was careful about when she accessed the site in a shared office because of confidentiality issues:

The barriers of course are time, and I suppose that sometimes I'm careful when I flick on at work because people can go past and see, and that's likewise for other people's goals too, because I don't flick other people's goals and information up either and I suppose for me just not having a computer at home that's a barrier but I've worked around that so that's OK. (Grace, I)

Other participants were happy with the site and commented that they found it easy to access and use. One participant who had initially expressed some reservations about the ICT aspect of the leadership groups had been pleasantly surprised by how userfriendly it was:

It's one of the simplest, easiest sites I've ever been on. (Karen, I)

Having people's photos on the site and the fact that these appeared next to every forum entry and chat comment was appreciated by participants in this group as it seemed to add a human touch.

The other thing I like is having people's photos up there because it just reminds you and you feel like you're actually communicating with a person not with a computer. (Karen, I)

Health issues impacted on the participation of two of the participants at different times as did overseas holidays and work commitments such as Education Review Office visits which required a lot of preparation and paper work. 
Table 4-4 below summarises the participation of LALG2 group members.

\begin{tabular}{|l|c|c|c|c|c|c|}
\hline & Grace & Heather & Isabel & Jane & Karen & Lisa \\
\hline $\begin{array}{l}\text { Reflective } \\
\text { journal } \\
\text { entries }\end{array}$ & 15 & 9 & 7 & 8 & 23 & 8 \\
\hline $\begin{array}{l}\text { Forum } \\
\text { postings }\end{array}$ & 12 & 2 & 4 & 5 & 19 & 3 \\
\hline $\begin{array}{l}\text { Chat } \\
\text { sessions }\end{array}$ & 8 & 5 & 9 & 7 & 14 & 4 \\
\hline $\begin{array}{l}\text { Emails } \\
\text { sent }\end{array}$ & 21 & 20 & 13 & 17 & 56 & 11 \\
\hline
\end{tabular}

Table 4-4: LALG2 participation

The leadership journeys of the three of the LALG2 participants are presented in Chapter 5 which as previously mentioned also focuses on the different levels of activity of research participants. Appendix C contains the leadership journeys of the other three LALG2 participants.

\subsection{Comparison between the two research groups}

There were both similarities and differences between the ways the two groups participated in the blended action learning process. All participants in both groups were committed to the leadership learning process and made an effort to both attend face-to-face meetings and to participate in online activities. Both groups had similar barriers to participation which included time and various access problems. Time was viewed as more of a barrier by LALG2 participants with five of the six group members mentioning this in their second interview compared to only two LALG1 members. The groups also differed to some degree in how they engaged with the online activities. Although both actively participated in chat sessions and used the reflective journals, the first research group was more active on the site as shown by their initiation of discussions, reflections on articles and willingness to participate in online action learning forums. There was less online interaction between members of the second group and although some early forum discussions involving participants' goals received responses from most group members, other forum discussions received little response. This lack of involvement was noted by one LALG2 group member: 
We didn't really get involved in very much, they [the forums] didn't really sort of go anywhere and I can take some responsibility. I started a couple of things but nothing really happened from them so I just left them. (Karen, I)

The heavy workload involved in formal leadership positions certainly impacted on people's participation. Several LALG2 group members commented in the final interviews that they would have liked to be more active on the site. These admissions reflect the findings from a study of e-learning groups in which two thirds of respondents said they would like to have contributed more than they did (McConnell, 2006). Heather admitted that her lack of activity was partly due to a lack of confidence in responding to other participants' postings. When asked if I could have done anything to help her feel more confident, she replied:

I knew you were available; I just didn't take full advantage of that availability so no you were fine. It was just me not getting on with it basically. Which is a shame because I think it's a very good tool because you can do it whenever you've got time, you don't have to meet, you don't have to go anywhere, you can do it right there and then. (Heather, I)

The stress levels faced by some people in the second group over the time of the research may have been one of the possible reasons for their lower level of activity and engagement. These pressures were noted by group members:

Everybody seemed so busy and so stressed. It worried me a little bit and some people seemed more busy and more stressed than others. (Karen, I)

Heather thought participation in the group would have been helpful to the people who were finding their work situations difficult:

A lot of people I felt were at a point where they were feeling like walking away from the position they were in but they didn't and I'm sure that being able to sit in the group and share it all and say how they are feeling is what meant they didn't. They didn't feel isolated or unsupported being part of the leadership group. (Heather, I)

Other possible factors influencing the participation of members included the timing of the research groups and career stages and personality of group members. Beginning the second research group in November was, in hindsight, not conducive to the success of the online interactions. Not only were people very busy at the end of the year, they also did not develop the habits of going online regularly and starting and participating in online forums. The importance of regular participation early in the life of an online community to its later success has been emphasised by Tarmazi et al. (2007). 
The members of the second research group were on the whole considerably older than the members of the first group, and in several cases were more advanced in their careers having been in formal leadership positions for much longer. They were therefore more advanced in their leadership journeys and their learning curve was not as steep as many of the LALG1 members. This effect of experience on leadership learning was one of the factors considered by Hirst et al. (2004) in their study of Australian research and development teams. These authors predicted that newer leaders would learn significantly more from participation in leadership development programmes than would more experienced leaders. This hypothesis was based on the idea that learning in areas such as encouraging teamwork, managing people, understanding the organisation and technical knowledge is already established to some degree in experienced leaders, and therefore new knowledge will be used to refine existing schemas rather than form them. Hirst et al.'s study confirmed that while new leaders did learn significantly more than experienced leaders, the experienced leaders in their study also reported enhanced learning.

One group member who was fairly new to the Wellington region commented in her final interview that one of her main motivations for joining the group was to build relationships with other ECE teachers.

I'm aware that I need to meet other people of like so that by having those relationships you can actually have conversations that actually influence some of the things that you do and for me, that's been made available through this process. (Isabel, I)

Both groups chose to look at their personality type and leadership style and as a trained Myers Briggs Type Indicator facilitator, I was able to offer a session at one of the faceto-face meetings of each group on personality type and leadership style. This process revealed that the make-up of the two groups was very different with all but one LALG1 member expressing a preference for extraversion and all members of LALG2, except one person who was absent at the meeting expressing a preference for introversion. This difference may also partially explain the enthusiasm of LALG1 members for interacting on the online site as while extroverts are more energised by people contact and learn well through interactions with others, introverts prefer quiet reflection and may prefer to learn through individual activities such as reading and reflecting (Lawrence, 1993). Although use of the Myers Briggs type indicator was not an important factor in the context of this study, the sessions held were valued by participants as they contributed to their understanding of themselves and others, and also contributed to my understanding of some of the differences between the two groups. 


\subsection{Chapter summary}

There were more similarities than differences between the two leadership action groups. Both groups participated actively in the blended action learning process and were very positive about the value of this approach to their leadership development. Specific comments from participants of both groups on various aspects of this process will be presented and discussed in Chapter 6. The consideration and comparison of these two units of analysis has identified a number of implications for future leadership development using blended action learning. These include: the timing of the start of leadership action learning groups; the make-up of the groups; and the need for a flexible approach to be taken by the facilitator when working with different groups. The beginning stages of any group using online activities are crucial to its success. Future blended action learning groups should be started earlier in the year to allow the groups to develop regular patterns of use of the different online activities. The most effective group composition seems to be a group of people at different stages of their careers, and if group membership was able to be selected, then a mixture of experience and service type would be preferable. The value of mixed groups will be discussed further in Chapter 6. Facilitators working with blended action learning groups need to be flexible and not expect all groups to interact and learn in the same ways. The role of the facilitator is the focus of Chapter 7. 


\section{Individual Leadership Journeys}

"We don't receive wisdom, we must discover it for ourselves after a journey that no one can take for us or spare us." (Marcel Proust)

\subsection{Chapter overview}

This chapter presents the in-depth learning journeys of six participants. The purpose of presenting the individual leadership journeys in this way is to illustrate the different learning paths of participants and the issues they faced as a result of participation in the blended action learning process. The learning journeys of the other six participants have been included as Appendix C. The six leadership journeys included in this chapter were chosen to illustrate differing levels of participation and different experiences. The journeys of three of the more active and three of the less active participants from across the two groups will be described. The more active participants were chosen because of their sustained use of the online site, in particular their reflective journal postings. The less active members were chosen as their participation was restricted or interrupted for various reasons. All the participants' comments, whether they were from interviews, journals, chats or forum entries, are presented in chronological order so that progression can be shown.

\section{$5.2 \quad$ Key words}

In line with the principle of abstraction and generalisation (Klein \& Myers, 1999), the participants' own words will be used extensively in this chapter in order that connections to later theory are clear to the reader. For this reason key words used by participants that illustrate the leadership learning process and that are significant in terms of the model of leadership learning that will be presented later in the penultimate chapter are highlighted (in bold) in this chapter. These words in different forms are:

- $\quad$ realising - also awareness, identifying

- $\quad$ reflecting - also examining

- $\quad$ acting - also deciding, changing

- $\quad$ empowerment

- confidence.

These terms illustrate aspects of the process that all the participants went through to a greater or lesser extent as a result of their participation in the blended action learning groups. A visual representation of this leadership learning process, which includes the development of awareness leading to increased confidence, will be presented in Chapter 8 . 


\subsection{Active participation}

The leadership journeys of three participants, two from LALG1 and one from LALG2, who were particularly active on the online site, will be presented in this section. The leadership goals that participants chose to work on, the progress they made towards meeting these goals, and the shifts in practice they made, will all be discussed as will how ICT supported their leadership learning.

\subsubsection{Diana's leadership journey - ‘Peace at all costs'}

Diana was in her second formal leadership position when she joined the first research group. She was confident in her use of ICT and had participated in some online training and in chat sessions. Most of Diana's online interactions occurred while she was at her workplace, although she did have access to a dial-up connection at home. Although she had not regularly kept a reflective journal prior to participation in the research, Diana was in the habit of writing reflections at different times. She had been in her current centre for 3 years and worked with a relatively large team of staff. At the first whole day meeting of the group Diana identified that she was very much an affiliative leader who valued a harmonious work environment and endeavoured to build strong relationships within her teaching team. However, this leadership style did not fit all situations. Diana reflected in her first journal entry that the group process had been useful in helping her with this recognition:

The others helped me realise that a crucial element of this whole debate within myself was that I value very much what my staff think of me, and sometimes that hinders me being their leader. (RJ)

Her reflections on this situation led her to the decision to try some different leadership approaches in situations she was coping with at work. In the leadership goal that she posted a few days after the first meeting she identified two staff situations in which she needed to use a different leadership style from the affiliative and supportive styles that she mainly used. These situations were both described in detail and then action steps that Diana intended to take were identified. The changes in leadership style had mixed success as the following excerpt from a chat session shows:

I have made my expectations quite clear regarding what I want done this week, and have been very much a pace-setting leader. Unfortunately the reaction was a rather impressive 'tantrum' yesterday. (C)

The particular situation referred to in the quote above came to a head and the staff member resigned. This led Diana to reflect in her journal that she needed to overcome her tendency for "peace at all costs". Changing the way she worked with her team also involved strategies such as coaching and sharing responsibilities 
aimed at empowering staff. The success of this approach with one teacher was commented on in the following journal entry:

The next day, [a teacher] told me how empowering she found this discussion - and I thought back to the observer/presenter/enabler exercise, and also to Fiona's reflection about this, and reflected on the success of this way of empowering my team members to be leaders. (RJ)

Diana reflected in subsequent forum discussions on this idea of giving staff more responsibility and decided that distributing leadership would allow them to make real decisions. In the second interview, she reflected on benefits of this new approach with the teaching team:

What I've really noted is the synergy between the group has just been growing and growing because I've been empowering them and giving them real things to make some real decisions about. (I)

A specific example of how this new approach was making a difference to how she worked with team members was her use of different strategies in staff meetings in order to encourage the contribution of less vocal team members. This change was very successful and led to the following reflection:

I have realised as I wrote the above, that there are many strategies to empower my team. Giving them 'real decisions' is definitely one of them, and my recent goal shows I have realised this. However, this was another strategy to empower my team ensuring that they all have a voice during staff meetings. (RJ)

This comment also shows the value of the writing process in aiding reflection. Diana chose to continue working on empowering her team and also identified a new goal which was becoming more confident at managing conflict. She wrote that she wanted to learn more about conflict resolution techniques through reading, investigating courses, and revising conflict resolution policies. The specific issue of conflict arising in the staff team while Diana was absent was the focus of the first online action learning forum entitled 'Why can't I go away'. The action learning forum discussion led Diana to reflect on her personal conflict resolution skills as her reply to another participant's questions showed:

I don't actually think that I do have very good conflict resolution skills - I would much rather avoid conflict (as would the majority of my team members) - and that is what my current goal is about. I am learning some things - but what I find hardest is the courage to confront it. $(\mathrm{F})$ 
The online action learning forum process helped Diana realise that in order to feel more comfortable in dealing with conflict, she needed to change the way she reacted to conflict situations. In response to a question posed in the forum she admitted:

I would very much like to be more courageous. I avoid conflict like the plague, and I wish this weren't the case. Something I have realised lately, is that I can read about and go to courses about conflict, but nothing helps if I don't have the courage to actually stand up to it! (F)

She continued to work on addressing conflict situations that arose within her teaching team in various ways including making conflict resolution the focus of a teacher only day, asking for help from management and insisting that teachers sorted out their own conflicts rather than always bringing them to her. By the time of the final interview she felt she had made considerable progress towards meeting her goal:

We've certainly taken some steps and I guess the most profound of those steps is that I've stopped running from conflict and I've started to stand albeit shakily and look at it in the face and say to myself and to the people involved "we need to sort this out and we need to give it the time and energy it deserves." So that's been a real struggle, a real challenge and a real growth. (I)

\section{Use of ICT to support Diana's learning journey}

Diana highly valued the ICT aspects of the leadership learning process. In particular she appreciated the immediacy of the online interactions and the strong relationships built as a result of the frequent interactions between group members. Diana also valued the written aspect of the reflective journalling process. She appreciated having time to think about her writing and began to use this form of interaction with a team member she was supervising as part of a teacher registration process. Although she valued the questioning process, Diana also liked to be offered suggestions to evaluate in her own context and she found the forum discussions useful for getting different perspectives on issues.

\section{Summary of Diana's leadership journey}

Diana was a very active member of LALG1. She used her reflective journal extensively, and contributed to forum discussions and chat sessions. Throughout her leadership journey, Diana became more aware of her own preferred leadership style and her natural inclination to avoid conflict at all costs. Although by the time of the final interview she admitted she still found dealing with conflict challenging, she was facing up to it and supporting her team to do the same. This confidence continued to grow and nearly a year after the final interviews, Diana told me how she was dealing with conflict situations more rapidly and confidently (Personal communication, 30/10/08). 
The leadership action learning group process encouraged her to explore new ways of demonstrating leadership, and through this process she identified that she had become more confident in her leadership and more empowering of her teaching team.

\subsubsection{Fiona's leadership journey - 'I used to do it all'}

Fiona had worked in the same centre for 6 years and had been in a formal leadership role for the last 2 years at the time the first leadership action learning group began. She was also very confident in her use of ICT and enjoyed reflective writing although had not previously kept a reflective journal. Fiona's online participation was solely at work. While she did have a computer at home with a dial-up connection, she tended not to use it to access the online site. The goal she identified at the first whole day face-to-face meeting and reflected on in the triad action learning process that was detailed in Chapter 4, was that she wished to change the fact that she was solely responsible for the leadership and management of her service. Her first journal entry made two days after the meeting explained what she wanted to happen:

I used to do it all and just use my own time but that's not what I want anymore. I'm so proud of our centre and our reputation and I want to continue to do the best job I can but I want this to be manageable for me and a reasonable amount for my employers to expect of me. (RJ)

In her first leadership goal posted in the leadership goals and actions forum, she expressed her intention of asking for help and taking it when offered. She also reflected that her previous way of operating may have been partly due to her need to be seen to be coping as the following comment illustrated:

I think if I really examine myself I could say that I feel like if I ask for help I am not doing my job well enough. (F)

Fiona also identified action steps that would help her reach her goal including looking at her workload, sharing more responsibilities with other teachers and asking for administrative support. It did not take long for Fiona to take action and start making changes in the way she worked. In a journal entry written a week after the first meeting she reflected on the fact that once she made up her mind that changes had to be made, implementing the changes was not that difficult. An example was devising a system whereby other teachers could deal with enrolment enquiries rather than passing them on to her, a change that had benefits for both Fiona and her teachers. She was pleased with the fact that she had engaged in this problem solving process:

I also felt good that I had identified a problem and then made an action step to solve it and I do think it will make a real difference in my work, and in the confidence of the other teachers. (RJ) 
Fiona shared her reflections on the progress she had made with other group members in a forum entry in which she reflected on how the decision to make changes in one area had resulted in her noticing other areas in which changes could also be made. This conclusion led to the following realisation:

It shows me that change and improvements are mindsets and that the decision to make a decision is sometimes more important than the actual decisions made! (F)

In the same posting she reflected on the importance of self-awareness and of the value of being proactive when dissatisfied with work issues.

Taking an honest look at myself has been an important part of this leadership group work already. I've also realised I can't feel frustrated and disgruntled and wait for things to change around me, I need to take action myself - be the change you want to see in the world! (F)

The shifts in practice Fiona made as part of implementing her goal included delegating tasks such as staff training to another teacher. This caused Fiona to reflect in both reflective journal entries and in chat sessions on how she was working to empower the other teachers in her centre. Further thinking on how the teaching team could be encouraged to take on more responsibility, and recognising that if individual team members were unable to fulfil their responsibilities for various reasons it wasn't entirely Fiona's responsibility, resulted in the following reflection:

That doesn't mean I have to do it on top of all of my stuff!!!! BIG REALISATION. It's my employer's responsibility to make up for the rest of what isn't done and it's not just for me to carry it all. See how valuable this whole process is Kate - for me that's a really big thing, because I do try to be all things to everyone, all of the time and I spend so much time exhausted and feel like I've worked 10 years or more in the last 7. (RJ)

This mind shift - that she was not entirely responsible for making up for other people's lack of completion - led to a sense of relief, and appreciation for the leadership learning process. This view was expressed in the following journal entry:

It's a good feeling to know that the weight of the world isn't just on my shoulders anymore and I'm not such an island .... So that's an enormous change too and Kate, I can't help but think how much this course has helped me because I really did need help and to help myself and without this structure and guidance, I'm not sure that would have happened so it really did just come about at the perfect time and I'm looking forward to becoming this new type of leader. (RJ) 
The shift in focus from asking for help to supporting other teachers to take more responsibility was identified in Fiona's second leadership goal that related to increasing the participation of other teachers in the centre. The strategies identified included identifying teachers' strengths and encouraging them to take up leadership opportunities. This revised goal raised other challenges such as learning ways in which to empower others as shown by the following online action learning forum entry:

I am learning that sometimes being supportive is not the same as being empowering. I am learning to put time into helping people learn, rather than always doing for them, and then having them teach on to someone else, so I am saving time in the long run but also building up lots of skills at the same time. (F)

These changes had a positive impact not only on Fiona but also on the other teachers whose attitude changed from one of dependence to one of active participation. In the final interview conducted five months after the leadership action learning group began, Fiona commented that she was still learning about how to effectively encourage leadership in others:

I think I always had that idea that to be really supportive of people you did things, you might rescue them or you are the supportive one because you carry everything, but I've learned that that's not the way and I'm still working on that all the time. (I)

This shift around the way she worked with others was the most valuable learning Fiona took from her participation in the leadership action learning group, and the aspect of her leadership she felt most positive about.

\section{Use of ICT to support Fiona's learning journey}

Fiona was very confident in her use of the online site. She particularly valued the resources available on the site and the reflective journalling process. Two aspects of the reflective journalling process Fiona identified as particularly useful for her leadership learning were that the process of writing made her reflect more deeply, and that the facilitator's questions encouraged her to think more broadly. Use of the reflective journal and participation in other online activities helped Fiona meet the goals she set for herself as part of her involvement in LALG1.

\section{Summary of Fiona's leadership journey}

Fiona was one of the more active members of LALG1. She used the reflective journal regularly, and although she did not participate in many chat sessions because of a lack of easy access to a computer outside work hours, she was a valuable contributor to forum discussions. Throughout her leadership journey, Fiona took opportunities to ask for support and to work with other teachers in ways that encouraged them to take on more responsibilities. This relieved her of some of her workload and meant that she felt 
more in control of her work. Fiona tried out different leadership strategies over the course of the research such as coaching and encouraging reflection, and she felt that these different ways of working had empowered others and created a stronger team.

\subsubsection{Grace's leadership journey - ‘Out of my comfort zone’}

Grace had been in her first leadership role for less than a year when she joined the second leadership action learning group. She did not have a lot of experience with ICT and was mostly self-taught. She did not have a computer at home but regularly spent time at her centre out of work hours which was when she used the online site. Although she had not ever kept a reflective journal, Grace reflected regularly and did write informal reflections. She was struggling somewhat with her leadership role partly because of issues with the teachers in her centre, and partly because her centre was undergoing a lot of change. Her feelings about this situation were explained in her first journal entry in which she reflected that her recent experiences had taken her "way out of my comfort zone".

Grace's natural leadership style was a collaborative one that encouraged leadership in others, although this was proving a challenge with her current teaching team due to their lack of experience and skills. In her initial goal, set after the first face-to-face meeting, she identified that she wanted to encourage the teachers to use their initiative and become more independent. Implementation of this goal included taking on a more directive leadership style at times as the following reflection on an interaction with her teachers shows:

I had a very positive leadership day today. I had a staff meeting with the team and was very directive in my approach, I presented the meeting in a very structured way (but friendly) asking the team where they were at with understanding routines, rosters and responsibilities. With the answers I was able to gauge that one of the teachers was following through well on their tasks and had a good understanding of their responsibilities while the other needed to acknowledge that they hadn't followed through on a number of things, I asked them what they needed to do to complete the job rather than what support they needed and they had to come up with answers. (RJ)

This reflection also highlights the beginning of Grace's realisation that different leadership strategies were needed in different situations with different people. Grace tried using the action learning questioning process to help teachers become more aware of their responsibilities and although this was aimed at fostering the teachers' independence and involving them in the leadership of the centre, it proved to be a slow process:

I think that ultimately the questioning process will foster the expectation that the teachers need to think for themselves. Ideally I would like for us to collectively own the programme however I am needing to really drive it. (RJ) 
Having to shoulder most of the responsibility for the effective working of the centre was very draining and toward the end of 2007, Grace reflected that the stress she was under in terms of workload and the umbrella organisation expectations made it a challenge to deal with staff problems.

When I had a think about it I worked out that people issues, particularly difficult ones that relate to performance, personal and professional limitations, I find the hardest ones to deal with. I guess I'm trying to avoid dealing with the real hard stuff because I'm struggling to manage everything else. (RJ)

Having a break away from work over Christmas enabled Grace to gain a different perspective on her leadership role. She identified that she needed to slow down the rate of change that was occurring in her centre, and that she needed to try and look at issues more analytically and less personally. The following reflective journal entry extract was an attempt to explain how the leadership learning process, in particular the leadership frameworks that we had discussed, had helped provide some clarity in dealing with issues:

Professionally speaking I think that I have been able to draw on experiences over the last 10 months to develop the skill of really looking upon this as a leader. It is still taking me time to work through these things and I guess the little bits and pieces of leadership experience have started to form some skills, I know that I have a lot to learn yet but the part when I can separate from the comments, situations and teachers' reactions and come up with a wider picture solution is borne from my personal development and development as a leader. (RJ)

As a result of this greater confidence in her own leadership, Grace began to encourage a higher level of participation in the running of the centre from one of her other teachers. This was done by giving her more responsibility which resulted in a considerable increase in confidence. This heightened Grace's awareness of the importance of using different strategies with different teachers as the following comment shows:

It's made me aware of the challenge of working with the group and yet having to respond to different individuals. I never would have known that a year ago, it would never even have entered my head that it would be that specific. (I)

Overall Grace valued her participation in the leadership action learning process. In particular she appreciated having frameworks to guide her leadership and feedback on her reflections. In the final interview she commented: 
I found it immensely helpful and I'm really grateful that I had the opportunity to do this because I think my leadership would have been a hell of a lot more disorganised and harder having not. So I've certainly got a great deal out of it. (I)

\section{Use of ICT to support Grace's learning journey}

The online reflective journal was the ICT tool most valuable to Grace in her leadership learning. She found reflective journalling a very enabling activity and commented that the facilitator's reflective questions helped her gain different perspectives on her situation. Grace also valued the collegial nature of the chat sessions and commented that the lighter side of chat was a great release when she was feeling overwhelmed with work issues. She also thought that the questions that were posed in chat sessions were helpful in encouraging her think, and to reflect on her situation.

\section{Summary of Grace's leadership journey}

Grace was one of the most active members of LALG2. She used her reflective journal extensively, writing in-depth reflections, and also began this group's only online action learning forum discussion. Grace was struggling with her leadership role when she joined the leadership group and although she faced continuing challenges in her centre context throughout the process, she gradually became more confident and more strategic in her leadership. She learnt to use different leadership styles in different situations and, as her repertoire expanded, she felt that the confidence of her teachers and their ability to contribute to the leadership of the centre also grew.

\subsubsection{Section summary}

These three participants all participated actively in the blended action learning activities and contributed regularly to the online site, although in all three cases there were gaps in participation due to ill health and work demands. Long and thoughtful reflective journal entries characterised the contributions of these and other active participants. These in-depth reflections allowed them to work through issues they were facing in their leadership roles and as these reflections were shared with the facilitator, I became more aware of their situations and hence could both support and challenge them more effectively. In all three cases, growing confidence in their own leadership encouraged these participants to foster leadership in their teaching teams and they perceived that leadership became distributed to some degree across team members.

\subsection{Less active participation}

The leadership journeys of three participants, one from LALG1 and two from LALG2, who participated less actively in the research groups will be presented in this section. The leadership goals these participants identified and the actions they took as a consequence will again be discussed as will the barriers to their participation and how the ICTs available supported their leadership learning. 


\subsubsection{Emma's leadership journey - 'I'm far too soft'}

Emma had been in her second formal leadership position for 6 months when she joined the first leadership action learning group. She was not particularly experienced in the use of ICT and did not regularly engage in formal reflection. At the start of the group the only computer she had access to was a shared work computer. The goal she identified at the first face-to-face meeting was dealing with conflict, but upon reflection she decided to change it to time management as she was struggling with balancing the responsibilities of professional development, staff development, working with children and families and her own well-being. Implementation of this goal involved Emma increasing the number of staff meetings and reorganising the administrator's hours so that the small office space could be used more efficiently.

Emma had connection difficulties that impacted on her early participation. Her work computer was extremely slow and as she demonstrated to me at the time of the second interview, online activities took minutes when they should have taken seconds. In this interview she commented:

\section{It's like I'm not participating, well I'm not. (I)}

Emma did manage to take part in several chat sessions and also used the online journal to reflect on the issues she was facing with one of her staff members. About three months after the start of the group she bought herself a laptop and so could access the online site from home. She described the satisfaction of being able to participate more easily:

It is so nice to come home from our meeting tonight and go onto the website. And it works. So much better than looking and hoping it might work. (RJ)

She continued to work on empowering her staff members and also trying out different leadership strategies. In her updated goal posted on the leadership goals and actions forum she reflected:

To improve Time Management I think that the best thing I can do is to continue to empower my staff by extending their knowledge and learning in new areas. This keeps them motivated and focused on their jobs and the centre environment. Through this I am able to focus on other areas of the centre and we all win. I need to work more on being a leader and making some decisions for the centre. I tend to discuss most things with the team first. And while this is a good thing sometimes it puts me in a difficult situation. (F) 
In this posting Emma reflects on her realisation that the democratic leadership style was not always the best approach. Although she naturally valued harmony and wanted every team member to feel positive about their work, Emma realised that sometimes she needed to be clearer about her expectations so that staff practices were more consistent. This led her to set a new goal around creating a positive centre environment. In the final interview, Emma reflected that one of the things she had learnt about herself over the course of the group was that she was "far too soft, far too nice". Participation in the group had caused her to reflect on her personal leadership style and she identified that she needed to get a bit tougher in order to deal with some of the issues she faced. She was still working on this aspect of her leadership at the time that data collection stopped.

\section{Use of ICT to support Emma's learning journey}

The tool on the online site Emma found most useful was the online reflective journal. A couple of times she wrote a reflection straight after dealing with a difficult issue and she found this process a good release. Writing down her thoughts and feelings in this way also helped her let go of problems instead of going home and dwelling on them. She also valued the facilitator feedback which gave her a different perspective on issues. Emma valued the chat for keeping in touch with other group members and she liked to be able to revisit what she and other people had written. Emma commented that the early problems with accessing the site had impacted on her ongoing participation as she did not really get into the pattern of using the site regularly. She favoured the face-to-face interactions because of this; however, she did also value the online activities as she saw them as complementary to the meetings.

\section{Summary of Emma's leadership journey}

Emma was an enthusiastic member of LALG1 though she was the least active online participant. She was the only group member not to participate in the online action learning forums probably because her early lack of participation meant she did not become as confident in online interactions. Although she identified that she was more self-aware as a result of her participation in the group, there had not been the same shifts in practice that the more active participants experienced.

\subsubsection{Jane's leadership journey - 'What kind of leader do I want to be?'}

Jane was another new head teacher who had been in her current role less than a year. She was the most experienced participant in the use of ICT for online learning as her previous study had included online learning components. She had access to the online site both at work and at home although she only had a dial-up connection at home which sometimes made access to the chat sessions problematic. She described herself as reflective although did not regularly engage in written reflections. Just before the start of LALG2, Jane had had an unpleasant experience whereby her leadership style was personally attacked by a teacher who had recently left the centre. This experience had 
knocked her confidence in her leadership and caused her to reflect deeply on her leadership style. Over the course of the first whole day face-to-face meeting, Jane became clearer about the sort of leader she wanted to be. The first goal she set, and shared in the leadership goals and actions forum, related to effectively building her new team:

I want to work out how to create an environment where we get to know and trust each other so we feel comfortable to share issues professionally and work effectively as a team. $(\mathrm{F})$

Strategies to support this goal included developing an induction plan for a new teacher, a task which Jane entered into with enthusiasm. She began a forum discussion on induction and received suggestions from other group members. At this early stage in the life of the group, Jane was feeling positive about the progress she was making as the following reflective journal entry shows:

I am starting to feel like that I am starting to get it all under control. I have worked out that I needed to delegate more... I think I am starting to enjoy my job again - I know it is only early days but thank goodness I am starting to get it under control. Yipeeeeee! (RJ)

Jane's participation was restricted for a while as she was very busy preparing for an Education Review Office visit and she took a lot of paper work home to deal with in the time she may have gone online. At the second interview, she commented on the usefulness of the process for helping her move on from her feelings of anxiety:

It helped me formulate a plan and once I've got a plan I can move but I felt like I was just going round in circles prior to that not being able to get anything to go forward so that's been an amazing tool. (I)

After the Christmas break, Jane set a new goal arising from the Education Review Office visit around teachers working together to ensure they used effective questioning with individual children, an issue that the team did not all see as a problem. After this goal setting and a couple of reflective journal entries, the only online participation for about six weeks was a brief chat session. Jane also missed the face-to-face meeting held over this period. During this time she attended another leadership course that I was involved with and I hoped that this may have encouraged her to reflect more on her leadership and become more active in the group once again. A journal entry about a month after she attended this course revealed that Jane had indeed been reflecting on her leadership and was still struggling with the type of leader she wanted to be:

Since I attended the leadership course in the holidays I have been on what is quite a personal confidence building journey ... I don't know what my leadership personality 
looks like. The natural me got it quite wrong and I have not been sure what my leadership face looks like. (RJ)

Although Jane had thought by addressing the induction issue that she would ensure the negative experience with the teacher she had had earlier in the year would not happen again in the future, she realised that issue was still not resolved.

These reflections have been quite difficult for me to deal with because I thought that I had dealt with the staff issue but I realise that just because she is not there that the issues raised have not gone away for me. (RJ)

In the final interview, Jane reflected that this process of developing her self-awareness was a necessary step and that unless she was able to decide who she was as a leader and how she wanted to demonstrate leadership, she would continually stumble. She was still trying out different leadership approaches, was learning to trust more in her current team, and had learnt that it was all right to make mistakes. Although the action learning process could have been used to help Jane work through her personal doubts about her leadership, she did not see how it could have helped:

And I still don't know how I would use the action research [learning] even now to move me on but some of that is because I don't know where I'm going. (I)

Although she was not feeling much more confident about her leadership, participation in the action learning group had provided her with a process to start moving forward:

The first little bit gave me the hook that I needed to get in safely and it's provided a safe framework for me to explore in. (I)

\section{Use of ICT to support Jane's learning journey}

Jane found the chat sessions the most useful tool on the online site as she felt that these were most similar to the face-to-face meetings which she particularly enjoyed. The support of the group was very important to Jane as seeing that other people were struggling or had previously struggled gave her some confidence that she was not alone and that she would eventually feel more in control. Jane also appreciated having access to the resources as they helped her determine where she was going in her leadership journey.

\section{Summary of Jane's leadership journey}

Although Jane was initially an active participant in LALG2, and developed a goal and actions that she thought would help her move on from her unpleasant experience, she later realised that the issues were more complex. The process of relooking at her leadership role had caused a crisis in confidence that she was just coming out of by the end of the data collection period. While she did not engage in the online action learning 
group activities to any extent in the later stages of the data gathering process, she was able to share her reflections in the subsequent face-to-face meetings. Soon after the final interview Jane did acknowledge that she had moved on from her unpleasant experience and was beginning to enjoy her leadership role more (Personal Communication, 23/7/08). Although the blended action learning process may have helped Jane to work through these issues sooner; she chose to do this by herself and shared her reflections with group members after the event.

\subsubsection{Lisa's leadership journey - 'I want to be prepared'}

Lisa was an experienced head teacher who had been in her current leadership role for over 10 years. She was not particularly experienced in the use of ICT and although she reflected regularly, she had not previously kept a reflective journal. Lisa had recently had a significant increase in the size of her teaching team which was causing some issues; however, her first goal posted a couple of days after the first face-to-face meeting, related to including and involving all committee members. Despite this prompt start to online participation, Lisa was only able to contribute one more forum posting and one reflective journal entry before the end of the year because of difficulties with internet access. This lack of participation caused her some disappointment as the following comment shows:

It hasn't really worked for me this year mainly because I haven't had the internet access. I've felt a bit frustrated and left out. I've felt as though I haven't really got a start of it. (I)

By the time LALG2 met again at the beginning of 2008, Lisa's connection problems were resolved and she became more active in online activities, posting a second goal, participating in chat sessions and making more regular reflective journal entries. Lisa's second goal related to developing confidence in building her team, and many of her journal entries included reflections on how she was dealing with a challenging team member. She identified that she needed to be firm in dealing with this teacher's behaviour as it affected team dynamics, and she used some of the resources on the site to help her plan her approach. Comments made in her reflective journal showed how she felt pleased about how she was dealing with this situation:

I feel now I have had the talk with [name] I am more confident and determined to act upon any signs of her stress returning... I am sure there will be challenges along the way and I do feel confident to manage these. (RJ)

In the final interview Lisa talked about her developing self-awareness, reflecting that although she was more aware of her natural leadership style, this did not prevent her learning and using other leadership styles when required. She was now more confident in dealing with conflict situations and felt comfortable to reflect and plan rather than 
thinking that she had to come up with an immediate solution, as the following comment shows:

When I have different situations, whether they're positive or they're conflict ones, I'm just spending more time preparing and thinking what questions I want to ask. (I)

Lisa also discussed her developing self-confidence and her consciousness of using different leadership approaches with different teachers. She shared the fact that she had started keeping a personal journal in addition to the online reflective journal and said that she intended to continue this reflective journalling in order to help her further develop her leadership capabilities. Overall she was very positive about her experience, commenting that:

I certainly feel more empowered to do further learning and readings and to just keep improving myself. (I)

\section{Use of ICT to support Lisa's learning journey}

As previously mentioned Lisa's use of ICT was initially restricted because of access issues and later restricted because of workload issues. Lisa did value the reflective journalling process, in particular the questions and comments from the facilitator which helped her identify future actions. She also appreciated the resources available on the online site and used these at different times to help her develop greater self-awareness and an awareness of alternative leadership styles and approaches.

\section{Summary of Lisa's leadership journey}

Lisa was unable to actively participate in the online activities of LALG2 for several months; however, despite this slow start, she eventually increased her activity. She also developed the habit of reflective journalling which she kept up, both online and in paper form, after the conclusion of the data collection phase of the research. This reflection helped Lisa develop greater self-awareness and also encouraged her to do more reading and research around different leadership practices. Lisa used the blended action learning process to reflect on her leadership style, to try out different approaches and in the process felt that she had become a more confident leader.

\subsubsection{Section summary}

The three participants whose leadership journeys were described in this section participated fully in the face-to-face meetings but were less active on the online site. Reasons for this lack of activity varied from access problems to personal issues. This lack of activity meant that the facilitator was less aware of the thoughts and feelings of the participants and therefore was less able to support or challenge them in their leadership learning. This in turn meant that the shifts in practice were not as significant although there was a greater self-awareness and an increase in confidence in most cases. 


\subsection{Discussion}

The leadership journeys presented in this chapter illustrate the different paths travelled by participants from both leadership groups. As mentioned earlier, the learning journeys of the remaining six participants are included in Appendix C. The following table summarises the leadership goals, use of ICT, and shifts of practice of the three more active and three less active participants described in this chapter.

\begin{tabular}{|c|c|c|c|}
\hline Participant & Leadership goals & Use of ICT & Shifts in practice \\
\hline Diana & $\begin{array}{l}\text { To feel more confident } \\
\text { in using different } \\
\text { leadership approaches. } \\
\text { To become more } \\
\text { comfortable in } \\
\text { managing conflict. }\end{array}$ & $\begin{array}{l}\text { Wrote frequent and } \\
\text { long reflective journal } \\
\text { entries and contributed } \\
\text { to forum discussions } \\
\text { including action } \\
\text { learning forums. }\end{array}$ & $\begin{array}{l}\text { Became more } \\
\text { confident in using a } \\
\text { range of leadership } \\
\text { approaches and in } \\
\text { dealing with conflict } \\
\text { more rapidly and } \\
\text { confidently. }\end{array}$ \\
\hline Fiona & $\begin{array}{l}\text { To share leadership } \\
\text { and management tasks } \\
\text { with other teachers in } \\
\text { order to reduce } \\
\text { workload and stress. }\end{array}$ & $\begin{array}{l}\text { Wrote long and } \\
\text { reflective journal } \\
\text { entries and started and } \\
\text { contributed to forum } \\
\text { discussions. }\end{array}$ & $\begin{array}{l}\text { Began to share } \\
\text { leadership } \\
\text { responsibilities with } \\
\text { other teachers and to } \\
\text { empower them to take } \\
\text { more responsibility. }\end{array}$ \\
\hline Grace & $\begin{array}{l}\text { To encourage } \\
\text { independence and } \\
\text { responsibility in other } \\
\text { teachers through the } \\
\text { use of different } \\
\text { leadership approaches. }\end{array}$ & $\begin{array}{l}\text { Wrote long and } \\
\text { frequent reflective } \\
\text { journal entries. } \\
\text { Contributed to forum } \\
\text { discussions and chat } \\
\text { sessions. }\end{array}$ & $\begin{array}{l}\text { Became more } \\
\text { confident in using a } \\
\text { range of leadership } \\
\text { approaches in } \\
\text { different situations. }\end{array}$ \\
\hline Emma & $\begin{array}{l}\text { To use time more } \\
\text { effectively and to } \\
\text { empower staff by } \\
\text { using effective } \\
\text { leadership approaches. }\end{array}$ & $\begin{array}{l}\text { Early participation } \\
\text { restricted. Used } \\
\text { reflective journal and } \\
\text { participated in chat } \\
\text { sessions. Least active in } \\
\text { forums among LALG1 } \\
\text { members. }\end{array}$ & $\begin{array}{l}\text { Became more aware } \\
\text { of her natural } \\
\text { approaches to } \\
\text { leadership and the } \\
\text { need to be more } \\
\text { assertive at times. }\end{array}$ \\
\hline Jane & $\begin{array}{l}\text { To create an } \\
\text { environment of trust } \\
\text { within the teaching } \\
\text { team. } \\
\text { To understand own } \\
\text { natural leadership style. }\end{array}$ & $\begin{array}{l}\text { Valued chat sessions } \\
\text { over other tools } \\
\text { although also made } \\
\text { some use of journal and } \\
\text { forum discussions. }\end{array}$ & $\begin{array}{l}\text { Developed a greater } \\
\text { understanding of } \\
\text { different leadership } \\
\text { approaches and own } \\
\text { natural lea dership } \\
\text { style. }\end{array}$ \\
\hline
\end{tabular}




\begin{tabular}{|l|l|l|l|}
\hline Participant & \multicolumn{1}{|c|}{ Leadership goals } & \multicolumn{1}{c|}{ Use of ICT } & \multicolumn{1}{c|}{ Shifts in practice } \\
\hline Lisa & $\begin{array}{l}\text { To become more } \\
\text { confident in her } \\
\text { leadership approaches } \\
\text { in a range of contexts. }\end{array}$ & $\begin{array}{l}\text { Restricted initially by } \\
\text { access problems. Made } \\
\text { minimal use of online } \\
\text { tools apart from the } \\
\text { reflective journal. }\end{array}$ & $\begin{array}{l}\text { Became more self- } \\
\text { aware and more } \\
\text { confident in using } \\
\text { different leadership } \\
\text { approaches. }\end{array}$ \\
\hline
\end{tabular}

Table 5-1 : Summary of participation of more and less active group members

The leadership journeys raise a number of issues relevant to this research including: an understanding of how the ICT tools contributed to their leadership learning; access to the online site; use of the site; and progress made towards meeting goals and increasing leadership capabilities. Two different access issues affected the online activity of participants; the ability to access the online site both at work and at home, and having uninterrupted access to the site. A number of participants had access to the online site both at home and at work. However, this did not appear to affect levels of activity as none of the three more active participants whose journeys are described above regularly accessed the site outside work hours, whereas all the less active group members could eventually access the site out of work hours; having access restricted by internet outages or computer problems was a more significant issue. The two participants whose initial interactions were restricted did not participate as actively in online activities, perhaps because they did not develop the habit of doing so early in the life of the group. Different ICT tools were valued more highly by different participants. Although the more active participants all commented on the importance of the reflective journalling process to their leadership learning, some of the less active participants favoured technologies such as chat that mirrored the face-to-face interactions. On the whole, all the technologies were seen as having a place and they had different and complementary roles as will be seen in Chapter 6.

Progress towards meeting leadership goals and the development of greater confidence in leadership roles was more pronounced among the more active participants. Although as will be seen in Chapter 6, all participants were positive about the impact of their participation, the more active participants reported more significant shifts in practice and greater confidence in their ongoing leadership capabilities. The data collection period in this study was less than seven months for both groups and it is likely that there were ongoing shifts in practice and increases in confidence that were not documented in this study. Personal comments made by Diana and Jane in this chapter provide examples of how leadership learning was ongoing, partly as a result of the continued interactions and partly because of the time taken to assimilate new learning before it is put into practice. Hirst et al. (2004) found a lag between learning and facilitative leadership, a term they use to describe leaders who "promote respect and positive relationships between team members, productive conflict resolution, and open expression of ideas and opinions" (p. 
312). They explain this lag in terms of the time leaders take to consolidate their new ideas and concepts into practical skills and new behaviours.

Reflective practice was key to leadership learning. The more the participants engaged in reflective journalling, the greater their critical reflection on leadership practices and the more input the facilitator was able to provide. Another reason for the deeper and profound modes of learning (Paterson \& West-Burnham, 2005) being more obvious amongst the more active participants could be the shared nature of the reflection that occurred when participants regularly used the online tools such as the reflective journal and forum discussions. The value of shared reflection has been emphasised by Raelin (2002) who suggests that it allows for support and feedback from others and offers alternative ways of thinking and acting. The higher levels of participation also seemed to impact on the distribution of leadership throughout the teaching teams of participants showing a link between greater confidence and the empowerment of others.

\subsection{Chapter summary}

A summary of the learning journeys of 6 of the 12 research participants has been presented in this chapter. Various factors such as access issues and personal circumstances impacted on the levels of activity of different participants. Preferences for the technologies available on the online site varied between the participants with the reflective journal being the most favoured tool overall. The journeys of three of the more active participants illustrate a depth of reflection, a determination to address leadership issues and to make shifts in practice. Sustained use of the online site by these participants meant that reflection was shared and the facilitator was able to both support and to challenge their leadership development in meaningful ways. Although the less active participants also made shifts in their leadership practice and all developed a greater awareness of their authentic leadership, the learning they reported was not as deep or profound as that of the more active members. 


\section{The Blended Action Learning Group Process: An Analysis}

"Learn from yesterday, live for today, hope for tomorrow. The important thing is not to stop questioning." (Albert Einstein)

\subsection{Chapter overview}

This chapter presents an analysis of the blended action learning process based on the views of participants on various aspects of their involvement. The chapter begins with a discussion of a range of aspects of the blended action learning process, and this is followed by an exploration of the effect of participation in the blended action learning groups, and of the different technologies used on the site. The views of members of both leadership action learning groups are discussed and conclusions drawn as to the appropriateness of the process and the different technologies used; relevant literature will also be referred to.

\subsection{The blended action learning process}

This section of the chapter will focus on the blended action learning process and include a discussion of how action learning, in particular the process of identifying issues, reflecting and being questioned by others, encourages learning. The online action learning process, the empowering nature of action learning, and the blended approach to learning will all be discussed.

\subsubsection{The action learning process}

Action learning occurred both at face-to-face meetings and online. At the meetings, participants had 30 to 40 minutes each to share the issue or problem they were working on and to be questioned by the facilitator and other group members. The action learning process expedites the practice of learning from experience and supports individual development through the giving and receiving of feedback (Bowerman, 2000). Action learning also encourages reflection, focuses on the questioning process and discourages participants from offering solutions. The action learning process used in this study encouraged the participants to engage in reflection, both individual and shared. Marquardt has suggested that the action learning process encourages reflection as it "deliberately carves out the time and creates the conditions for reflecting and listening" (2004b, p. 81). Anecdotal comments by participants confirmed that engagement in the action learning process had increased the amount of reflection they were doing:

I feel I am reflecting a lot more on my leadership styles and how they affect others these days. (Amy, F) 
I have reflected so much since doing this course on my leadership and how to deal with others. (Beth, C)

Some of this reflection was individual and some was shared as the following comment illustrates:

I guess we've got the reflective journal just for yourself then you've got that shared reflection thing as well so you've got 2 forms of reflection. (Fiona, I)

The importance of shared reflection to learning is emphasised by Barth (1987, cited in National College for School Leadership, 2003), who, in a discussion of the value of collaborative learning, suggests that "the most powerful form of learning comes not from listening to the good works of others but from sharing what we know with others" (p. 15). This view is supported by West-Burnham (2003), who believes that "the most powerful basis for profound learning is supported reflection". The value of shared reflection in an online environment is discussed by McConnell (2006) who suggests that it results in new understandings and new knowledge.

Questioning both by the facilitator and by other participants supported the different forms of reflection. The value of questioning in encouraging reflection is promoted by Francis and Cowan (2008) who believe that being questioned by others jolts the learner into deeper thinking. The questioning approach used was highly valued by participants.

That action learning process I did find very useful. And again practising that skill of not answering people's questions for them or giving advice but questioning them was interesting, watching other people learn those skills as well. (Fiona, RJ)

It was not, however, an easy process to learn and put into practice, and the questioning did not always happen. Zuber-Skerrit (2002) has commented that questioning in an action learning context is not a simple task and requires knowledge, skills, intuition and a caring attitude. There was a tendency among some group members to want to give advice, and participants took a while to become comfortable with listening and then questioning as the following comment shows:

I suppose to critique, the group didn't always question, use the questions. I know I do the same thing - we're all trying to solve each other's problems and it's a really hard model to get out of. (Grace, I)

Some participants did not feel confident in asking questions and therefore tended not to participate as much in the face-to-face action learning sessions as others. 
I found that incredibly hard not to give solutions so I found myself not asking many questions at all. (Heather, I)

The triad process used at the first meeting was useful as it meant all participants were able to practise each of the three roles of presenter, enabler and observer. This process is also recommended in leadership learning groups run as part of the National College for School Leadership as it encourages the reframing of issues and the generation of future possibilities for action (National College for School Leadership, 2003). Having the opportunity to practice the action learning process at the first meeting was seen to be important.

Having that session to do it and setting that tight framework about how to go about it. I think if it had been handed to me on a sheet it wouldn't have happened. I think it's something that needs to be practised and I think that was really useful coming together trying it out in the small groups so again it was only 3 of us. (Jane, I)

Using the process over a period of time and being given additional resources at face-toface meetings on questioning techniques gradually made it easier for most participants as the following comments illustrate:

I found it really rewarding in the end. At first I felt a bit frustrated by for one thing, not being able to offer suggestions which I desperately wanted to do, so it took a lot of effort to hold back on and also when I posed a question or a problem not being just offered some solutions or some people's advice... but after going through it a few times I do now see the value of coming to your own conclusions because the questions are really prompting it's not like you really get there on your own. (Charlotte, I)

\subsubsection{Action learning online}

As mentioned earlier, the action learning process initially occurred only at the face-toface meetings and then later took place online as well as face-to-face. The online action learning gave participants more time to think about the questions they could ask and this made the process easier as the following comment shows:

It did with practice get a lot easier and the online was just good for that in that you could think about it for a while because also when people are talking, if you're thinking of questions, I'm not listening. (Fiona, I)

Action learning online involved participants identifying and describing a specific issue they were grappling with in a forum space. Over the course of about a week, the facilitator and other participants asked questions in order to help the group member reflect on their situation. This process was viewed positively: 
I did the first one and the feedback I got was just really valuable, really helpful. The fact is that a lot of my leadership challenges are specific and this situation happened, and I'm working out how to respond to it - any thoughts, any ideas, any questions? (Diana, I)

One of the online action learning forums from LALG1 is presented on Table 6-1 below to illustrate the process:

\begin{tabular}{|c|c|}
\hline Charlotte & $\begin{array}{l}\text { Can I get critique of my decisions in this role? } \\
\text { Where can I get true critique of my ideas and actions in this role? I feel } \\
\text { like I am flying unguided, and I think I would benefit from some more } \\
\text { decision making input from others (management committee, assistant } \\
\text { head teacher, ...) Everyone just agrees with me all the time!!! } \\
\text { I wonder whether this is simply a phenomenon of the role, or if it is a } \\
\text { signal I am giving off that says, "Don't worry, I have everything under } \\
\text { control." I would like people (particularly the committee) to engage more } \\
\text { with what I suggest, and to problematise before agreeing with me. }\end{array}$ \\
\hline Kate & $\begin{array}{l}\text { Hi Charlotte, } \\
\text { Some questions for you to ponder: } \\
\text { In what ways do you currently seek feedback from the committee and } \\
\text { assistant head teacher? } \\
\text { Do you give them time to consider new ideas/suggestions before } \\
\text { committee meetings? (Thinking of different personality types here - some } \\
\text { people need time to think things through) } \\
\text { Kate }\end{array}$ \\
\hline Charlotte & $\begin{array}{l}\text { Hi Kate, } \\
\text { These are very good questions (you're pretty good at this activity, aren't } \\
\text { you? } \\
\text { The first question has really made me think. I think the only way I really ask } \\
\text { for feedback from the committee is at meetings. I write a topic on the agenda, } \\
\text { explain my view on it in the meeting, then everyone agrees with me. } \\
\text { Which brings me to your second question: I don't give them time to } \\
\text { consider my ideas before the meetings! } \\
\text { I read in that Visionary Director book, that you can type up a list of notes to } \\
\text { hand out before staff meetings. This prepares people, and also saves time } \\
\text { going over boring house-keeping details like dates to remember. I have } \\
\text { suggested this to the teachers and am going to try it before the next staff } \\
\text { meeting. Perhaps I should try this with the management committee too? } \\
\text { As for the assistant head teacher, I am getting more comfortable in asking } \\
\text { her for feedback - we have started to really settle into a working } \\
\text { partnership in the past week or so. She is definitely the type to need time } \\
\text { to process things before responding, so giving her my ideas in advance of } \\
\text { a face-to-face would be useful too I think. } \\
\text { Thanks, from Charlotte. }\end{array}$ \\
\hline
\end{tabular}




\begin{tabular}{|c|c|}
\hline Amy & $\begin{array}{l}\text { Do you actually ask them "What do you think about ....? or "How do you } \\
\text { feel about...?' Amy }\end{array}$ \\
\hline Charlotte & $\begin{array}{l}\text { Hi Amy, } \\
\text { I do ask those questions, but I am beginning to realise that I justify my } \\
\text { own idea or solution first. I will explain the situation, explain what I } \\
\text { think needs to be done and why, and then ask, "What do you think about } \\
\text { this?" } \\
\text { I can see that this isn't a good way to get real engagement in the issues } \\
\text { from people. I wonder: should I be holding back my ideas for longer? } \\
\text { Perhaps I should simply explain the situation and not give any ideas at } \\
\text { first. This would be a more genuine way to ask for input. I am a little } \\
\text { conflicted with this idea though, because I like meetings to move along at } \\
\text { a good pace. Also, sometimes I know more about the situation because of } \\
\text { the role I'm in, and I want feedback on my ideas rather than a whole new } \\
\text { set of ideas. Is this a fair comment? } \\
\text { From Charlotte. }\end{array}$ \\
\hline Diana & $\begin{array}{l}\text { Hi Charlotte, } \\
\text { Long time, no write - on my part! I am sorry about that. I am intrigued } \\
\text { about your idea of writing notes before staff meetings. Have you tried it? } \\
\text { If so how did it work? And, just to satisfy my curiosity, how often do } \\
\text { you meet as a staff, and how long do you meet for? } \\
\text { As I read through this forum, I noticed that most have asked you about } \\
\text { gaining feedback internally, from those within your organisation. This is } \\
\text { my instinct too - when I read your question, I replied in my mind, "Have } \\
\text { you asked for feedback?" This feedback is really helpful, as it is given by } \\
\text { those who really understand the situation from the inside. There are two } \\
\text { comments I would like to add (not really reflective questions, but they } \\
\text { may be reflective comments!): firstly that some people feel uncomfortable } \\
\text { offering this sort of feedback, fearing it might offend. Have you assured } \\
\text { those you want feedback from that it is OK for them to do so, and that } \\
\text { you will receive it in an objective manner? Secondly, my experience is } \\
\text { that some members of my management group agree with me a lot } \\
\text { because they respect that I am offering a professional opinion within a } \\
\text { context they might not be trained in. Would this be the case for any of } \\
\text { your management committee? } \\
\text { I hope that helps! } \\
\text { Diana } P\end{array}$ \\
\hline
\end{tabular}




\begin{tabular}{|l|l|}
\hline Beth & $\begin{array}{l}\text { Hi Charlotte, } \\
\text { Perhaps you appear to be so confident that people don't think to } \\
\text { question what you are saying, if you openly asked for their opinion on an } \\
\text { issue before giving your opinion do you think they might give you a } \\
\text { different viewpoint. } \\
\text { Beth } \\
\text { Charlotte, just re-read first part and gosh you have mentioned already } \\
\text { about letting them comment first!!!! Also could you not say I am seeking } \\
\text { an opinion on my idea, Beth }\end{array}$ \\
\hline Charlotte & $\begin{array}{l}\text { Thanks Beth, that's a good phrase to use: seeking opinions on my idea. I can } \\
\text { see that it would be good to sometimes ask the committee for ideas first, and } \\
\text { sometimes more appropriate to just ask for feedback on my ideas. }\end{array}$ \\
$\begin{array}{l}\text { Thanks everyone for the action-learning/ prompting. In hindsight, I feel } \\
\text { a bit silly that I didn't come up with some of that stuff without this } \\
\text { process! But I guess that's the beauty: the questioning shows us we } \\
\text { kind of already know the answers ourselves. I'm not sure whether I'm } \\
\text { supposed to wrap this forum up at any particular point, but I feel like } \\
\text { I've got what I needed out of it now. } \\
\text { Cheers! From Charlotte. }\end{array}$ \\
\hline
\end{tabular}

\section{Table 6-1: Sample online action learning forum}

This last comment from the participant who began the discussion (bolded above) illustrates the value of this process. The questioning process supports participants to reflect on and identify possible strategies and also empowers them as they come up with their own solutions. Diana, who used this process to work through an issue involving conflict between staff members in her absence, posted the following comment:

Thanks again for your thought provoking questions; they have really helped me to think this all through! (Diana, F)

As mentioned in the previous chapter, only one member of LALG2 started an online action forum. Even though only the facilitator and one other participant responded, she still found the process very valuable.

I found that immensely useful. I was extremely busy at the time as everyone else was but I thought the process was extremely useful and I know it was only a week but I got a lot from that. I got a great deal from that and I know there were only a couple of responses but the process as a whole of typing it all out, writing it all down plus the feedback from other people as well. I'd sorted out the problem in a week and that was a big problem for me. It was a stressful one and I actually thought that that process was brilliant. (Grace, I) 


\subsubsection{The blended learning approach}

The combination of face-to-face and online learning was seen to be a useful combination by all participants. The importance of starting the group with a face-toface meeting was mentioned by several people and the following comment illustrates why it was seen to be so important:

I thought the all day meeting at the beginning was really good; it was a really good way to get to know people and form relationships because you were there the whole day so you really got a good chance to get to know people and also to be heard for the first time and listening to others. (Amy, I)

Having met the other participants face-to-face meant that some trust has been built which resulted in people then feeling comfortable to interact online, as Isabel explained:

I think online works because we've met the people and I think if I hadn't physically met them I'd probably feel different but because I'd physically met the people, I don't have any qualms about it whatsoever. (Isabel, I)

This preference for starting online groups with a face-to-face meeting is supported by Garrison and Anderson (2003) who believe that an initial face-to-face meeting may "have an accelerating effect on establishing social presence and can shift the group dynamics much more rapidly to intellectually productive activities" (p. 54). These authors also suggest that the value of some face-to-face interactions more than compensates for the loss of flexibility with regard to location and time. The participants in an online professional development course for health workers (Brosnan \& Burgess, 2003) also emphasised the value of meeting face-to-face at the beginning of the course in order to establish relationships and build trust. The participants in this study considered that these initial interactions encouraged them to be more open in later online interactions. The use of a blended learning approach in leadership development programmes for school leaders is one of the factors identified in a discussion of effective e-learning practices (McFarlane, Bradburn \& McMahon, 2003). This report also recommended arranging a face-to-face meeting before any online interactions take place.

Continuing to meet face-to-face was also seen to be valuable and this reflects earlier research on blended action learning groups which emphasised the value of ongoing meetings (Powell, 2001; Roche \& Vernon, 2003). Several participants commented that the face-to-face interactions were more focused, probably because they were synchronous, and felt that it was worth making the effort to travel to occasional face-toface meetings. However, they would not have liked too many more face-to-face meetings as they were time consuming and one of the major benefits of the blended approach was the flexibility of the online interactions. Participants commented that to 
get the equivalent experience without the online component, the group would have to meet extremely frequently which would not be manageable for them.

I couldn't possibly make or I probably wouldn't want to make a commitment to come face-to-face every week for 2 or 3 hours which I think we would need to do to actually achieve that involvement. (Beth, I)

The complementary nature of face-to-face meetings and online interactions is discussed by Garrison and Kanuka (2004), who suggest that online written communication "encourages reflection and precision of expression" (p. 97), while face-to-face verbal interactions are richly dynamic. The view that blended learning has more to offer than either of the two elements on their own (Garrison et al., 2001; Garrison \& Vaughn, 2008; Rovai \& Jordan, 2004) is supported by this research study. The face-to-face interactions complemented the online interactions and the combination offers a rich learning environment as the participants' comments show:

It has been very successful for me too. It's great having the face-to-face with potentially constant contact in between. It reinforces the learning for me, and helps me to reflect on it and explore it at greater depth. (Diana, C)

The mix of the online and the face-to-face was really, really important because I think one without the other wouldn't have worked so well, I think you needed both kinds of contact to work. The personal contact helped build relationships and that sense of trust. (Fiona, I)

The online interactions meant that when someone had an issue they wanted to discuss, they received immediate support. An example of this was when one group member wanted some ideas for interview questions and the facilitator and several group members responded with suggestions. The value of this prompt response was noted by Fiona who likened it to having a community she could talk to. She also commented on the fact that issues facing participants did not have to wait for discussion at a face-toface meeting but could be addressed quickly. A number of participants made a positive comparison between this model of professional development and other experiences they had had. One of the features of this approach that was appreciated by some participants was the ongoing nature of this professional learning experience compared with one-off courses. Diana particularly valued the combination of different elements:

It has been probably the most valuable professional development I've had and I think it's due to that kind of small group intensive, really proactively facilitated type environment and that there has been in that environment things for everyone, there have been the readings, there's been the personal face-to-face stuff for those people who really like the networking stuff, there's been the one-on-one for people who get more out of that situation so it's been all these things and normally you would only get one 
of those things in a professional development experience and sometime none. So I think the model is a really, really good model. (Diana, I)

Participants also commented on the fact that the writing process helped them solve problems even without anyone else's input. Having to write rather than just share verbally in a face-to-face situation was also seen to encourage deeper reflection.

As I start to write I start to think and my thinking is quite externalised and as I start to think and reflect some things come out that surprise me. (Diana, I)

These views concur with Bird's (2006) belief that in action learning, reflection is enhanced more by text-based communication than by verbal interactions. Garrison et al. (2000) discuss the advantages of text-based communication suggesting that it allows time for reflection and also "encourages discipline and rigour in our thinking and communicating" (p. 90). Garrison and Anderson (2003), in a discussion of the characteristics of text-based interaction, suggest that face-to-face interactions are "generally less systematic, more exploratory and less attentive to others' views" (p. 26). They promote the opportunities offered by writing for the construction of meaning and the communication of ideas and questions. This view is also supported by MacKnight (2000) who believes that asynchronous discussions promote deeper reflection and encourage the giving and receiving of feedback.

\subsubsection{The empowering nature of action learning}

Several participants reflected in the final interview on their experience that the action learning process empowered the presenter and made it more likely that the solution they came up with would be workable. According to Zuber-Skerrit (2002), action learning encourages the development of learners as experts and helps participants accept that they own their own problems and solutions. The value of coming up with solutions to problems they were facing rather than being given solutions by others was commented on by participants:

The questions do definitely push you in different directions and it is more satisfying to have come up with a solution yourself and maybe it sticks a bit more if you have come up with it yourself. (Charlotte, I)

It grows you as opposed to you always relying on somebody else for solutions and in that way I think it's good learning for your own future because then you don't have to feel swamped by problems ... you can then think now 'what's a good course of action here?', 'what do I know that I could apply to this situation?' (Heather, I)

The empowering nature of action learning was discussed in Section 2.5.2 of the literature review and was evident in this research study. Participants became more reflective, more aware of listening to others, more confident in their leadership 
capacities and in their ability to solve their own problems. As Morris (1997, p. 50) has suggested, action learning "seeks to empower everyone to learn from personal experience, and to find the confidence (and possibly the courage) to act in the light of that experience". The confidence that participants developed through their participation in the blended action learning process was illustrated both by more confident actions taken by participants, and by feelings of greater confidence reported by participants. Examples of both forms of evidence of increased confidence are given below.

\section{Confident actions:}

I am finding that I have been considerably more assertive all around with parents which is great and perhaps the start of me having the confidence to speak out!!! (Beth, $\mathrm{RJ})$

I also felt good that I had identified a problem and then made an action step to solve it and I do think it will make a real difference in my work, and in the confidence of the other teachers. (Fiona, RJ)

\section{Self-reporting of increased confidence:}

It felt good to be confident enough to easily fill the head teacher role and make decisions without feeling like I should wait until she gets back. (Amy, RJ)

Things have been much better possibly because I'm feeling more confident in what I'm doing. (Grace, C)

\section{Transfer of skills}

Participants' comments illustrated how the skills developed through participation in the blended action learning process, in particular listening skills and the use of questioning, were transferred to other situations. The challenge of listening to others then questioning, and the realisation that they often tended to give advice or not to listen effectively in other contexts, was commented on by two participants:

I have to be so careful about leaping in and solving things. I have to watch that - I do have to really watch that. (Karen, I)

I think through this whole process I've become a better listener. I thought I was always a good listener but when I really listen to myself when we've had staff meetings or just talking to people generally I'm a bit worried that it'll go off the subject and I won't be able to say what's important to me so most probably tended to interrupt. So I'm trying to ... hold back on that a little bit more. (Lisa, I) 
A number of participants commented that the process of listening and questioning was how ECE teachers worked with young children, although they did not often use it with other adults. The following example illustrates this realisation:

I mean we do it with the children. I heard myself do it with the children this morning... So we're asking them to problem solve so we as adults need to learn to do that with each. (Isabel)

Fiona, who started using questioning more to encourage one of her teachers to reflect on their practice, commented:

In effect I did with her what I do so naturally with the children but before Saturday's exercise, maybe don't do often enough with adults. (Fiona, F)

These comments demonstrate how the skills developed in the action learning process were transferred to interactions outside the group. The transformative and empowering nature of action learning has been commented on by McGill and Brockbank (2004) who have suggested that processing action learning skills in the context of the group deepens their use in other situations. Marquardt (2004b) agrees suggesting that:

As we help others with their problems and receive help with ours, we develop a number of important personal professional competencies such as how to give and receive feedback and help, how to solve problems, how to listen, how to do systems thinking, how to be more courageous, and how to take risks (p. 38).

Examples of all these personal and professional competencies could be seen in the blended action learning groups as participants enhanced their skills and tried out new ways of demonstrating leadership.

\subsubsection{Section summary}

Participants reported that the blended action learning process encouraged them to reflect on their experiences, and the questioning process helped them to identify future actions with regard to their leadership goals. The action learning that occurred online was particularly valuable as it gave participants the time to construct and to respond to questions, although the face-to-face interactions were also highly valued as they helped build strong and trusting relationships. The empowering nature of action learning promoted in much of the literature was evident in this study and reflected in the views of the participants who reported an increase in skills and competencies and a growing confidence in their leadership practice. 


\subsection{Participation in the action learning groups}

This section of the chapter focuses on participation in the action learning groups previously described in Chapter 4. Different aspects of participation that will be focused on include the benefits of group participation, in particular the reduction in isolation, the support received from others, and the advantages of having diversity within the group.

\subsubsection{Benefits of group participation}

An important aspect of the leadership development process was participation in the blended action learning groups. These groups differ from most professional development networks because of their small size, and because of their focus on reflection and the structured use of questioning. Benefits of being part of such a group, according to participants, included gaining different perspectives on leadership practice.

I really truly enjoyed hearing other people talk about what their issues and problems are, because there's always something you can learn. (Karen, I)

This sharing of leadership practice was not something participants had experienced before, as most professional development opportunities involve the transfer of knowledge from the facilitator to participant rather than the sharing of practice between group members.

I think it's listening to how other people deal with things and I don't think I've had the opportunity to do that before ... to have access to talk to people about or just even to listen to them talk about the problems they're having and how they feel about it and what they do about it. (Isabel, I)

This emphasis on leaders learning from each other is similar to the approach promoted in the New Visions leadership development programme (National College for School Leadership, 2005; Paterson \& West-Burnham, 2005) discussed in Chapter 2, whereby knowledge is created by interactions between individuals. Stoll, Robertson, ButlerKisber, Sklar and Whittingham (2007) also emphasise the value of leaders developing professional relationships with other leaders from different contexts believing that "it is vital that leaders have 'boundary breaking' authentic community learning experiences across contexts to challenge them to reflect on their values, assumptions about learning and beliefs about pedagogy and policies" (p. 64). The benefits of sharing experiences is also emphasised by Francis and Cowan (2008, p. 329) who suggest that "the learner's experiences become a richer source of critical reflection when enhanced by the experiences of, and interaction with, other learners". 
Hearing different perspectives helped participants gain clarity and identify possible actions they could take with regard to their own leadership goals. Participants from both groups also picked up on other people's goals or ideas and were able to transfer these to their own context. The value of hearing different points of view and different approaches to workplace issues has been emphasised by Marquardt (2004b). He also suggests that multi-problem action learning helps change the approaches people use in their own contexts as the following two examples show:

The other thing that I loved hearing about were your efforts in distributing leadership .... I am already thinking about how I can do this with my own team. (Charlotte, F)

It was interesting to think about Jane's ideas on induction as I took a bit of this and applied it to one of the teachers. (Grace, RJ)

The impact of hearing other group members reflect on the issues they were facing and identifying the actions they intended to take may not have been immediate, but there were longer-term benefits as the following comment shows:

I found it helpful to listen to each person bring up the goal they chose and then everybody's input ... because listening to other people and what they have learnt and the wisdom they have learnt is really helpful because it comes to mind when you come across an issue. You can think about what one of the people in the group has said and think that's one way of handling that. (Heather, I)

Being part of the group and developing a personal relationship with other participants and the facilitator gave participants the motivation to make shifts in their practice, another benefit of group participation as Diana describes:

It gave me the courage and in a sense it was an accountability thing because I said in my journal and I said to these people in chats or in forums or wherever that I was going to do these things and getting that out on paper and telling a group of people who you admire ... made me feel like I had to. (Diana, I)

\section{Reduction of isolation}

One of the most valued aspects of participation in the group was a reduction in the feeling of isolation often experienced by those holding leadership positions in the ECE sector. This isolation can relate to the fact that people holding senior positions are unable to share the issues they are facing with team members in their own settings either because of their sensitive nature, or because team members not holding leadership positions would not understand their perspective. The following comment illustrated how participation in the group allowed participants to share the issues they were facing which otherwise would have remained private: 
It is one of the greatest things about this cluster group, is to have the freedom of speech and professional companionship which we are unable to have in our teams because of hierarchy. I get on beautifully with the teachers at my centre ... but there is still always a certain distance there when it comes to work issues, right? (Charlotte, RJ)

Participants who worked for larger organisations, and who did have colleagues in similar positions to themselves, commented that they would not necessarily feel able to talk freely to these colleagues about leadership issues, because of the lack of a trusting relationship. They appreciated having the opportunity to share freely with other leaders:

I found [the group] really useful and thought provoking and I think we're isolated little islands in our communities now and it's lovely to think that you had things in common and you weren't alone. I really enjoyed listening to the others and where they were at and learning from that too. (Lisa, I)

Hearing others talking about the issues they were facing also helped reduce the sense of isolation described above. The realisation that other people were facing similar problems to them was described by participants as being quite a relief. The recognition that they are not the only one struggling and that others may be facing similar issues can result in people feeling more supported and more confident in their own leadership (Marquardt, 2004b), as can be shown by the following comment:

What I've liked the most about the getting together is that I wasn't on my own in this. I remember acknowledging to Heather that I felt like everybody was going to realise that I was a fraud and she said "oh I felt like that when I first started as well" but actually hearing it within the group. (Jane, I)

\section{Group size}

The small group size made it easier for participants to get to know and trust each other. While six in a group was ideal in terms of the action learning model, it has been suggested that this is quite a small number in terms of generating online discussions. Rovai (2007) recommends 10 students as the minimum number needed in an online group in order that there are enough interactions, and McConnell (2006) used a similar number when forming action research groups for participants enrolled in an online Masters of Education programme. These larger numbers are not, however, appropriate for blended action learning groups. Stewart and Alexander's (2006) study of blended action learning used between four and eight people per set and although they suggest a larger number would have created more lively discussion; they agree that a smaller number is more suitable for the combined face-to-face and online interactions. More than six people would not have worked in a face-to-face action learning context due to the amount of time needed for people to present their issues and be questioned. 


\subsubsection{Support from others}

An important benefit of participation in the group was the support received from other group members. This was particularly evident in LALG1 due to the large number of forum discussions. An example of the kind of supportive comments given to other group members is the following forum posting made in response to an updated goal:

You are very insightful and knowledgeable about yourself and your team. It's great how you are putting in the positive work now and empowering your team members. If they are anything like my team members, their commitment and enthusiasm will really increase - along with your sense of achievement and effectiveness as a leader. Well done! (Diana, F)

This support was greatly appreciated as the following comment from a chat session illustrates:

I honestly don't know how I would have coped without all the support from you and the group Kate. (Amy, C)

The wisdom and input of the more active group members were particularly appreciated because the more interactions there were the richer the learning experience for other participants, as the following comment shows:

I feel particularly grateful for the more active members of the group, who are so dedicated and intelligent and helpful and kind and professional at the same time. (Charlotte, RJ)

Participants in both groups developed trust in each other and in the facilitator and were therefore able to share the issues they were facing no matter how personal. The importance of developing trust in professional learning communities has been emphasised by Hargreaves (2007) who suggests that an atmosphere of trust allows emotional issues to be surfaced. Brockbank and McGill (2007) stress the value of learners being able to express their emotions as they believe that this may help deepen the learning experience. This view is supported by Marquardt (2004b, p. 38) who suggests that multiple format action learning tends to illicit "the personal, heartfelt, and urgent problems faced by individuals, who otherwise may feel alone in trying to resolve the issues". The importance of creating a climate in which feelings and emotions can be honestly expressed and accepted has also been stressed by Boud and Walker (1998) in a discussion of contexts that support meaningful reflection.

The expressions of empathy that characterised the group interactions particularly at face-to-face meetings and also in some online interactions also helped strengthen the group relationships. Empathy has been defined as "an understanding of the world from 
the other's point of view, her feelings, her experience and behaviour, and of the communication of that understanding in full" (McGill \& Brockbank, 2004, p. 176, original italics). Understanding each other's contexts and the sometimes lonely position that leaders found themselves in was helpful in encouraging participants to address issues and develop leadership strategies. An example of an expression of empathy is the following comment made in response to a leadership goal posting:

I REALLY identify with your goal!! I have exactly the same questions for myself right now, and look forward to learning alongside you as you tell us about your actions. (Charlotte, F)

The confidentiality agreements made at the beginning of each group were important in allowing participants to feel able to explore the issues and problems they were facing in more depth.

It's better professional development for me personally because I don't have to worry about what I'm saying and often in professional development you do and that means that you can go through those layers and work out problems by talking and also by typing. So that it's the confidentiality part that is probably the most significant in terms of more learning, getting more depth out of it. (Grace, I)

The confidentiality agreements helped participants to be open and honest in their interactions as did the fact that the groups had a diverse membership, a factor which will be explored in the next section.

\subsubsection{Group diversity}

Having a range of service types, rather than having all participants from one service such as kindergarten, and also having differing amounts of leadership experience in the group, was also seen to be positive.

I think having a range of people with a range of experiences and services was really useful in that you got a more diverse group of people. (Fiona, I)

I think I gained more from it because they were from different areas of early childhood and the different situations that were having to be dealt with within the different organisations. (Isabel, I)

Diversity in group member characteristics such as age, experience, gender and ethnicity is believed to contribute to the success of action learning groups, as according to Marquardt (2004b, p. 51), "people with different perspectives will challenge our assumptions". Although the research group participants were the same gender and of similar ethnicity, a reflection of people occupying formal leadership positions in New Zealand ECE services, there was diversity in age, experience and service type. 
Marquardt also emphasises the value of having organisational diversity in multiproblem action learning groups suggesting that "most of us are able to be more open and honest with people who are not working with or for us" (p. 37). This view was supported by participants who found that having this group quite separate from one's work and personal life was an advantage and that being in a group with members from a variety of organisations meant that people could open up more.

I am amazed at the comfort this group brings to me. I love the feeling of having a secret support network - secret in that it is private and hidden from anyone in my real life. This offers such a unique sense of safety and quiet. (Charlotte, RJ)

I was able to be completely honest in the group knowing that I'm not bumping into them on a daily basis. (Jane, I)

\subsubsection{Section summary}

The perceptions of participants indicate that involvement in the action learning groups had a number of benefits including: the sharing of practice which led to an increased awareness of different perspectives; a reduction in isolation; and the support received from others. Participation in these groups has similar benefits to participation in communities of practice, that is the chance to share knowledge and practices. As was discussed in the literature review, participation in action learning groups requires a higher level of commitment than does participation in communities of practice, which are larger and have a greater focus on practice. The high level of trust that developed in each group encouraged the sharing of emotional issues and this helped deepen the learning experience. The diversity of the group and the small group size also contributed to its effectiveness. Participation in the blended action learning groups, where there was an emphasis on shared learning rather than transmission of knowledge, encouraged cooperation and empowered participants to take control of their own learning.

\subsection{Using the different technologies}

This section of the chapter presents the views of the participants on the different technologies available on the site: reflective journals; forums; and chat sessions. Although a wiki was used to record the interactions of two of the meetings of LALG1, it was not really picked up on by participants and did not make a valued contribution to the leadership learning process. Emails were another available tool; however, these were primarily used by the facilitator to encourage participation, and to give information about meetings or the use of the site and therefore will not be discussed in this section. 


\subsubsection{Online reflective journals}

All participants commented on the value of the online reflective journal and several specified that it was the most important tool available on the online site. Some of the comments regarding the benefits of journalling are given below:

I did really like the online journals. I think again for me because it's written and I do think a lot as I write, I think also having it shared with you was good again in that you're accountable, but also your questions did raise other questions and other points and I think that's really useful. (Fiona, I)

When I start writing then the more you write, the more you make sense of what you're thinking which is good. (Heather, I)

These comments reflect previous research that found journalling encouraged reflective practice (Loo \& Thorpe, 2002). Recommendations from Loo and Thorpe's study include: that objectives are provided to help in the structuring of journals; that participants are reminded to do entries; that they are given regular feedback; and that facilitators also keep a journal so that they understand the process. All these guidelines were followed in this study including the provision of resources on reflective journalling which offered different formats and ideas for getting started. The use of reflective journals to support learning and foster reflection in blended learning environments has been promoted by Garrison and Vaughn (2008) and reflective journalling to support action learning has also been recommended (O'Neil \& Marsick, 2007).

The reflective journal was used in a variety of ways. Some participants used the journal more as a diary to record leadership related events, whereas most engaged in varying levels of reflection. Hatton and Smith (1995), in their discussion of reflection in teacher education, propose four types of writing, three of which are forms of reflection. The four types of writing are: descriptive writing (non-reflective), descriptive reflection, dialogic reflection and critical reflection. Descriptive reflection involves a description of events that also has a reflective element and may involve the recognition of alternative viewpoints. Dialogic reflection is characterised by a stepping back from the event or issue being reflected on and involves a more analytical view. Critical reflection demonstrates an awareness of multiple viewpoints and takes account of the broader context. Examples of all these forms of reflective writing could be seen in reflective journal entries as is shown in Table 6-2 below: 


\begin{tabular}{|c|c|}
\hline Reflection Type & Example \\
\hline $\begin{array}{l}\text { Descriptive } \\
\text { reflection }\end{array}$ & $\begin{array}{l}\text { The new format head teachers' meeting last Thursday went really } \\
\text { well - I ran the first hour and then [name] took the chair for the } \\
\text { second hour and really good discussion ensued. Next week } \\
\text { [name] will chair the second hour, and so on until I hope } \\
\text { everyone will have a turn. We discussed privacy, the Act, issues } \\
\text { arising, our practice, TR etc. [name] was well prepared and it was } \\
\text { a valuable session. I suggested the change to give others more of a } \\
\text { say and to give them the experience that differs from chairing } \\
\text { their own staff meetings. It also stops me talking too much and } \\
\text { taking over the whole } 2 \text { hours. (Karen) }\end{array}$ \\
\hline $\begin{array}{l}\text { Dialogic } \\
\text { reflection }\end{array}$ & $\begin{array}{l}\text { Later in the week I also spoke to her assertively about how I saw } \\
\text { her response to a parent and how that parent viewed her } \\
\text { response. This was difficult and I was angry at the time and } \\
\text { would like to be able to be more assertive without the emotional } \\
\text { issues coming to the fore, and get us to a point where we can look } \\
\text { at each other's viewpoints, I have a dominant personality when I } \\
\text { analyse myself which isn't always ideal so I need to do some work } \\
\text { on accepting other viewpoints as well. This seems to be an area } \\
\text { that I move away from - emotional confrontations or where there } \\
\text { are very different perspectives - an area to work on I think. (Beth) }\end{array}$ \\
\hline $\begin{array}{l}\text { Critical } \\
\text { reflection }\end{array}$ & $\begin{array}{l}\text { After reading the initial entries into my forum, I went to re- } \\
\text { read Rodd's chapter - I had read it some time ago. As I read it, } \\
\text { I felt a 'niggle' which I couldn't quite define. I decided to leave } \\
\text { it at that, and come back to read the chapter again in a few } \\
\text { weeks. I did this last weekend. As I read, I realised what was } \\
\text { bothering me. The process by which to resolve a conflict is } \\
\text { straightforward and sensible, however it assumes that those } \\
\text { resolving the conflict have the professionalism and rational } \\
\text { ability to move from their 'conflict emotions' to defining } \\
\text { 'conflict issues'. (My terms.) I just don't know if my staff } \\
\text { members are at this point - and to be perfectly honest I don't } \\
\text { know if I possess these skills either. It made me realise that I } \\
\text { expect my staff to follow a resolution process, without having } \\
\text { actually trained or equipped them to do so. (Diana) }\end{array}$ \\
\hline
\end{tabular}

(Hatton \& Smith, 1995)

Table 6-2: Levels of reflection 
In general, the more active participants engaged in more dialogic and critical reflection, whereas the less active participants, who tended to write shorter journal entries, engaged mostly in descriptive writing and descriptive reflection. These levels of reflective writing can be linked to the different modes of learning, shallow, deep and profound (Paterson \& West-Burnham, 2005) discussed in Section 2.7.2 of the literature review and in the leadership journey chapter. While all types of reflection are likely to lead to deep learning, critical reflection is most likely to encourage triple loop learning and contribute to profound learning.

Several participants appreciated being able to pour their hearts out in the journal and used it to process their thoughts when they were facing difficult situations at work:

I'm sure with all of us at the times of our need the input was much greater. I found when I needed the diary [journal], it was fantastic. (Beth, I)

The confidentiality agreements and the fact that individual reflective journals were only accessible to me meant that participants felt able to freely share their feelings and emotions. The importance of confidentiality in journal writing is emphasised by Moon (2006) who suggests this will lead to honesty and more in-depth reflection. Moon also discusses the value of journalling in encouraging the expression of emotion, suggesting that the process of journal writing allows emotions to be surfaced and leads to increased confidence. This view is supported by Boud (2001) who suggests that journal writing can help learners work through strong emotions which may otherwise inhibit future reflection and learning. It has also been suggested that the sharing of strong emotions through critical reflection encourages double loop learning (Brockbank \& McGill, 2007).

The value of the responses made by the facilitator to reflective journal entries will be explored in depth in Chapter 7.

\subsubsection{Online forums}

There were a number of different types of forum discussions on the online site including forums where participants posted their goals, forums where group members posted reflections on articles they had written, and forums where participants who wanted ideas from other group members on various topics such as induction procedures or interview questions started discussions. A sample forum discussion is included as Appendix F. As mentioned in the previous chapter, a large number of forums were started by LALG1 members and not so many by LALG2 members. Forums were seen to be useful by some participants for sharing ideas and their focused nature was also valued: 
I find them really useful. I feel like the things that people write there and that I write there are a bit more considered. I think that you get some really useful feedback and ideas and questions and things in that context. (Charlotte, I)

Having different viewpoints in the forum discussion was also seen to be useful:

I found when we put up our issues and everyone gave quick fire - that was good once again it made you think about things and different perspectives. (Beth, I)

Jane from the second research group, who started two forum discussions, commented that it was the process of writing her thoughts down that was helpful:

The start of the forums wasn't so much looking for answers. It was like using the diary [journal] in a public sense, putting it out there. (Jane, I)

Overall, forum discussions were valued by participants because they could be accessed at any time, supported the sharing of ideas, and provided a record of leadership goals and discussion. A study of the effect of asynchronous online discussions on student learning in a blended learning environment (Wu \& Hiltz, 2004) supports this view of the value of forum discussions. Students in Wu and Hiltz's study appreciated the flexibility and convenience of forums, and the opportunity to share experiences. The Moodle platform made it easy for participants in the current study to start and contribute to forum discussions, and hence provided an opportunity for participants to share in the facilitation and shape the directions of the action learning group discussions. This ability of participants to be able to address authentic topics and issues of personal interest in forum discussions is also emphasised by Rovai (2007), who suggests that the discussion of topics meaningful to students increases their motivation.

\subsubsection{Online chat}

The chat, the only synchronous tool on the online site, was seen as the least useful technology in terms of the learning process, but was seen to be important in terms of the social aspect of the group, particularly in the early stages when people did not know each other as well.

The chats I did think were useful for keeping everyone in touch. I really did think that they had a place for that reason if not for any kind of leadership learning really. (Fiona, I)

These views on the efficacy of chat reflect an earlier study that found synchronous forms of interaction to be "useful in building a sense of community and connection with other online learners and less useful in building cognitive presence or task accomplishment" (Stein et al., 2007, p. 105). This study also reported that chat sessions complement other interactions as "the informal nature of a group chat lends itself to 
exploring different perspectives in a way that more formally written discussion postings do not" (p. 111). The value of using a synchronous online tool to strengthen group identity has been emphasised by Anderson (2006) who suggests that synchronous tools enhance social presence.

Many participants had never participated in a chat session before and were unsure what to expect:

With the chat line I didn't even know what to expect I didn't know whether we would be talking about some of the issues on the chat line but then I thought it's just to get to know each other and very personal. (Lisa, I)

Although chat sessions were synchronous, there was a slight delay in sending and receiving messages and when there were a number of people involved, responses to comments were often separated by other comments. This phenomenon has been described as a serious flaw by Looi (2005); however, although it caused confusion at times, it did not seem to worry participants as the following comment shows:

Actually, the tricky timing thing just adds a bit of humour to it! It was nice to have a more immediate form of contact with some group members... I think it will add to the level of familiarity and trust in the forums and other activities. (Charlotte, RJ)

The chat sessions were often where participants' senses of humour emerged. In the first LALG2 chat session when all but one participant was logged on, a comment on the greeting process started the following conversation:

\begin{tabular}{|l|l|}
\hline Jane: & Oh hi Karen too \\
\hline Grace: & Hi Heather \\
\hline Karen: & $\begin{array}{l}\text { Hello Jane, this feels a bit like an up to date version of The Waltons as } \\
\text { we name each other... }\end{array}$ \\
\hline Grace: & You can be Mary Ellen Karen \\
\hline Karen: & Thank you Grace - always aspired to a name change! \\
\hline Isabel: & Well I'm not going to be john boy \\
\hline Jane: & Me neither, I don't remember the Waltons \\
\hline Karen: & $\begin{array}{l}\text { OK I admit to being the oldest and remembering the Waltons - very } \\
\text { cheesy American show }\end{array}$ \\
\hline
\end{tabular}

Table 6-3: Sample chat conversation

Subsequent chat sessions with this group featured conversations on the fate of a rabbit eating the lettuces in the garden of one of the participants, and alternative career pathways for disillusioned ECE teachers. 
This lighter side of chat sessions was valued by members of both groups particularly after a long day at work, and an advantage of chat over other means of communication was that it sometimes revealed another side of participants that would not otherwise have been shown:

Sometimes it was just frivolous chat about the cat had to go to the vet or something like that and I think that's all good stuff as well .... I thought that was really human and that lets you see another side of these people that maybe if you'd just been in a group physically you wouldn't have shared that sort of stuff with but you're kind of sitting there by yourself and you're feeling a bit frivolous or mischievous or whatever and I think it's good. (Isabel, I)

The value of chat for getting to know people as individuals has been promoted by MacDonald (2008) who suggests that it can fulfil the role of casual conversations in a face-to-face environment. The personal interactions that occurred both in chat sessions and in face-to-face meetings when we had an icebreaker round of trauma, trivia and joy, helped build trust between group members. Bird (2006) suggests that personal disclosure is just as likely to happen online as face-to-face but may take more time. Having the face-to-face interactions first certainly encouraged the personal disclosure and this was continued in the regular chat sessions. Although it was the lighter side of chat that stuck in people's minds, opportunities were taken to discuss issues of relevance to group members such as staff shortages, non-contact time and Education Review Office visits.

LALG2 experienced some problems in later chat sessions because they were unable to type in responses or they suddenly lost their connection. These difficulties were the focus of several comments made by participants in chat sessions:

Hi to all that are logged on and are allowed to participate according to IT law!!! (Isabel, C)

Isn't modern technology a pain - I may be on for the duration but may not - if I suddenly leave it is NOT by choice - Hi all. (Karen, C)

\subsubsection{Section summary}

Overall participants valued all of the technologies used on the online site, as they saw them as having different purposes. The online journal provided an opportunity for deep reflection on a personal basis and the responses made by the facilitator assisted in this process as will be seen in the next chapter. The various forum discussions provided an opportunity for participants to share the goals they were working on and to discuss issues related to their work contexts. Chat sessions also allowed participants to discuss issues and keep in personal contact between face-to-face meetings. The use of a variety of media fits with the theory of media synchronicity discussed in Section 2.7.1 of the 
literature review chapter which promotes multiple media use (Dennis et al., 2008; Dennis \& Valacich, 1999). The reflective journals and forum discussions are characterised by lower synchronicity and support conveyance as they allow for information exchange and then consideration. Chat sessions on the other hand have relatively high synchronicity, support convergence, and offer a greater level of interaction and immediate feedback.

The permanent record of interactions provided by Moodle was appreciated by participants; unlike face-to-face interactions, the content of chat sessions, forum discussions and journal entries could be revisited. This permanence is seen as one of the benefits of online interactions (Garrison \& Vaughn, 2008). The combination of asynchronous and synchronous tools is seen to provide for the different communication styles of individual learners and to minimise communication barriers (So \& Brush, 2008). The use of a range of synchronous and asynchronous tools in order to accommodate a diversity of learners is also recommended by MacDonald (2008). As was mentioned in Chapter 5, while some participants preferred reflective journalling, others preferred forums or chat sessions. The multiple tools available therefore supported the need for a range of options.

\subsection{Ongoing interactions}

At the end of the data gathering phase of the research, both groups decided they wished to continue meeting and interacting. LALG1, for whom data collection finished at the end of 2007, continued meeting through 2008 and decided they wished to continue meeting in 2009. LALG2, whose data collection phase ended in June 2008 continued meeting for the remainder of that year and also into 2009. The members of both groups agreed that they would take turns at organising and facilitating the meetings in 2009. Despite this agreement, the facilitator still needed to take a role in organising the meetings and although participants took some responsibility, the action learning groups did not become self-sufficient. After the conclusion of the data collecting phase of the research the meetings were not held as frequently and the majority of the interactions occurred face-to-face rather than online. Although several participants continued to write in their reflective journals and email the facilitator, the only interactions between group members happened at the ongoing face-to-face meetings or at a personal one-to-one level. However, the interactions were still highly valued by participants. Several group members commented that they thought the strong relationships built through the process meant that group members would keep in contact at the conclusion of the research process.

\subsection{Chapter summary}

Data collected from both research groups strongly support the benefits of using ICT to support leadership development. Participants valued the blended learning approach; the face-to-face meetings were seen to be important for establishing and maintaining 
relationships and for practising action learning whereas the online postings and interactions encouraged reflection and leadership learning. Participation in the group was perceived to reduce the feeling of isolation experienced by those in leadership positions. The small group size appeared to support the development of trust between participants and it was evident from the data that all participants felt a sense of commitment to the group. The diverse membership of the groups exposed participants to different ideas and practices, and the confidentiality agreements encouraged honest and meaningful sharing of experiences and reflection. All the technologies used were valued as they offered different and complementary approaches to the leadership learning process. Overall the evidence indicates that the blended action learning process enabled and empowered participants to work through issues they were facing and in the process they developed greater self-awareness and confidence in their leadership practices. 


\section{Role of the Blended Action Learning Facilitator}

"Someone who will provide new lenses through which learners can refocus on their work." (Costa \& Kallick, 1995)

\subsection{Chapter overview}

One of the aims of this research is to explore the role of the blended action learning facilitator. This chapter outlines the role I took in this study as blended action learning facilitator and also presents participant perspectives from both research groups about my facilitator role. The chapter begins with an account of my facilitation experiences. This is followed by a discussion of participant perspectives of different aspects of my role, and my reflections on the various aspects of the role. The facilitator role is then analysed with reference to relevant literature, and a model that illustrates the different aspects of the facilitator role put forward. This is followed by the presentation of a model of stages of blended action learning facilitation, and the chapter concludes with some recommendations for future blended action learning facilitation.

\subsection{Facilitator experiences}

This section will begin with a definition of the facilitator role and discussion of my previous online facilitation experience. This will be followed by an account of my preparation for, and execution of, this blended facilitation role.

\subsubsection{Facilitator or action learning coach?}

Different terms are used for the facilitation role taken in action learning groups. Marquardt (2004b) makes a distinction between a facilitator and a learning coach, suggesting that while a facilitator focuses on group process and motivates participants, a learning coach focuses on learning and empowers participants. He rejects the use of the term facilitator in the context of action learning as he sees this as a controlling role fostering dependence; whereas the action learning coach according to Marquardt encourages independence through the fostering of reflection and critical thinking. McGill and Brockbank (2004) take an opposing view, suggesting that the term facilitator is appropriate as it implies a rendering of assistance. Heron's (1999, p. 1) definition of a facilitator as "a person who has the role of empowering participants to learn in an experiential group" also fits well with the role taken in this research, hence the term facilitator will be used in the discussion of this role. 


\subsubsection{Previous experience in blended facilitation}

The role of online facilitator was relatively new for me although I am an experienced facilitator in the area of face-to-face professional development. My only previous experience in online facilitation had been with a work group in 2006 and this had not been particularly successful. Reasons for this lack of success included that: participation in the online activities was voluntary so not all participants in the leadership cluster group actually used the site; the site was not ready to use immediately after the group met as it took a while to set up; and the site was not easy to use once participants were able to access it. From this experience I learnt some useful lessons that I was able to transfer to the research groups. These included that it is important to use a userfriendly online learning platform and to have the site operational at the time of the first group meeting, and also that it was important to have the participants able to start discussions rather than just responding to facilitator postings.

\subsubsection{Preparation of the online learning site}

I spent several weeks before the first LALG1 meeting setting up the Moodle site with some assistance from the hosting company. This included customising the site, adding activities and resources and generally becoming familiar with the features. The value of dedicating time to the design of e-learning experiences is emphasised by Garrison and Anderson (2003) who suggest that it may be a more complex process than designing a face-to-face learning experience. I also wrote a two page instruction sheet to help participants access and use the site and made sure pictures of all participants were taken at the preliminary interviews and posted prior to the first meeting. A new course within the site was set up for the second research group and was configured in a similar way to that for the first group.

\subsubsection{Ongoing facilitation}

Online facilitation began with an email the day after the first meetings to let participants know what the first online tasks were. My previous experience had shown the importance of getting people to use the site as soon as and as often as possible and I think my frequent emails encouraged this. The importance of the introductory and orientation stages of an e-learning experience to later motivation has been emphasised (Garrison \& Anderson, 2003); therefore my explanations and encouragement were likely to have been valuable. I also acknowledged people's responses promptly and tried to be encouraging and supportive. Examples of emails sent to both groups in the first few weeks with the purpose of encouraging their participation are presented in Table 7-1 below. 


\begin{tabular}{|c|c|}
\hline $\begin{array}{l}\text { LALG1 } \\
\text { week } 1\end{array}$ & $\begin{array}{l}\text { Morena everyone, } \\
\text { I was very excited to go onto the website this morning and find so many } \\
\text { postings! Thank you to all of you who have added your profiles and goals } \\
\text { and started on your reflections. Thanks also for enabling your email } \\
\text { addresses and where appropriate changing them to personal addresses. I } \\
\text { notice that the whole forum posting is sent by email and will look at } \\
\text { whether I can alter the settings to change this. Will let you know. } \\
\text { You may have noticed that I have rearranged the topics on the site so it is } \\
\text { easier to access the assignments, forum and chats. This means that the } \\
\text { numbering I put on the instruction sheet now no longer applies but } \\
\text { hopefully this isn't a problem. } \\
\text { Don't forget the first chat time is this afternoon at } 1.30 \text {. I look forward to } \\
\text { talking with some of you. } \\
\text { Keep warm, } \\
\text { Cheers, Kate }\end{array}$ \\
\hline $\begin{array}{l}\text { LALG2 } \\
\text { week } 2\end{array}$ & $\begin{array}{l}\text { Kia ora everyone, } \\
\text { Thank you for your postings so far and for the replies to each others' goals. } \\
\text { In the information I gave you the day we met I included a sheet with some } \\
\text { guidelines for participation (a copy of which is also posted on the site). I } \\
\text { didn't go through these with you though hope you have had a chance to } \\
\text { read them. With regard to the journal entries, I suggest that you try to do } \\
\text { an entry at least once a week, rather than waiting for something of great } \\
\text { significance to write about, even if it is very brief. This will get you in the } \\
\text { habit of journal writing. } \\
\text { It will also be great to see people starting some forum discussions. These } \\
\text { could be about something you would like other people's ideas on such as } \\
\text { time management or about an issue you are dealing with. Instructions on } \\
\text { starting a forum are on the instruction sheet. I also look forward to } \\
\text { someone starting a discussion on one of the articles or book chapters } \\
\text { posted on the site. Please get in touch with me if the instructions I have } \\
\text { given you on how to begin discussions aren't clear. } \\
\text { I'm looking forward to our chat tomorrow night, } \\
\text { Regards, Kate }\end{array}$ \\
\hline
\end{tabular}

Table 7-1: Facilitator emails to encourage participation 
The frequent sending of emails to both groups and individuals continued throughout the time each action learning group was active. Emails included reminders about meetings and chat times, information about changes to the site, and about online learning processes. Sometimes emails contained information about new initiatives or ideas regarding the use of ICT in services. In addition to keeping in touch via email, I endeavoured to respond promptly to each new journal entry and forum posting. Sometimes I was uncertain whether to be the first person to respond to a new forum posting; although I wanted to be supportive, I also wanted to encourage interactions between participants. Storck and Storck (2004) recommend that the leader in an online community of practice should not start discussions or post near the beginning of discussions so as to encourage group participation. I concurred with this principle and believed that in many cases other participants' contributions were more valuable than mine as they were more likely to understand each other's issues and to respond accordingly. I also had the opportunity to interact regularly with individual participants via the online journals.

The facilitator's level of activity in online learning environments has been the subject of other research. Rovai (2007) developed some principles for online instructors as a result of his synthesis of relevant research literature on effective facilitation. These include: that facilitators should not respond too quickly in order to encourage student responses; that encouragement should be provided and challenging questions asked; and that discussion forums should be monitored and closed off when topics have run their course. The dilemma of deciding on the appropriate level of participation has been discussed by Mazzolini and Maddison (2003), who suggest that the instructor role in an online discussion forum can vary from very prominent, a role described as a 'sage on the stage' to less prominent, a 'guide on the side'. These authors believe that the optimal degree of instructor visibility will vary according to the purpose of the discussions. Where the aim of the interactions is to encourage student-student interactions, then the instructor should stand back to encourage others to participate. Students in their study did, however, appreciate frequent contributions by their instructor and as will be discussed in a later section of this chapter, the degree of facilitator input will vary as the group becomes more established and has different requirements.

\subsubsection{Section summary}

Facilitation of blended action learning groups differs from facilitation of face-to-face groups in a number of ways. Although some of the interpersonal skills required are the same, the role requires a greater degree of flexibility and there is a greater emphasis on encouraging participation and on promoting self-directed learning. These different roles will be explored in more depth in a later section of this chapter. 


\subsection{Participants' perspectives on the facilitator role}

Participants were asked to comment on the facilitator role in both follow-up interviews. Comments were also made on the online site in reflective journals, chats and forum discussions. Different aspects of the facilitator role will be discussed in the following section. This discussion will include facilitator reflections and where appropriate relevant literature.

\subsubsection{Role in relation to different technologies}

The facilitator role in relation to the different technologies used in the blended action learning process will now be discussed. This section will include facilitator reflections, examples of responses and participant comments.

\section{Online reflective journals}

One of the most challenging aspects of facilitating these groups from my perspective was deciding how to respond to the online reflective journal entries. The importance of those responding to reflective journals being very clear about their purpose and influence is emphasised by Fenwick (2001), who suggests that facilitators should enter the process of responding as "gentle others interested in meaningful dialogue, offering encouraging and substantive responses, and committing ourselves to the importance of journaling in learning" (p. 46). The reflective journals in this study were very personal documents and often contained emotional responses to people and situations. It has been suggested that the provision of feedback on reflective journals requires great sensitivity (Moon, 2006) and this was certainly the case in this research. I was aware of trying to be supportive yet professional in my responses. After a couple of months of responding, I realised that the most effective responses involved acknowledging feelings followed by questioning to encourage reflection. The process I used in responding to journal entries is illustrated in Figure 7-1 below: 


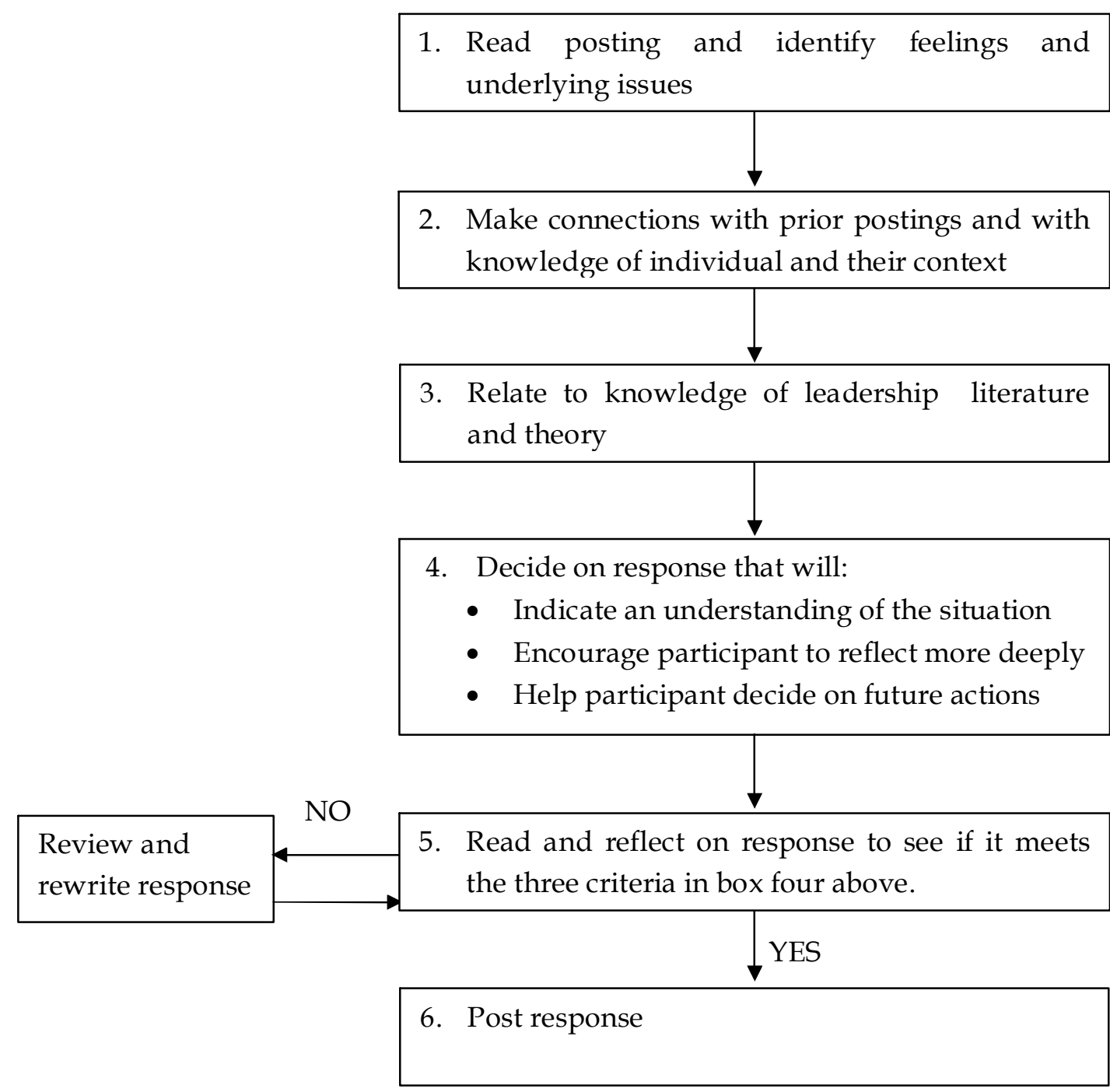

Figure 7-1: Process used in formulating responses to journals

Examples of some of the responses I made are given in Table 7-2 below:

\begin{tabular}{|l|l|}
\hline $\begin{array}{l}\text { Response } \\
\text { to Amy }\end{array}$ & $\begin{array}{l}\text { You must feel really pleased about your time as a relieving head } \\
\text { teacher. Even though you probably knew yourself that things had gone } \\
\text { well, it would have been lovely to receive all the positive feedback. } \\
\text { Do you think it is going to be challenging to go back to your job and not } \\
\text { have designated leadership responsibilities or do you think you have } \\
\text { enough leadership opportunities within your current role? } \\
\text { I look forward to reading your new goal. }\end{array}$ \\
\hline $\begin{array}{l}\text { Response } \\
\text { to Lisa }\end{array}$ & $\begin{array}{l}\text { Thank you for clarifying this Lisa. It can be hard to help someone with } \\
\text { an issue if they don't see there is an issue to address. How do you think } \\
\text { you can raise [name] awareness of her behaviour and what effect it has } \\
\text { on others? Could you share some of your observations regarding } \\
\text { interactions you have observed [name] having and get her to reflect on }\end{array}$ \\
\hline
\end{tabular}




\begin{tabular}{|l|l|}
\hline $\begin{array}{l}\text { what was happening in these situations? You may need to be quite } \\
\text { specific about behaviours and ask things like 'what could you have } \\
\text { done differently?' and 'what effect do you think this had?' Hope the } \\
\text { articles are of some use and if not I may have others. Look forward to } \\
\text { hearing how you get on. }\end{array}$ \\
\hline
\end{tabular}

Table 7-2: Facilitator responses to reflective journal entries

The balance of challenge and support that I endeavoured to provide was picked up by a participant when she was asked about the sort of things I did that made her think.

Questions that you'd ask, and supportive comments like just acknowledging how people are feeling and things like that. Because sometimes you just need that support and then maybe the odd question to get you thinking on the right track. (Amy, I)

The fact that the responses to the journals were written meant that participants had time to reflect on the responses as the following comment from a reflective journal illustrates:

Thanks for your feedback Kate, I do find it really, really helpful and I think that because it's in written form it gives me time to think about it and you feel challenged sometimes by the comments but because it's not face to face, there's no need to get defensive so the ICT part has a real bonus here too. (Fiona, RJ)

A number of different roles taken in responding to reflective journals have been discussed by Fenwick (2001). Some of the roles relevant to the facilitator role in this study include:

- Comforter - affirming the writer's strengths and interests;

- Mirror - reflecting the writer's thoughts and themes;

- $\quad$ Provoker - challenging and questioning the writer;

- Learning director - assisting the writer in seeing the learning journey unfold; and

- Friend in dialogue - showing agreement and occasionally offering advice.

The responses made to the journals varied according to the type of reflection being shared. The more in-depth the journal reflections were, the more opportunity I had to question and to challenge the thinking of participants. Reflective rather than descriptive entries (Hatton \& Smith, 1995) made it easier to encourage critical reflection and deeper learning. When participants shared less of themselves and wrote only factual accounts of their practice, reflection was more difficult to encourage.

For active participants such as Grace from the second group, the responses added considerably to the already valuable process of writing a reflective journal. She 
compared the feedback received on journal entries to the benefits of a high impact workout:

You can do your own reflective journal but the feedback; it's like doing a workout. If you go to the gym and do an hour's workout you can burn 500 calories but if you've got 10 minutes afterward when you do a high impact, you can burn off three times the number of calories. Just to illustrate, you're getting a heck of a lot more value by doing that little bit extra so it's a bit like that, that there is immense value in doing your own reflective journal without getting any feedback but in terms of reflection, the feedback that you gave in that question format or the affirmations too. "It must have been really difficult for you" those sorts of things, yes it was, that makes me feel good, someone has recognised that which feels nice. So that made the reflective journals for me anyway, work three-fold, in terms of reflection. (Grace, I)

\section{Forums}

I did not have such an active role in forum discussions as I did in journals and chat. The aim was to be supportive and encourage other group members to respond and participate in discussion. Examples of my responses are given in Table 7-3 below:

Thanks Karen for starting our discussion on this chapter. Who else has read it and what do you think about the ideas presented?

Thanks for this Fiona - a great start. I look forward to reading other people's thoughts.

I agree that having a shared vision is very important. What have you tried so far to get people involved in rewriting the vision? Some other group members may have some ideas for what may work in this situation. Suggestions anyone?

\section{Table 7-3: Facilitator responses to forum entries}

As discussed in Section 7.2.4, I took the 'sage on the side' role (Mazzolini \& Maddison, 2003) as I endeavoured to encourage interactions between participants. This aspect of my role was commented on by one participant:

In the forums you are like a wise voice; a very appreciated tutor. (Charlotte, RJ)

Rovai (2007) discusses what he sees as the crucial role of instructors in facilitating online discussions. He recommends giving positive feedback on postings but not becoming the centre of attention by taking too active a role in online discussions. In an earlier article, Rovai (2000) discusses the need for facilitators to find a balance between providing immediate feedback which reassures participants and allowing responses from other participants which encourages group interactions. 


\section{Chats}

My role in chat sessions depended on how many group participants were involved in each session. With the first research group, no chat time could be found when everyone could participate so initially three different times were agreed on and later this was reduced to two. When there was only one participant on chat, the conversation often focused on issues facing that participant, whereas when there was a larger group of participants, conversation tended to vary between discussion on work issues and lighter and more social discussions. The following extract of a chat involving three participants and myself shows that balance.

\begin{tabular}{|c|c|}
\hline Diana: & $\begin{array}{l}\text { Charlotte - the best thing for me when I am a bit busy or stressed is } \\
\text { a good laugh. I am really enjoying the 'silly' part of this chat because } \\
\text { I need a good laugh at the moment - so thanks guys! Sometimes if I } \\
\text { can't find anything else to laugh about, I go and get a good comedy } \\
\text { DVD and have a laugh that way. }\end{array}$ \\
\hline Charlotte: & $\begin{array}{l}\text { That's great advice! I am reading a very entertaining book at the } \\
\text { moment and it is working well for escapism }\end{array}$ \\
\hline Kate: & $\begin{array}{l}\text { Charlotte - would you like time for a discussion on keeping on top } \\
\text { of things - could we do it online? }\end{array}$ \\
\hline Amy: & $\begin{array}{l}\text { I will have to have a go at that. It is hard when you're stressed } \\
\text { though Charlotte, laughing is great for breaking tension but doesn't } \\
\text { always get the work load done though. }\end{array}$ \\
\hline Diana: & $\begin{array}{l}\text { I'm a fan of escapism - in appropriate doses - it can really provide } \\
\text { balance in my life! } 9\end{array}$ \\
\hline Charlotte: & $\begin{array}{l}\text { Maybe online is a better idea. I just wondered if people had tips } \\
\text { they'd be happy to share, probably perfect for a forum. }\end{array}$ \\
\hline Diana: & $\begin{array}{l}\text { You're right Amy, it doesn't get the workload done. For me though, } \\
\text { a good laugh (for not too long a time) can really refocus me and } \\
\text { make me much more efficient. }\end{array}$ \\
\hline Amy: & I guess it depends what you are stressed over? \\
\hline Diana: & Very true. \\
\hline Kate: & $\begin{array}{l}\text { Yes I think it would work as a forum, that gives people time to think } \\
\text { \& they can add suggestions as they think of them Charlotte }\end{array}$ \\
\hline Charlotte: & $\begin{array}{l}\text { One tip I got when I started this job was to do one thing at a time. } \\
\text { Apparently multi-tasking is making us stupider. I am a chronic } \\
\text { multi-tasker in the office... I swivel my chair from the laptop to the } \\
\text { PC to the filing cabinet and back, with several pieces of paperwork } \\
\text { in my lap. }\end{array}$ \\
\hline Amy: & $\begin{array}{l}\text { Yep I think I must be stupid too then cos I like to multi task too. One } \\
\text { tip I got was to try and only touch each piece of paper once deal } \\
\text { with it then file it. I do it sometimes. }\end{array}$ \\
\hline
\end{tabular}




\begin{tabular}{|l|l|}
\hline Kate: & $\begin{array}{l}\text { I think that is a bit of a personality thing - some people seem to be } \\
\text { very orderly and sequential in their work \& others of us tend to be } \\
\text { more random! }\end{array}$ \\
\hline Diana: & $\begin{array}{l}\text { It would be great as a forum Charlotte - I think all of us would be } \\
\text { interested in exploring other people's ideas. Gosh - I just had a } \\
\text { picture of myself Charlotte on my swivel chair - it describes me so } \\
\text { well! Amy - along the same lines, I was once told - don't put it } \\
\text { down, put it away. }\end{array}$ \\
\hline Charlotte: & $\begin{array}{l}\text { That's also excellent advice Amy ... I'm going to try that one-touch } \\
\text { thing. }\end{array}$ \\
\hline
\end{tabular}

\section{Table 7-4: Sample chat conversation}

I tried to step back when there were enough participants to have a good conversation but took a more active role when there were fewer people. This was picked up by one of the participants in a reflective journal entry that talked about her first chat session which the excerpt in Table 7-4 is taken from:

The chat tonight was also great. ... I think it will add to the level of familiarity and trust in the forums and other activities. I was interested to note how little you added there. ... I imagine you are quiet in the chats in order to foster our growing independence as a group, right? (Charlotte, RJ)

With the second research group, an evening was found where everyone could participate at the same time each week. Personal commitments meant that the number of people online varied from week to week. As with the first research group, my role varied according to the number of participants. The following comment was made in one of the follow-up interviews which illustrates the role I endeavoured to take:

You keep the chats going well and you're there but you're not dominating. (Karen, I)

\section{Emails}

I used emails to encourage participation (see Table 7-1 for examples), to communicate information about meetings, to remind participants of chat sessions, and for some communications between the facilitator and individual participants. Participants replied to these emails and sometimes used group emails to communicate with each other. Examples of the content of these group emails included messages to explain the writer's absence from face-to-face meetings or chat sessions, and explanations for their lack of activity on the site. Emails were used mainly to support organisational aspects of the leadership development process rather than the learning process itself. 


\subsubsection{Section summary}

The role of the blended action learning facilitator varied according to the different technologies used. Responses to the online reflective journals, which could only be seen by individual participants, involved a balance of active listening to demonstrate understanding, and questioning to encourage reflection. In forum discussions and chat sessions I endeavoured to support participation by giving positive feedback, but tried to remain in the background encouraging dialogue between participants and taking the role of a 'guide on the side' rather than a 'sage on the stage' (Mazzolini \& Maddison, 2003). Emails were used for information exchange and encouraging participation.

\subsection{Analysis of the blended action learning facilitator role}

Two important and complementary aspects of the blended facilitator role were providing a structure and process that enabled learning, and acting as a trusted inquisitor, a term that will be explained in Section 7.5.1. These two facets of the role will be discussed in the following section as will the balance between them.

\subsubsection{An enabler of leadership learning}

This aspect of the blended facilitator role involves designing and facilitating a structured learning process, motivating and encouraging participants, offering technical support and providing resources.

\section{Process designer and facilitator}

An important part of my role was setting up and maintaining the online site, and facilitating the online interactions. This aspect of the role included clarifying expectations and providing guidance on the use of the site. Clarity of roles and expectations was very important in this study and has been emphasised as a key aspect of the facilitator's role in encouraging reflective learning (Brockbank \& McGill, 2007). This clarity was established in a number of ways, particularly at the initial face-to-face meetings. The three roles I articulated to the participants at the initial group meetings were that I would: facilitate the leadership action learning group in ways that supported leadership learning; encourage online learning; and gather research data that will contribute to the understanding of effective leadership development in the New Zealand ECE sector. Participants were asked to discuss what they saw as their role, and agreed on a number of values and behaviours such as using questioning that would support the learning of others, showing respect, and learning about themselves from others. Confidentiality was another important expectation that needed to be emphasised at the early stages of the group interactions. This was signalled in the information sheet sent to participants before they agreed to participate and was reiterated at the first interviews and face-to-face meetings. 
As mentioned in Chapter 4, I developed some participation guidelines which outlined expectations regarding participant input. This is one of the recommendations from Stewart and Alexander's (2006) study, which found that problems occurred because of a lack of specific information on the structure and expectations of the blended action learning process. McConnell (2006) describes the clarification of roles as setting up protocols and sees it as a necessary aspect of fostering group management. Rovai (2007) believes having clear guidelines makes students "better able to judge their own behaviour and engage in self-reflection and self-regulation" (p. 80). The usefulness of these guidelines was commented on by participants:

The email you've just sent that was really good, that was really helpful and clear... I think it sounded realistic and I think it is helpful actually to lay down some expectations. (Diana, I)

The importance of the facilitator showing flexibility in the organisation of the site and in the use of the blended action learning activities was also appreciated.

You were also really flexible and I really value flexibility in terms of changing the forums ... you didn't walk into the process with this is how it's going to go A B C D and $E$, you walked in and said well here are some options and there may be more as we go along and let's start with this lot and see what happens. (Diana, I)

I found you were quite responsive to what we wanted to do and I felt that you would alter something to suit the needs of what we all wanted and that was really useful, so being flexible was important. (Grace, I)

Examples of this flexibility included the way that resources were added and that the site was rearranged to make different activities more accessible. The role of the facilitator in posting new material and organising and archiving material is noted by MacDonald (2008) who suggests that this task is important in keeping the group area alive. Flexibility and adaptability of design has been promoted by Stewart and Alexander (2006) in their study of blended action learning and by Garrison and Anderson (2003) who suggest that it is important that "design and redesign continue throughout the educational experience as collaboration and shared control introduce a creative element of uncertainty" (p. 78).

The importance of the facilitator providing a structured process and keeping participants on track was commented on by different participants. When asked how I encouraged participation, responses included:

Keeping us on task - because I'm sure we could get well off task if someone didn't keep us on track. Discussions sometimes get sidetracked. (Amy, I) 
Although action learning groups can operate without an independent facilitator, this role was valued by participants:

I think it just works really, really well and that's why people participate. If it wasn't properly facilitated then people wouldn't participate in the way that they are. (Grace, I)

The use of skilled external facilitators in leadership learning groups is recommended by the National College for School Leadership (2003). They suggest that the role of external facilitators should be to: ensure all participants have an equal voice; offer challenge and accountability; and organise and negotiate both process and content. Other aspects of the process designer and facilitator role include encouraging and acknowledging contributions and providing feedback. Prompt responses to postings and frequent communication were particularly appreciated by participants.

It's definitely more motivating to put something up when you know that you are going to get some sort of response.... You always have something to say about it, not just "yes, yes very good" it is something constructive each time. (Charlotte, I)

I've always had very quick feedback and anytime when I have asked for anything by email or when I've put something in a journal. (Heather, I)

These responses reflect Mazzolini and Maddison's (2003) findings that participants in online discussions appreciated "the perceived enthusiasm of and expertise of instructors who post relatively frequently" (p. 252).

Heron's (1999) work on modes of facilitation is useful in reflecting on this aspect of my facilitator role. Heron describes three modes of facilitation: the hierarchical mode; the cooperative mode; and the autonomous mode. In the hierarchical mode, the learning process is directed by the facilitator, in the cooperative mode it is shared between the facilitator and participants, and in the autonomous mode, the participants take control of the learning process. In this research study, I operated somewhere between the hierarchical and cooperative modes. According to McGill and Brockbank (2004), it is appropriate for the facilitator to adopt the hierarchical mode in the early stages of an action learning group when the participants are learning about the action learning process. The design of the website and the facilitation of the face-to-face action learning group meetings were examples of how I acted in the hierarchical mode; however, over time there was movement towards the cooperative mode. Examples of sharing power with group members include their instigation of a range of forum discussions and their questioning role in the online action learning forums. The group meetings that took place after the conclusion of the data collection phase marked a move toward the autonomous mode of facilitation. This fits with Revans' (1998) view on the eventual independence of action learning groups discussed earlier in Section 2.6.1 of the literature review. Garrison and Anderson (2003) also discuss the benefits of the 
evolution of responsibility and control moving towards the learner throughout the learning process. This movement from the hierarchical towards the cooperative mode was noted by participants in LALG1 as the quote below shows:

Particularly at the beginning you were the leader of the group and that's become kind of less obvious as we've gone along which is what you deliberately set out to do. (Diana, I)

The movement towards cooperation was not as marked with the second research group as they did not engage as actively in the site as the first group and only a few participants initiated forum discussions and engaged in online action learning.

The importance of learners taking responsibility for the direction of their learning is emphasised by Francis and Cowan (2008, p. 339) who suggests that this "encourages them to engage actively with the contradictions and dilemmas in which their professional practice is embedded". Brockbank and McGill (2007) emphasise the value of the learner being engaged in an active process with the facilitator and other participants through reflective dialogues as this will encourage both independence and interdependence. They also suggest that the optimal learning relationship is "mutual, open, challenging, contextually aware and characterized by dialogue" (p. 209). The value of online learning environments in focusing more closely on the learning interests of the students, rather than the transmission of knowledge that occurs in most face-toface settings, has also been emphasised (McConnell, 2006).

\section{Motivating and encouraging participation}

Some participants engaged in online activities more regularly than others and another aspect of my role was motivating and encouraging the participation of individuals. Although participants were already motivated to some degree as they had chosen to be part of the research, they were all very busy, and without reminders and encouragement they could easily forget to make regular contributions to the online activities of the group. This aspect of my enabler role was appreciated by participants as the following comment shows:

Prompting and reminding is an important part of your role that I think is pretty essential, if there wasn't somebody to remind people to participate and motivate people to remember to contribute, it wouldn't work at all I don't think. (Charlotte, I)

Participants were encouraged and reminded through emails, phone calls and text messages. If a participant had not been online for a period of time I would usually send them a message and occasionally phoned them at work. Text messaging was used to remind participants of chat times and was requested by three participants in LALG1. Garrison et al. (2000) comment on the importance of the facilitator having a continual presence, characterised by frequent contact, as this is likely to increase participation. 
One thing I found difficult in my role as online facilitator was getting the right balance between being encouraging but not too demanding. Knowing the busyness of a head teacher's job, I had to be mindful of not expecting too much, yet I wanted participants to use the site as it was critical to my research. Sometimes when participants had not been online for a week or so I would worry that they were not finding it useful or had lost interest. Usually there was a very good reason such as ill health, connection problems or they were just particularly busy. Several participants from both groups commented that they found my reminders useful.

There needs to be a facilitator who keeps people on track who reminds them. If people don't like it tough they'll tell you, "stop nagging me Kate" and I'm quite sure they wouldn't because we make a commitment before we start. (Karen, I)

Because I was concerned that they may find my reminders irritating, I checked this out with participants in LALG2 and the following response was a typical reaction.

Kate: So what about when I send out little reminders about things - is that helpful? Gosh yes. When I open up the email I don't go "not Kate again". (Isabel, I)

\section{Provision of resources}

The ongoing provision of resources was also seen to be a valuable part of the facilitator role. The availability of a range of relevant literature enabled participants to access resources appropriate to their leadership goals and situations. The following comments show that these were useful:

There is nowhere else I could find a collection of articles or collection of readings around leadership. It's so good to just be able to go somewhere and do some reading and actually have articles I know someone else has read and found interesting or useful. (Diana, I)

The articles, I read a number when we started and that's simply because I had the time to and I found them really, really useful, I really enjoyed them. (Grace, I)

\subsection{Stages of blended action learning facilitation}

The provision of resources by action learning facilitators is commented on by Pedler and Abbott (2008), and Powell (2001), who contrasts this approach of having a 'learning bank' with the more traditional method of the teacher deciding what resources were appropriate and supplying these to the participants. Brockbank and McGill (2007) describe a key facilitator role as making available a wide range of learning resources including themselves as a flexible resource for the group's use. The value of stimulating 
reflective practice in head teachers through the consideration of appropriate readings is also emphasised by the National College for School Leadership (2003).

\section{Providing technical support}

Providing technical support was another aspect of the enabler role, particularly for those who were struggling with the technology. This support was provided in different ways including spending time before face-to-face meetings and at the second interviews going onto the online site with individuals to help with issues they were having. Participants also rang me during chat sessions if they were having problems.

The technical support was there and you were able to support us whether you went and asked people or whether you knew I'm not sure but certainly when there was a sort of "Ah I don't know what to do" ... you were on the end of the phone. (Diana, I)

Remember the second meeting we had and I arrived just a bit earlier than the others ... and we went on the site there and you showed me how to use things. (Heather, I)

This support, which could be likened to the role of a help desk operator, was more necessary in the early stages of each group, and once participants became familiar with the site, they became more independent in their use of it. Stewart and Alexander (2006) emphasise the importance of technical support to the success of blended action learning, as their study found that the technical problems experienced by participants impacted negatively on collaboration between group members. The importance of participants in leadership development programmes that involve e-learning receiving ongoing ICT support has been emphasised in a discussion of indicators for effective practice by McFarlane et al. (2003).

One aspect I did not act on quickly enough was the problems that LALG2 members had with having their chat sessions interrupted. These problems started soon after this group began and although I contacted the site administrator a number of times, the issue was not resolved until the site was upgraded in April 2008. This upgrade meant that chat session postings were sent and received much faster, and there were no interruptions, but by this time several members of the group had got out of the habit of regularly chatting online.

\subsubsection{Trusted inquisitor}

Another important aspect of the facilitator role was both supporting and challenging participants in their leadership learning. This facet of the role will be known as that of the 'trusted inquisitor'. This term is an oxymoron as it combines two contradictory ideas, those of trust (confidence and belief) and inquisition (searching inquiry). The trusted inquisitor role involved forming and encouraging trusting relationships characterised by empathy and support; and also questioning and challenging 
participants to encourage reflective practice and leadership learning. Other aspects of the trusted inquisitor role include building relationships, providing expertise, and role modelling and coaching.

The trusted inquisitor role has some similarities to that of a critical friend. Costa and Kallick (1993) define a critical friend as a "trusted person who asks provocative questions, provides data to be examined through another lens, and offers critique of a person's work as a friend" (p. 50). Expanding on the analogy of providing a different view of one's practice, these authors also suggest that critical friends are "willing to provide new lenses through which learners can refocus on their work" (Costa \& Kallick, 1995, p. 154). There is possibly an inherent tension between the roles of critic and friend; however, the concept of a critical friend is seen to be more complex than the simple balance between the two potentially contrasting roles as it is the combination of these roles that provides richness. The deeper and more trusting the relationship becomes, the greater the amount of critique that can be offered (Swaffield, 2007). Although there are differences between the trusted inquisitor and critical friend roles which will be discussed in a later section, some of the literature on critical friends will be referred to in an analysis of this aspect of the facilitator role, as will action learning and reflective practice literature.

\section{Developing trust}

In order to effectively facilitate the leadership action learning groups, I needed to establish strong and trusting relationships with group members. Robinson (2007) has suggested that four interpersonal qualities: respect; integrity; competence; and consideration for others influence how trustworthy others find us. Trust is developed when relationships are characterised by reliability and honesty (Hunter, Bailey \& Taylor, 1999). It is particularly important in action learning groups; if trust does not exist, participants are not going to feel able to share perceived weaknesses or vulnerabilities (McGill \& Brockbank, 2004; Miller, 2003; Day, 2000) and without this disclosure, there will be little growth and consequently learning will be limited. Trust was developed initially in the face-to-face interactions including the first interview and the first group meeting. The importance of these initial face-to-face interactions was commented on by a participant:

The personal contact helped build relationships and that sense of trust. (Fiona, I)

Trust was further built in the subsequent face-to-face and online interactions. Trusting relationships are also characterised by respect and confidentiality. As a facilitator I worked hard to get to know the participants and find out how I could best support them in their leadership learning. The following comments were made during the final interviews about the importance of the facilitator building strong and respectful relationships in order to facilitate learning: 
Forming strong relationships with us in the beginning was important, so building that trust and that privacy and friendship. (Amy, I)

It's always respectful and that makes a huge difference and that allows us especially as head teachers to trust in you and if you don't have trust then you have nothing. I trust in the fact that I can write and say anything to you about anyone and I know that it's not going to go any further, that you'll be honest with us in a way that we can cope with. (Beth, I)

The importance of the facilitator's role in enhancing social presence is discussed by Swan and Shih (2005), whose research found that instructor behaviour significantly impacted on student perceptions of social presence. Garrison and Anderson (2003) advocate for the use of different approaches with different students suggesting that the "greatest challenge for teachers in establishing social presence is setting the right tone at the right time" (p. 81). I was aware of changing my approach depending on the person and the situation. Some participants required more support and others responded to a greater degree of challenge. These individual approaches were appreciated by participants.

I think that at times the questions you asked or the statements you made ... were being deliberately engineered to me because you knew who I was and knew things about me about how I respond or how I would think depending on the way you wrote it or what you wrote. I do feel really strongly that you knew who I was and the information you offered on a theoretical basis and also the information you offered about people was engineered towards who I am. (Diana, I)

The things that occurred at the time that they occurred were all quite relevant and I feel like it was all quite scheduled for us and where we were as opposed to following a formula and my concern with following a formula is you might lose that personal help stuff that's going on. (Jane, I)

This last comment reflected the fact that at times the facilitator and researcher roles were blurred. An example of this was in the interviews when the planned questions may have raised issues around participants' leadership goals so the conversation often deviated to allow participants to reflect and identify future actions.

\section{Building relationships between participants}

The role of the facilitator in helping build relationships between participants was also significant. Close relationships between group members are important to the success of action learning (McGill \& Brockbank, 2004; Prideaux, 1997), and as discussed in Chapter 6, participants highly valued their participation in the group and the support they received from other group members. My role in supporting these strong relationships included role modelling respectful relationships and encouraging the 
sharing of both personal and professional information and perspectives. This function was appreciated by participants from both groups:

You have a very relaxed but efficient way of working with us that's also set the tone for the group and how we treat each other. (Fiona, I)

Well it was a relaxed atmosphere... You set it up in such a way that makes it like that so nobody ever felt that they couldn't participate. (Heather, I)

Various strategies were used to help develop social presence within the leadership action learning groups. These included the use of icebreakers to help participants to get to know each other and the sharing of leadership journeys at the first face-to-face meeting. Subsequent face-to-face meetings were started with a round of trauma, trivia and joy, an activity suggested for use with action learning groups (McGill \& Brockbank, 2004). This encouraged participants to share what was happening in their personal and/or professional lives and helped build trust within the group. The value of personal and professional updates in professional development group meetings has been emphasised by Bennett et al. (1997), whose research found these interactions helped build close relationships between participants.

\section{Providing support}

Part of building a trusting relationship with participants included providing support. In addition to the practical and technical support outlined in the section on the enabler role, I also offered emotional support. Certain personal skills and qualities enhance the facilitator's ability to provide emotional support. Both action learning and critical friend literature identify a number of skills and qualities that are relevant to this aspect of the blended action learning facilitator's role. These include self-awareness, empathy, authenticity and listening skills (Marquardt, 2004b; McGill \& Brockbank, 2004); and respect, empathy, and listening (MacBeath, 1998; Swaffield, 2005, 2007). Self-awareness involves being aware of one's own strengths and limitations. The National College for School Leadership recommends that facilitators have highly developed emotional intelligence and effective communication skills (National College for School Leadership, 2003). The importance of facilitators possessing a high degree of emotional intelligence has also been emphasised by Stewart (2006) and by Brockbank and McGill (2007), who in addition suggest that facilitators who demonstrate authenticity, acceptance and trust, and empathetic understanding will encourage double loop learning.

My previous facilitator training and experience meant that I was confident in my faceto-face facilitation role and this confidence was appreciated by participants:

You're a very, very good facilitator. You are a very good group facilitator, no flattery you are. (Karen, I) 
My previous experience made me aware of many of the important face-to-face facilitator strategies mentioned in the action learning literature such as positive body language, active listening, clarifying, restatement and summary (McGill \& Brockbank, 2004). Some of these skills can be transferred to the online environment and the importance of actively listening and demonstrating understanding with reference to the written responses to reflective journal entries has been commented on earlier in this chapter. This communication of understanding is an important aspect of the action learning facilitator's role. It can be linked to empathy (McGill \& Brockbank, 2004) and is more likely to encourage further reflection and learning (Brockbank \& McGill, 2007). Examples of supportive statements indicating understanding in response to reflective journal entries are given in Table 7-5 below:

\begin{tabular}{|l|}
\hline Supportive responses to reflective journal entries \\
\hline You must have felt rather shattered ... \\
\hline I can understand your mixed feelings at the moment ... \\
\hline I can understand how upset you must be after all that has happened ... \\
\hline It sounds as if you are quite frustrated with the lack of understanding ... \\
\hline
\end{tabular}

Table 7-5: Supportive responses to journal entries

The following comments illustrate how this supportive aspect of the role was valued by participants:

To me the journal was good because I knew that you understood and it wasn't necessarily that you put in pages of response or anything like that, I knew that you knew where I was coming from and that you would give me honest comments, things to make me think. (Beth, I)

The affirmations too. "It must have been really difficult for you" those sort of things ... that makes me feel good, someone has recognised that which feels nice. (Grace, I)

The importance of facilitators tailoring their interventions in order to support participant learning is emphasised by MacDonald (2008). She suggests that face-to-face interactions are a more powerful means of providing individual support than asynchronous contact; however, in this study, the individual support provided through the responses to the reflective journals was seen to be extremely valuable. The asynchronous tools such as the reflective journals and forums provided opportunities to support participants in a more considered way although this may not have been as effective without the earlier face-toface interactions that helped build trusting relationships.

Although I was not as confident in the online facilitation because of my lack of experience, the asynchronous nature of most of the online interactions allowed me time to reflect on my responses and over time I developed greater confidence in this aspect of the role. 


\section{Questioning and encouraging reflection}

The other main function of the trusted inquisitor role was the use of questioning in order to encourage reflection and leadership learning. Questioning can be challenging to participants, and this challenge will not be accepted and reflected on unless a trusting relationship has first been built; hence the earlier emphasis on relationship building and providing support. As McGill and Brockbank (2004, p. 179) recommend, "the place for questioning comes after contributions have been received without judgement, so that some trust and confidence have been established".

Questioning is a key feature of an action learning facilitator's role (Marquardt, 2004b) and is essential in promoting reflective practice (Angeli et al., 2003; Loo \& Thorpe, 2002, MacKnight, 2000). The type of questioning used is critical; McGill and Brockbank (2004) promote the use of enabling questions to support the presenter's learning, encourage reflection and help them generate their own solutions. This questioning style is known as Socratic questioning and enables the speaker to "struggle with the issue under consideration, challenging embedded paradigms, encouraging consideration of possibilities, without restricting the range of possible solutions, and without providing a ready-made solution" (McGill \& Brockbank, p. 180). Table 7-6 below contains questions I asked in different parts of the online environment.

\begin{tabular}{|l|}
\hline Facilitator questions that encourage reflection \\
\hline Responses to online journal entries: \\
\hline What do you think is holding you back? \\
\hline What do you plan to do from here on to help ensure things keep improving? \\
\hline How can you encourage her to take more responsibility? \\
\hline Responses to action learning forums: \\
\hline How would you personally like to deal with conflict differently? \\
\hline $\begin{array}{l}\text { What happens when people have different views on a subject? When are you able to } \\
\text { discuss different views as a team without people feeling uncomfortable? }\end{array}$ \\
\hline $\begin{array}{l}\text { What aspects of the advice you gave regarding how to deal with ... are you now } \\
\text { unsure of? }\end{array}$ \\
\hline Questions in chat sessions: \\
\hline Have you thought about how you want to work together ideally? \\
\hline What is something you have some control over that you would like to work on? \\
\hline Have you thought about what you want to achieve in the meeting? \\
\hline
\end{tabular}

Table 7-6: Facilitator questions that encourage reflection 
The value of the questioning process has been illustrated and discussed in previous sections and the following comments relate specifically to my role in the questioning process.

You use the action learning techniques all the time, like when I write a reflective journal you seldom ever give an answer instead of a question, you almost always write your response in the form of a question which does really encourage more reflection. (Charlotte, I)

I think the most significant influence has been the style of questioning, particularly I think of those reflective journals or even in the chat. That style of questioning: "how do you?" "what do you think?" The ones that have encouraged me to peel back the layers and reflect. (Grace, I)

Although participants perceived that I used questioning well, when I looked back particularly on the reflective journal entries, I felt that I could have questioned more in some situations. However, my use of questioning did develop and become more effective over the course of the research and was stronger with LALG2 than with LALG1.

The blended action learning format meant that questioning occurred at both face-toface meetings and online. In some respects, the trusted inquisitor role was easier in the online context because it allowed me time to consider my responses to reflective journal entries and action learning forums. These responses also required more consideration; because they were written, they became a permanent record, hence the need to work through the process outlined in Figure 7-1. The importance of writing to reflection is emphasised by Barth (2001) who suggests that "when we write, we become responsible for our words and ultimately become more thoughtful human beings" (p. 39).

\section{Content expertise}

The importance of the facilitator having some expertise in the specific area they are supporting was raised by a participant in the first final interview of LALG1. It was very important to her that she could trust my knowledge and skills around leadership:

We have to believe that the facilitator has the knowledge, they have to be expert, they have to have done the time and I see that as crucial because that gives them the credibility so I think that's really important. (Beth, I)

I was somewhat surprised by this comment so I asked the other participants whether they also thought that this was important. They were very clear that some degree of expertise in leadership was essential to the effective functioning of the action learning groups in this research study, and that facilitation skill alone was not sufficient. The reasons given for this included that $\mathrm{I}$ had an understanding of the context in which the participants were working and therefore gave clear and simple responses and also that 
my knowledge helped participants identify potential solutions to the problems they were facing, as the following comment shows:

Whatever we were asking and whatever we were discussing, whatever issue came up, you had knowledge that you were able to share with us or you had knowledge about that particular issue maybe and therefore knew how to ask a question to help whoever it was think it through, work it through and come to a solution or point us in the right direction to find the solution as well. (Heather, I)

The action learning literature does not generally suggest that the facilitator should have expertise in the subject under discussion placing more emphasis on facilitation skills (Marquardt, 2004b; McGill \& Brockbank, 2004). However, Bennett (1997) lists acting as subject expert as a possible action learning facilitator role, Pedler and Abbott (2008) emphasise the importance of facilitators having context knowledge, and Bray (2002) suggests that facilitators should have rich experiences related to the subject area to share. Bray also cautions against the delivery of content suggesting that it is the facilitator's role to encourage self-learning. My expertise was not used as the basis for giving advice, but rather knowing how best to support the learning of participants. The importance of balancing theoretical knowledge with the intrapersonal and interpersonal intelligence skills discussed earlier was recognised by participants.

It wasn't just your theoretical knowledge; I think it was your knowledge of people as well. I do actually think you're quite wise about people. (Diana, I)

Although at times I was, like the participants, tempted to offer advice, I tried to resist this temptation and only ask questions that would encourage reflection. Some of the online activities, particularly forum discussions, did involve everyone sharing their knowledge and expertise; however, when it came to participants sharing and reflecting on their leadership issues, action learning techniques were used. I strongly valued the knowledge of the participants and believed that they had the capabilities to solve their own problems. As O'Neil (1997) suggests in commenting on the role of the set advisor, "the learning that the set members come to of their own accord is far more valuable that any we could hope to bring" (p. 254).

\section{Role-modelling and coaching}

Another aspect of the trusted inquisitor role was acting as a role model and coach. This included modelling the action learning skills, in particular questioning, and coaching the participants in the development of these new skills. The importance of role modelling appropriate responses and comments in an online environment has been emphasised by Garrison and Anderson (2003) who suggest that the facilitator sets the tone for the way the group interacts, in particular demonstrating the effective use of questioning. This view is supported by Swan and Shih (2005) whose research found 
that students modelled their interactions on those of the instructor. Participants commented on the role I took in modelling different skills and coaching.

The coaching - getting us to look at things ourselves and find our own answers, also teaching us how to coach was really good and having to actually sit there and do it that first day was a really good way of learning it. (Amy, I)

The coaching role also involved providing participants with options as to how they might proceed in their leadership journeys. Having some knowledge and expertise in the area of leadership made this process easier as I was able to make them aware of possible directions they could take. This coaching role can be seen as providing a map but not telling the participants which route to take, and is similar to the role of the online tutor in mapping out individual learning pathways as recommended by McConnell (2006).

The importance of modelling effective questioning techniques is supported by MacKnight (2000), who suggests that these will be picked up and used by participants in subsequent online discussions. Some participants also found they could transfer the skills developed in the action learning process, in particular the use of questioning, to other face-to-face situations:

Apart from the questions being really good they've also taught me a way to deal with other people. Just by reading your questions it's helped me learn how to question as well. (Fiona, I)

The action learning techniques were not always easy to use, and as previously mentioned I was sometimes tempted to suggest solutions. On occasion, when participants were struggling with particular issues and wanted ideas on how to move forward, these were given as the following comment shows:

You did some gentle questioning but on the other hand you also said some things outright and at that point of time I actually needed both .... There were times when questions were really, really helpful and there were times when suggestions were helpful. (Diana, I)

McGill and Brockbank (2004) discuss the importance of the facilitator modelling selfdisclosure so as to encourage the participation of others. Although I was not participating in the action learning process, I did participate in activities at meetings such as the trauma, trivia and joy round in order to encourage the sharing of personal and professional perspectives. In online interactions I attempted to have an approachable presence, a necessary quality of a collaborative facilitator according to McConnell (2006). 


\section{Comparing and contrasting the trusted inquisitor role with that of a critical friend}

As mentioned earlier, there are some similarities between the role of the trusted inquisitor and that of the critical friend. These similarities include the importance of trust to the relationship, and the use of questioning to encourage reflection. There are, however, also crucial differences, in particular the group aspect of the critical friend role and the content expertise required by the trusted inquisitor. Critical friend relationships tend to be between individuals or between school communities and individuals. They also usually involve the collection and feedback of data gained from visiting settings and making observations (Swaffield, 2005). The trusted inquisitor role as enacted in this study differed from this in that it involves facilitation of a group and included the building of relationships between group members.

The importance of the trusted inquisitor having some expertise provides a contrast with the role of the critical friend, as according to Swaffield (2005), critical friends do not necessarily need to have a high level of technical competence in the area they are supporting. Swaffield does, however, suggest that critical friends do need to be familiar with the context so their questions encourage reflection rather than lengthy explanations. A grasp of current thinking in educational leadership is among the skills recommended for facilitators of leadership learning groups, as is practical knowledge of professional learning practices and principles (National College for School Leadership, 2003).

\subsubsection{Balance between acting as enabler and trusted inquisitor}

Both the enabler and trusted inquisitor roles were essential and complementary aspects of the blended action learning facilitator role. The enabler role, which focused on encouraging online participation, included designing and facilitating the blended action learning process, motivating and encouraging participants, providing resources, and offering technical support. This enabling role provided the platform for meaningful leadership learning to occur and it was the trusted inquisitor role that inspired that process. The main purpose of the trusted inquisitor role was supporting and challenging participants in their leadership learning, twin principles in encouraging honest self-disclosure according to Pedler and Abbott (2008). This role involved a number of complementary facets including building trust, building relationships between participants, providing support, offering leadership expertise, questioning, and coaching and role-modelling. The complementary aspects of the role are summarised in Figure 7-2 below. 


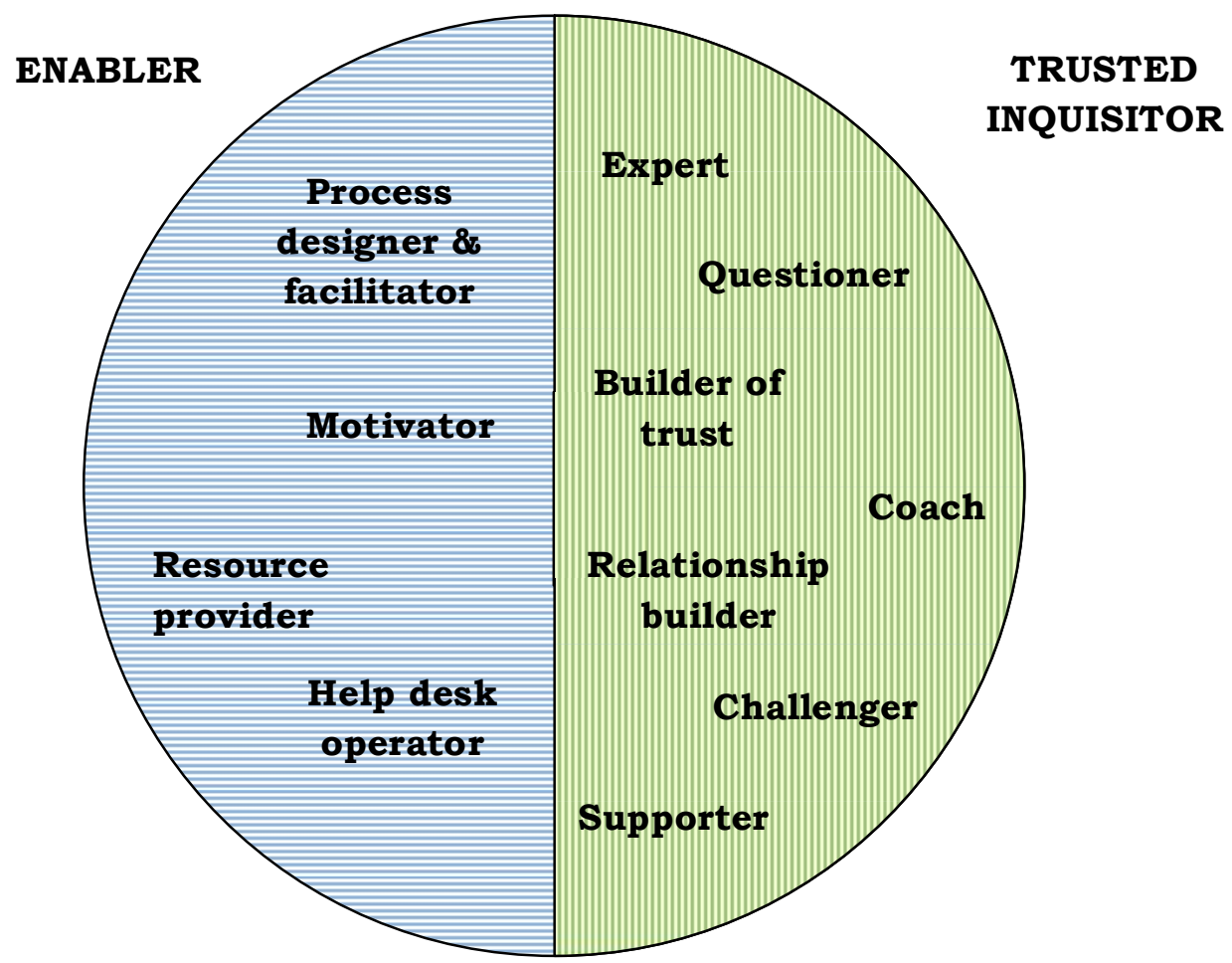

Figure 7-2: Two aspects of the facilitator role

The balance between the enabler and trusted inquisitor roles changed over the course of the research groups and varied between the two action learning groups. The importance of responding flexibly to different groups is emphasised by Boud and Walker (1998, p. 204) who suggest that "to repeat the same approaches, processes, practices with every group of learners does not respect the variation in experience that necessarily exists". The balance of roles also changed within each group. A strong trusted inquisitor relationship did not develop to the same extent with all participants and I spent more time in the enabler role with some group members who needed ongoing encouragement to participate. A willingness to engage was a key to the success of the relationships and in general terms, the more willing participants were to engage in the action learning process, the stronger the trusted inquisitor relationship became. Although I felt I had good relationships with all participants, relationships were strongest with those who were more reflective, more active in their online interactions and more open to learning.

\subsection{Stages of blended action learning facilitation}

Although the role taken by the facilitator varied over the course of the blended action process according to the needs of the group and of each individual, five distinct stages of blended action learning facilitation can be identified. These stages are illustrated in Figure 7-3 below. 


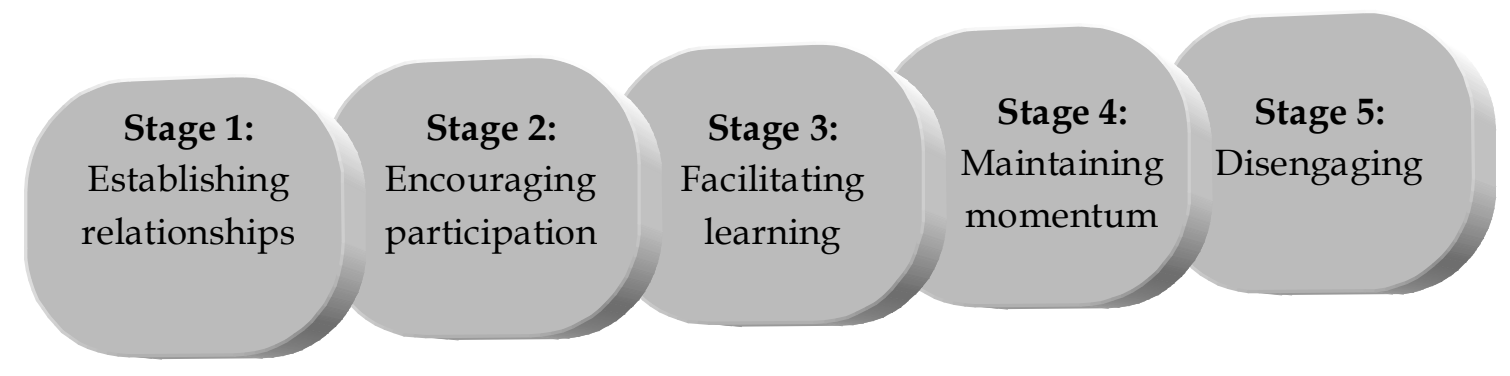

Figure 7-3: Stages of blended action learning facilitation

This model of the stages of blended action learning facilitation is based on my reflections on the various activities I engaged in over the course of the blended action learning groups. My role varied as the groups progressed and as the support and encouragement they needed changed. This model may be useful to future blended action learning facilitators because of its contribution to understanding the different aspects of the role. Table 7-7 below provides a description of each stage and this will be followed by a more detailed discussion of the type of activities engaged in the course of each stage.

\begin{tabular}{|l|l|}
\hline \multicolumn{1}{|c|}{ Name of stage } & \multicolumn{1}{c|}{ Description of stage } \\
\hline $\begin{array}{l}\text { Stage 1: Establishing } \\
\text { relationships }\end{array}$ & $\begin{array}{l}\text { Getting to know the participants, establishing trusting } \\
\text { relationships and clarifying processes }\end{array}$ \\
\hline $\begin{array}{l}\text { Stage 2: Encouraging } \\
\text { participation }\end{array}$ & $\begin{array}{l}\text { Encouraging participants to write online reflective } \\
\text { journals and to participate in forums and chat sessions }\end{array}$ \\
\hline $\begin{array}{l}\text { Stage 3: Facilitating } \\
\text { learning }\end{array}$ & Taking the role of a trusted inquisitor \\
\hline $\begin{array}{l}\text { Stage 4: Maintaining } \\
\text { momentum }\end{array}$ & Maintaining frequent contact with participants \\
\hline Stage 5: Disengaging & $\begin{array}{l}\text { Allowing participants to chose their level of } \\
\text { participation }\end{array}$ \\
\hline
\end{tabular}

Table 7-7: Stages of blended action learning facilitation

\section{Stage 1: Establishing relationships}

The focus of the facilitator role in the initial stages of each group was on establishing relationships and building up the level of trust within each group. This involved spending time getting to know participants, helping them to get to know each other, and supporting them to become familiar with the online site. Individual meetings with participants prior to the first group meeting began the process of establishing relationships. Activities were also provided at the first meetings that enabled me to learn more about participants and that 
encouraged them to get to know each other. These included icebreaker activities and the sharing of leadership journeys. Another important aspect of the first meetings was the clarification of roles and the provision of instructions for using the online site.

\section{Stage 2: Encouraging participation}

In the second stage, the focus changed to encouraging participation. Participants required varying amounts of encouragement and support, and key aspects of this stage of the role included coaching them in the use of action learning and promoting the use of the online site through reminders and positive feedback on postings. Key activities in this stage were: encouraging participation in all online activities through frequent emailing, responding quickly and enthusiastically to initial postings, and offering technical support and coaching to those who were having difficulties using the site. Changes were also made to the site to allow participants easier access to forum discussions as a result of feedback from participants in LALG1.

\section{Stage 3: Facilitating learning}

The third stage, facilitating learning, was where the action learning process became most effective in supporting leadership learning. Participants were by this stage familiar with me, with each other, with the online site and with the action learning process. My role in this stage involved both supporting and challenging individuals and the group as a whole using action learning techniques. This involved responding to online reflective journal entries in ways which demonstrated an understanding of each participant and which encouraged reflection through questioning as illustrated in Figure 7-1. Other activities important in this stage were the ongoing facilitation of action learning at face-to-face meetings, supporting forum and chat session interactions, and initiating online action learning forums. These activities encouraged reflection on participants' leadership practice leading to action being taken on leadership goals.

\section{Stage 4: Maintaining momentum}

The fourth stage involved maintaining the momentum established in the previous stage and included continued encouragement of participation, facilitation of learning and provision of expertise. My role in this stage included organising follow-up face-to-face meetings, regular emailing to encourage participation, replies to postings, using text reminders for chat, contacting participants who had not been online for a while, archiving older material and the introduction of new resources to the site.

\section{Stage 5: Disengaging}

In the final stage, my role became less active as the participants chose their own level of activity. I stayed in contact but reduced my expectations of their involvement. Activities in this stage involved occasional emailing, organisation of face-to-face meetings and responding to entries on the online site. Participants were encouraged to decide on how they wished the group interactions to continue and to take more responsibility for these interactions. 


\subsubsection{Balance between roles in various stages}

The balance between the enabler and trusted inquisitor role varied between the different stages of blended action learning facilitation according to the strategies used at each stage and the needs of both individual participants and each group. The following table illustrates and explains the approximate balance between enabler (E) and trusted inquisitor (TI) at each stage.

\begin{tabular}{|l|l|l|}
\hline \multicolumn{1}{|c|}{$\begin{array}{c}\text { Names of } \\
\text { stages }\end{array}$} & $\begin{array}{c}\text { Balance of } \\
\text { enabler/trusted } \\
\text { inquisitor role }\end{array}$ & \multicolumn{1}{|c|}{ Explanation } \\
\hline $\begin{array}{l}\text { Establishing } \\
\text { relationships }\end{array}$ & $\begin{array}{l}\text { In this initial stage, much time was spent on } \\
\text { establishing personal relationships and building } \\
\text { trust with and between participants, hence the } \\
\text { greater emphasis on the trusted inquisitor role. } \\
\text { Participants were also introduced to the site and } \\
\text { given instructions on its use. }\end{array}$ \\
\hline $\begin{array}{l}\text { Encouraging } \\
\text { participation }\end{array}$ & $\begin{array}{l}\text { This stage was focused on encouraging } \\
\text { participants to become frequent users of the site } \\
\text { and included motivating participants and } \\
\text { coaching them in the use of action learning. Both } \\
\text { enabler and trusted inquisitor behaviours were } \\
\text { used in equal proportions in this stage. }\end{array}$ \\
\hline learning & $\begin{array}{l}\text { This stage of the process concentrated mainly on } \\
\text { the action learning process and although it } \\
\text { involved aspects of the enabler role including } \\
\text { providing resources, the primary focus was } \\
\text { promoting action learning through questioning } \\
\text { and encouraging reflection. }\end{array}$ \\
\hline
\end{tabular}

Table 7-8: Balance of roles in the different stages 


\subsection{Recommendations for future blended action learning facilitation}

Although the roles taken and strategies used by blended action learning facilitators will vary according to the context in which the facilitator is operating and the individuals they are working with, some general recommendations can be made. The following list of suggestions has been developed as a result of the facilitation experience gained over the course of this study. These are:

- $\quad$ Build strong and trusting relationships with participants by getting to know them well, offering them support and demonstrating empathy.

- Help make connections between participants by encouraging them to share both personal and professional perspectives in both face-to-face and online interactions.

- $\quad$ Provide a mirror to encourage participants' reflection. This involves helping them see what is happening in their own contexts.

- Use questioning to challenge participants' thinking and to encourage their reflection.

- Show flexibility in responding to individuals within a group and also in responding to different groups.

- $\quad$ Provide a map (or in electronic form a global positioning satellite) to show participants possible directions for their personal journeys.

- Provide appropriate resources to support the ongoing learning of participants.

- $\quad$ Engage in reflection on your facilitation role and ask for feedback from participants.

\subsection{Chapter summary}

The facilitator has a critical role to play in encouraging leadership development through blended action learning. Facilitation of online activities differs in some respects from face-to-face facilitation. Although many of the interpersonal skills required are similar, online facilitation requires a greater emphasis on collaborative learning and the encouragement of reflective practice. The facilitator's role also varied according to the online technologies used. Responding to reflective journal entries was one of the most important roles undertaken by the facilitator in this study and effective responses involved a balance of support and challenge. Analysis revealed that the blended action learning facilitator took two complementary roles, enabling leadership learning and acting as a trusted inquisitor. Enabling learning involved designing and facilitating the blended action learning process, motivating and encouraging participants, offering technical support, and providing appropriate resources. This role enables learning to occur whereas the complementary role of the trusted inquisitor focuses on deepening the learning. This role involved establishing trusted relationships with and between participants, providing emotional support, questioning in order to encourage reflection, 
providing leadership expertise, and role-modelling and coaching. The balance between these two roles varied over the life of the blended action learning groups and five distinct stages of blended action learning facilitation were identified as a result of this study. These stages and the recommendations made for future blended action learning facilitation make a useful contribution to the increase in our knowledge and understanding of the role of the blended action learning facilitator. 


\section{The Leadership Learning Process}

"The only real voyage of discovery consists not in seeking new landscapes but in having new eyes." (Marcel Proust)

\subsection{Introduction}

This chapter brings together all the elements of the leadership development process. The chapter has three main sections. The first of these sections describes how the community of inquiry framework was modified to make it fit better with the emerging study findings. The second section focuses on an analysis of the participants' leadership journeys, in particular the movement from awareness to increased confidence in leadership practice. A model of leadership learning using ICT, which is one of the main findings of this study, is presented in this section. This model contributes to our understanding of leadership development by illustrating the learning process that occurred as a result of participation in this research study. The final section of the chapter considers each of the components of the model in more detail, and relates them to the research data presented in previous chapters. Throughout the chapter, broader theoretical concepts will be related to particular findings from the data in line with the principle of abstraction and generalisation (Klein \& Myers, 1999) in order that the reader can follow the process by which theory was developed.

\subsection{Revised community of inquiry framework}

The choice of the community of inquiry model as a framework for data analysis was justified in Section 3.3.6 of the methodology chapter. The model was subsequently modified as a result of the initial phase of data analysis in order to make it more compatible with the results emerging from this study. This modification follows Gerbic and Stacey's (2005) recommendation that in the analysis of online content, a model fitting the aims and context of the research be chosen and modified. The original framework was designed for a more structured online learning experience with a larger group of participants; the changes that were made reflect the smaller group size chosen for this research study and the more collaborative nature of blended action learning. Whereas traditional distance learning methods involve a relatively high degree of information transfer and teacher direction, blended action learning involves the participants learning from each other at least as much as from the facilitator whose role is more that of "a reflective online discourse analyser"(Bird, 2006, p. 9). As previously mentioned in Chapter 3, NVIVO was used to store and analyse preliminary data from the first research group. Nodes were created using the existing categories of the community of inquiry model and the various data sources were entered into the framework. The following sections outline firstly how each of the three types of 
presence apply to the blended action learning process, and secondly, how each was modified as a result of this data analysis process.

\subsubsection{Cognitive presence}

The original cognitive presence stages are a triggering event, followed by exploration, integration and resolution. Evidence of all these stages was found in the research data from this study and examples from different LALG1 participants of each of the four stages are presented below. The presentation of these examples is followed by an explanation of how the original framework was modified to reflect more effectively the context of blended action learning.

Triggering events included the identification by participants of problems or issues, and the presentation of information about these problems or issues (Garrison \& Anderson, 2003). The following excerpt from Amy's reflective journal, in which she documents her recognition that taking on a formal leadership role means that her focus had to shift from concentrating on her own practice to demonstrating a greater awareness of her team members and their needs, illustrates this process of identification:

I think the big thing I noticed on my first week of being head teacher was having to really closely think about and be interested in my other staff members and what they were doing or needed, instead of more what I am doing, as they were looking to me for leadership. This is obviously a new concept and challenge to me but one I have quite enjoyed. (Amy, RJ)

The second stage of cognitive presence, exploration, involves considering ideas or information that may be relevant to the issue identified (Garrison \& Anderson, 2003). Different viewpoints may be explored in this stage and ideas brainstormed. The following extract from a reflective journal illustrates Beth's thoughts on the issue of reflective practice in her team:

Something else I have given a lot of thought to is reflective practice and I realise that we don't really do it well in the respect that [name] doesn't like to take responsibility and look at her own behaviour... I have reflected considerably, once again perhaps this shows an area as a leader I could work on. (Beth, RJ)

The third stage, integration, involves creating a meaningful explanation or solution for the problem being faced (Garrison \& Anderson, 2003). The goal setting process used in this study encouraged participants to reflect on issues and then come up with actions to address issues they were dealing with. The following extract from Charlotte's leadership goal forum shows how the action learning process used at the first meeting encouraged her to develop specific strategies to address the problem she had identified: 
My first goal within this leadership cluster is about my assistant head teacher ... The strategies I came up with during our three-person discussion on Saturday are:

- I will talk to [name] directly about monitoring her tone of voice and language when directing the teachers. I will give her some simple strategies to deal with stressful times, and to let go of her fixation on routines.

- I will speak to the employment co-ordinator (a parent) about the situation. In this way there will be another person with whom the teachers can discuss any concerns they have while I'm away.

- I will give [name] copies of the handouts about emotional intelligence that Kate gave us. (Charlotte, F)

The fourth stage, resolution, involves applying solutions to address the issues or problems identified. In the case of traditional online learning environments, this may be a theoretical process, as participants are likely to be working on teacher directed projects; however, in the research study the solutions were able to be implemented as the following reflective journal entry shows:

I have introduced a fortnightly meeting with the three staff members so that there is always another person present, I have raised the opportunity of every staff member being given the opportunity to talk and give their opinion on what is working well, what needs to be changed and just general ideas. Hopefully this will give everyone the chance to have a voice and say what needs to be said out in the open rather than behind backs. (Beth, RJ)

\section{Revised stages of cognitive presence}

Although examples of each of the four original stages of the community of inquiry framework were evident, they did not exactly match the activities described in the original model. There was more evidence of reflection in the research data and the blended action learning process made it more likely that participants would come up with their own solutions rather than being given ideas and answers by others. As a result of the initial phase of data analysis, the four stages in the revised model were retained but renamed, and their focus slightly changed. The original stages of cognitive presence relate to the revised stages as follows. The triggering event was renamed 'Identifying the problem' as in action learning, the participant identifies their own problem rather than being given a theoretical issue to consider as in the original model. The exploration or inquisitive phase that follows involves exchanging information and the presentation of different ideas for consideration. Reflecting on actions is a critical part of this step and although reflection is mentioned in the community of inquiry model, it does not receive much emphasis in this stage and it is seen to fit better in the integration stage that follows. Because of the importance of reflection to action learning, this stage was renamed 'reflecting' and involves both private and public reflection. The integration stage is where ideas are synthesised and solutions created. In terms of action learning, this involves identifying actions and setting goals, hence the change to 
the term 'deciding'. The final stage of resolution involves applying and testing solutions, and is equivalent to the acting phase in action learning, hence the term 'acting' replaces resolution.

Table 8-1 below summarises the similarities and differences between the original cognitive presence stages and the modified stages of cognitive presence that were developed as a result of the initial process of data analysis.

\begin{tabular}{|l|l|l|l|}
\hline $\begin{array}{l}\text { Original } \\
\text { cognitive } \\
\text { presence } \\
\text { stages }\end{array}$ & Indicators & $\begin{array}{l}\text { Revised } \\
\text { cognitive } \\
\text { presence } \\
\text { stages }\end{array}$ & Indicators \\
\hline $\begin{array}{l}\text { Triggering } \\
\text { event }\end{array}$ & $\begin{array}{l}\text { Recognising the } \\
\text { problem. } \\
\text { Sense of } \\
\text { puzzlement. }\end{array}$ & $\begin{array}{l}\text { Identifying } \\
\text { the problem }\end{array}$ & $\begin{array}{l}\text { Recognising the problem. } \\
\text { Presenting information. } \\
\text { Asking questions. }\end{array}$ \\
\hline Exploration & $\begin{array}{l}\text { Information } \\
\text { exchange. } \\
\text { Suggestions for } \\
\text { consideration. } \\
\text { Brainstorming. }\end{array}$ & Reflecting & $\begin{array}{l}\text { Personal narratives and } \\
\text { descriptions. } \\
\text { Reflection on action. }\end{array}$ \\
\hline Integration & $\begin{array}{l}\text { Connecting ideas. } \\
\text { Creating solutions. }\end{array}$ & Deciding & $\begin{array}{l}\text { Integrating information } \\
\text { from various sources. } \\
\text { Identifying strategies and } \\
\text { actions. }\end{array}$ \\
\hline Resolution & $\begin{array}{l}\text { Testing and } \\
\text { defending solutions. }\end{array}$ & Acting & $\begin{array}{l}\text { Implementing solutions. } \\
\text { Reporting back on } \\
\text { solutions. }\end{array}$ \\
\hline
\end{tabular}

Table 8-1: Revised cognitive presence categories

\subsubsection{Social presence}

The three aspects of social presence in the original community of inquiry model are 'affective', 'open communication' and 'cohesive'. In analysing data from the first research group it was found that the cohesive category which involves addressing the other participants by name and the use of communication for social purposes was redundant as this occurred in virtually all postings. This category would be more relevant in larger online groups where people had not met each other and were working on establishing relationships. Numerous examples were found of the other two categories. Affective responses, as explained in Section 3.3.6, are emotional responses that tacitly recognise the reciprocal relationships in communities (Garrison \& Anderson, 2003). They include: expression of emotion through the use of emoticons 
such as smiley or sad faces; repetitive punctuation and conspicuous capitalisation; use of humor; and self-disclosure or the presentation of personal details. The following table presents a number of short excerpts showing responses from this category:

\begin{tabular}{|l|l|}
\hline Affective response & Category illustrated \\
\hline $\begin{array}{l}\text { I'm a fan of escapism - in appropriate doses - it can } \\
\text { really provide balance in my life! @ (Diana, C) }\end{array}$ & $\begin{array}{l}\text { Expression of emotion using } \\
\text { emoticons }\end{array}$ \\
\hline $\begin{array}{l}\text { Okay, I really am going now. Diana, Happy } \\
\text { Birthday!!!!!!!!!!!!!!!!!!!!!!! (Charlotte, C) }\end{array}$ & $\begin{array}{l}\text { Expression of emotion using } \\
\text { repetitive punctuation }\end{array}$ \\
\hline $\begin{array}{l}\text { THANK YOU VERY MUCH FOR SHARING THAT } \\
\text { WONDHERFUL SUPPORT. (Diana, F) }\end{array}$ & $\begin{array}{l}\text { Expression of emotion using } \\
\text { capitalisation }\end{array}$ \\
\hline $\begin{array}{l}\text { Beth: Are you at work Emma? } \\
\text { Emma: Yes I live here (Beth, Emma, C) }\end{array}$ & Use of humour \\
\hline $\begin{array}{l}\text { Am on a new "me" regime, eating wise and going to the } \\
\text { gym!!! Heavens it is a worry, but am determined it will } \\
\text { last, I can but hope. (Beth, C) }\end{array}$ & Self-disclosure \\
\hline
\end{tabular}

Table 8-2: Examples of affective responses

The second category of social presence, open communication, is characterised by responses that demonstrate respect and encourage participation and interaction (Garrison \& Anderson, 2003). Such responses include direct responses to the messages of others, asking questions, complimenting others, and expressing agreement. Examples of these types of responses were also frequently seen and some are listed in Table 8-3 below: 


\begin{tabular}{|l|l|}
\hline Open Communication & Category illustrated \\
\hline $\begin{array}{l}\text { Yes Beth and Fiona I agree open ended questions are a } \\
\text { lot more thought provoking and I tend to take things on } \\
\text { board more and feel more empowered if I figure them out } \\
\text { for myself than if someone tells me. (Amy, F) }\end{array}$ & Referring to others' messages \\
\hline $\begin{array}{l}\text { When you say, "...my expectations that they should } \\
\text { work in a more democratic way...," do you mean that } \\
\text { you are not listened to, or that decisions are made when } \\
\text { you are not around? (Charlotte, F) }\end{array}$ & Asking questions \\
\hline $\begin{array}{l}\text { I think you're doing amazingly well Beth - so much } \\
\text { more confident than last time we did this together - yay } \\
\text { you! (Fiona, C) }\end{array}$ & Complimenting each other \\
\hline $\begin{array}{l}\text { Gosh Emma I so relate to what you are saying although } \\
\text { sometimes I feel that at least I can shut the lid on the } \\
\text { computer, people aren't so easy!!! (Beth, C) }\end{array}$ & Expressing agreement \\
\hline
\end{tabular}

\section{Table 8-3: Examples of open communication}

\section{Revised stages of social presence}

As can be seen from the examples given above, there was overlap between the different social presence categories and some of these messages could have fitted in more than one category. It was also noticed that there were similarities between the open communication category and the facilitating discourse category of teaching presence which will be discussed in the next section. There did not seem to be a category that represented the sharing of information about work-based practices that encouraged reflective practice. Although this is allowed for in the exploration stage of cognitive presence, in the context of this study this sharing did not often relate to the participant's leadership goals, but rather to everyday issues that came up in forum discussions and in chat sessions. The social presence categories were therefore changed in the revised community of inquiry model to 'sharing' (online interactions of a personal nature) and 'supporting' (online interactions that support reflection and information sharing). The examples given in Table 8-2 and Table 8-3 above are even more relevant to the revised categories both of which play an important role in maintaining the relationships built up in the face-to-face meetings that were interspersed with the online interactions.

Table 8-4 below summarises the similarities and differences between the original social presence stages and the modified action learning process. 


\begin{tabular}{|c|c|c|c|}
\hline $\begin{array}{l}\text { Social presence } \\
\text { stages }\end{array}$ & Indicators & $\begin{array}{l}\text { Revised social } \\
\text { presence stages }\end{array}$ & Indicators \\
\hline Affective & $\begin{array}{l}\text { Expression of } \\
\text { emotions. } \\
\text { Use of humour. } \\
\text { Self-disclosure. }\end{array}$ & $\begin{array}{l}\text { Sharing: Online } \\
\text { interactions of a } \\
\text { personal nature } \\
\text { that build trust } \\
\text { within the group }\end{array}$ & $\begin{array}{l}\text { Expressing emotions. } \\
\text { Use of humour. } \\
\text { Sharing personal } \\
\text { information. }\end{array}$ \\
\hline $\begin{array}{l}\text { Open } \\
\text { communication }\end{array}$ & $\begin{array}{l}\text { Asking } \\
\text { questions. } \\
\text { Complimenting } \\
\text { expressing, } \\
\text { appreciation. }\end{array}$ & $\begin{array}{l}\text { Supporting: } \\
\text { Online interactions } \\
\text { between group } \\
\text { members that } \\
\text { support reflection } \\
\text { and information } \\
\text { sharing }\end{array}$ & $\begin{array}{l}\text { Exchanging information } \\
\text { related to work practices. } \\
\text { Asking questions of each } \\
\text { other in order to clarify } \\
\text { \& encourage reflection. } \\
\text { Complimenting, } \\
\text { expressing appreciation. }\end{array}$ \\
\hline Cohesive & $\begin{array}{l}\text { Vocatives. } \\
\text { Salutations. }\end{array}$ & (not applicable) & \\
\hline
\end{tabular}

Table 8-4: Revised social presence categories

\subsubsection{Teaching presence}

Teaching presence relates to the design, facilitation and direction of the learning process. The first category of the original community of inquiry model, instructional design and organisation, is concerned with setting curriculum, designing the learning process and establishing protocols (Garrison \& Archer, 2003). Several aspects of this category are not relevant to the blended action learning process as unlike distance education courses, blended action learning is a collaborative process with no set curriculum. There were, however, times when direction was given including the provision of guidelines on participation and the posting of the messages that asked for particular input from participants. An example of one such message is the following posting sent by the facilitator after the first face-to-face meeting:

Your input is requested in 3 areas of the website:

- personal profiles - please change your password, add a short introduction and decide if you wish to activate your email address. Remember you are able to change the email address to which messages are sent re online activities.

- learning forum - please add your leadership goals and proposed actions as discussed in your group of 3 on Saturday.

- online reflective journal - please start your journal with some reflections on how useful you found the first meeting. Possible focus questions are: what did you find particularly useful? what didn't you find useful? suggestions for improvement. 
The second category, facilitating discourse, was more relevant to this research study as its focus is on the construction of personal meaning and the development of mutual understanding (Garrison \& Anderson, 2003). Aspects of facilitating discourse include: setting the climate for learning; encouraging and acknowledging contributions; seeking to reach consensus; identifying areas of agreement and disagreement; and drawing in participants. Not all of these indicators are relevant to this study as participants were engaged in their own unique learning journey rather than all focused on the same learning outcomes as is the case in many e-learning experiences. However, many indicators were relevant, and examples of facilitating discourse from both the facilitator and participants are included in Table 8-5 below.

\begin{tabular}{|l|l|}
\hline Facilitating discourse & Category illustrated \\
\hline $\begin{array}{l}\text { Thank you for your input so far on the site. I have enjoyed } \\
\text { reading your personal profiles, goals and journal entries. It's } \\
\text { great to see people responding to others' goals as well ... } \\
\text { If you are wanting some ideas about journal writing there } \\
\text { are some resources (including a very short \& practical one) } \\
\text { on journal writing in topic 7. (Kate, email) }\end{array}$ & $\begin{array}{l}\text { Setting the climate for } \\
\text { learning }\end{array}$ \\
\hline $\begin{array}{l}\text { Well done Charlotte for being the first to get your goals } \\
\text { written! They sound really specific, positive and } \\
\text { manageable, I look forward to hearing how you get on. } \\
\text { (Fiona, F) }\end{array}$ & $\begin{array}{l}\text { Encouraging and } \\
\text { acknowledging } \\
\text { contributions }\end{array}$ \\
\hline $\begin{array}{l}\text { I know you have had a lot of staff illness so have probably } \\
\text { not been able to focus much on your goal - at least you are } \\
\text { well this time. Are you still focusing on time management } \\
\text { or do you have a new goal to share with the group? I know } \\
\text { you are working on keeping a positive attitude within the } \\
\text { team so do you have anything to share with regard to this? } \\
\text { (Kate, F) }\end{array}$ & $\begin{array}{l}\text { Drawing in } \\
\text { participants }\end{array}$ \\
\hline
\end{tabular}

Table 8-5: Examples of facilitated discourse

The final category of teaching presence, direct instruction, relates to the role of the expert teacher as the shaper of the learning experience. Indicators in this category include presenting content and questions, focusing the discussion, injecting knowledge from diverse sources, diagnosing misconceptions, and offering alternative ideas (Garrison \& Anderson, 2003). This role was taken by the facilitator in this research study to some extent; relevant resources were provided as a source of knowledge and questions were asked to encourage reflection. The main differences between the original community of inquiry category and the blended action learning process were 
that: the facilitator was not driving the learning in a prescribed direction as is suggested in the community of inquiry framework; the facilitator role involved acting as a trusted inquisitor rather than as a direct instructor; and participants also took some of the teaching presence roles. Examples of postings relevant to this category are contained in Table 8-6 below.

\begin{tabular}{|l|l|}
\hline Direct instruction & $\begin{array}{l}\text { Category } \\
\text { illustrated }\end{array}$ \\
\hline $\begin{array}{l}\text { Do you think it is going to be challenging to go back to your job } \\
\text { and not have designated leadership responsibilities or do you think } \\
\text { you have enough leadership opportunities within your current } \\
\text { role? (Kate, response to RJ entry) }\end{array}$ & $\begin{array}{l}\text { Asking } \\
\text { questions }\end{array}$ \\
\hline $\begin{array}{l}\text { Hi all, read a really interesting quote about leadership in } \\
\text { Howard Gardner's book 'Leading Minds' - the book itself is not } \\
\text { really worth reading but this quote stood out for me. It went } \\
\text { along the lines of: }\end{array}$ & $\begin{array}{l}\text { Injecting } \\
\text { keadership is all about judgment - making judgments about } \\
\text { from diverse } \\
\text { what is relevant and what needs to be done. There are times } \\
\text { when leaders need to go out alone in order for others to have } \\
\text { somewhere to follow. } \\
\text { Anyway, I thought this was just so applicable to how I feel } \\
\text { sometimes having responsibility that others in our team maybe } \\
\text { don't feel, and at times, the isolation of the position and having to } \\
\text { make decisions. There is a lot more I could say on the topic but I } \\
\text { thought I'd throw this quote out there and see what you all have to } \\
\text { say about it! (Fiona, F) }\end{array}$ \\
\hline
\end{tabular}

Table 8-6: Examples of direct instruction

\section{Revised stages of teaching presence}

Although the original community of inquiry model acknowledges that teaching presence can be shared between the facilitator and participants, the original categories do not adequately reflect the collaborative nature of blended action learning and the changed nature of the facilitator role. Nor do they reflect the fact that each participant in a multi-problem action learning group has a unique learning experience unlike participants in an online learning course with a prescribed curriculum. For these reasons, teaching presence was renamed 'facilitated learning', as this title reflects more clearly the group nature of the blended action learning experience. The original category of design and organisation was renamed 'organising' and this includes discussion on the use of the site as well as the provision of instructions and guidelines. The category of facilitating discourse was retained and this includes dialogue that takes place as a result of others' posting that is supportive and includes acknowledgement of contributions and the giving of feedback. The final category of 
direct instruction was changed to 'focusing and challenging' and this includes interactions that provide new information and challenge others' thinking.

Table 8-7 below summarises the similarities and differences between the original teaching presence stages and the modified action learning process of facilitated learning.

\begin{tabular}{|l|l|l|l|}
\hline $\begin{array}{l}\text { Teaching } \\
\text { presence }\end{array}$ & Indicators & $\begin{array}{l}\text { Facilitated } \\
\text { learning }\end{array}$ & Indicators \\
\hline $\begin{array}{l}\text { Design and } \\
\text { organisation }\end{array}$ & $\begin{array}{l}\text { Setting curriculum. } \\
\text { Designing methods. } \\
\text { Utilising medium } \\
\text { effectively. }\end{array}$ & Organising & $\begin{array}{l}\text { Providing instructions } \\
\text { and guidelines. } \\
\text { Clarifying expectations. } \\
\text { Asking questions related } \\
\text { to site use. }\end{array}$ \\
\hline $\begin{array}{l}\text { Facilitating } \\
\text { discourse }\end{array}$ & $\begin{array}{l}\text { Setting climate for learning. } \\
\text { Encouraging \& } \\
\text { acknowledging } \\
\text { contributions. } \\
\text { Seeking to recognise } \\
\text { consensus. }\end{array}$ & $\begin{array}{l}\text { Facilitating } \\
\text { discourse }\end{array}$ & $\begin{array}{l}\text { Encouraging and } \\
\text { acknowledging } \\
\text { contributions } \\
\text { Encouraging reflection } \\
\text { Providing feedback }\end{array}$ \\
\hline $\begin{array}{l}\text { Direct } \\
\text { instruction }\end{array}$ & $\begin{array}{l}\text { Presenting content/ } \\
\text { questions. } \\
\text { Focusing discussion. } \\
\text { Injecting knowledge from } \\
\text { diverse sources. } \\
\text { Diagnosing } \\
\text { misconceptions. } \\
\text { Offering alternative ideas. }\end{array}$ & $\begin{array}{l}\text { Focusing } \\
\text { and } \\
\text { challenging }\end{array}$ & $\begin{array}{l}\text { Introducing new } \\
\text { resources, perspectives } \\
\text { and ideas. } \\
\text { Asking challenging } \\
\text { questions that will help } \\
\text { solve problems. }\end{array}$ \\
\hline
\end{tabular}

Table 8-7: Revised teaching presence categories

The revised community of practice stages developed as a result of the initial phase of data analysis are summarised in Table 8-8 below. These stages were further adapted as a result of the leadership journey analysis but before that modification process is described (in Section 8.3 below), the revised model will be discussed in relation to: the facilitator role; the online tools; and the second research group. 


\begin{tabular}{|l|l|l|}
\hline Cognitive presence stages & \multicolumn{1}{|c|}{ Social presence stages } & \multicolumn{1}{|c|}{$\begin{array}{c}\text { Facilitated learning } \\
\text { stages }\end{array}$} \\
\hline Identifying the problem & Sharing & Organising \\
\hline Reflecting & Supporting & Facilitating discourse \\
\hline Deciding & & Focusing and challenging \\
\hline Acting & & \\
\hline
\end{tabular}

Table 8-8: Revised community of inquiry model

\subsubsection{Revised community of inquiry in relation to the facilitator role}

The two different aspects of the facilitator role, enabling learning and acting as a trusted inquisitor, can be linked to particular stages of the revised community of inquiry model. The enabling learning facet of the role relates most closely to the facilitated learning aspect of the revised community of inquiry model and can be connected with all three stages of facilitated learning. Organisational aspects of facilitated learning closely relate to the enabler roles of designing and facilitating a structured learning process and providing technical support. Elements of facilitating discourse in the enabler role include encouraging and acknowledging contributions as a way of motivating participants. The enabler role of providing resources also links with the introduction of new resources and ideas in the focusing and challenging stage of facilitated learning. The trusted inquisitor facet of the role relates to both the facilitated learning and the social presence aspects of the revised community of inquiry model. Features of the trusted inquisitor role that link with the facilitating discourse aspect of facilitated learning include providing support, and role modelling and coaching. The focusing and challenging stage of facilitated learning closely relate to the challenging and questioning facets of the trusted inquisitor role. A number of aspects of the trusted inquisitor facet of the role also relate to the social presence aspect of the revised community of inquiry model. These include building relationships and providing support for participants. Although the facilitator supported the progression of participants through the stages of cognitive presence, this was an individual process, and there is no direct link to this aspect of the revised model. The links between the facilitator role and the revised community of inquiry model are illustrated in Figure 8-1. 


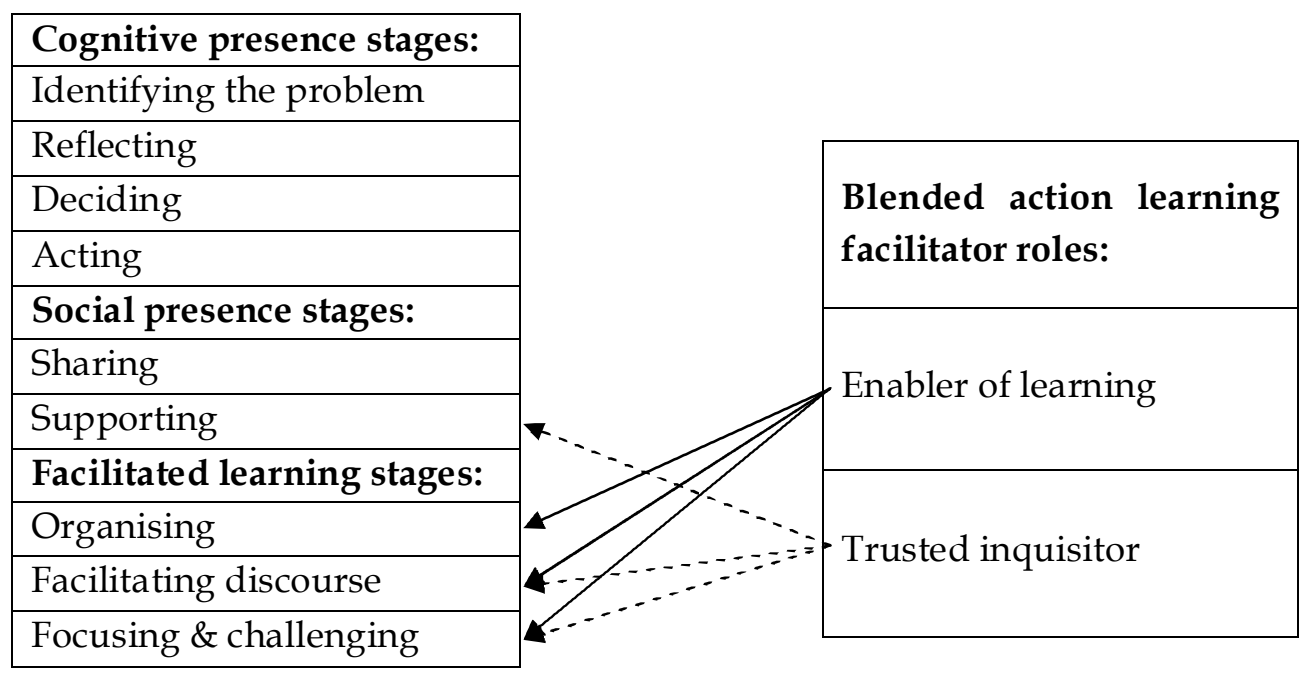

Figure 8-1: Linking facilitator role to revised model

\subsubsection{Revised community of inquiry in relation to online tools}

Preliminary data analysis identified that the discourse used in the different online technologies was more closely related to some types of presence than others. The online reflective journal entries revealed clear evidence of the stages of cognitive presence. Problems and issues were recognised and reflected on, and strategies identified and put into action. These actions were reflected on and modified in light of experience. The facilitator responses to reflective journal entries involved both facilitating discourse and focusing and challenging. Forum entries involved the greatest variety of categories as there was evidence of all three aspects of the model. Some forum discussions related to working through issues and problems and therefore illustrated cognitive presence stages. Both aspects of social presence, supporting and sharing also characterised forum entries as did the facilitated learning stages of facilitating discourse and focusing and challenging. The chat function of the online site had a definite bias toward social presence with many interactions being focused on exchanging information on both personal and work issues. Emails were most frequently used by the facilitator to discuss organisational aspects of the online learning site. Figure 8-2 illustrates the links between the various online tools and the revised model. 


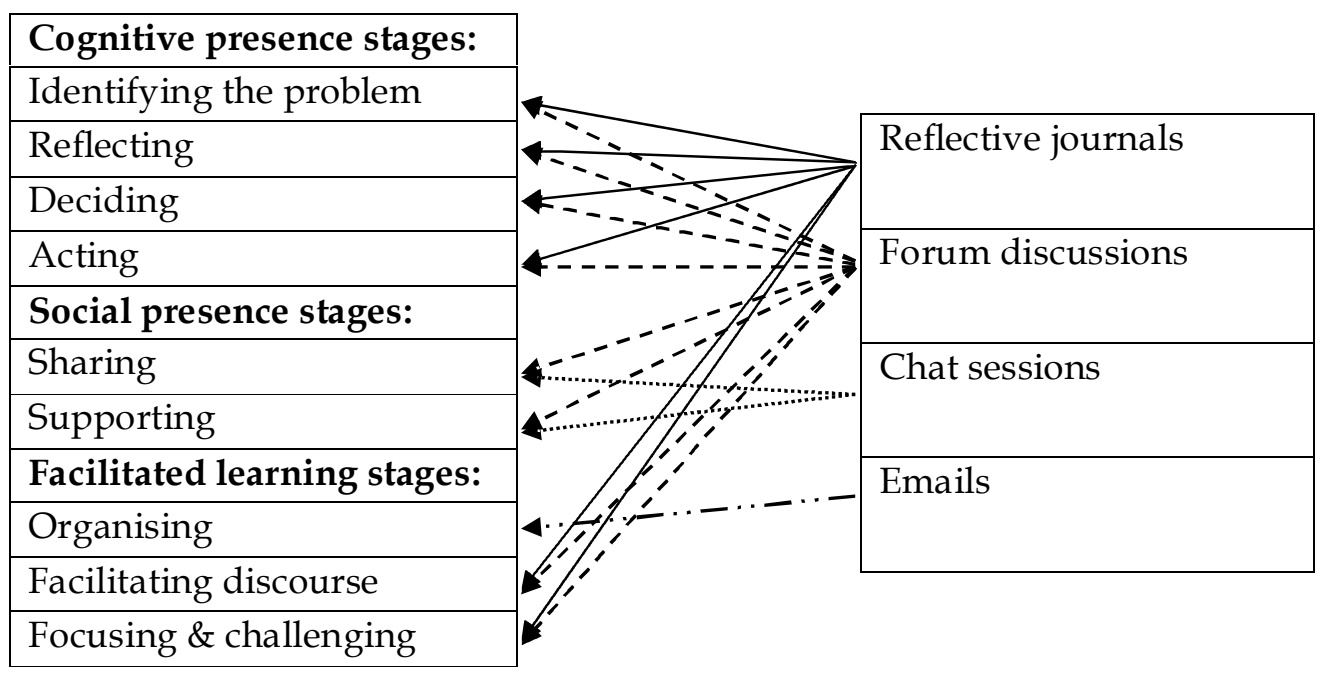

Figure 8-2: Linking online tools to revised model

\subsubsection{Revised community of inquiry model and LALG2}

As previously mentioned, the revised community of inquiry model was developed as a result of the analysis of data from the first research group. Data from the second research group were examined as they became available to see if they fitted in the revised categories and this proved to be the case. The revised model was then set aside while the second major phase of data analysis was carried out.

\subsubsection{Section summary}

The choice of the community of inquiry model as a research framework provided a useful structure for the initial analysis of data. This phase of the data analysis resulted in a revised community of inquiry model that represented more clearly the learning experiences that occurred in the blended action learning groups. Of the three types of presence in the original model, cognitive presence is most applicable in its current form, although the names of the stages were changed to reflect more closely the blended action learning process. Both the social presence and teaching presence aspects required greater modification due to the smaller group size and the more collaborative nature of the blended action learning process and were eventually replaced by three aspects of the model of leadership learning to be presented in the next section. Despite the changes made, the revised community of inquiry model still did not fully illustrate the leadership learning that occurred as a result of participation in the blended action learning groups. One of the main restrictions of the revised model is that it does not illustrate the progression that participants made over the time they were involved in the blended action learning groups. This progression was illustrated in the leadership journeys that were presented in Chapter 5 and was also referred to by participants who made numerous references in online postings to 'being on a journey', 'moving forward', 'taking steps', or 'making progress'. For this reason a secondary phase of data analysis began which will be described in the next section. 


\subsection{Leadership journey data analysis}

The second distinct phase of data analysis involved the compilation and analysis of individual participants' chronological leadership journeys. This process involved taking all the interview material and postings, including reflective journals, forum entries and chat sessions, and arranging them in date and time order. The six leadership journeys presented in Chapter 5 represent a sample of these voyages. This material was analysed by reading each leadership journey and looking for commonly occurring themes. This additional stage of data analysis allowed progression to be seen and revealed a number of recurring categories including: developing awareness of different aspects of leadership practice; decisions about making changes or acting differently; shifts in practice; and greater confidence in leadership practice leading to the distribution of leadership. Each of these categories will be discussed in detail in following sections and examples given from the research data, however prior to that discussion, the model of leadership learning will be presented.

\subsubsection{Model of leadership learning using ICT}

Both the leadership journey phase of data analysis and the revision of the community of inquiry model described in the previous section contributed to the model of leadership learning which will now be presented. Figure 8-3 below illustrates the process of leadership learning using ICT that occurred as a result of participation in the blended action learning process used in this study. This process of leadership learning, which involved the development of awareness leading to greater confidence and distributed leadership through a process of recognising, reflecting, realising and responding, was influenced by four key elements. These are: the role taken by the facilitator, which involved enabling learning and acting as a trusted inquisitor; the blended action learning process of questioning and reflection; the ICT tools used; and participation in the blended action learning group which involved both sharing and support. The following sections will give a more detailed explanation of the contribution of the analysis of leadership journeys to this model, and will include examples from the research data. Each of the components of the model will be discussed in more detail in Section 8.4. 


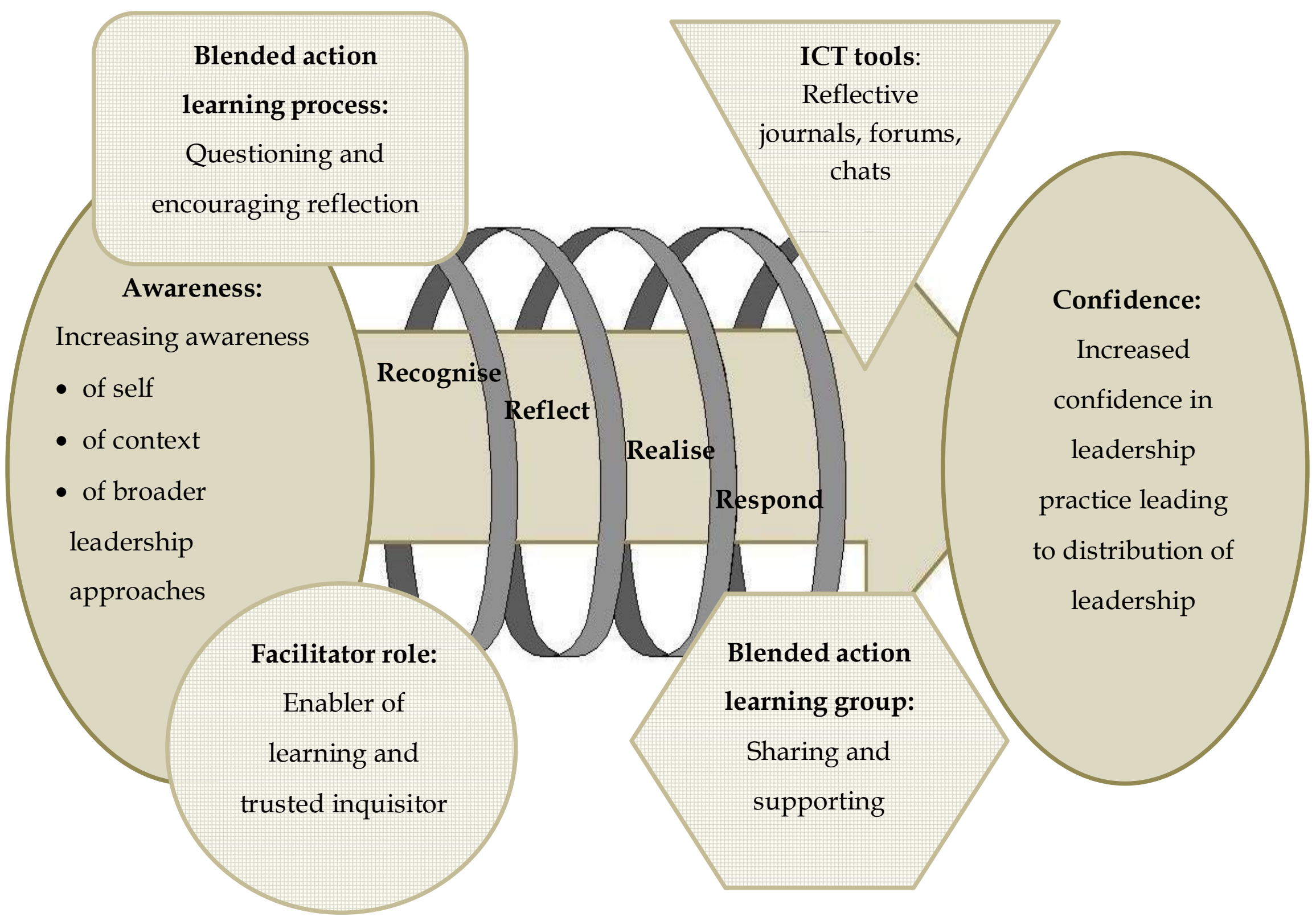

Figure 8-3: Model of leadership learning using ICT 


\subsubsection{Development of awareness}

Greater awareness of different aspects of leadership was repeatedly revealed in the leadership journeys of the 12 participants. Initial analysis of the leadership journeys revealed both the development of self-awareness and broader awareness of one's own situation (realisation). Further analysis of these broad categories revealed that under the heading of awareness, three differing forms of awareness rather than two could be recognised. These were self-awareness, awareness of one's own context, and increased awareness of broader leadership approaches and styles. Although there is some overlap between these categories, they do seem to represent distinct aspects of awareness. Table 8-9 below shows examples of each of the three forms of awareness.

\section{Self-awareness}

I have been reflecting on how I appear to staff and I do know I come across as having a viewpoint and possibly not taking on other's view points. (Beth, RJ) I feel like I've developed over that 6 months and I've more of a picture of myself as a leader and in the same way I've kind of identified the things that I'm not comfortable doing and that I need to work on and, for example I've realised that I often try to initiate far too many things at once. (Charlotte, I)

Awareness of own context

I realised that they are used to being told or asked to do things and so my style of working as a team equally and using initiative was confusing them. (Amy, RJ) I am convinced there is no place especially in a structure like ours, for just one leader - it is possible and desirable for there to be many leaders, albeit at different stages and levels of leadership, all of whom can be nurtured and supported to grow into leaders beyond their own area, to be effective advocates for children and ece. (Karen, RJ)

\section{Awareness of leadership in general}

Having the framework for shared leadership and having some understanding of the different styles of leadership is allowing me to think well this is what I need to do here, this is what I need to do here, so I'm kind of more of a leader. (Jane, I) I'm learning and reading up a lot more about different leadership styles and situational leadership and looking at if I' $\mathrm{m}$ a coach to one teacher and a supporter to another teacher and not putting them all in the same little box. (Lisa, I)

\section{Table 8-9: Examples of forms of awareness}

The development of self-awareness has been identified as a key goal of leadership development programmes (Donaldson, 2008; National College of School Leadership, 2005), and an important contributor to effective leadership practice (Ancona et al., 2007; George et al., 2007; Raelin, 2003). These authors all emphasise the importance of leaders 
reflecting on their life experiences and asking for feedback from others in order to learn more about themselves as leaders. Self-awareness is also one of the four domains of emotional intelligence and involves emotional self-awareness, accurate self-assessment and self-confidence (Goleman et al., 2002). According to Goleman et al., leaders with well developed self-awareness are reflective and thoughtful, and are likely to demonstrate authentic leadership. Several aspects of the leadership learning process contributed to the development of the study participants' self-awareness including the articles sent to them to read before the first face-to-face meeting, the leadership journey exercise used at the first meeting, the individual and shared reflection that occurred throughout the leadership learning process, the personality type and leadership style sessions, and the interview questions that also encouraged them to reflect on what they had learnt about themselves.

Participants in this study developed a greater awareness of their own context and of leadership in general alongside their developing self-awareness. As they became more aware of different leadership practices and styles, they applied these to their own situation and consequently became more conscious of how leadership was being enacted in their settings. The information provided on current leadership theory and practice and the resources available on the site both contributed to this wider consciousness. The importance of leadership development programmes offering leadership frameworks for leaders to consider and apply to their own contexts is emphasised by Donaldson (2008). Having leadership frameworks and models to draw on allowed participants to understand their own natural leadership style and strengths and also encouraged them to try out different ways of demonstrating leadership. The different reflective opportunities available encouraged participants to consider what approaches were most appropriate in their context. Several participants commented on their growing realisation that different leadership approaches were needed in different situations with different people.

\subsubsection{Shifts in practice}

Greater awareness of different approaches to leadership practice involved reflection, and led to clarification of the issues that needed to be addressed. In many cases this resulted in a decision to make changes or act in a different way. All 12 participants in this study were able to articulate shifts in practice that they had made as a result of participation in the blended action learning process, with the more active members articulating more significant shifts than the less active ones. Although the decision to do things differently was sometimes documented prior to the taking of action steps, in many cases the shift in practice was what was documented. The following examples illustrate responses that occurred as a result of the reflection process. 


\begin{tabular}{|l|}
\hline Shifts in practice \\
\hline $\begin{array}{l}\text { I have changed my tactics with her and am assuming more of a mentoring } \\
\text { position. (Charlotte, F) }\end{array}$ \\
\hline $\begin{array}{l}\text { The way I help other teachers do things now is different. Rather than doing it for } \\
\text { them or giving them too much support, giving them models or examples to go on, } \\
\text { but leaving them to do it and then checking back in. (Fiona, I) }\end{array}$ \\
\hline $\begin{array}{l}\text { I actually don't take on such a personal side of issues that arise now. I'm more } \\
\text { inclined to think about how it affects the whole picture (Isabel, I) }\end{array}$ \\
\hline I have worked out that I need to delegate more. (Jane, RJ) \\
\hline
\end{tabular}

Table 8-10: Examples of shifts in practice

\subsubsection{Developing confidence}

Developing self-awareness involved becoming more aware of one's strengths and limitations and one's values and motives. This self-knowledge resulted in greater selfconfidence among participants in this study and a willingness to tackle issues and make shifts in practice. Donaldson (2008) promotes the importance of leaders learning about themselves and suggests that through coming to understand themselves better, they gain "a level of control, confidence and self-efficacy as leaders" (p. 87). A number of aspects of the blended action learning process, including the reflective journalling process and the questioning used in both face-to-face and online action learning, supported the development of self-awareness. The cognitive presence stages of identifying, reflecting and responding acted as a catalyst for moving participants from becoming more aware to having greater confidence in their leadership, and could be seen across both groups. This increase in confidence was more marked in some participants than others. In general those who were less experienced in their leadership roles reported a greater increase in confidence and this was also related to the levels of engagement with the leadership learning process with more active participants reporting a greater increase in confidence. This increased confidence in practice was discussed in Section 6.2.4 and illustrated through examples of actions taken and through self-reporting. Table 8-11 contains more examples of the increased self-confidence reported by participants.

\section{Developing confidence}

I have to say this leadership research has done a great deal for my confidence at dealing with situations with staff. (Amy, C)

My self-belief has increased since doing the course so that is another plus. Thank you Kate, I have increased my skills in a number of ways so I am very pleased. (Beth, RJ)

Actually I do have more confidence in my role. (Heather, I)

I am more confident and determined to act. (Lisa, RJ)

Table 8-11: Examples of increased self-confidence 
The increased self-confidence demonstrated by participants in this study empowered them to make changes and to take action on issues, some of which they had been aware of for some time. Participation in a supportive group environment assisted in these shifts in practice some of which were documented in the leadership journeys presented in Chapter 5. Many of these journeys illustrate the increased self-confidence particularly among the more active participants.

\subsubsection{Distributing leadership}

Not only were individuals more confident, but also other teachers in the participants' centres often became empowered as leadership was distributed more widely. In some cases, empowering team members and distributing leadership was a specific goal, and in other cases it was a result of the increased confidence of the participants and their broader conceptions of what leadership could look like in their context. Some of the comments made by participants with regard to the distribution of leadership are shown in Table 8-12 below.

\begin{tabular}{|c|}
\hline dership \\
\hline $\begin{array}{l}\text { I am also focussing on empowering my teachers at the moment.... I have currently } \\
\text { got a strong team of leaders, and everyone (although they are relatively new } \\
\text { teachers) has the desire to take responsibility for things. It's very exciting. } \\
\text { (Charlotte, F) }\end{array}$ \\
\hline $\begin{array}{l}\text { I have really enjoyed the positive impact that giving my staff various tasks to be } \\
\text { autonomous and responsible for, has had on the team 'feel'. For this reason, one of } \\
\text { my next goals is to continue to empower my staff by offering them opportunities to } \\
\text { make 'real' decisions - hopefully moving more towards a staff that work 'with' } \\
\text { rather than 'alongside' each other. (Diana, F) }\end{array}$ \\
\hline $\begin{array}{l}\text { I think that the best thing I can do is to continue to empower my staff by extending } \\
\text { their knowledge and learning in new areas. This keeps them motivated and } \\
\text { focused on their jobs and the centre environment. (Emma, F) }\end{array}$ \\
\hline $\begin{array}{l}\text { I think my attitude and also that of our teachers has changed so much that there is } \\
\text { that expectation for participation and also the level of empowerment and support } \\
\text { for it to take place. (Fiona, RJ) }\end{array}$ \\
\hline
\end{tabular}

\section{Table 8-12: Examples of distributing leadership}

A link between increased self-awareness and the encouragement of leadership in others has been made by Raelin (2003), who suggests that distributed leadership begins with leaders knowing their own capabilities and how they impact on others. He also promotes the value of shared reflection for developing self-awareness. Ancona et al. (2007) suggest that leaders who know their strengths and limitations are more likely to search out and work with others whose strengths complement theirs. The greater distribution of leadership that resulted from participation in this current study can be linked to the 
distinction made between leader development and leadership development in Section 2.2.3 of the literature review. Day's (2000, p. 582) definition of leadership development as "expanding the collective capacity of organizational members to engage effectively in leadership development roles and processes" fits with the finding that a focus on the leadership development of individuals can result in leadership being distributed more widely. In this study distribution of leadership was restricted to the teaching teams of participants rather than a wider span of control and while much of the focus of the approach to leadership development in this study was on the individual leaders, a number of processes encouraged participants to address real issues that involved the building of social capital. These processes included discussion on the value of distributed leadership at the first face-to-face meetings, articles on the website that promoted notions of distributed leadership, encouraging participants to share their goals with colleagues and ask for feedback, and the action learning process as a whole which encourages deep reflection on work-based issues.

The role of the formal leader in encouraging distributed leadership was discussed in Section 2.2.2 of the literature review. The importance of formal leaders having the opportunity to focus on their role in distributing leadership through leadership development programmes has been emphasised (James et al., 2007). Harris (2008) describes formal leaders as the gatekeepers of distributed leadership as they can either encourage or discourage its development. She emphasises the importance of mutual trust and agreement about how leadership is to be distributed. The importance of trust in encouraging wider participation in leadership activities is also promoted by WestBurnham (2004), who also emphasises the role of the formal leader in encouraging distributed leadership. Data from this research study indicate that the process of devolving leadership responsibilities is more likely if the formal leader is secure in their knowledge of who they are as a leader and confident in their leadership practice.

\section{Links with individual leadership journeys}

Key words that illustrate the leadership learning process were highlighted throughout the leadership stories presented in Chapter 5. These words (realising, reflecting, acting, empowerment and confidence) are all discussed in this chapter and were integrated into the model of leadership learning presented earlier.

\subsubsection{Further revisions to community of inquiry model}

Further revisions were made to the revised community of inquiry model as a result of the second phase of data analysis described above. These revisions include replacing the social and facilitated learning with three of the elements of the model of leadership learning (Figure 8-3), and making further revisions to the stages of cognitive presence. 


\section{Replacement of social presence and facilitated learning aspects}

The social presence and facilitated learning aspects of the revised community of inquiry model do not form part of the model of leadership learning using ICT presented earlier in this chapter as their stages are adequately represented by other elements of the model. The facilitator role which was discussed in relation to the revised model in Section 8.2.4 encompasses all of the stages of facilitated learning and also contributes to the supporting stage of social presence. The blended action learning group aspect of the blended action learning process links strongly with the social presence aspect of the revised community of inquiry model and also to a lesser extent with the facilitated learning aspect. The two elements of social presence can also be linked with the facilitating discourse and the focusing and challenging stages of facilitated learning. The indicators of the facilitating discourse stage, encouraging and acknowledging contributions, encouraging reflection, and providing feedback were all demonstrated by participants in this study as well as by the facilitator. In the focusing and challenging stage, participants contributed their perspectives and ideas, shared resources, and questioned other participants to encourage their learning. The blended action learning process of questioning and encouraging reflection is most closely related to the facilitated learning stages of facilitating discourse and focusing and challenging. The use of questioning is particularly crucial to the focusing and challenging stage as it is the questioning that encourages participants to reflect more deeply and identify actions that will solve problems and help them reach their leadership goals. Figure 8-4 below illustrates how these stages are related to three of the facets of the model, the facilitator role, the blended action learning process and the blended action learning groups. 


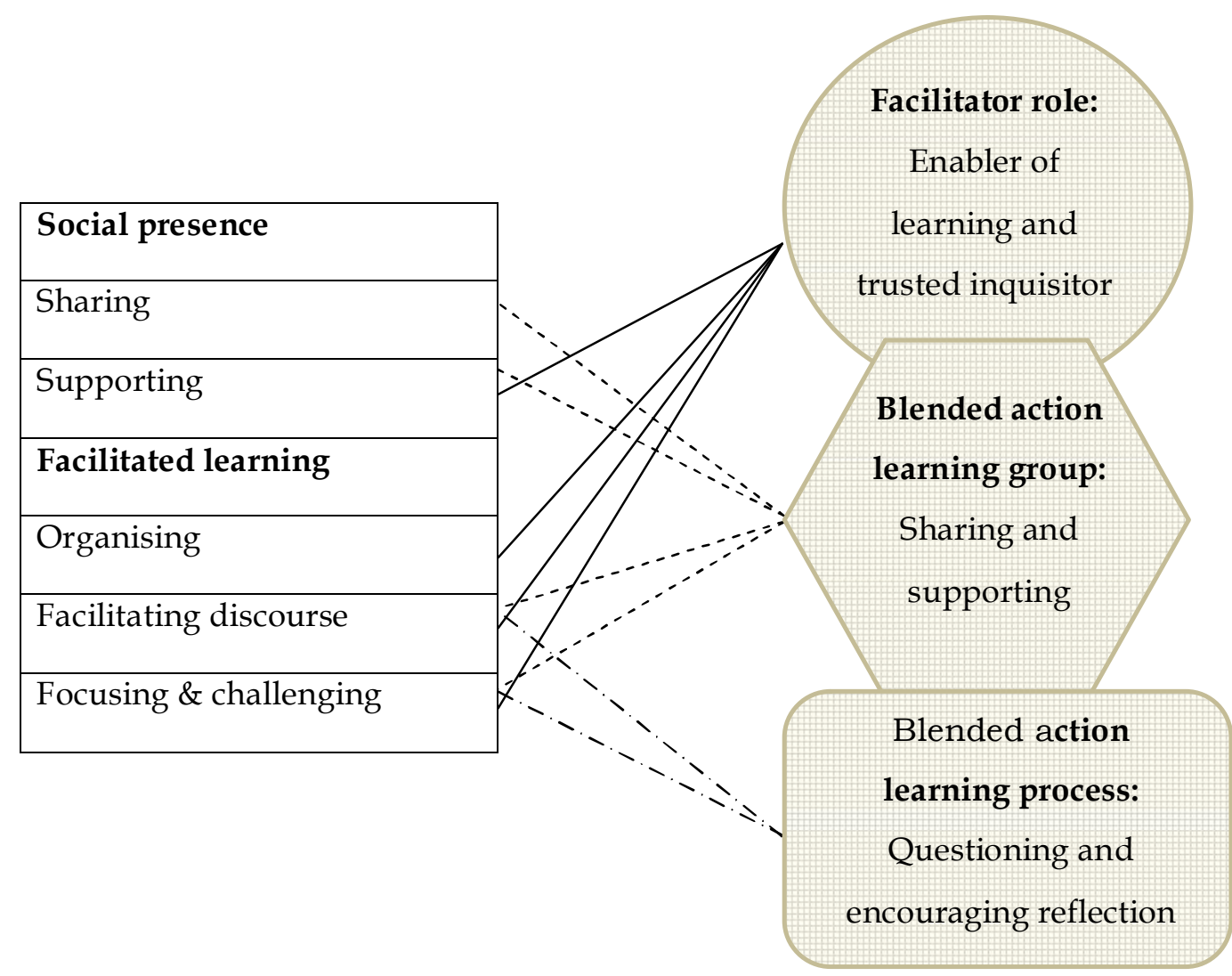

Figure 8-4: Links between the of inquiry model and aspects of leadership learning model

\section{Further revision of cognitive presence stages}

The original community of inquiry model was modified to reflect the increased selfdirection and greater emphasis on reflection occurring in blended action learning compared with more formal online learning environments. As a result of the leadership journey analysis process described above, the revised cognitive presence stages of identifying a problem, reflecting, deciding and acting were further modified and renamed as 'recognising', 'reflecting', 'realising' and 'responding'. This further modification reflects the finding that the process of reflection generally resulted in some new understanding or realisation, and that deciding and acting were not always separate processes. Participants in this study would often articulate their realisation or new understanding followed by their response, which would involve either a proposed shift in practice or some action already taken, hence the combining of the stages of deciding and acting. Two examples, both of which have already been referred to in previous chapters, are documented below to illustrate the revised stages. 


\begin{tabular}{|l|l|l|}
\hline $\begin{array}{l}\text { Revised } \\
\text { cognitive } \\
\text { presences } \\
\text { stages }\end{array}$ & $\begin{array}{l}\text { Example 1: Charlotte's issue of not } \\
\text { getting true critique of ideas and } \\
\text { actions }\end{array}$ & $\begin{array}{l}\text { Example 2: Fiona's issue of } \\
\text { carrying too many lea dership } \\
\text { responsibilities in her centre }\end{array}$ \\
\hline Recognising & $\begin{array}{l}\text { Charlotte recognised that she was } \\
\text { making many decisions in her } \\
\text { centre without input from others. }\end{array}$ & $\begin{array}{l}\text { Fiona recognised that she was } \\
\text { taking on more than her share of } \\
\text { workload and wanted to make } \\
\text { her position more manageable. }\end{array}$ \\
\hline Reflecting & $\begin{array}{l}\text { Charlotte reflected on this situation } \\
\text { aided by questions posed by the } \\
\text { facilitator and other participants in } \\
\text { an online action forum. For } \\
\text { example: "I wonder: should I be } \\
\text { holding back my ideas for longer? } \\
\text { Perhaps I should simply explain the } \\
\text { situation and not give any ideas at } \\
\text { first". }\end{array}$ & $\begin{array}{l}\text { Fiona reflected on how she } \\
\text { could address this issue in the } \\
\text { face-to-face meetings, forum } \\
\text { discussions and in her reflective } \\
\text { journal. For example: "I think if } \\
\text { I really examine myself I could } \\
\text { say that I feel like if I ask for help } \\
\text { I am not doing my job well } \\
\text { enough". }\end{array}$ \\
\hline Realising & $\begin{array}{l}\text { This led to the realisation that she } \\
\text { tended to present and justify her } \\
\text { view before asking for any input } \\
\text { from others. }\end{array}$ & $\begin{array}{l}\text { This led to the realisation that } \\
\text { she could make quite small } \\
\text { changes that would make a } \\
\text { difference to her workload and } \\
\text { would empower other teachers. }\end{array}$ \\
\hline Responding & $\begin{array}{l}\text { Charlotte decided to try seeking } \\
\text { others' opinions first on } \\
\text { occasions and also asking for } \\
\text { feedback on her ideas. This was } \\
\text { tried in subsequent meetings }\end{array}$ & $\begin{array}{l}\text { Fiona made many changes to } \\
\text { her leadership practice } \\
\text { including delegating more tasks } \\
\text { to other teachers and asking for } \\
\text { extra help when feeling } \\
\text { overloaded. }\end{array}$ \\
\hline
\end{tabular}

Table 8-13: Examples of recognising, reflecting, realising and responding

\subsubsection{Section summary}

This second stage of data analysis, which involved the compilation and analysis of the chronological leadership journeys of participants, revealed a number of recurring categories including development of awareness, shifts in practice, increased confidence and distribution of leadership. These aspects of the leadership learning process have all been incorporated into the model of leadership learning (Figure 8-3). The development of different forms of awareness appeared to result in shifts in practice which in turn led to greater confidence in leadership practice. This second phase of data analysis also resulted in modifications to the stages of the revised community of inquiry model; the previous modifications have been outlined in Section 8.2. 


\subsection{Components of the model of leadership learning using ICT}

The model of leadership learning presented earlier in this chapter (Figure 8-3) was developed from the results emerging from the two phases of data analysis. Two key aspects of the model that illustrated the leadership learning process taking place as a result of participation in this study have been discussed so far in this chapter. These are the development of awareness leading to increased confidence and the revised cognitive presence stages. Both of these aspects will be discussed again in the following sections in relation to the model of leadership learning. This will be followed by discussion of four other elements within this study that contributed to the leadership learning process and that also influenced the development of confidence and the stages of cognitive presence. One of these, the facilitator role was the focus of Chapter 7 and the other three, the blended action learning process, the ICT tools used, and participation in the blended action learning group were discussed in depth in Chapter 6. These four aspects link closely to social presence and facilitated learning in the revised community of inquiry model and have replaced them in the model of leadership learning using ICT.

\subsubsection{From awareness to confidence}

A key feature of the leadership learning process revealed in this study was the development of awareness leading to increased confidence. As discussed in section 8.3.2, this included increased self-awareness, heightened awareness of one's own context, and greater awareness of leadership in general including different frameworks and leadership styles. The four stages of cognitive presence acted as a catalyst for this development of awareness and for the movement towards the feeling of increased confidence in leadership practice expressed by participants, examples of which were presented in Section 8.3.4 above. This process was also influenced by the role taken by the facilitator and the blended action learning process, including group participation and the use of ICT tools. This movement from developing awareness to increased confidence was more obvious in some participants than in others. The more experienced and confident participants were when they joined the groups, the less evident this movement was. For the majority of participants in the study, the process of developing awareness leading to increased confidence was clearly apparent. In many cases an increase in personal confidence impacted more broadly and also resulted in the greater distribution of leadership as reported by participants. This aspect of the leadership learning process is illustrated in Figure 8-5. 


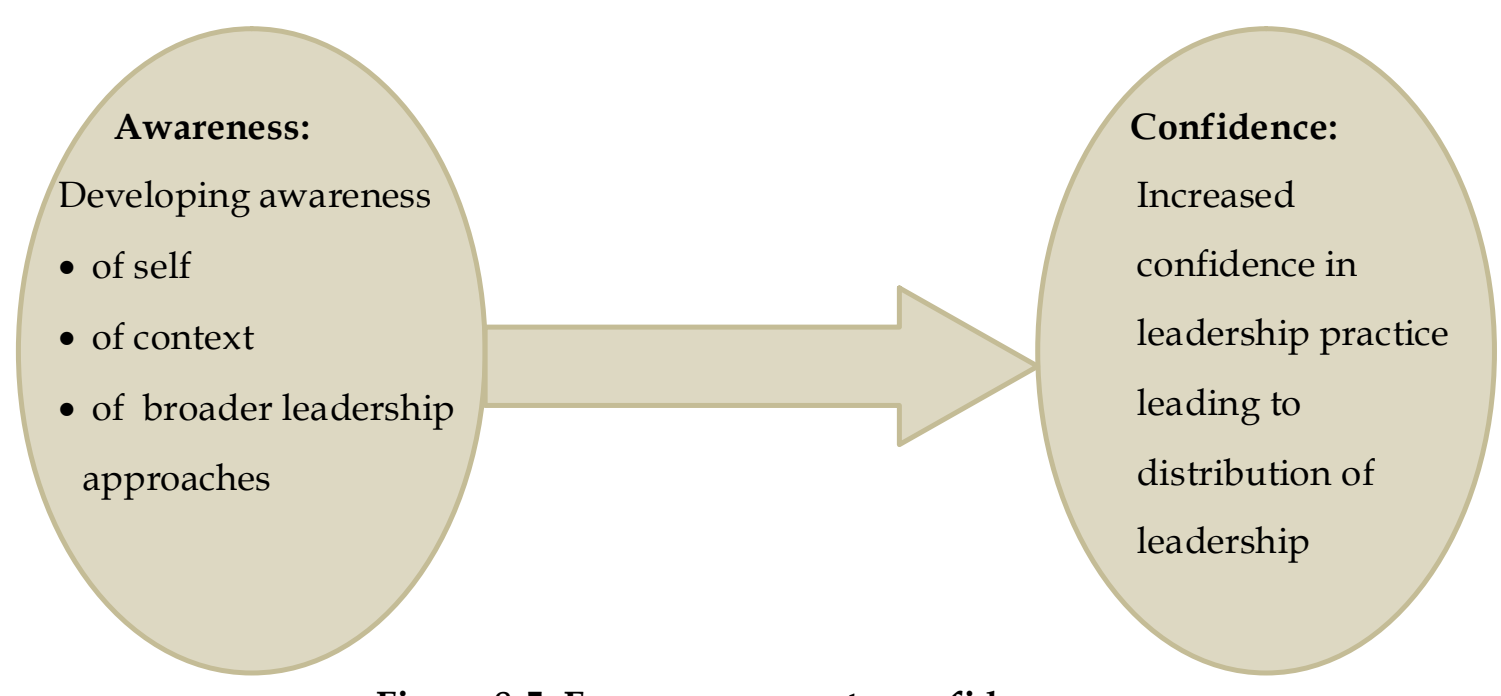

Figure 8-5: From awareness to confidence

\subsubsection{Evolving stages of cognitive presence}

This facet of the model illustrates the process by which participants develop meaning and understanding through ongoing discourse and reflection, and is critical to the development of awareness and the movement from awareness to confidence. The four other elements of the leadership learning process (to be discussed in more detail in the following sections) all impacted on movement through the revised stages, in particular the blended action learning process of questioning and encouraging reflection. The four revised stages of cognitive presence, recognising, reflecting, realising, and responding were repeated several times during the leadership journeys of most of the participants in this study as they became aware of a problem or issue (recognising), reflected on the issue, came to a realisation and then responded in ways that addressed the issue. The reflection process sometimes involved reflection on action, as participants reflected on past actions and how these might be modified in the light of new information, and sometimes involved reflection before action, as they reflected on what actions they might take. Reflection before action (in addition to reflection on action) is promoted by Greenwood (1998) who describes it as "thinking through what one wants to do and how one intends to do it before one actually does it" (p. 1049). Both these processes of reflection, which encourage the challenging of accepted ways of doing things, encourage double loop learning. This process, as previously mentioned in Section 2.7.2, involves the reinterpretation of events and encourages deeper learning. The processes of reflection on action and reflection before action were documented either in participants' reflective journals, forum entries, and chat postings or shared in the faceto-face meetings. This four stage process was not always linear, for example, sometimes realisation led to further reflection. For this reason the process is represented in the model by a spiral as is shown in Figure 8-6. 


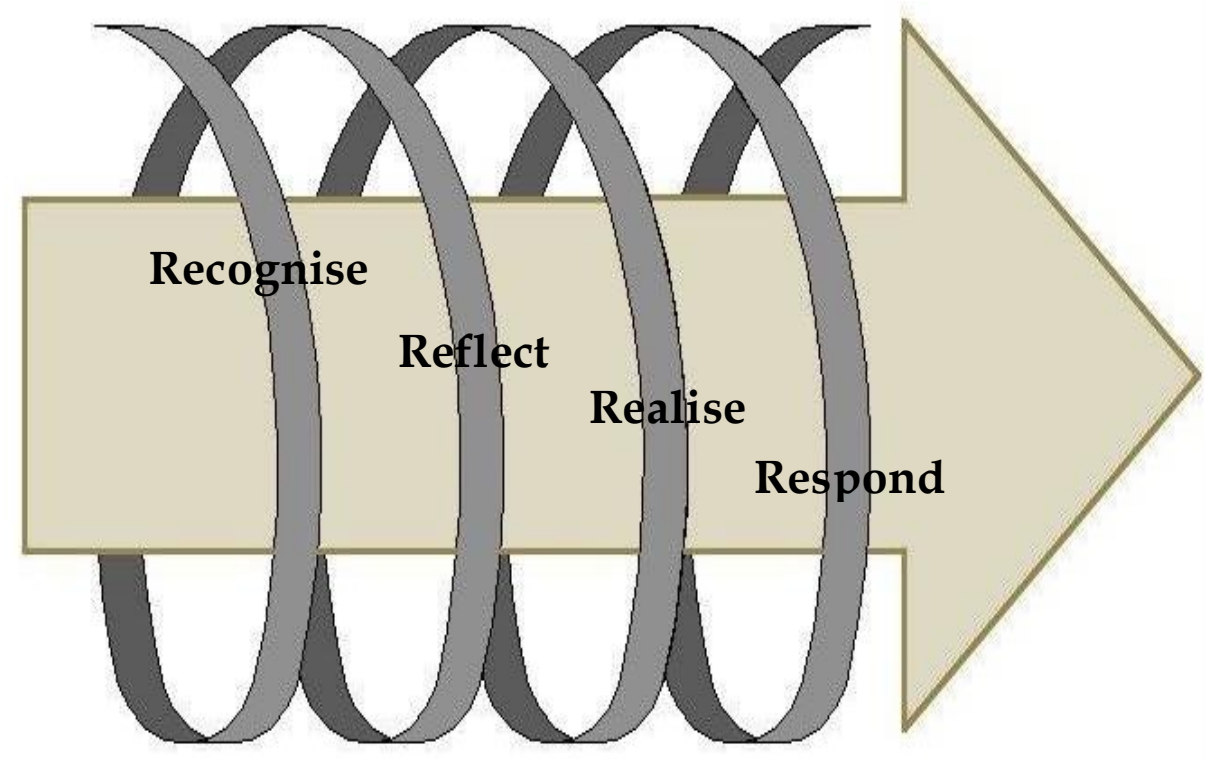

Figure 8-6: Recognising, reflecting, realising \& responding

\subsubsection{Impact of the facilitator role}

The facilitator, whose role in relation to the revised community of inquiry model has been discussed previously in this chapter (Section 8.2.4), had a critical role in the overall leadership learning process. Both aspects of the facilitator role, acting as an enabler of learning and as a trusted inquisitor were crucial and are included in Figure 8-7 which illustrates this role. The enabling learning facet of

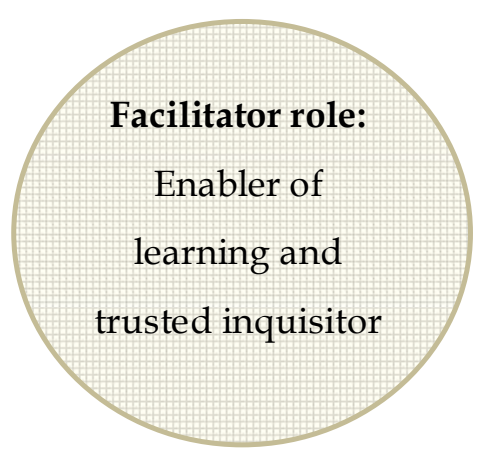

Figure 8-7: Facilitator role the role helped create the conditions needed for learning through designing and facilitating a structured learning process, motivating and encouraging participation, and providing resources and technical support. The trusted inquisitor facet of the role appeared to have had the most impact on leadership learning. Building trust with and between participants was an important contributor to the subsequent learning as the existence of trust encouraged people to be honest, to share their vulnerabilities and to learn about themselves as leaders. The provision of emotional support, and in particular the communication of understanding and demonstration of empathy, appeared to contribute to the reflection and learning of participants. The role of the trusted inquisitor in questioning and encouraging reflection also seems significant; participants were challenged to look at their issues differently and to reflect more, leading to deeper learning. The role of the trusted inquisitor in providing leadership expertise was also important because of the support given to participants in developing their awareness of different 
leadership approaches. Overall the facilitation role is a key contributor to leadership learning.

\subsubsection{Impact of the blended action learning process}

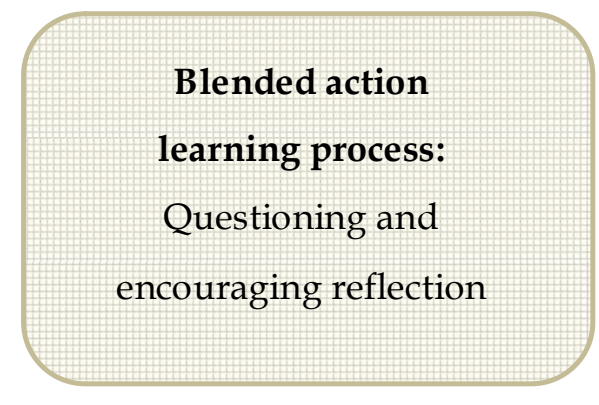

Figure 8-8: Blended action learning

The blended action learning process encouraged participants to reflect on their approaches and experiences and the use of questioning helped them to identify future actions with regard to their leadership goals. Both reflection and questioning appeared to have had a powerful impact on the leadership journeys of participants in both action learning groups and these two aspects are included in Figure 8-8 which illustrates this process. The blended action learning process was a major contributor to the movement of participants through the four revised stages of cognitive presence, recognising, reflecting, realising and responding. The questioning used in face-to-face meetings, in online action learning forums and in reflective journals encouraged participants to reflect on the issues they had recognised. The action learning that occurred online was particularly valuable as it gave participants the time to both construct and respond to questions. The blended action learning process helped them develop greater awareness and identify how they were going to respond to the issues they had identified. The questioning process also supported the development of the different forms of awareness which in turn contributed to the increased levels of self-confidence described by participants.

\subsubsection{Impact of the ICT tools}

The relationship between the online tools and the revised community of inquiry model was discussed earlier in this chapter in Section 8.2.5. This section will discuss the tools in relation to the overall process of leadership learning. All of the technologies used on the online site were valued by participants and contributed to the leadership learning process as they had different and complementary functions. The online journalling process supported the four revised stages of cognitive presences, in particular reflection, and also encouraged participants to develop the different forms of awareness described in Section 8.3.2. The confidentiality aspect of the reflective journals was important as it allowed participants to freely share their thoughts and feelings and this surfacing of emotions contributed to the increased self-confidence identified by participants. The forum discussions provided an opportunity for participants to share the goals they were working on with the group and to discuss issues related to their work contexts. This supported their leadership learning as they were able to address and gain different perspectives on issues 


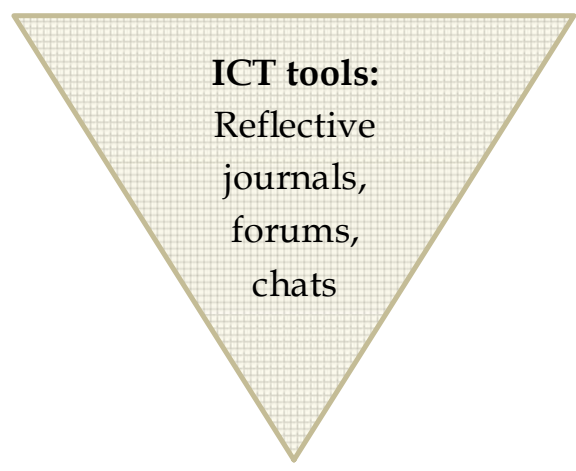

Figure 8-9: ICT tools they were facing. Chat sessions were particularly important in building and maintaining strong relationships between participants and made a major contribution to the sharing and supporting aspects of the blended action learning process. Because emails were used only in relation to the organisational aspects of facilitated learning rather than by the participants themselves, they are not included as one of the tools. The contribution of the three ICT tools is represented by Figure 8-9.

\subsubsection{Impact of participation in the blended action learning group}

Participation in the action learning groups had many benefits including participants gaining different perspectives on leadership practice, experiencing a reduction in their sense of isolation, and feeling supported by other group members. Discussing their leadership practice within the group made participants more aware of their own unique approaches to leadership. Hearing about the struggles of others appeared to increase their confidence as they realised that other leaders faced similar issues and that they were not alone. Through the sharing of their personal leadership stories and aspects of their everyday personal and professional lives, participants got to know each other well and developed trusting relationships. This high level of trust encouraged the sharing of emotional issues and hence the learning experience for individuals was deepened. These strong relationships laid the platform for interactions that supported leadership learning such as exchanging information related to

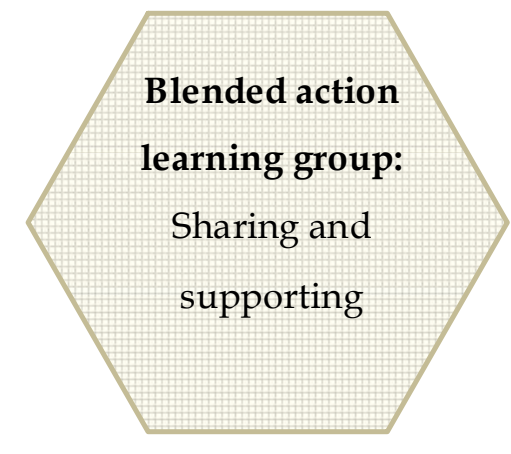

Figure 8-10: Blended action learning group work practices, asking questions of each other in order to clarify and encourage reflection, and complimenting each other and expressing appreciation. The two complementary aspects of participation in the blended action learning group are included in Figure 8-10 which represents this aspect of the model. A hexagonal shape was chosen to represent the six participants in each action learning group.

\subsubsection{Contribution of the model}

The model of leadership learning using ICT (Figure 8-3), the development of which has been explained in the previous sections, contributes to our understanding of the 
leadership development process employed in this research in a number of ways. Firstly, it illustrates the progress made by participants over the course of their involvement in the leadership development process. This progress can be seen through the reported development of different forms of awareness, the shifts in practice made and actions taken, the increase in confidence and the distribution of leadership that was described by some participants. A number of elements contributed to the leadership learning of participants and the confidence they developed in their leadership practice. These included the four elements discussed in previous sections and the revised stages of cognitive presence outlined in Section 8.4.2.

A second contribution of the model is its recognition of the importance of both the individual and group aspects of the learning process. Although the leadership journeys of individual participants were unique because of the different contexts they worked in, the different issues they faced and the different stages they were at in their leadership journeys, there were also aspects of collaboration and group learning. The leadership learning of individuals was supported by participation in the action learning groups. The other participants made a major contribution to each person's leadership learning by: providing different perspectives on leadership practice; reducing the feelings of isolation experienced by participants; and supporting each other's learning. The complementary aspects of the blended action learning facilitator role supported both the individual and group learning.

The third major contribution relates to a greater understanding of the importance of the different processes in supporting leadership learning. It was the combination of the action learning processes of reflection and questioning, participation in the action learning group, the use of appropriate ICTs, and the role of the blended action learning facilitator that contributed to the leadership learning of participants. The model illustrates these different aspects of the process and also recognises the importance of the stages of cognitive presence, in particular the importance of reflection to the leadership learning process and to the development of understanding and the sharing of knowledge.

\subsection{Chapter summary}

This chapter began with a description of the data analysis processes that occurred over the course of the study and that contributed to the model of leadership learning using ICT. The community of inquiry model was initially used as a framework for analysis and was useful in progressing the analysis of data. The main benefit of using this model was that it highlighted the importance of the different aspects of an online learning experience, that is the learning process (cognitive presence), the social interactions (social presence), and the facilitation process (teaching presence). The community of inquiry model was revised in the light of data emerging from the first research group, 
and the modifications made reflected the different context of blended action learning groups. The next section of the chapter focused on the leadership learning process as identified through the analysis of participants' leadership journeys. The model of leadership learning using ICT that was developed in this study was introduced in this section. The different aspects of the leadership learning process revealed in the leadership journey data analysis were then discussed and examples given. This was followed by a discussion on the different components of the model beginning with the development of awareness leading to enhancement of self-confidence and in some cases distributed leadership. This process was enhanced by the modified stages of cognitive presence, namely recognising, reflecting, realising and responding. Four other elements that make a significant contribution to the process of leadership learning using ICT were discussed in the final section of this chapter. They are the blended action learning facilitator role, blended action learning process, the ICT tools, and the blended action learning group. The chapter concluded with a discussion of the contribution of the model of leadership learning using ICT that illustrates the process of leadership learning that occurred as a result of participation in this study. 


\section{Conclusion}

"The hardest part is what to leave behind, ... It's time to let go!" (A.A. Milne)

\subsection{Chapter overview}

This concluding chapter begins by providing an overview of the research process and research findings. This is followed by a discussion of the role I took as an engaged researcher in this study. The focus of the next section of the chapter is an evaluation of the research according to the criteria used to assess interpretive research. The contribution of this research and implications for further research and practice are then discussed before the limitations of this research are commented on. Possible directions for future research are identified at the conclusion of the chapter.

\subsection{Overview of the research process}

This section will give an overview of the research process and will include a discussion of the gap in research on leadership development using ICT established in the literature review, and an overview of the research objectives and the research design. This will be followed by a discussion of how the research questions were answered.

\subsubsection{Research gap}

The literature review presented in Chapter 2 explored a number of different areas related to this study. These included: current thinking on both leadership theory and practice; approaches to leadership development; work-based learning; communities of practice; action learning; facilitation; and reflective practice. Discussion on communities of practice, action learning and reflective practice included an exploration of their nature, their use in organisations, leadership development and research, and how ICT is currently used to support them. An analysis of the links between these concepts and a reflection on how they can be used for research into the use of ICT to support leadership development in the ECE sector was also presented. This review established a gap in the literature in the area of the use of ICT to support leadership development using communities of practice, action learning and reflective practice. The few studies that explored the use of ICT in these areas identified a number of challenges including: the importance of building relationships between the participants before encouraging online communication and reflections; the choice and use of appropriate ICT; and the critical role of the facilitator in encouraging online participation and critical reflection.

\subsubsection{Research objectives}

The purpose of this research study was to explore how ICT can be used to support leadership development in the New Zealand ECE sector. Action learning groups were 
established involving either people in formal leadership positions in ECE or people expressing an interest in ECE leadership. These groups provided the research participants and the main data for the study. The blended action learning process involved both face-to-face and online interactions and the role of the blended action learning facilitator and the use of appropriate technologies were of particular interest in this study.

\subsubsection{Research design}

Important aspects of research design in this study included the research questions, units of analysis, methods of data collection and analysis, and the researcher role. The researcher role will be the focus of Section 9.3 below.

The overarching research question in this study was:

\section{How can ICT be used to support leadership development within the New Zealand early childhood education sector?}

Sub-questions arising from the literature related to how the blended action learning process supports leadership learning, what role the facilitator takes in the blended action learning process, and what technologies are most appropriate for supporting leadership development through blended action learning. Additional questions that arose during the study were: what are the leadership journeys of research participants? and How can the elements of blended action learning be integrated into a model of leadership learning that describes the process experienced by participants in this study? The answers to these questions will be summarised in Section 9.2.4 below. This research study took the form of a single embedded case, where the phenomenon of interest was the use of blended action learning to develop leadership in the New Zealand ECE sector, and the units of analysis were the two blended action learning groups. Data were generated in this study from the two groups and took various forms including interviews, individual and group emails, online reflective journal entries and responses, forum discussions, and chat sessions. Data analysis was an iterative process that involved data reduction, data display and the drawing of conclusions. I initially used the community of inquiry model as a framework for analysis and this was followed by the second major phase of data analysis, an analysis of individual leadership journeys.

\subsubsection{The research questions}

This section examines how the main research question in this study and each of the sub-questions was answered.

\section{Main research question}

The answer to the main research question - how can ICT be used to support leadership development in the New Zealand ECE sector? - is that leadership development can be 
supported through the use of blended action learning, which involves the use of ICTs such as online reflective journals, forum discussions, chats and emails. This study has shown this approach to leadership development to be very effective and to contribute to deep level learning in the specific context of this research. The four main elements that contributed to the learning of individual leaders who participated in the study were: the role taken by the blended action learning facilitator, the blended action learning process of questioning and encouraging reflection, the ICT tools, and the blended action learning group. Participants in this study reported increased selfawareness, and a greater awareness of their context and of different leadership approaches. The four stages of cognitive presence, recognising a problem, reflecting on what was happening, realising what the issue was, and then responding to the issue, encouraged this development of awareness and helped the participants to become more confident in their leadership practices leading in some cases to distributed leadership. The process by which ICT was used to support leadership learning was illustrated and presented in the previous chapter.

\section{Sub-questions}

The leadership journeys of three more and three less active participants were described in Chapter 5. These journeys offered an understanding of the process they went through in the course of their participation in this research study and included the setting of leadership goals, reflection on leadership practice and shifts made in practice. Comparison of the more and less active participants revealed that more active participation resulted in greater progress towards meeting leadership goals, greater shifts in practice and greater confidence in ongoing leadership capabilities.

Chapter 6, which focused on the blended action learning process, provided the detailed information that answers the sub-questions relating to the blended action learning process and the appropriate technologies. Vital components that contributed to the blended action learning process included the action learning approach of questioning and reflection, the ICT tools, and the blended action learning group. The blended action learning process encouraged participants to reflect on their experiences and the questioning process helped them to identify future actions with regard to their leadership goals. The online action learning process was particularly valuable as it gave participants the time to consider their questions and responses; although the face-toface interactions were also highly valued as they helped build strong and trusting relationships. The empowering nature of action learning promoted in much of the literature was evident in this study as participants developed skills and competencies and became more confident in their leadership practice. All the technologies used, namely online reflective journals, forum discussions and chats, were valued as they offered different and complementary approaches to assist in the leadership learning process. The small size of the action learning groups enabled participants to get to know each other well, and trust developed quickly within the groups. This trust 
encouraged participants to share their experiences and to identify and make changes in their leadership practice.

The role I took as action learning facilitator was the focus of Chapter 7 which outlined the two major aspects of the role, enabling learning and acting as a trusted inquisitor. The first aspect, enabling learning, involved designing and facilitating the blended action learning process, motivating and encouraging participants, offering technical support, and providing appropriate resources. The second aspect of the role, acting as a trusted inquisitor, focused on behaviour and support that deepened the learning and involved establishing trusted relationships with and between participants, providing emotional support, questioning in order to encourage reflection, providing content expertise, and role-modelling and coaching. The balance between these two aspects of the role varied over the life of the blended action learning groups and five distinct stages of blended action learning facilitation were identified as a result of this study. Online facilitation differs in some respects from face-to-face facilitation. Although many of the interpersonal skills required are similar, online facilitation requires a greater emphasis on collaborative learning and the encouragement of reflective practice. The nature of my role also varied according to the online technologies used. Responding to reflective journal entries was one of the most important activities I undertook in this study and effective responses involved a balance of support and challenge.

The approach to leadership development used in this study extended beyond the use of action learning, as some aspects of my facilitator role such as acting as a content expert, providing resources, and encouraging participants to share ideas as well as question each other, are not part of traditional action learning processes. This particular approach to leadership learning using ICT requires the facilitator to have content expertise and the ability to provide appropriate resources and technical support in addition to the skills required by traditional action learning facilitators. This broader approach to leadership development fits with Hirst et al.'s (2004) recommendation that leadership development programmes should use a combination of action learning and more traditional approaches such as a focus on encouraging teamwork, managing people, understanding the organisation, and possessing technical knowledge.

The final research sub-question relating to how the elements of blended action learning can be integrated into a model of leadership learning that describes the process experienced by participants in this study was addressed in Chapter 8 . This chapter presented the model of leadership learning using ICT and included discussion on the different components of the model beginning with the development of awareness leading to enhancement of self-confidence and in some cases distributed leadership. The enhancement of this process by the modified stages of cognitive presence, namely recognising, reflecting, realising and responding was also explained and the four other elements that make a significant contribution to the process of leadership learning 
using ICT were discussed. They are the blended action learning facilitator role, the blended action learning process, the ICT tools, and the blended action learning group.

\subsection{Researcher role}

The role I took in this study combined both research and facilitation. This combined facilitator/researcher role does not seem to be a common one in research and differed from other more commonly described roles such as those of participant observer or action researcher. The activities of the facilitator and the activities of the researcher overlapped in many of the interactions with participants. This overlap and the need for the engaged researcher to frequently swap between such activities has been signalled by Nandhakumar and Jones (1997) and was discussed in Section 3.3.8. An example of this overlap included the way interviews were undertaken; although the primary aim was data gathering, I also deviated from the interview questions at times to allow participants to discuss the issues they were currently dealing with and also facilitated reflection on leadership learning.

Three factors made balancing the two main components of the researcher's role more manageable in this particular study. These were my previous facilitation experience, my profile and professional credibility within the local ECE sector, and the use of the online site for gathering and storing data. My familiarity with, and experience in, faceto-face facilitation meant that I felt very comfortable in this aspect of my role. This confidence was picked on by participants and meant that the process of working with the groups flowed smoothly. The fact that I had previously facilitated a number of leadership development clusters and had accumulated a large number of relevant resources also helped. The online facilitation was more of a challenge as I was less experienced in this area, although as previously mentioned (in Section 7.5.1), the asynchronous nature of the online interactions allowed me to consider my responses and therefore reduced the challenge.

My profile and credibility within the sector made the process of recruiting participants easier. Although I had only met one participant from each of the two groups prior to the study, and some participants did not know of me at all, my relationship with various umbrella organisations through previous professional development facilitation meant that they were happy to pass on details to teachers who they thought may have been interested in participating in the study. The importance of these two factors, facilitation experience and professional credibility, is not something that could be expected of researchers or necessarily built into future studies. Professional credibility is clearly an asset and supports the facilitation role, but is something new researchers may not have had the time or opportunity to establish. Pauleen (2001) comments on the difficulty he had as a student researcher with no reputation, recruiting working professionals as participants in his study on virtual team facilitation. 
The third factor contributing to the successful balance of roles was independent of the actual researcher, hence has more relevance for future engaged researcher roles. Use of the online site to collect and store research data assisted the blending of my research and facilitation activities with the outcome being that my facilitation activities were more obvious to participants than was my researcher role. All the online interactions with participants generated data. However, because I was not obviously collecting data by asking specific questions, but rather facilitating their learning, the researcher role did not overwhelm the facilitator role. Participants were obviously aware of my researcher role and occasionally made comments about what may or may not be useful for my research but in general my facilitator role was more obvious to them. The use of an online site as a source of data collection contrasts with other more traditional research settings where interviews may be the main source of data. This difference is also an advantage to participants because in dedicating their time to the research they are also engaged in their own professional learning, not simply answering questions posed by the researcher.

I did not experience any particular conflicts between the two aspects of my role in this study partly because of the strong and trusting relationships I built with participants. These strong relationships helped them feel able to be direct and honest with me. On one occasion a participant asked that a particular issue that she had discussed in her reflective journal did not form part of the research data because of its sensitivity, otherwise participants were happy for me to use their thoughts and reflections. The ongoing and collaborative relationships with the research participants developed through regular face-to-face and online contact. This contact continued well after the end of the data collection process and both research groups continued to meet and interact. This close relationship made the ongoing use of member checks at different stages of the data analysis process easier, as I had ongoing contact with all participants.

My role as engaged researcher meant that I needed to be aware how my presence and actions influenced the research study. Two of Klein and Myers' (1999) principles, referred to in Section 3.2.1, have particular relevance to the researcher role in this study. The principle of interaction between the researcher and the subjects suggests that the data gathered are a result of the social interaction between the participants and researcher, rather than something independent of that relationship. This principle is addressed through my overt reflection on my role in much of the thesis, particularly in Chapters 4, 6 and 7. I was very aware that I had a significant influence on the leadership learning process and that my experiences formed an important part of the research data. The principle of multiple interpretations requiring sensitivity on the part of the researcher to potential conflicts arising from differing perspectives was not particularly relevant to this study as the participants were all from different organisations and were all working on their own leadership goals; however, I was aware of the potentially differing interpretations of participants on shared experiences. 


\subsection{Evaluation of the research}

The criteria that characterise constructivist research paradigms such as trustworthiness, transferability, credibility and confirmability, contrast to some extent with the criteria used to evaluate the quality of positivist research such as reliability and validity (Denzin \& Lincoln, 2005). Reliability refers to the consistency or accuracy of research data (Creswell, 2003). It has been argued that the concept of reliability is not directly applicable to interpretive research (Golafshani, 2003), although it has been related to the notion of trustworthiness which will be discussed in the following section. Validity refers to fitness of purpose. Both external and internal validity are used to evaluate positivist research studies. External validity relates to the extent to which results can be generalised to the population the sample is taken from, and internal validity relates to the extent that the findings arise from the research design.

\subsubsection{Trustworthiness}

Trustworthiness in interpretivist research relates to the worth of the findings and their authenticity and can be viewed as an overarching term that includes transferability, credibility and confirmability (Lincoln \& Guba, 1985). Transferability can be linked to external validity. It refers to the whether or not the findings of a study can be transferred to other contexts. Credibility has a similar meaning to internal validity and refers to whether the findings actually make sense to the study participants and the wider audience. Confirmability can be seen as analogous to objectivity and concerns the freedom from the unacknowledged bias of the researcher (Miles \& Huberman, 1994).

\subsubsection{Transferability}

Although the study of one or a few cases appears to provide a weak foundation for the transfer of findings to other contexts, case research allows for the possibility of transfer through the provision of rich description. This allows a reader to make links between their context and the research findings. According to Lincoln and Guba (1985) it is not the responsibility of the researcher to prove transferability; "it is his or her responsibility to provide the data base that make transferability judgments possible on the part of potential appliers" (p. 316). Rich description was used in the written account of this research study in order that the reader could build up a picture of the research setting and consider what aspects could be applied to their setting.

\subsubsection{Credibility and confirmability}

A number of factors increase the credibility of a study including: prolonged engagement with the research site in order that trust is built with the research participants; persistent observation that will help identify salient issues and events; and triangulation through the use of multiple sources of data or the identification of different ways of seeing the phenomena (Stake, 2005). Trust was built in this study 
through prolonged engagement with the research participants. This aspect of the researcher/facilitator role has been discussed extensively in Chapter 7. Observation was used in this research, not in the traditional sense, but through the study of participants' reflections and interactions. Multiple sources of data were used including interviews, reflective journals, forum discussions, chat postings and emails.

Member checks are another technique for establishing credibility (Lincoln \& Guba, 1985) that was extensively used in this study. Member checks in this research involved giving the research participants an opportunity to verify each of their interview transcripts; their leadership journeys; and also the emerging theory to see if this was representative of the participants' realities. The revised community of inquiry model and the stages of the facilitator role were examples of emerging theory that were checked with participants in the early to mid-stages of data analysis. A final member check involved inviting all participants to a presentation of research findings. This presentation was held in February 2009 and was attended by seven participants. Among the findings presented were the model of the two aspects of the facilitator role, the stages of blended action learning facilitation, and the model of leadership learning using ICT. Participants were asked for feedback both at the conclusion of the presentation and by email afterwards. Participants who could not attend the presentation were sent copies of the presentation slides and invited to comment on these. This feedback, which was shared with the research supervisors, resulted in some minor alterations to the model of leadership learning using ICT to more accurately reflect the participants' actual experiences.

Lincoln and Guba also recommend the keeping of a reflexive journal which may be both a personal reflective diary and also a log of the methodology and schedule of the research process. A reflexive journal was kept by the researcher in this study and it included reflections on different aspects of both the facilitation and research process. Excerpts from this reflective journal were viewed by the primary supervisor who also had access to the data on Moodle. Excerpts of raw data such as emails, chat session comments, forum and interviews have been included in Chapters 6 and 7 and in Appendices D, E and F to allow the reader to confirm the analysis as credible. Both triangulation and reflexive journals also help address issues of confirmability.

\subsubsection{Other evaluation criteria}

Coghlan and Pedler (2006) caution writers of action learning theses against assuming that their personal story is all that is necessary. They suggest three criteria for assessing action learning research: evidence of real problems recognised by people other than the researcher being addressed; evidence of action being taken to solve the problem or change the situation; and evidence of learning that has occurred. This learning may be personal learning by the researcher, practitioner learning or organisational learning. Chapter 5, which describes a number of the participants' individual leadership journeys, 
provides evidence of real problems and evidence of action, whereas evidence of learning is also provided in Chapter 6 which focuses on the blended action learning process.

Two of Klein and Myers' (1999) seven principles developed to assist in the process of conducting and evaluating interpretive field research in information systems have been discussed earlier in Section 9.3 in relation to the researcher role. Another two, the principles of contextualisation and dialogical reasoning, are more relevant to the research design and were discussed in Chapter 3, while another, the principle of suspicion, is not relevant to this research. This leaves two principles to be considered, the fundamental principle of the hermeneutic circle and the principle of abstraction and generalisation. The fundamental principle of the hermeneutic circle suggests that understanding of a system is gained through iteration between the whole and its interrelated parts. In terms of this study, an understanding of the use of ICT to support leadership development has been developed by looking at a number of different aspects of this process including: individual leadership journeys; the action learning groups; the blended action learning process; and the role of the blended action learning facilitator. The principle of abstraction and generalisation requires the researcher to relate broader theoretical concepts and abstractions to particular findings from the data, a process that enables the reader to follow the process by which theory is developed. This principle was followed in Chapter 8, in which the development of the model of leadership learning was illustrated with relation to particular findings and different aspects of the process.

\subsection{Contribution of the research}

This research has a number of implications for both future research and practice. The study makes a useful contribution to the understanding of leadership development using ICT, in particular the use of blended action learning, and the role of the blended action learning facilitator. The effectiveness of the action learning process in supporting leadership development has already been established in previous research (Bush \& Glover, 2004; Hirst et al., 2004; Paterson \& West-Burnham, 2005); however, blended action learning for leadership development appears to be a relatively new area of research. Blended action learning offers a learning experience that is richer than either face-to-face or online action learning used individually. Advantages of the blended approach include that the face-to-face interactions help develop and sustain strong and trusting relationships which encourage participants to share issues of importance to them, while the online interactions promote reflection and the sharing of practice. The ICT tools used to support the blended action learning process each play an important role. The process of leadership learning using ICT is represented in Figure 8-3 in Chapter 8 . This process, which involves participants developing self-awareness, greater awareness of their context and of leadership approaches, is supported by four key elements and encouraged by a four stage process of cognitive presence. The leadership 
learning process resulted in feelings of greater self-confidence, and in some cases led to the distribution of leadership.

The role of the blended action learning facilitator differs from that of the face-to-face action learning facilitator and has not been the subject of much previous research. This study contributes to the understanding of this role in three ways:

1. By offering a model of the blended action learning facilitator's role that involves two complementary aspects, enabling learning, and acting as a trusted inquisitor. Each of these aspects involves a number of related tasks including motivating and encouraging participation, offering support, providing resources and expertise, coaching, and encouraging reflection.

2. By offering a five stage model of blended action learning facilitation: establishing relationships; encouraging participation; facilitating learning; maintaining momentum; and disengaging.

3. By providing recommendations for future blended action learning facilitation.

All these contributions are of practical use to future facilitators wanting to use blended action learning and looking for some guidance on their role. These findings also contribute to filling the gap in knowledge around the role of the online facilitator as outlined in Section 2.8.2.

\subsubsection{Implications for research}

The contributions to research made by this study lie mainly in: the model of leadership development using ICT; the use of an online site in the data collection process; and the greater understanding of the combined role of the researcher and action learning facilitator. The model of leadership learning developed in this study contributes to our understanding of the leadership development process. It has the potential to assist future researchers working in this area by offering a framework to be critiqued. The advantages of using an online site for data collection, in that much of the data are captured online thereby reducing the need for as many interviews and also allowing the participants to spend more time on their leadership learning, was discussed in Section 9.3. This has implications for future research involving working participants. Previous findings that the use of action learning research methodologies allow participants to work collaboratively on real work-place issues and that those involved are offered relevant learning opportunities in return for being research participants (Pauleen \& Yoong, 2001, 2004) were verified in this study.

\subsubsection{Implications for practice}

Implications for practice include a greater understanding of the role of the blended action learning facilitator and of the process of leadership learning using ICT. This study also offers a possible solution to the gap in leadership development provision in 
the New Zealand ECE sector identified in earlier chapters. Advantages of this model of leadership development include: its blended approach which reduces the need for faceto-face meeting time and therefore travel; the emphasis on reflection in blended action learning which empowers participants to take action on work place issues that they are facing; and the support and sharing offered by the other participants in the communities of practice formed as part of the blended action learning process. It is likely that this approach to leadership development would need to be modified to make it more suitable to delivery on a larger scale. Possible modifications to align the approach more strongly with leadership development rather than leader development are signalled in the following section.

Other implications for practice relate to the potential use of aspects of the research findings in other professional development contexts. Study participants commented in the final member check that this approach to leadership development could have implications for other professional learning settings. They suggested that the progression from awareness to confidence was a feature of other learning situations, and that the stages of recognising, reflecting, realising and responding were a useful framework for encouraging reflective practice. The dual aspects of the blended action learning facilitator role identified in Section 7.4 also have practical implications for future facilitator practice as they provide a useful framework for understanding the different components of the role.

\subsection{Limitations of the research}

Limitations of a study refer to its possible shortcomings or defects. This study was focused on the use of ICT to support leadership development in the New Zealand ECE sector using blended action learning and did not attempt to address issues concerning other modes of leadership development or leadership development using ICT in other contexts. The ECE sector, although diverse, has some unique characteristics and what may be appropriate in this context may not apply elsewhere. The study did, however, attempt to provide sufficiently rich data so that readers can determine whether the finding may be transferable to their own contexts. Although the use of ICT to support leadership development is the main focus, the use of blended action learning and the role of the blended action learning facilitator were also explored.

Although this study had a limited number of participants, the close and prolonged interaction between the researcher and the participants and the use of multiple methods of data collection added to the credibility of the study. Participation in the action learning groups was open to any teachers in the sector who were interested in leadership learning and was not confined to those who had designated leadership roles. This fits with the literature on the importance of leadership development in conjunction with leader development, a concept (discussed in Section 2.2.3) that fosters 
the distribution of leadership. Teachers from a range of ECE services such as kindergartens, playcentres, home-based care, and education and care centres were invited to participate, and the participants in the two research groups did represent a diversity of services. Although the study considered the effectiveness of this model of leadership development, it not did investigate its efficiency or cost, another possible limitation.

An additional possible limitation of the study was the relatively short period of data collection. More leadership learning leading to the continued distribution of leadership may have been evident if follow-up interviews were conducted several months after the end of the original data collection period. Anecdotal evidence from participants indicated that learning was ongoing and a lag between leadership development and facilitative leadership has been identified in other research (Hirst et al., 2004). However, this extension to the data collection process was not practical, as although the research groups did continue to meet after the close of the data collection period, the initial information given to participants specified a particular time period for data collection and it would have been an imposition to request extra interviews outside this time period.

\subsubsection{Limitations of this approach to leadership development}

Many aspects of this approach to leadership development were valued by participants and contributed to meaningful reflection and shifts in practice. These included the action learning process, the small and diverse nature of the action learning groups, the use of a dedicated online site and a variety of ICT tools, and the different facets of the facilitator role that enabled learning and offered both support and challenge. Other useful aspects not so closely related to the action learning process included the sharing of current research on leadership theory and practice and the provision of a number of relevant resources. This process does, however, have some limitations, namely the focus on individual leaders and the limited opportunities for shared reflection.

In order to fully justify the title of leadership development, rather than leader development, the organisations of participants in this research study could have been more fully involved. James et al. (2007) emphasise the importance of leadership development models being congruent with the type of leadership they support, and as distributed forms of leadership were being encouraged throughout this study, a greater emphasis could have been put on encouraging participants to think more specifically about how their personal leadership development impacted on others and on their organisation as a whole. Although most participants shared their goals and actions with colleagues, this was voluntary and participants could have worked in isolation. Greater involvement of participants' organisations could have included asking for more specific feedback from colleagues. The use of 360 degree feedback as an element of effective leadership development programmes has been promoted in a number of 
studies (Bush \& Glover, 2004; Day, 2000; Raelin, 2003; West-Burnham, 2003). According to Raelin, feedback from trusted colleagues helps develop self-awareness and helps leaders see whether they are behaving as they wish with regard to their impact on others. The importance of feedback in developing self-awareness is also emphasised by McGill and Brockbank (2003, p. 158), who suggest that "constructive feedback increases our self-awareness, offers us more options on how we can relate to others, and the opportunity to change our behaviour". As the facilitator in this study, I could have more specifically encouraged participants to think about the impact of their leadership on their organisations through the questioning process.

Although shared reflection was encouraged as part of the blended action learning process, much of the reflection occurred as a result of the reflective journalling process and therefore was visible only to the blended action learning facilitator. Although some participants cut and pasted sections of their journal into forum discussions, shared reflection may have been further encouraged if participants had used a blog. Advantages of using blogs would include that participants would be more aware of each other's reflective practice, and through commenting could have offered different perspectives. Disadvantages could include a greater time commitment, though if blog entries were taken from reflective journal entries, then this could be minimised.

\subsection{Directions for future research}

While this research study focused on the use of ICT to support leadership development in the New Zealand ECE sector, the use of blended action learning has potential for use in other contexts. Future research could focus on the use of blended action learning for professional development on topics other than leadership or for leadership development in other sectors. Healthcare and social services are two sectors in which face-to-face action learning is currently used and future research could investigate the use of blended action learning in these settings. Blended action learning as a leadership development approach in some of the contexts described in Section 2.5.4 is therefore another avenue for future research. The distribution of leadership that occurred through the use of the blended action learning process was discussed in Section 8.3.5. This aspect of leadership development could also be an area with potential for future research with participants being encouraged to focus on the building of social capital through the greater involvement of their own organisations as discussed in Section 9.6.1 above. Research participants in this study commented on the potential transfer of this approach, in particular the cycle of recognising, reflecting, realising and responding to other contexts such as the teacher registration process.

Modification could be made to the approach used in this study by, for example, prolonging the data gathering process to look at longer-term impacts or by using different technologies such as blogs or Chatterbox, a tool that would allow for real-time 
conversations. Further research could also be conducted into how much face-to-face contact was needed to make this approach successful. While it was relatively easy for participants in the research groups in this study to attend face-to-face meetings, this model of leadership learning has potential for use with participants who are more geographically isolated. Although some face-to-face contact is essential, the greater use of technologies such as Chatterbox may provide a substitute for some face-to-face interactions and could be included in future research studies. Another possible area of future research arising out of this study is further investigation into whether personality type influences blended learning preferences. In this study the participants with a preference for extraversion engaged more with the online activities than did the participants with a preference for introversion. Future research could investigate the design of blended learning activities that appealed to people with different personality preferences.

\subsection{Chapter summary}

This concluding chapter began with a brief overview of the research process including the identification of the gap addressed by this research, the research objectives, the research design, and the research findings. This section was followed by an analysis of the researcher role and an evaluation of the research process. The contributions of the study to both research and practice were the focus of the next section, and this was followed by discussion of the limitations of the research including the limitations of this particular approach to leadership development. The chapter ended with the identification of some possible directions for future research. 


\section{References:}

Action Science Network. (2006). What is action science? Retrieved 4 December, 2006, from http://www.actionscience.com

Ancona, D., Malone, T., Orlikowski, W., \& Senge, P. (2007). In praise of the incomplete leader. Harvard Business Review, 85(2), 92-100.

Anderson, N. (2006). Socio-cultural approaches to literacy. In A. Martin \& D. Madigan (Eds.), Digital literacies for learning (pp. 183-195). London: Facet Publishing.

Anderson, T., \& Kanuka, H. (2003). E-research : methods, strategies, and issues. Boston: Allyn \& Bacon.

Angeli, C., Valanides, N., \& Bonk, C. (2003). Communication in a web-based conferencing system: the quality of computer-mediated interaction. British Journal of Educational Technology, 34(1), 31-43.

Archer, N. (2006). A classification of communities of practice. In E. Coakes (Ed.), Encyclopedia of communities of practice in information and knowledge management (pp. 21-29). Hershey, PA: Idea Group.

Argyris, C. (1999). On organizational learning (2nd ed.). Oxford: Blackwell.

Argyris, C., Putnam, R., \& McLain Smith, D. (1985). Action science. San Francisco: Jossey-Bass.

Aubrey, C. (2007). Leading and managing in the early years. London: Sage Publications.

Barab, S. (2003). An introduction to the special issue: Designing for virtual communities in the service of learning. The Information Society, 19, 197-201.

Barry, D. (1991). Managing the bossless team: Lessons in distributed leadership. Organizational Dynamics, 21,31-47.

Barth, R. (2001). Stepping back. Journal of Staff Development, 22(3), 38-41.

Bartol, K., \& Srivastava, A. (2002). Encouraging knowledge sharing: The role of organizational reward systems. Journal of Leadership and Organization Studies, $9(1), 64-76$. 
Benbasat, I., Goldstein, D., \& Mead, M. (1987). The case research strategy in studies of information systems. MIS Quarterly, 11(3) 369-386.

Bennett, C., Chapman, A., Cliff, D., Garside, M., Hampton, W., Hardwick, R., et al. (1997). Hearing ourselves learn: the development of a critical friendship group for professional development. Educational Action Research, 5(3), 383-402.

Bennett, N., Wise, C., Woods, P., \& Harvey, J. (2003). Distributed leadership. Nottingham, UK: National College for School Leadership.

Bennett, R. (1997). Effective set advising. In A. Mumford (Ed.), Action learning at work (pp. 179-182). Aldershot: Gower.

Bennis, W. (2007). The challenges of leadership in the modern world. American Psychologist, 62(1), 2-5.

Bird, L. (2006). Action learning sets: the case for running them online. Retrieved 5 May, 2006, from http://www.coventry.ac.uk/iped/papers/downloads/workbasedlearningwks p4jan2006/LenBirdActionLearningSetsOnline.doc

Bloom, P. J., \& Bella, J. (2005). Investment in leadership training: The payoff for early childhood education. Young Children, January, 32-40.

Boud, D. (2001). Using journal writing to enhance reflective practice. New Directions for Adult and Continuing education, Spring (90), 9-18.

Boud, D. (2006). Creating the space for reflection at work. In D. Boud, P. Cressey \& P. Docherty (Eds.), Productive reflection at work (pp. 158-169). London: Routledge.

Boud, D., \& Walker, D. (1998). Promoting reflection in professional courses: the challenge of context. Studies in Higher Education, 23(2), 191-206.

Bourner, T., \& Lawson, J. (2003). Introducing action learning into a business school. In R. Kaye \& D. Hawkridge (Eds.), Learning and Teaching for Business (pp. 60-73). London: Kogan Page.

Bowerman, J. (2000). Strategizing at work: practitioner perspectives on doctoral set working. Journal of Workplace Learning, 12(3), 124-130.

Braa, K., \& Vidgen, R. (1999). Interpretation, intervention, and reduction in the organizational laboratory: a framework for in-context information system research. Accounting, Management and IT, 9, 25-47. 
Bradshaw, P., Powell, S., \& Terrell, I. (2004). Building a community of practice:

Technological and social implications for a distributed team. In P. Hildreth \& C. Kimble (Eds.), Knowledge networks: Innovation through communities of practice (pp. 184-201). Hershey, PA: Idea Group.

Brandl, K. (2005). Are you ready to "Moodle"? Language Learning \& Technology, 9(2), 1623.

Bray, J. (2002). Virtual tutoring in hospitality - a "learnt system" of professional practice. International Journal of Contemporary Hospitality Management, 14(1), 21-27.

Brockbank, A., \& McGill, I. (2007). Facilitating reflective learning in higher education (2nd ed.). Maidenhead, Berkshire: McGraw-Hill.

Brockbank, A., McGill, I., \& Beech, N. (2002). Reflective learning in practice. Aldershot: Gower.

Brookfield, S. (1995). Becoming a critically reflective teacher. San Francisco: Jossey-Bass.

Brosnan, K., \& Burgess, R. (2003). Web based continuing professional development - a learning architecture approach. Journal of Workplace Learning, 15(1), 24-33.

Bunning, C. (1997). Placing action learning and action research in context. In A. Mumford (Ed.), Action learning at work (pp. 25-29). Aldershot: Gower.

Burns, J. (1978). Leadership. New York: Harper \& Row.

Burns, P. (2001). Report on a virtual action learning set. Action Learning News, 20(2), 2-7.

Bush, T., \& Glover, D. (2004). Leadership development: Evidence and beliefs. Nottingham: National College for School Leadership.

Buysse, V., Sparkman, K., \& Wesley, P. (2003). Communities of practice: Connecting what we know with what we do. Exceptional Children, 69(3), 263-277.

Charmaz, K. (2000). Grounded theory: Objectivist and constructivist methods. In N. Denzin \& Y. Lincoln (Eds.), Handbook of qualitative research (2nd ed., pp. 509-538). London: Sage Publications.

Christians, C. (2000). Ethics and politics in qualitative research. In N. Denzin \& Y. Lincoln (Eds.), Handbook of qualitative research (2nd ed., pp. 133-155). Thousand Oaks, CA: Sage Publications. 
Chua, A. (2006). The role of technology in supporting communities of practice. In E. Coakes (Ed.), Encyclopedia of communities of practice in information and knowledge management (pp. 447-452). Hershey, PA: Idea Group.

Clarkin-Phillips, J. (2007). Distributing the leadership: A case study of professional development. Unpublished master's thesis. University of Waikato, Hamilton, New Zealand.

Clawson, V., Bostrom, R., \& Anson, B. (1993). The role of the facilitator in computersupported meetings. Small group research, 24(4), 547-565.

Coghlan, D., \& Pedler, M. (2006). Action learning dissertations: structure, supervision and examination. Action Learning: Research and Practice, 3(2), 127-139.

Cohen, L., Manion, L., \& Morrison, K. (2000). Research methods in education (5th ed.). London: RoutledgeFalmer.

Conger, J., \& Toegel, G. (2003). Action learning and multirater feedback: Pathways to leadership development. In S. Murphy \& R. Riggio (Eds.), The future of leadership development (pp. 133-151). New Jersey: Lawrence Erlbaum Associates.

Cook, S., \& Brown, J. (1999). Bridging epistemologies: The generative dance between organizational knowledge and organizational knowing. Organization Science, 10(4), 381-400.

Cordoba, J., \& Robson, W. (2006). Understanding communities of practice to support collaborative research. In E. Coakes (Ed.), Encyclopedia of communities of practice in information and knowledge management (pp. 558-564). Hershey, PA: Idea Group.

Costa, A., \& Kallick, B. (1993). Through the lens of a critical friend. Educational Leadership, 51(2), 49-51.

Costa, A., \& Kallick, B. (1995). Through the lens of a critical friend. In A. Coster \& B. Kallick (Eds.), Assessment in the learning organization: Shifting the paradigm (pp. 153-156). Alexandria, Virginia: ASCD.

Creswell, J. (1994). Research design. London: Sage Publications.

Creswell, J. (1998). Qualitative inquiry and research design. London: Sage Publications.

Creswell, J. (2003). Research design: qualitative, quantitative, and mixed methods approaches. London: Sage Publications. 
Crotty, M. (1998). The foundations of social research. Sydney: Allen \& Unwin.

Cyboran, V. (2005). Fostering workplace learning through online journaling. Performance Improvement, 44(7), 34-39.

Daft, R., Lengel, R., \& Trevino, L. (1987). Message equivocality, media selection and manager performance: Implications for information systems. MIS Quarterly, 11, 355-366.

Daroszewski, E., Kinser, A., \& Lloyd, S. (2004). Online, directed journaling in community health advanced practice nursing clinical education. Journal of Nursing Education, 43(4), 175-180.

Daudelin, M. (1996). Learning from experience through reflection. Organizational Dynamics, 24(3), 36-48.

Davenport, E., \& Hall, H. (2002). Organizational knowledge and communities of practice. Annual Review of Information Science and Technology, 36, 171-227.

Davenport, T., \& Prusak, L. (2000). Working knowledge: How organizations manage what they know. Boston: Harvard Business School Press.

Day, C. (2003). What successful leadership in schools looks like: Implications for policy and practice In B. Davies \& J. West-Burnham (Eds.), Handbook of educational leadership (pp. 87-204). London: Pearson Education.

Day, C., Harris, A., Hadfield, M., Tolley, H., \& Beresford, J. (2000). Leading schools in times of change. Buckingham: Open University Press.

Day, D. (2000). Leadership development: A review in context. Leadership Quarterly, 11(4), 581-613.

de Souza, C., \& Preece, J. (2004). A framework for analyzing and understanding online communities. Interacting with Computers, 16(3), 579-610.

Dennis, A., Fuller, R., \& Valacich, J. (2008). Media, tasks, and communication processes: A theory of media synchronicity. MIS Quarterly, 32(3), 575-600.

Dennis, A., \& Valacich, J. (1999). Rethinking media richness: Towards a theory of media synchronicity. Paper presented at the 32nd Hawaii International Conference on System Sciences, 5-8 January, Hawaii. 
Densten, S., \& Gray, J. (2001). Leadership development and reflection: what is the connection? International Journal of Educational Management, 15(3), 119-124.

Denzin, N., \& Lincoln, Y. (2000). Introduction: The discipline and practice of qualitative research. In N. Denzin \& Y. Lincoln (Eds.), Handbook of qualitative research (2nd ed., pp. 1-28). London: Sage Publications.

Dewey, J. (1933). How we think. Boston: Heath.

Dickson, G. (2008). Leadership as knowledge mobilization: Building coalitions for evidencebased change. Paper presented at the 9th European Conference on Knowledge Management, 4-5 September, Southampton.

Dickson, G., Hamilton, D., \& Taylor, M. (2006). Twenty-first Century Leadership Development. BC School Leadership e-journal. 5, 4-18.

Donaldson, G. (2008). How leaders learn. New York: Teachers College Press.

Dotlich, D., Noel, J., \& Walker, N. (2004). Leadership passages. San Francisco: Jossey-Bass.

Drath, W., McCauley, C., Palus, C., Van Velsor, E., O'Connor, P., \& McGuire, J. (2008). Direction, alignment, commitment: Towards a more integrative ontology of leadership. The Leadership Quarterly, 19(6), 635-653.

Ebbeck, M., \& Waniganayake, M. (2003). Early childhood professionals: Leading today and tomorrow. Sydney: MacLennan \& Petty.

Eisenhardt, K. (1989). Building theories from case study research. Academy of Management Review, 14(4), 532-550.

Elgort, I. (2006). Online journals as a learning tool. Workshop presentation, 21 March, 2006, Victoria University of Wellington, Wellington.

Feltham, S. (2005). Leading the way. New Zealand Education Gazette, 84(10), 1,4,5.

Fenwick, T. (2001). Responding to journals in a learning process. New Directions for Adult and Continuing education, Spring (90), 37-48.

Ferraro, J. (2000). Reflective practice and professional development (Publication no. ED449120). Retrieved 15 May, 2006, from ERIC Digest. 
Fielden, K. (2005). Venturing into murky ground: Teaching, testing and evaluating critical reflection. New Zealand Journal of Applied Computing and Information Technology, 9(1), 25-29.

Fink, D. (2005). Developing leaders for their future not our past. In M. Coles \& G. Southworth (Eds.), Developing leadership: Creating the schools of tomorrow (pp.120). Maidenhead: Open University Press.

Francis, H., \& Cowan, J. (2008). Fostering an action-reflection dynamic amongst student practitioners. Journal of European Industrial Training, 32(5), 336-346.

Friesen, S., \& Clifford, P. (2003). Working across different spaces to create communities of practice in teacher professional development. Paper presented at the MICTE 2003 Multimedia, Information and Communication Technologies. Retrieved 11 July, 2005, from http://www.galileo.org/research/publications/different_spaces.pdf.

Garrison, D. (2006). Online community of inquiry review: social, cognitive, and teaching presence issues [Electronic Version], 61-72. Retrieved 17 July, 2007, from http://www.ucalgary.ca vaughn/coiissues.pdf.

Garrison, D., \& Anderson, T. (2003). E-Learning in the 21st century. London: RoutledgeFalmer.

Garrison, D., Anderson, T., \& Archer, W. (2000). Critical inquiry in a text-based environment: Computer conferencing in higher education. The Internet and Higher Education, 2(2-3), 87-105.

Garrison, D., Anderson, T., \& Archer, W. (2001). Critical thinking, cognitive presence, and computer conferencing in distance education. American Journal of Distance Education, 15(1), 7-23.

Garrison, D., \& Cleveland-Innes, M. (2005). Facilitating cognitive presence: Interaction is not enough. American Journal of Distance Education, 19(3), 133-148.

Garrison, D., Cleveland-Innes, M., Koole, M., \& Kappelman, J. (2006). Revisiting methodological issues in transcript analysis: Negotiated coding and reliability. The Internet and Higher Education, 9(1), 1-8.

Garrison, D., \& Kanuka, H. (2004). Blended learning: Uncovering its transformative potential in higher education. The Internet and Higher Education, 7(3), 95-105. 
Garrison, D., \& Vaughn, D. (2008). Blended learning in higher education. San Francisco: Jossey-Bass.

Geoghegan, N., Petriwskyj, A., Bower, L., \& Geoghegan, D. (2003). Eliciting dimensions of leadership in educational leadership in early childhood education. Journal of Australian Research in Early Childhood Education, 10(1), 12-21.

George, B., Sims, P., McLean, A., \& Mayer, D. (2007). Discovering your authentic leadership. Harvard Business Review, 85(2), 129-138.

Gerbic, P., \& Stacey, E. (2005). A purposive approach to content analysis: Designing analytical frameworks. The Internet and Higher Education, 8(3), 45-59.

Golafshani, N. (2003). Understanding reliability and validity in qualitative research. The Qualitative Report, 8(4), 597-607.

Goleman, D., Boyatzis, R., \& McKee, A. (2002). Primal leadership. Boston: Harvard Business School Press.

Grant, H., \& Crutchfield, L. (2008). The hub of leadership: Lessons from the social sector. Leader to Leader, Spring, 45-52.

Gray, B. (2004). Informal learning in an online community of practice. Journal of Distance Education, 19(1), 20-35.

Gray, D. (1999). Work-based learning, action learning and the virtual paradigm.

Retrieved 5 May, 2006, from http://www.leeds.ac.uk/educol/documents/00001260.htm

Greenwood, J. (1998). The role of reflection in single and double loop learning. Journal of Advanced Nursing, 27(5), 1048-1053.

Gregor, S. (2006). The nature of theory in information systems. MIS Quarterly, 30(3), 611-642.

Grey, A. (2004). The quality journey: Is there a leader at the helm? New Zealand Research in Early Childhood Education, 7, 91-102.

Gronn, P. (2002). Distributed leadership as a unit of analysis. The Leadership Quarterly, 13(4), 423-451.

Gunawardena, C., Lowe, C., \& Anderson, T. (1997). Analysis of a global online debate and the development of an interaction analysis model for examining social 
construction of knowledge in computer conferencing. Journal of Educational Computing Research, 17(4), 397-431.

Hackett, S. (2001). Educating for competency and reflective practice: Fostering a conjoint approach in education and training. Journal of Workplace Learning, 13(3), 103-112.

Hard, L. (2004). How leadership is understood in early childhood education and care. Journal of Australian Research in Early Childhood Education, 11(1), 123-131.

Hargreaves, A. (2007). Sustainable professional learning communities. In L. Stoll \& K. Louis (Eds.), Professional learning communities (pp. 181-195). Maidenhead, Berkshire: McGraw Hill.

Hargreaves, A., \& Fink, D. (2003). Sustaining leadership. In B. Davies \& J. WestBurnham (Eds.), Handbook of educational leadership and management (pp. 435-450). London: Pearson Education.

Hargreaves, A., \& Fink, D. (2006). Sustainable leadership. San Francisco: Jossey-Bass.

Harris, A. (2003). Teacher leadership: A new orthodoxy. In B. Davies \& J. WestBurnham (Eds.), Handbook of educational leadership and management (pp. 44-50). London: Pearson Longman.

Harris, A. (2004). Distributed leadership and school improvement. Educational Management Administration and Leadership, 32(1), 11-24.

Harris, A. (2008). Distributed leadership: according to the evidence. Journal of Educational Administration, 46(2), 172-188.

Hatton, N., \& Smith, D. (1995). Reflection in teacher education: Towards definition and implementation. Teaching and Teacher Education, 11(1), 33-49.

Henderson-Kelly, L., \& Pamphilon, B. (2000). Women's models of leadership in the childcare sector. Australian Journal of Early Childhood, 25(1), 26-31.

Heron, J. (1999). The facilitator's handbook. London: Kogan Page.

Hildreth, P., Kimble, C., \& Wright, P. (2000). Communities of practice in the distributed international environment. Journal of Knowledge Management, 4(1), 27-38.

Hogan, C. (2002). Understanding facilitation: Theory and principles. London: Kogan Page 
Horan, T., \& Wells, K. (2005). Digital communities of practice: Investigation of actionable knowledge for local information networks. Knowledge, Technology, and Policy, 18(1), 27-42.

Hough, B., Smithey, M., \& Evertson, C. (2004). Using computer-mediated communication to create virtual communities of practice for intern teachers. Journal of Technology and Teacher Education, 12(3), 361-385.

Howell, F. (1997). Action learning and action research in management education and development. In A. Mumford (Ed.), Action learning at work (pp.375-385). Aldershot: Gower.

Hoyrup, S. (2004). Reflection as a core process in organisational learning. Journal of Workplace Learning, 16(8), 442-454.

Hoyrup, S., \& Elkjaer, B. (2006). Reflection: taking it beyond the individual. In D. Boud, P. Cressey \& P. Docherty (Eds.), Productive reflection at work (pp. 29-42). London: Routledge.

Huberman, A., \& Miles, M. (1998). Data management and analysis methods. In N. Denzin \& Y. Lincoln (Eds.), Collecting and interpreting qualitative materials (pp. 179-210). Thousand Oaks, CA: Sage Publications.

Hunter, D., Bailey, A., \& Taylor, B. (1992). The zen of groups. Auckland: Tandem Press.

Hunter, D., Bailey, A., \& Taylor, B. (1999). The essence of facilitation. Auckland: Tandem Press.

Iles, P., \& Preece, D. (2006). Developing leaders or developing leadership? The academy of chief executives' programmes in the north east of England. Leadership, 2(3), 317-340.

James, K., Mann, J., \& Creasy, J. (2007). Leaders as lead learners: A case example of facilitating collaborative leadership learning for school leaders. Management Learning, 38(1), 79-94.

Jarvinen, A., \& Poikela, E. (2001). Modelling reflective and contextual learning at work. Journal of Workplace Learning, 13(7/8), 282-289.

Johnson, C. (2001). A survey of current research on online communities of practice. The Internet and Higher Education, 4(1), 45-60. 
Jonassen, D., \& Land, S. (2000). Preface. In D. Jonassen \& S. Land (Eds.), Theoretical foundations of learning environments (pp. iii-ix). New Jersey: Lawrence Erlbaum Associates.

Jones, A., \& Preece, J. (2006). Online communities for teachers and lifelong learners: a framework for comparing similarities and identifying differences in communities of practice and communities of interest. International Journal of Learning Technology, 2(2/3), 112-137.

Jones, C., \& Pound, L. (2008). Leadership and management in the early years: From principles to practice. Maidenhead, UK: Open University Press.

Kagan, S., \& Bowman, S. (1997). Leadership in early care and education: Issues and challenges. In S. Kagan \& B. Bowman (Eds.), Leadership in care and education (pp. 3-8). Washington DC: NAEYC.

Kagan, S., \& Hallmark, L. (2001). Cultivating leadership in early care and education. Childcare Information Exchange, 140, 7-12.

Kakabadse, N., Kakabadse, A., \& Kouzmin, A. (2003). Reviewing the knowledge management literature: towards a taxonomy. Journal of Knowledge Management, 7(4), 75-91.

Kimball, L., \& Ladd, A. (2004). Facilitator toolkit for building and sustaining virtual communities of practice. In P. Hildreth \& C. Kimble (Eds.), Knowledge networks: Innovation through communities of practice (pp. 202-215). Hershey, PA: Idea Group.

Kimble, C., \& Hildreth, P. (2005). Virtual communities of practice. In M. Khosrow-Pour (Ed.), Encyclopedia of information science and technology (pp. 2991-2995). Hershey, PA: Idea Group.

King, K. (2002). Identifying success in online teacher education and professional development. The Internet and Higher Education, 5(3), 231-246.

King, N. (2007). Template Analysis. Retrieved 5 December, 2008, from http://www.hud.ac.uk/hhs/research/template_analysis/whatis.htm

Klein, H., \& Myers, M. (1999). A set of principles for conducting and evaluating interpretive field studies in information systems. MIS Quarterly, 23(1), 67-93.

Kling, R., \& Courtright, C. (2003). Group behavior and learning in electronic forums: A sociotechnical approach. The Information Society, 19(3), 221-235. 
Kolb, D. (1984). Experiential learning. Englewood, NJ: Gower.

Kolb, J., \& Rothwell, W. (2002). Competencies of small group facilitators: what practitioners view as important. Journal of European Industrial Training, 26(2-4), 200-203.

Koo, L. (1999). Learning action learning. Journal of Workplace Learning, 11(3), 89-94.

Kort, E. (2008). What, after all, is leadership? ‘Leadership' and plural action. The Leadership Quarterly, 19(4), 409-425.

Lai, K., Pratt, K., Anderson, M., \& Stigter, J. (2005). Literature review and synthesis: Online communities of practice. Wellington: Ministry of Education.

Lambert, L. (2003a). Leadership capacity for lasting school improvement. Alexandria, VA: ASCD.

Lambert, L. (2003b). Shifting conceptions of leadership: towards a redefinition of leadership for the 21st century. In B. Davies \& J. West-Burnham (Eds.), Handbook of educational leadership and management (pp. 5-15). London: Pearson Longman.

Land, S., \& Hannafin, M. (2000). Student-centred learning environments. In D. Jonassen \& S. Land (Eds.), Theoretical foundations of learning environments (pp. 1-24). New Jersey: Lawrence Erlbaum Associates.

Lau, F. (1999). Toward a framework for action research in information systems studies. Information Technology and People, 12(2), 148-175.

Lave, J., \& Wenger, E. (1991). Situated learning: Legitimate peripheral participation. Cambridge: Cambridge University Press.

Lawrence, G. (1993). People types and tiger stripes. Gainesville, FL: Center for Applications of Psychological Type.

Lee, A. (1991). Integrating positivist and interpretivist approaches to organizational research. Organization Science, 2(4), 342-365.

Leithwood, K., \& Day, C. (2007). What we learned: A broad view. In C. Day \& K. Leithwood (Eds.), Successful principal leadership in times of change (pp. 189-203). Dordrecht, The Netherlands: Springer. 
Leithwood, K., Jantzi, D., \& Steinbach, R. (1999). Changing leadership for changing times. Buckingham: Open University Press.

Lincoln, Y., \& Guba, E. (1985). Naturalistic inquiry. Beverly Hills: Sage Publications.

Lincoln, Y., \& Guba, E. (2000). Paradigmatic controversies, contradiction and emerging confluences. In N. Denzin \& Y. Lincoln (Eds.), Handbook of qualitative research (2nd ed., pp. 163-188). London: Sage Publications.

Lipman, M. (1991). Thinking in education. Cambridge: Cambridge University Press.

Lizzio, A., \& Wilson, K. (2004). Action learning in higher education: an investigation of its potential to develop professional capability. Studies in Higher Education, 29(4), 469-488.

Loo, R., \& Thorpe, K. (2002). Using reflective learning journals to improve individual and team performance. Team Performance Management, 8(5-6), 134-139.

Looi, C. (2005). Exploring the affordances of online chat for learning. International Journal of Learning Technology, 1(3), 322-338.

MacBeath, J. (1998). 'I didn't know he was ill': The role and value of the critical friend. In L. Stoll \& K. Myers (Eds.), No quick fixes: Perspectives on schools in difficulty. London: Falmer Press.

MacDonald, J. (2008). Blended learning and online tutoring (2nd ed.). Aldershot: Gower.

MacKnight, C. (2000). Teaching critical thinking through online discussions. Educause Quarterly, 4, 38-41.

Maher, M., \& Jacob, E. (2006). Peer computer conferencing to support teachers' reflection during action research. Journal of Technology and Teacher Education, 14(1), 127-150.

Makinster, J., Barab, S., Harwood, W., \& Andersen, H. (2006). The effect of social context on the reflective practice of preservice science teachers: Incorporating a web-supported community of teachers. Journal of Technology and Teacher Education, 14(3), 543-579.

Margerison, C. (2005). Work-based action learning and applied organization science: a process for management research and organization development. Action Learning: Research and Practice, 2(2), 171-186. 
Marquardt, M. (1999). Action learning in action. Palo Alto, CA: Davies-Black.

Marquardt, M. (2004a). Harnessing the power of action learning. Training and Development, 8(6), 26-32.

Marquardt, M. (2004b). Optimizing the power of action learning. Mountain View, CA: Davies-Black.

Marquardt, M., \& Waddill, D. (2004). The power of action learning: a conceptual analysis of how the five schools of adult learning theories are incorporated with the practice of adult learning. Action Learning: Research and Practice, 1(2), 185-202.

Marsick, V., \& O'Neil, J. (1999). The many faces of action learning. Management Learning, 30(2), 159-176.

May, H. (2001). Politics in the playground. Wellington: Bridget Williams Books.

Mazzolini, M., \& Maddison, S. (2003). Sage, guide or ghost? The effect of instructor intervention on student participation in online discussion forums. Computers $\mathcal{E}$ Education, 40(3), 237-253.

McCain, D., \& Tobey, D. (2004). Facilitation basics. Alexandria, VA: ASTD Press.

McConnell, D. (2006). E-learning groups and communities. Maidenhead, Berkshire: Open University Press.

McDermott, R. (2001). Knowing in community: 10 critical success factors in building communities of practice. Retrieved 4 October, 2006, from http://www.co-il.com/coil/knowledge-garden/cop/knowing.shtml

McFadzean, E. (2002). Developing and supporting problem solving teams: part 2 facilitator competencies. Management Decision, 40(6), 537-551.

McFarlane, A., Bradburn, A., \& McMahon, A. (2003). E-Learning for leadership: emerging indicators of effective practice: National College for School Leadership.

McGill, I., \& Brockbank, A. (2004). The action learning handbook. London: RoutledgeFalmer.

McLeod, L. (2002). Leadership and management in early childhood centres. Unpublished PhD thesis, Massey University, Palmerston North, New Zealand. 
McNair, V. (2004). Using a virtual learning environment to build reflective practice among student teachers. Retrieved 15 May, 2006, from http://www.ltscotland.org.uk/connected/connected12/specialfeature/index.a $\underline{s p}$

Meade, A. (2000). The early childhood landscape in New Zealand. In J. Hayden (Ed.), Landscapes in early childhood education (pp. 83-93). New York: Peter Lang Publishing.

Meade, A. (2003). ECE centres of innovation in New Zealand. Paper presented at the Leadership and Management in the Early Years Conference, Pen Green Leadership Centre, Corby, North Hamptonshire.

Merriam, S. (2002a). Introduction to qualitative research. In S. Merriam (Ed.), Qualitative research in practice (pp. 3-17). San Francisco: Jossey-Bass.

Merriam, S. (2002b). Assessing and evaluating qualitative research. In S. Merriam (Ed.), Qualitative research in practice (pp. 18-33). San Francisco: Jossey-Bass.

Meyer, K. (2004). Evaluating online discussions: Four different frames of analysis. Journal of Asynchronous Learning Networks, 8(2), 101-114.

Miles, M., \& Huberman, M. (1994). Qualitative data analysis. Thousand Oaks, CA: Sage Publications.

Miller, P. (2003). Workplace learning by action learning: a practical example. Journal of Workplace Learning, 15(1), 14-23.

Ministry of Education. (1996). Te Whaariki. Wellington: Learning Media.

Ministry of Education. (2002). Pathways to the future: Nga huarahi arataki. Wellington: Learning Media.

Ministry of Education. (2004). The role and potential of ICT in early childhood education. Wellington: NZCER.

Ministry of Education. (2005a). Foundations for discovery. Supporting learning in early childhood education through information communication technologies: a framework for development. Wellington: Learning Media.

Ministry of Education. (2005b). Speech notes: NZ Principal Federation's moot.

Retrieved 1 July, 2005, from http:/ /www.minedu.govt.nz 
Ministry of Education. (2006a). Enabling the 21st century learner. Wellington: Learning Media.

Ministry of Education. (2006b). Ministry of Education annual report. Wellington: Ministry of Education.

Ministry of Education. (2007a). Briefing for the incoming Minister of Education. Retrieved 11 November, 2008, from http://www.minedu.govt.nz/ /media/MinEdu/Files/TheMinistry/BriefingI ncomingEducationMinister05Dec07.pdf.

Ministry of Education. (2007b). Ministry of Education annual report. Wellington: Ministry of Education.

Ministry of Education. (2008a). Briefing to the incoming Minister of Education. Retrieved 17 December, 2008, from http://www.beehive.govt.nz/sites/all/files/MinEdu_BIM.pdf.

Ministry of Education. (2008b). Ministry of Education annual report. Wellington: Ministry of Education.

Ministry of Education. (2008c). Education report: Annual census of early childhood education services: July 2008. Retrieved 6August, 2009, from http://educationcounts.govt.nz/statistics/ece

Moon, J. (2006). Learning journals: A handbook for reflective practice and professional development (2nd ed.). London: Routledge.

Moore, J., \& Barab, S. (2002). The inquiry learning forum: A community of practice approach to online professional development. TechTrends, 46(3), 44-49.

Morgan, G. (1997). What is leadership? Walking around a definition. Boston: Center for Career Development in Early Care and Education.

Morris, J. (1997). Minding our Ps and Qs. In M. Pedler (Ed.), Action learning in practice (3rd ed., pp. 49-59). Aldershot: Gower.

Muijs, D. Aubrey, C., Harris, A., \& Briggs, M. (2004). How do they manage? Journal of Early Childhood Research, 2(2), 157-169.

Mumford, E. (2006). Researching people problems: some advice to a student. Information Systems Journal, 16(4), 383-389. 
Mumford, A. (1997). Appendix 2: A review of the literature. In M. Pedler (Ed.), Action Learning in Practice (3rd ed., pp. 373-392). Aldershot: Gower.

Myers, M. (2004). Qualitative research in information systems. Retrieved 22 June, 2006, from http://www.misq.org/discovery/MISQD_isworld/

Nandhakumar, J., \& Jones, M. (1997). Too close for comfort? Distance and engagement in interpretive information systems research. Information Systems Journal, 7(2), 109-131.

National College for School Leadership. (2003). Too busy to learn? An introduction to collaborative leadership learning. Nottingham: National College for School Leadership.

National College for School Leadership. (2005). Programme guide: New visions programme for early headship. Nottingham: National College for School Leadership.

New Zealand Educational Institute. (2006). Quality public education for the 21st century. Wellington: NZEI.

New Zealand Government. (2005). The digital strategy: Creating our digital future. Retrieved 16 August, 2005, from http:/ / www.digitalstrategy.govt.nz.

New Zealand Government . (2008). The digital strategy 2.0. Retrieved 16 December, 2008, from http://www.digitalstrategy.govt.nz.

Nicholls, M. (2006). Communities of practice and the development of best practices. In E. Coakes (Ed.), Encyclopedia of communities of practice in information and knowledge management (pp. 66-67). Hershey, PA: Idea Group.

Nonaka, I. (1994). A dynamic theory of organizational knowledge creation. Organization Science, 5(1), 14-37.

Nupponen, H. (2006). Leadership concepts and theories. Australian Journal of Early Childhood, 31(1), 43-50.

O'Hara, S., Bourner, T., \& Webber, T. (2004). The practice of self-managed learning. Action Learning: Research and Practice, 1(1), 29-42.

O'Neil, J. (1997). Set advising: More than just process consultancy. In M. Pedler (Ed.), Action learning in practice (3rd ed., pp. 243-255). Aldershot: Gower.

O'Neil, J., \& Marsick, V. (2007). Understanding action learning. New York: Amacom. 
Orlikowski, W., \& Baroudi, J. (1991). Studying information technology in organizations: Research approaches and assumptions. Information Systems Research, 2(1), 1-28.

Osmond, J., \& Darlington, Y. (2005). Reflective analysis: Techniques for facilitating reflection. Australian Social Work, 58(1), 3-14.

Palinscar, A., Magnusson, S., Marano, N., Ford, D., \& Brown, N. (1998). Designing a community of practice: Principles and practices of the GIsML community. Teaching and Teacher Education, 14(1), 5-19.

Palloff, R., \& Pratt, K. (1999). Building learning communities in cyberspace. San Francisco: Jossey-Bass.

Paterson, F., \& West-Burnham, J. (2005). Developing beginning leadership. In M. Coles \& G. Southworth (Eds.), Developing leadership: Creating the schools of tomorrow (pp. 108-126). Maidenhead, Berkshire: Open University Press.

Patton, M. (2002). Qualitative research and evaluation methods (3rd ed.). Thousand Oaks, CA: Sage.

Pauleen, D. (2001). A grounded theory of virtual education: Building relationships with virtual team members. Unpublished PhD thesis, Victoria University of Wellington, Wellington.

Pauleen, D., \& Yoong, P. (2001). Relationship building and the use of ICT in boundarycrossing virtual teams. Journal of Information Technology, 16(4), 205-220.

Pauleen, D., \& Yoong, P. (2004). Studying human-centred IT innovation using a grounded action learning approach. The Qualitative Report, 9(1), 137-160.

Pedler, M. (1997). What do we mean by action learning? A story and three interpretations. In M. Pedler (Ed.), Action learning in practice (3rd ed., pp. 61-75). Aldershot: Gower.

Pedler, M., \& Abbott, C. (2008). Am I doing it right? Facilitating action learning for service improvement. Leadership in Health Services, 21(3), 185-199.

Pedler, M., Burgoyne, J., \& Brook, C. (2005). What has action learning learned to become? Action Learning: Research and Practice, 2(1), 49-68.

Pen Green Research. (2004). NPQICL induction programme. Nottingham: National College for School Leadership. 
Penney, D., \& Leggett, B. (2005). Connecting initial teacher education and continuing professional development through action research and action learning. Action Learning: Research and Practice, 2(2), 153-169.

Pfaffman, J. (2005). Open source solutions: Moodle. Learning \& Leading with Technology, $33(2), 42,45$.

Powell, J. (2001). Using learning styles and action learning, over the internet, to drive learning for innovation in small and medium enterprises - a case study from construction [Electronic Version], 97-111. Retrieved 15 May, 2006, from http://www.portlandpress.com/pp/books/online/vu/pdf/vu_ch8.pdf.

Prideaux, G. (1997). Making action learning more effective. In A. Mumford (Ed.), Action learning at work (pp. 169-175). Aldershot: Gower.

Raelin, J. (2000). Work-based learning: The new frontier of management development. New Jersey: Prentice Hall.

Raelin, J. (2002). I don't have time to think! versus the art of reflective practice. Reflections - The SoL Journal on Knowledge, Learning and Change, 4(1), 66-79.

Raelin, J. (2003). Creating leaderful organizations. San Francisco: Berrett-Koehler Publishers.

Raelin, J. (2004). Don't bother putting leadership into people. Academy of Management Executive, 18(3), 131-135.

Raja, J., Huq, A., \& Rosenberg, D. (2006). The role of trust in virtual and co-located communities of practice. In E. Coakes (Ed.), Encyclopedia of communities of practice in information and knowledge management (pp. 453-458). Hershey, PA: Idea Group.

Redmond, P., \& Lock, J. (2006). A flexible framework for online collaborative learning. The Internet and Higher Education, 9(4), 267-276.

Revans, R. (1997). Action learning: Its origins and nature. In M. Pedler (Ed.), Action learning in practice (pp. 3-13). Aldershot: Gower.

Revans, R. (1998). ABC of action learning. London: Lemos \& Crane.

Reynolds, B., \& Cardno, C. (2008). Leadership dilemmas in New Zealand early childhood education and care centres. Journal of Educational Leadership, Policy and Practice, 29(1), 18-29. 
Reynolds, M. (1998). Reflection and critical reflection in management learning. Management Learning, 29(2), 183-200.

Robertson, J. (2005). Coaching leadership. Wellington: NZCER.

Robinson, V. (2004). New understandings of educational leadership. set 2004, 3, 39-43.

Robinson, V. (2007). School leadership and student outcomes: Identifying what works and why. NSW: Australian Council for Educational Leaders.

Robinson, V., Irving, S., Eddy, D., \& Le Fevre, M. (2008). Capability in the leadership of teaching and learning in New Zealand: the validity and utility of a selfassessment tool. In M. Brundett \& M. Crawford (Eds.), Developing school leaders (pp. 155-172). London: Routledge.

Roche, V., \& Vernon, M. (2003). Developing a virtual learning community of managers in rural and remote health services. Retrieved 5 May, 2006, from http://www.abc.net.au/rural/ruralhealth2003/stories/s799695.htm

Rodd, J. (2001). Building leadership expertise of early childhood professionals. Journal of Early Childhood Teacher Education, 22(1), 9-12.

Rodd, J. (2006). Leadership in early childhood (3rd ed.). Crows Nest, NSW: Allen \& Unwin.

Rourke, L., Anderson, T., Garrison, D., \& Archer, W. (2001). Assessing social presence in asynchronous text-based computer conferencing [Electronic Version]. Journal of Distance Education, 14. Retrieved 14 November, 2007, from http://cade.athabascau.ca/vol14.2/rourke_et_al.html.

Rovai, A. (2000). Building and sustaining community in asynchronous learning networks. The Internet and Higher Education, 3(4), 285-297.

Rovai, A. (2007). Facilitating online discussions effectively. The Internet and Higher Education, 10(1), 77-88.

Rovai, A., \& Jordan, H. (2004). Blended learning and sense of community: A comparative analysis with traditional and fully online graduate courses. International Review of Research of Open and Distance Learning, 5(2), 1-13.

Saint-Onge, H., \& Wallace, D. (2003). Leveraging communities of practice for strategic advantage. Boston: Heinemann-Butterworth. 
Schlager, M., \& Fusco, J. (2003). Teacher professional development, technology and communities of practice: Are we putting the cart before the horse? The Information Society, 19, 203-220.

Schlager, M., Fusco, J., \& Schank, P. (2002). Evolution of an online community of practice. In K. Renninger \& W. Shumar (Eds.), Building virtual communities (pp. 129-158). Cambridge: Cambridge University Press.

Schomburg, R. (1999). Leadership development in early childhood education. Journal of Early Childhood Teacher Education, 20(2), 215-219.

Schon, D. (1983). The reflective practitioner Aldershot: Ashgate.

Schon, D. (1987). Educating the reflective practitioner. San Francisco: Jossey-Bass.

Schulz, K. (2005). Learning in complex organisations as practicing and reflecting. Journal of Workplace Learning, 17(8), 493-507.

Schwandt, T. (2000). Three epistemological stances for qualitative inquiry. In N. Denzin \& Y. Lincoln (Eds.), Handbook of qualitative research (2nd ed., pp. 189-214). London: Sage Publications.

Schwarz, R. (2005). The skilled facilitator approach. In R. Schwarz, A. Davidson, M. Carlson \& S. McKinney (Eds.), The skilled facilitator fieldbook. (pp. 3-14). San Francisco: Jossey-Bass.

Schwen, T., \& Hara, N. (2003). Community of practice: a metaphor for online design? The Information Society, 19(3), 257-270.

Scrivens, C. (2002). Redefining leadership for early childhood services. Delta, 54(1\&2), 43-56.

Scrivens, C. (2003). Educational leadership: What might we learn from research in schools? Early Education, 31, 29-35.

Sergiovanni, T. (2001). The principalship: A reflective practice perspective (4th ed.). Boston: Allyn \& Bacon.

Sergiovanni, T. (2009). The principalship: A reflective practice perspective (6th ed.). Boston: Pearson.

Sernak, K. (2005/2006). Creating a learning community of leaders. The International Journal of Technology Knowledge and Society, 1(5), 147-156. 
Sharratt, M., \& Usoro, A. (2003). Understanding knowledge-sharing in online communities of practice [Electronic Version]. Electronic Journal of Knowledge Management, 1, 187-196. Retrieved 16 June, 2006, from http://www.ejkm.com.

Shea, P. (2006). A study of students' sense of learning community in online environments [Electronic Version]. Journal of Asynchronous Learning Networks, 10(1). Retrieved 19 July, 2007, from http://www.sloanc.org/publications/jaln/v10n1/v10n1_4shea.asp.

Shuttleworth. (2005). The ongoing development of an effective model of action learning for use by the busy GP veterinary surgeon. Action Learning: Research and Practice, 2(2), 205-211.

Smith, C., \& Piele, P. (2006). School leadership (4th ed.). Thousand Oaks, CA: Corwin Press.

Smith, M. (2005). Strategies for successful fellowships: Nurturing early childhood leaders. Young Children, 66(1), 12-18.

Smith, P. (2006). Collective learning within CoPs. In E. Coakes (Ed.), Encyclopedia of communities of practice in information and knowledge management (pp. 30-31). Hershey, PA: Idea Group.

So, H., \& Brush, T. (2008). Student perceptions of collaborative learning, social presence and satisfaction in a blended learning environment: Relationships and critical factors. Computers $\mathcal{E}$ Education, 51(1), 318-336.

Southworth, G. (2002). What is important in educational administration: Learningcentred school leadership. New Zealand Journal of Educational Leadership, 17, 5-9.

Southworth, G. (2005). Overview and conclusions. In M. Coles \& G. Southworth (Eds.), Developing leadership: Creating the schools of tomorrow (pp. 158-173). Maidenhead, Berkshire: Open University Press.

Spillane, J. (2006). Distributed leadership. San Francisco: Jossey-Bass.

Spillane, J., Halverson, R., \& Diamond, J. (2004). Towards a theory of leadership practice: a distributed perspective. Journal of Curriculum Studies, 36(1), 3-34.

Stake, R. (1995). The art of case study research. Thousand Oaks, CA: Sage Publications.

Stake, R. (2000). Case studies. In N. Denzin \& Y. Lincoln (Eds.), Handbook of qualitative research (2nd ed., pp. 435-454). Thousand Oaks, CA: Sage Publications. 
Stake, R. (2005). Qualitative case studies. In N. Denzin \& Y. Lincoln (Eds.), The sage handbook of qualitative Research (3rd ed., pp. 443-466). Thousand Oaks, CA: Sage Publishing.

Stein, D., Wanstreet, C., Glazer, H., Engle, C., Harris, R., Johnston, S., et al. (2007). Creating shared understanding through chats in a community of inquiry. The Internet and Higher Education, 10 (2), 103-115.

Stewart, J.-A. (2006). High-performing (and threshold) competencies for group facilitators. Journal of Change Management 6(4), 417-439.

Stewart, J.-A., \& Alexander, G. (2006). Virtual action learning: experiences from a study of an SME e-learning programme. Action Learning: Research and Practice 3(2), 141159.

Stoll, L., \& Bolam, R. (2005). Developing leadership for learning communities. In M. Coles \& G. Southworth (Eds.), Developing leadership (pp. 50-64). Maidenhead, Berkshire: Open University Press.

Stoll, L., Fink, D., \& Earl, L. (2003). It's about learning (and it's about time). London: RoutledgeFalmer.

Stoll, L., Robertson, J., Butler-Kisber, L., Sklar, S., \& Whittingham, T. (2007). Beyond borders: can international networks deepen professional learning community? In L. Stoll \& K. Louis (Eds.), Professional learning communities (pp. 63-76). Maidenhead, Berkshire: McGraw Hill.

Storck, J., \& Storck, L. (2004). Trusting the knowledge of large online communities: Strategies for leading from behind. In P. Hildreth \& C. Kimble (Eds.), Knowledge Networks: Innovation through communities of practice (pp. 243-255). Hershey, PA: Idea Group.

Stott, K., \& Sing Kong, L. (2005). Developing innovative leadership. In M. Coles \& G. Southworth (Eds.), Developing leadership: Creating the schools of tomorrow (pp. 95107). Maidenhead, Berkshire: Open University Press.

Swaffield, S. (2005). No sleeping partners: relationships between head teachers and critical friends. School Leadership and Management, 25(1), 43-57.

Swaffield, S. (2007). Light touch critical friendship. Improving Schools, 10(3), 205-219. 
Swan, J., Newell, S., Scarborough, H., \& Hislop, D. (1999). Knowledge management and innovation: networks and networking. Journal of Knowledge Management, 3(4), 262-275.

Swan, S., \& Shih, L. (2005). On the nature and development of social presence in online course discussions. Journal of Asynchronous Learning Networks, 9(3), 115-136.

Takeuchi, H., \& Nonaka, I. (2004). Knowledge creation and dialectics. In H. Takeuchi \& I. Nonaka (Eds.), Hitotsubashi on knowledge management (pp. 1-28). Singapore: John Wiley \& Sons.

Talking Heads. (2002). Talking heads report. Retrieved 10 December, 2006, from http://www.intra.ultralab.net/ leonie/cothsreport02/index.html

Tarmazi, H., de Vreede, G., \& Zigurs, I. (2007). Leadership challenges in communities of practice: Supporting facilitators via design and technology. International Journal of e-Collaboration, 3(1), 18-39.

Thornton, K. (2005). Courage, commitment and collaboration: Notions of leadership in the New Zealand ECE 'Centres of Innovation'. Unpublished master's thesis, Victoria University of Wellington, Wellington.

Thornton, K. (2008). Guest editorial: Leadership under the spotlight. The First Years, 10(1), 3-4.

Thorpe, R., Taylor, M., \& Elliot, M. (1997). Action learning in an academic context. In M. Pedler (Ed.), Action learning in practice (pp. 145-172). Aldershot: Gower.

Timperly, H. (2005). Distributed leadership: Developing theory from practice. Journal of Curriculum Studies, 37(4), 395-420.

Tu, C., \& McIsaac, M. (2002). The relationship of social presence and interaction in online classes. American Journal of Distance Education, 16(3), 131-150.

Wagner, C., \& Bolloju, N. (2005). Supporting knowledge management in organizations with conversational technologies: Discussion forums, weblogs, and wikis. Journal of Database Management, 16(2), 1-8.

Walker, A., \& Dimmock, C. (2005). Developing leadership in context. In M. Coles \& G. Southworth (Eds.), Developing leadership (pp. 80-94). Maidenhead, Berkshire: Open University Press. 
Walsham, G. (1995). Interpretive case studies in IS research: nature and method. European Journal of Information Systems, 4(2), 74-81.

Waltonen-Moore, S., Stuart, D., Newton, E., Oswald, R., \& Varonis, E. (2006). From virtual strangers to a cohesive online learning community: The evolution of online group development in a professional development course. Journal of Technology and Teacher Education, 14(2), 287-311.

Waring, T., \& Wainwright, D. (2008). Issues and challenges in the use of template analysis: Two comparative case studies from the field. The Electronic Journal of Business Research Methods, 6(1), 85-94.

Weinstein, K. (1995). Action learning. London: HarperCollins.

Weinstein, K. (2002). Action learning: The classic approach. In Y. Boshyk (Ed.), Action learning worldwide: Experiences of leadership and organisational development (pp. 318). Basingstoke: Palgrave McMillan.

Wenger, E. (1998). Communities of practice: Learning, meaning and identity. Cambridge: Cambridge University Press.

Wenger, E. (2004). Knowledge management as a doughnut: Shaping your knowledge strategy through communities of practice. Ivey Business Journal, 68(3), 1-8.

Wenger, E. (2006). Communities of practice: a brief introduction. Retrieved 30 August, 2006, from http://www.ewenger.com/theory/index.htm

Wenger, E., \& Snyder, W. (2000). Communities of practice: The organizational frontier. Harvard Business Review, 78(1), 139-145.

Wesley, P., \& Buysse, V. (2001). Communities of practice: Expanding professional roles to promote reflection and shared inquiry. Topics in Early Childhood Special Education, 21(2), 114-123.

West-Burnham, J. (2003). Learning to lead. In B. Davies \& J. West-Burnham (Eds.), Handbook of Educational Leadership and Management (pp. 57-59). London: Pearson Education.

West-Burnham, J. (2004). Building leadership capacity - helping leaders learn [Electronic Version], 1-6. Retrieved 20 October, 2008, from http://forms.ncsl.org.uk/mediastore/image2/randd-building-leadcapacity.pdf 
Williams, C., \& Leitch, R. (2005). Building leadership capabilities: What does that mean? How can it be done? New Zealand Principal's Magazine, 1-3.

Willis, V. (2004). Inspecting cases against Revans' 'gold standard' of action learning. Action Learning: Research and Practice, 1(1), 11-27.

Woo, Y., \& Reeves, T. (2007). Meaningful interaction in web-based learning: A social constructivist approach. The Internet and Higher Education, 10(2), 15-25.

Wu, D., \& Hiltz, S. (2004). Predicting learning from asynchronous online discussions. Journal of Asynchronous Learning Networks, 8(2), 139-152.

Yin, R. (2003). Case study research (3rd ed., Vol. 5). Thousand Oaks, CA: Sage Publications.

Yoong, P. (1996). A grounded theory of reflective facilitation: Making the transition from traditional to GSS facilitation. Unpublished PhD thesis, Victoria University of Wellington, Wellington.

Yoong, P., \& Gallupe, B. (2001). Action learning and groupware technologies: a case study on GSS facilitation research. Information Technology \& People, 14(1), 78-90.

Yoong, P., Thornton, K., \& Watson, J. (2006). Online action learning and knowledge sharing: The case of the Pacific village. Paper presented at the Asia-Pacific International Conference on Knowledge Management, Hong Kong, 11-13 December.

Yuthas, K., Dillard, J., \& Rogers, K. (2004). Beyond agency and structure: Triple-loop learning. Journal of Business Ethics, 52(2), 229-243.

Zhang, J., \& Faerman, S. (2007). Distributed leadership in the development of a knowledge sharing system. European Journal of Information Systems, 16(4), 479493.

Zuber-Skerrit, O. (2002). The concept of action learning. The Learning Organization, 9(3), 114-124.

Zuber-Skerritt, O. (1992). Professional development in higher education: A theoretical framework for action research. London: Kogan Page. 


\section{SCHOOL OF INFORMATION MANAGEMENT}

\section{Appendix A - Participant Information Sheet}

Project title: The Use of ICT to support leadership development in the New Zealand ECE sector

Researcher: Kate Thornton, School of Information Management, Victoria University of Wellington

Thank you for showing an interest in participating in this research study exploring how leadership development in the New Zealand early childhood education sector can be supported through the use of information and communication technologies (ICT). I am currently studying for my PhD at Victoria University of Wellington. As part of this study, I will be establishing and facilitating several small groups of between 6 and 8 teachers who wish to collaboratively work on issues and challenges related to their leadership roles. Participation is not restricted to those teachers in formal leadership positions but is open to anyone interested in learning more about leadership.

Participation in these groups will involve both face-to-face meetings and online interactions. Each group will begin with one full day meeting so that participants can get to know each other and establish some goals to work on. It is likely that this first meeting will take place in [date]. An exact date and venue will be negotiated with participants. There will be another two or three face-to-face meetings over the course of the year and in between these, a virtual learning environment will be used for communication. This system will allow online chat, discussion forums, document sharing and wikis. Participants will also be asked to keep an online reflective journal. The groups will continue until the end of 2007.

Confidentiality of information shared within each group is of fundamental importance. The information shared by participants in each of the professional learning groups will remain confidential to that group and may not be shared with anyone outside that group. Any information that participants provide that is used in the research will not be attributed to individuals and participants will not be able to be identified in any way. 


\section{SCHOOL OF INFORMATION MANAGEMENT}

It is hoped that this research study will benefit the participants as well as the researcher. Participants will have the opportunity to develop their leadership capabilities while working in a collaborative group environment. In return for this professional learning opportunity, participants will agree to be interviewed by the researcher and allow their online reflections and discussion to form part of the research data. Interviews will be audio-taped and transcribed. You will receive a copy of your transcribed interview for review and feedback, to ensure factual material has been recorded correctly. Data that is collected, collated and analysed may be published in academic conferences and form the basis of journal articles. Throughout the project, raw data will be protected by password and will be destroyed two years after the conclusion of the project.

Participants have the right to withdraw from this study at any time during the course of the professional learning groups. Any contributions these participants have made up until that time will be withdrawn from the research data.

You may have further questions and you are welcome to contact me with these. You may also wish to contact my research supervisor Dr Pak Yoong on 4635878 for further information about the study or the informed consent requirement.

The consent form is attached. If you agree to participate, please complete the form, sign it and return it to me in the stamped and addressed envelope by [date].

Regards,

Kate Thornton

Phone: 044757241 or 021668207

Email: kate.thornton@vuw.co.nz 
SCHOOL OF INFORMATION MANAGEMENT

\section{Appendix B - Consent to Participation in Research}

The use of ICT to support leadership development in the New Zealand ECE sector

[Please mark each box with a tick to indicate agreement, then sign and date this form]

1. I have been given and have understood an explanation of this research and the confidentiality conditions.

2. I have had an opportunity to ask questions and have them answered to my satisfaction.

3. I agree to be interviewed by Kate Thornton for the purposes of this research and I consent to the use of my perceptions, experiences, opinions and information in this research providing they are not attributed to me.

4. I agree to participate in a leadership professional development group facilitated by Kate Thornton and to have my reflections and online discussions used as research data.

5. I understand that all the data collected will be destroyed 2 years after the conclusion of the study

6. I understand that I may withdraw from this research before the conclusion of the action learning groups without giving any reason, In the event that I withdraw any contributions I have made will be excluded from the research data

Name:

Signed:

Date: 


\section{Appendix C - Additional Leadership journeys}

\begin{tabular}{|c|c|c|}
\hline Participant & Leadership goals and shifts in practice & Use of ICT \\
\hline Amy & $\begin{array}{l}\text { Amy was the only participant not in a formal leadership position when she joined LALG1. } \\
\text { The goal she chose to work on initially related to improving the communication and } \\
\text { dynamics between members of her teaching team: } \\
\qquad \text { My goal is to have a more collaborative relationship with my work colleagues; this can be } \\
\text { tricky in a } 3 \text { teacher situation when the other two teachers have a lot more time together } \\
\text { due to my family commitments and commitments to myself. } \\
\text { Amy resolved this situation by directly addressing the issues she had with her colleagues, a } \\
\text { process she found empowering. When she took on a relieving leadership position later in } \\
\text { the research process, she chose a new goal of leading by example and modelling respectful } \\
\text { ways of talking with children, and dealing with challenging behaviour. Strategies she used } \\
\text { included encouraging initiative and independence in the other teachers and giving lots of } \\
\text { praise and encouragement. She noted the importance of a head teacher thinking closely } \\
\text { about and being interested in what other team members were doing. Amy acknowledged } \\
\text { the value of her participation in the leadership learning process to her new position in the } \\
\text { following chat comment: } \\
\qquad \text { I have to say this leadership research has done a great deal for my confidence at dealing with } \\
\text { situations with staff. } \\
\text { Towards the end of the research Amy took on a permanent leadership position. In the final } \\
\text { interview she reflected on her increased self-awareness and self-confidence. She also reiterated } \\
\text { her realisation that leadership was not restricted to those people holding formal leadership } \\
\text { positions: }\end{array}$ & $\begin{array}{l}\text { Amy was confident in } \\
\text { her use of ICT and } \\
\text { participated fully in all } \\
\text { online activities. She } \\
\text { commented on the value } \\
\text { of the reflective journal } \\
\text { in allowing her to write, } \\
\text { be listened to, and } \\
\text { receive feedback. She } \\
\text { also thought that the } \\
\text { online action forums } \\
\text { helped develop coaching } \\
\text { skills. }\end{array}$ \\
\hline
\end{tabular}




\begin{tabular}{|c|c|c|}
\hline Beth & $\begin{array}{l}\text { Beth chose to address issues she was having with a colleague as her first leadership goal and } \\
\text { after the first face-to-face meeting expressed her appreciation of having the opportunity to focus } \\
\text { on her leadership practice: } \\
\qquad \text { I had an interesting week after our course and on reflection this happened due to the } \\
\text { confidence I gained in my own leadership and the guidance received from talking to } \\
\text { everyone. } \\
\text { One aspect of her leadership practice she wanted to develop was her assertiveness and she } \\
\text { reflected on how these increased skills could be transferred to other situations: } \\
\text { This week I told one parent that they were being disrespectful and they needed to treat ECE } \\
\text { teachers like they would a primary teacher and I felt confident doing it which is totally } \\
\text { different than normal. I wasn't angry, I just felt used and the more assertive comments came } \\
\text { naturally, a good thing I think. } \\
\text { Later on in the leadership learning process Beth adapted her goal and chose to work on } \\
\text { developing professional relationships within her soon to be expanded team. } \\
\text { In the final interview Beth commented that she had learnt a lot about herself and her } \\
\text { natural leadership style. She also reflected on her enhanced confidence and increased skills: } \\
\text { more prepared to say "hey look I need you to ..." and probably use more open communication. }\end{array}$ & $\begin{array}{l}\text { Beth struggled with } \\
\text { accessing and using the } \\
\text { online site although over } \\
\text { time, she gained in } \\
\text { confidence. She was the } \\
\text { most frequent } \\
\text { participant in chat } \\
\text { sessions and also } \\
\text { contributed the most } \\
\text { forum postings among } \\
\text { members of LALG1. } \\
\text { Beth found the most } \\
\text { useful tool to be the } \\
\text { reflective journal } \\
\text { because of the responses } \\
\text { she received from the } \\
\text { facilitator. }\end{array}$ \\
\hline Charlotte & $\begin{array}{l}\text { Charlotte chose an initial goal of improving relationships between two of her staff, as she } \\
\text { was planning an overseas trip and wanted to make sure the centre ran smoothly in her } \\
\text { absence. She identified a number of strategies including: talking to the teachers concerned } \\
\text { directly; offering them resources; and engaging the help of a support person. These actions } \\
\text { resulted in more open and honest communication between team members in her centre. } \\
\text { Charlotte used the online forums to get advice from other group members on topics such as } \\
\text { time management and interviewing. A later goal involved empowering the other teachers }\end{array}$ & $\begin{array}{l}\text { Charlotte valued all } \\
\text { aspects of the leadership } \\
\text { learning process. She } \\
\text { was particularly active } \\
\text { in starting and } \\
\text { contributing to forum } \\
\text { discussion and she }\end{array}$ \\
\hline
\end{tabular}




\begin{tabular}{|c|c|c|}
\hline & $\begin{array}{l}\text { in her centre to share in the leadership responsibilities: } \\
\text { I am also focussing on empowering my teachers at the moment... I have currently got a } \\
\text { strong team of leaders, and everyone (although they are relatively new teachers) has the } \\
\text { desire to take responsibility for things. It's very exciting. They have ideas all the time, and } \\
\text { implement them. } \\
\text { In the action learning forum she started, Charlotte reflected on the fact that she received } \\
\text { little feedback from others on her ideas. She appreciated the questioning process in helping } \\
\text { her identify possible solutions to the issue she was grappling with. } \\
\text { The following comment made in her final interview sums up the benefits Charlotte obtained } \\
\text { from her participation in the leadership learning process: } \\
\text { I feel like I've developed over that } 6 \text { months and I've more of a picture of myself as a leader and in } \\
\text { the same way I've kind of identified the things that I'm not comfortable doing and that I need to } \\
\text { work on. }\end{array}$ & $\begin{array}{l}\text { commented on the } \\
\text { benefits of this blended } \\
\text { form of professional } \\
\text { development. }\end{array}$ \\
\hline Heather & 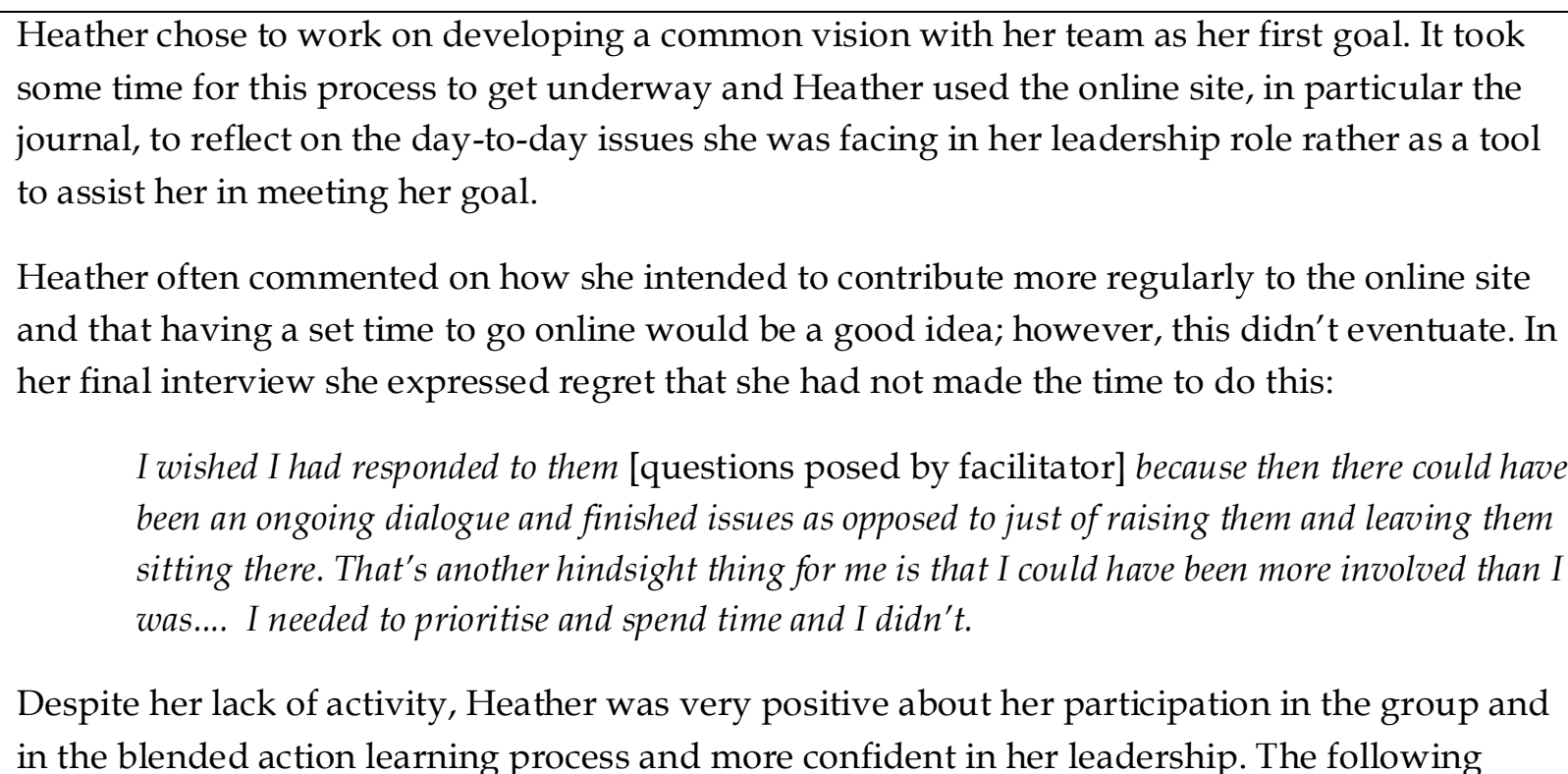 & $\begin{array}{l}\text { Although Heather was } \\
\text { confident with ICT, she } \\
\text { was not so confident in } \\
\text { posting on the site. She } \\
\text { was one of least active } \\
\text { participants although } \\
\text { she did begin a forum } \\
\text { discussion. }\end{array}$ \\
\hline
\end{tabular}




\begin{tabular}{|c|c|c|}
\hline & $\begin{array}{l}\text { comment was made in the final interview: } \\
\text { I'm probably happier in my leadership now than I was then and I think it's because I now know } \\
\text { there are different ways of leading, that there isn't one set way that I have to learn how to do it. } \\
\text { When I first came into this role I just was aware of how much I needed to learn and felt quite } \\
\text { inadequate along the way at times but it's been really interesting to listen to other people because } \\
\text { you know that other people have similar struggles along the way. } \\
\text { Heather also identified that she had made a shift in the way she dealt with issues and was } \\
\text { working out strategies to deal with problems instead of leaving them or hoping they would go } \\
\text { away. }\end{array}$ & \\
\hline Isabel & $\begin{array}{l}\text { Isabel chose to work on time management skills as her first goal. She was relatively new to her } \\
\text { current position and to Wellington, and was finding her job frustrating as she was struggling to } \\
\text { achieve her goals in the non-contact time she had been allocated. This situation made her } \\
\text { consider making a change as she was also used to a more hands-off strategic role, rather than a } \\
\text { role that involved so much teaching. } \\
\text { Because there have been many things that haven't worked well for me in the position I am in at } \\
\text { the moment I feel it is time to be looking elsewhere. } \\
\text { Isabel used the action learning process and group to find out from other participants how their } \\
\text { services were run and how they dealt with certain issues as the following comment illustrates: } \\
\qquad \text { We're all from the same profession but different areas of the same profession it actually gives you } \\
\text { a bit of an insight into how the sectors of the ECE system work } \\
\text { A second goal related to developing a shared philosophy and she also worked on leading her } \\
\text { team's professional development on assessment and encouraging them to take more } \\
\text { responsibility. Examples of this included asking teachers to take on roles such as organising } \\
\text { excursions, writing parent newsletters and taking on associate teacher roles. Isabel commented } \\
\text { in a forum discussion that this approach of focusing on strengths and encouraging the } \\
\text { distribution of leadership was something that came naturally but that she was not previously }\end{array}$ & $\begin{array}{l}\text { Isabel was one of the } \\
\text { least active members of } \\
\text { LALG2. She enjoyed } \\
\text { chat sessions but only } \\
\text { having a dial-up } \\
\text { connection home meant } \\
\text { she often felt frustrated } \\
\text { by her inability to } \\
\text { respond promptly to the } \\
\text { comments of others. } \\
\text { Because she didn't use } \\
\text { the journal regularly, } \\
\text { she also did not tend to } \\
\text { access the resources or } \\
\text { contribute to forum } \\
\text { discussions. }\end{array}$ \\
\hline
\end{tabular}




\begin{tabular}{|c|c|c|}
\hline & $\begin{array}{l}\text { aware of: } \\
\qquad \text { I believe I work this way, not always knowing it. } \\
\text { Some of the shifts in practice Isabel identified as a result of her participation in the leadership } \\
\text { action learning group included standing back from situations instead of taking them personally } \\
\text { as the following comment shows: } \\
\qquad \text { I actually don't take on such a personal side of issues that might arise now. I'm more inclined to } \\
\text { think about it as how it affects the whole picture. }\end{array}$ & \\
\hline Karen & $\begin{array}{l}\text { Karen was the most experienced member of LALG2 and did not have any particular leadership } \\
\text { issues she wanted to work on unlike most other participants. She chose to work on completing } \\
\text { an induction package for staff which involved a consultation process with teachers who had } \\
\text { been recently appointed in her service. Over the course of the lea dership action learning group, } \\
\text { Karen became more aware of the pressures experienced by head teachers and she reflected on } \\
\text { her role in supporting and mentoring her own staff who were in this position: } \\
\qquad \text { It's really drawn my attention to the tensions between being a hands-on teacher and being in } \\
\text { charge of the centre and that's what all my staff are. } \\
\text { This realisation led her to set up more regular meetings with her staff to encourage them to } \\
\text { share any issues they were facing. She also decided to distribute leadership more widely by } \\
\text { encouraging head teachers to take on different responsibilities such as facilitating meetings. The } \\
\text { following comment illustrated her belief in the value of distributed leadership: } \\
\text { I am convinced there is no place especially in a structure like ours, for just one leader - it is } \\
\text { possible and desirable for there to be many leaders, albeit at different stages and levels of } \\
\text { leadership, all of whom can be nurtured and supported to grow into leaders beyond their own } \\
\text { area, to be effective advocates for children and ece. }\end{array}$ & $\begin{array}{l}\text { Karen was the most } \\
\text { active member of } \\
\text { LALG2 contributing the } \\
\text { most reflective journal } \\
\text { entries and forum } \\
\text { posting and } \\
\text { participating in the most } \\
\text { chat sessions. She } \\
\text { initially had some } \\
\text { reservations about using } \\
\text { the site but found it very } \\
\text { easy to navigate. }\end{array}$ \\
\hline
\end{tabular}


APPENDIX C

\begin{tabular}{|l|l|}
\hline $\begin{array}{c}\text { The more I read on leadership and anything related to it, the more confused I become.... I've } \\
\text { taken to carrying a book around to record ideas, quotes, notes etc on leadership and related } \\
\text { issues. }\end{array}$ \\
$\begin{array}{l}\text { One of the shifts in practice Karen made over the course of her participation was a greater use of } \\
\text { questioning in order to help people identify actions to address the issues they were facing rather } \\
\text { than providing a solution for them. }\end{array}$ \\
\hline
\end{tabular}




\title{
APPENDIX D
}

\section{Appendix D - Extract from Charlotte's second interview}

23/7/2007

\begin{abstract}
(Facilitator's questions and comments in italics)
How are you finding the combination of online and face-to-face compared with any other professional development you have done?

I think it's a really good amount; it's a good combination, because the face-to-face does make it a bit more real. I really enjoyed seeing everyone again the other night and just sort of it made me more inspired to go back on again after sort of slightly forgetting who everybody was a little bit, especially people who hadn't been on very much. There were a couple of people who have been on there a lot and I felt like I still knew them through that (because you'd been talking to them or interacting with them?). Actually I've emailed with a couple of people that's another ICT thing.

I've found the ICT part of it really fantastic because it's always there whereas with courses and things the amount of difficulty it's been to make dates where we can all meet only once every 6 weeks or whatever. It's quite hard to find those times and in between that's a very long time if we weren't having any contact at all, whereas that constant weekly dropping in and out of that site is really great support to have there all the time. It's easy and quick to develop that closeness.
\end{abstract}

\section{What have been some of the enablers?}

Email enablement has been really helpful; I think it's really good because it tells me when something new is on there and then I go and have a look at everything. I really love being able to see it whenever I've got a minute at quite random times. I find that really useful. It's much more pleasurable at home anyway. I've done a couple of things from here and not had so much energy for it. I know that there's other things I need to get back to.

\section{What about barriers?}

Probably time, being really busy - I think that's it really. I definitely am wanting to go on. It's incredible how hard it is to even sometimes get 10 minutes in your whole week. 


\title{
APPENDIX E
}

\section{Appendix E - Extract from Heather's final interview $17 / 6 / 2008$}

\author{
(Facilitator's questions and comments in italics)
}

What have you learnt about yourself as a leader?

I've learnt my style of leadership. I've probably learnt that it's OK to have a different style of leadership. Everybody is going to have a different well not everybody, there are different styles, there's no one set correct way to be doing it therefore you work out what's right for you and what's right for your team. So that's good to have worked that one out because yes then you are less hard on yourself I think.

So before you became involved in this you didn't feel the same?

I'm probably happier in my leadership now than I was then and I think it's because I now know there are different ways of leading, that there isn't one set way that I have to learn how to do it. When I first came into this role I just was aware of how much I needed to learn and felt quite inadequate along the way at times but it's been really interesting to listen to other people because you know that other people have similar struggles along the way.

So it's sort of affirming?

It's affirming, it is affirming

And I think part of that is a personality thing as well and a heritage thing for me to try and live up to what I think I'm meant to and I'm getting better at not doing that so much as working out what's right

So is that other people's expectations on you or did you put those on yourself?

I think I put, I think I allow what I perceive as other people's expectations along the way in life to have affected the way I've done things to the point where I used to be a terrible people pleaser and you can't please everybody and there's no point in trying because you end up wounded all over the place because of course you don't meet everyone else's expectations because you can't It's not possible, nobody can.

So you sort of feel more comfortable? Yes. 


\section{Appendix F - Forum discussion: Reflection on a quote}

Hi all, read a really interesting quote about leadership in Howard Gardner's book 'Leading Minds' - the book itself is not really worth reading but this quote stood out for me. It went along the lines of:

Leadership is all about judgment - making judgments about what is relevant and what needs to be done. There are times when leaders need to go out alone in order for others to have somewhere to follow.

The quote was Henry Kissinger but I don't have the exact words as i traded the book in at $2^{\text {nd }}$ hand book store and forgot to record the exact quote first!

Anyway, I thought this was just so applicable to how $\mathrm{i}$ feel sometimes having responsibility that others in our team maybe don't feel, and at times, the isolation of the position and having to make decisions. There is a lot more $i$ could say on the topic but $i$ thought I'd throw this quote out there and see what you all have to say about it!

Fiona $(2 / 8 / 2007,11.32 \mathrm{am})$

Hi Fiona, Really liked your quote and it is so true. It is often a lonely place being the leader and in some ways I am always thankful that I only have two team members. My husband runs a huge zone with a large number of staff (In the hundreds) and he has found it really interesting. Different responses, friends who can't cope with your changed role, and the high level of responsibility. We have talked about it heaps and decided it comes down to being respected not necessarily liked, being fair and equitable. My ride has come so will sign off be in touch later.

Beth $(2 / 8 / 2007,4.53 \mathrm{pm})$

Hi Beth and Fiona, I do like the quote and I agree with you Beth about being respected but not every ones best friend and being fair and equitable - not that I am in a head teacher role but doing this course has really opened my eyes to those values.

Amy $(7 / 8 / 2007,8.07 \mathrm{pm})$

Thought I would share some ideas about non-traditional leadership skills that I heard from a woman called Jolene Brown over the weekend. She had interviewed 100 creative and innovative leaders and she shared 4 of the important leadership characteristics she found:

1. they were unthreatened by conditions of ambiguity and disorder 
2. they actively broadened their knowledge base (this included working collaboratively with others to get new ideas and perspectives)

3. they communicated carefully with others and they did it often

4. they chose to enjoy their journey

This last one relates well to the fish book as the ideas included:

- learn to accept things you cannot control or change

- learn to look for humour every day

- associate with people who enjoy their journey (it's hard to soar with the eagles when you're surrounded by turkeys) - Jolene was from the US

Kate $(13 / 8 / 2007,10.14 \mathrm{am})$

Hi Fiona, "It's lonely at the top" - one of the quotes that comes from somewhere in the deep recesses of my mind - I think that my mother said it, but I'm not quite sure! I think it is necessary for the leader to provide vision, and to sometimes "go out alone in order for others to follow". I also think that sometimes the leader has to "go out alone" for other reasons: sometimes the confidentiality of another person has to be respected; sometimes an unpopular decision has to be made; and other times its important to be alone so i can sort myself out in order to carry on. Does this sound familiar to anyone else?

Diana $\odot(14 / 8 / 2007,2.45 \mathrm{pm})$

So true Diana,

In the first month of this job, I was quietly shocked at the isolation of being 'at the top'. Even in my role as assistant head teacher, I had not had anywhere near the sense of responsibility which comes with this role. I now understand the slight distance that past centre leaders have seemed to maintain. You've really spelt out the main reasons well too.

It is one of the greatest things about this cluster group, to have the freedom of speech and professional companionship which we are unable to have in our teams because of hierarchy. I get on beautifully with the teachers at my centre, and consider most of them friends as well, but there is still always a certain distance there when it comes to work issues, right?

Charlotte $(20 / 8 / 2007,6.43 \mathrm{am})$ 